\title{
Fracture pattern characterization of the Tensleep Formation, Teapot Dome, Wyoming
}

\author{
Bryan C. Schwartz \\ West Virginia University
}

Follow this and additional works at: https://researchrepository.wvu.edu/etd

\footnotetext{
Recommended Citation

Schwartz, Bryan C., "Fracture pattern characterization of the Tensleep Formation, Teapot Dome, Wyoming" (2006). Graduate Theses, Dissertations, and Problem Reports. 4266.

https://researchrepository.wvu.edu/etd/4266

This Thesis is protected by copyright and/or related rights. It has been brought to you by the The Research Repository @ WVU with permission from the rights-holder(s). You are free to use this Thesis in any way that is permitted by the copyright and related rights legislation that applies to your use. For other uses you must obtain permission from the rights-holder(s) directly, unless additional rights are indicated by a Creative Commons license in the record and/ or on the work itself. This Thesis has been accepted for inclusion in WVU Graduate Theses, Dissertations, and Problem Reports collection by an authorized administrator of The Research Repository @ WVU. For more information, please contact researchrepository@mail.wvu.edu.
} 


\title{
Fracture Pattern Characterization of the Tensleep Formation, \\ Teapot Dome, Wyoming
}

\author{
Bryan C. Schwartz \\ Thesis submitted to the \\ Eberly College of Arts and Sciences at \\ West Virginia University \\ in partial fulfillment of the requirements \\ for the degree of \\ Master of Science \\ in \\ Geology \\ Committee Members: \\ Dr. Thomas Wilson, Chair \\ Dr. Jaime Toro \\ Dr. Mark McKoy \\ Department of Geology and Geography \\ Morgantown, West Virginia \\ 2006
}

Keywords: Teapot Dome, Tensleep, Fractures, FracGen, Borehole Imaging Copyright 2006 Bryan C. Schwartz 


\begin{abstract}
Fracture Pattern Characterization of the Tensleep Formation, Teapot Dome, Wyoming

Bryan C Schwartz

This study presents a detailed analysis of open fracture systems observed in FMI logs through the oil producing Tensleep Formation at Teapot Dome. Open fracture systems in the Tensleep were compared to surface fracture distributions reported by Cooper (2000). Systematic fracture sets observed in the Tensleep consisted primarily of $\mathrm{W}$ and WNW striking sets oriented obliquely to the northwest trending hinge of the Dome and dipping on average between $78^{\circ}$ and $58^{\circ}$. Hinge-parallel and hingeperpendicular sets, common at the surface, were rarely encountered in the wellbore. Observations were made in vertical wells along the hinge of the anticline where bedding is nearly horizontal, and the probability of intersecting vertical fractures, small. The present day maximum compressive stress inferred from drilling induced fractures is oriented, on average, $\mathrm{N} 80 \mathrm{~W} . \mathrm{CO}_{2}$ flooding and hydraulic fracturing will generally enhance production along the $\mathrm{W}$ and $\mathrm{WNW}$ open fracture trends.
\end{abstract}

2D fracture networks were created of the Tensleep Formation using the NETL program FRACGEN. Fracture orientation, dip and aperture measurements were calculated directly from FMI logs. Fracture dip, bedding plane dip, and the frequency of fractures per foot of borehole were used to determine fracture spacing. Fracture spacing appeared to increase in a broad linear fashion as the thickness of the Sandstone A and Sandstone B increased. The Dolomite B layer revealed a broad linear decrease per bed thickness. A histogram of fracture apertures indicated an exponential decay distribution. There are many small apertures (less than 0.0012in) and few large apertures (greater than $0.0028 \mathrm{in}$ ). A power law relationship between aperture and length was used to estimate fracture length in the Tensleep. Fracture lengths estimates range from 0.47 meters to 27.42 meters. Fracture lengths were shorter for the Sandstone A and Dolomite B layers, and larger for the thicker Sandstone B layer. 


\section{Acknowledgements}

There are many people and organizations that have provided me with support to complete this thesis. This support has come in the form of financial, logistical, encouragement, or the sharing of ones personal knowledge.

I would like thank the Department of Energy: NETL for providing me assistance through the University Partnership. Duane Smith was an integral part of the University Partnership by assisting me with my many tasks.

Without the Rocky Mountain Oilfield Testing Center, there would be no data for analysis. The people at the RMOTC have been most helpful in providing me with more information than I could possibly use. Brian Black, Vicki Stamp, and Tom Anderson made sure what I requested was delivered in a timely manner. For that, thank you.

Every once in awhile I encounter people that are more interested in sharing their knowledge and understanding, for them it seems to be about the experience of nurturing an impressionable mind. For their support and help in enhancing my knowledge and abilities I would like to thank Dr. Wilson, Dr. Toro, Mark McKoy and Mark Milliken. They have given me a part of their time, wisdom, and understanding which will stay with me for my lifetime.

Lastly, I thank my parents. Without their continued support, my education would not have been possible. Their patience and selflessness has shaped me into the person I am today. 


\section{Table on Contents}

Table of Contents $\quad \ldots \ldots \ldots$ iv

List of Figures $\quad \ldots \ldots . . . \mathrm{V}$

List of Tables $\quad \ldots \ldots \ldots$ ix

1.0 Introduction $\quad \ldots \ldots \ldots 1$

2.0 Geology of Teapot Dome $\quad \ldots \ldots \ldots 7$

3.0 Data Analysis from FMI Log $\quad \ldots \ldots . . .22$

4.0 Estimation of Fracture Length and Spacing $\quad \ldots \ldots . . .54$

5.0 FracGen Models $\quad$........ 77

6.0 Conclusions $\quad \ldots . . . .99$

Appendix A: FMI Log Interpretation $\quad \ldots \ldots \ldots 107$

Appendix B: FracGen Modeling $\quad \ldots \ldots \ldots 130$

References $\quad \ldots \ldots \ldots 145$ 


\section{List of Figures}

Figure 1-1: Location of Teapot Dome $\quad \ldots \ldots \ldots 2$

Figure 1-2: Location of wells with Swell Tests $\quad \ldots \ldots \ldots 3$

Figure 1-3: Location of wells with FMI Images $\quad \ldots \ldots \ldots .5$

Figure 1-4: Viscosity of Reservoir Fluids $\quad$....... 6

Figure 2-1: Location of Teapot Dome $\quad \ldots \ldots \ldots 8$

Figure 2-2: Oil Production from the Salt Creek Anticlinal System $\quad$........ 9

Figure 2-3: Location Map of Teapot Dome $\quad$........ 10

Figure 2-4: Cooper's Fracture Model $\quad$........ 12

Figure 2-5: Cooper's (2000) Idealized Fracture Set $\quad \ldots \ldots \ldots 12$

Figure 2-6: Timeslice of seismic survey of Teapot Dome

Figure 2.7: Low-Angle Reverse Faults in Wyoming $\quad$........ 15

Figure 2-8: Correlation of Geophysical Logs for FMI wells $\quad$........ 17

Figure 2-9: Photo of Oil Staining in Core for Sandstone B Layer $\quad$........ 18

Figure 2-10: Photo of Tensleep outcrop (Alcoa Reservoir) _....... 20

Figure 2-11: Oil Staining Bound by Bedding Plane $\quad \ldots \ldots \ldots .21$

Figure 2-12: Oil Communication Through Fractures $\quad$........ 21

Figure 3-1: Location of Wells with Geophysical Wells $\quad$........ 23

Figure 3-2: Well Log Correlation for Wells with FMI Logs $\quad$........ 24

Figure 3-3: Well 48-x-28 Core Photo of the Top of Sandstone B $\quad$........ 26

Figure 3-4: Well 48-x-28 Core Photo of Dolomite C1

Figure 3-5: Thickness of Sand A, Dol B, and Sand B $\quad$........ 30

Figure 3-6: NW-SE Cross-Section at Teapot Dome $\quad$........ 30 
Figure 3-7: Location of Wells with FMI Logs $\quad \ldots \ldots . . .31$

Figure 3-8: Isochron Map of Tensleep Reflector $\quad$........ 34

Figure 3-9: Rose Diagrams of Cooper's Proposed Fracture Model $\quad$........ 35

Figure 3-10: Rose Diagrams/Stereonets of Sandstone A Fractures $\quad$........ 36

Figure 3-11: Rose Diagrams/Stereonets of Dolomite B Fractures $\quad$........ 37

Figure 3-12: Rose Diagrams/Stereonets of Sandstone B Fractures $\quad$........ 38

Figure 3-13: Sandstone A, Dolomite B, and Sandstone B analysis $\quad$........ 39

Figure 3-14: Fracture Spacing vs. Bed Thickness $\quad \ldots \ldots . . .43$

Figure 3-15: Fracture Spacing vs. Bed Thickness - Sandstone A and B ....... 43

Figure 3-16: Fracture Density Sandstone A $\quad \ldots . \ldots .44$

Figure 3-17: Fracture Density Dolomite B $\quad \ldots \ldots . . .44$

Figure 3-18: Fracture Density Sandstone B $\quad \ldots \ldots . . .45$

Figure 3-19: Fracture Density Sandstone A, Dolomite B, Sandstone B $\quad \ldots . . . .45$

Figure 3-20: Fracture Aperture vs. Bed Thickness $\quad \ldots \ldots . . .48$

Figure 3-21: Distribution of Fracture Apertures $\quad \ldots \ldots . . .48$

Figure 3-22: Rose Diagrams/Stereonets of Drilling Induced Fractures $\quad \ldots . \ldots . .51$

Figure 3-23: World Stress Map $\quad \ldots . \ldots . . .53$

Figure 4-1: Fractures Intersecting Borehole $\quad \ldots \ldots . . .55$

Figure 4-2: Fracture Pole Vector $\quad \ldots \ldots . . .56$

Figure 4-3: Geometry and Fracture Projection $\quad \ldots \ldots . \ldots 58$

Figure 4-4: Fracture Aperture Vs. Fracture Length $\quad \ldots \ldots \ldots 61$

Figure 4-5: Fracture Aperture Vs. Fracture Length $\quad \ldots \ldots . .61$

Figure 4-6: Relationship between Fracture Length and Aperture $\quad \ldots \ldots \ldots 62$ 
Figure 4-7: Histogram of Fracture Aperture $\quad$........ 66

Figure 4-8: Geometric Model to Determine Fracture Spacing $\quad$........ 69

Figure 4-9: Core Schematic for Geologic Method $\quad \ldots \ldots \ldots .73$

Figure 5-1: FRACGEN Model of Oriskany Sandstone Gas Reservoir $\quad$........ 78

Figure 5-2: FRACGEN Model of Sandstone A Layer in Well 48-x-28 $\quad$........ 84

Figure 5-3: FRACGEN Model of Dolomite B Layer in Well 48-x-28 $\quad$........ 85

Figure 5-4: FRACGEN Model of Sandstone B Layer in Well 48-x-28 $\quad$........ 86

Figure 5-5: FRACGEN Model of Sandstone A Layer in Well 71-1-x-4 ….... 87

Figure 5-6: FRACGEN Model of Sandstone B Layer in Well 71-1-x-4 $\quad$........ 88

Figure 5-7: FRACGEN Model of Dolomite B Layer in Well 67-1-x-10 ….... 89

Figure 5-8: FRACGEN Model of Sandstone B Layer in Well 67-1-x-10 ........ 90

Figure 5-9: FRACGEN Model of Sandstone A Layer in Well 67-1-x-10 _....... 91

Figure 5-10: FRACGEN Model of Dolomite B Layer in Well 61-2-x-15 _....... 92

Figure 5-11: FRACGEN Model of Sandstone B Layer in Well 61-2-x-15 ........ 93

Figure 5-12: FRACGEN Model of Sandstone A Layer in Well 25-1-x-14 _....... 96

Figure 5-13: FRACGEN Model of Dolomite B Layer in Well 25-1-x-14 _....... 97

Figure 5-14: FRACGEN Model of Sandstone B Layer in Well 25-1-x-14 _....... 98

Figure 6-1: Map of Major Normal Faults at Teapot Dome $\quad$........ 102

Figure A-1: FMI Tool $\quad$......... 108

Figure A-2: Typical FMI Header Information $\quad$ ….... 109

Figure A-3: Directional Information from FMI Log $\quad \ldots \ldots \ldots 112$

Figure A-4: Curve Fitting for FMI Log Interpretation $\quad$........ 115

Figure A-5: Tadpole Plots on FMI Logs $\quad$........ 115 
Figure A-6: Continuous Fracture as Seen in FMI Log $\quad \ldots \ldots \ldots 116$

Figure A-7: Lithologically Bound Fracture as Seen in FMI Log $\quad$........ 117

Figure A-8: Partially Healed Fracture as Seen in FMI Log $\quad$........ 120

Figure A-9: Healed Fracture as Seen in FMI Log $\quad$........ 120

Figure A-10: Drilling Induced Fracture as Seen in FMI Log $\quad$........ 121

Figure B-1: FRACGEN Input File (Type 1 Fracture Model) $\quad$........ 124

Figure B-2: FRACGEN Output for Model 1 Fracture Set $\quad$........ 125

Figure B-3: FRACGEN Input File (Type 2 Fracture Model) $\quad$ ….... 126

Figure B-4: FRACGEN Output for Model 2 Fracture Set $\quad$........ 127

Figure B-5: FRACGEN Input File (Type 3 Fracture Model) $\quad$ ….... 128

Figure B-6: FRACGEN Output for Model 3 Fracture Set $\quad$ _....... 129

Figure B-7: FRACGEN Output - Uniform Length Distribution $\quad$........ 131

Figure B-8: FRACGEN Output - Uniform Length Distribution $\quad$ ….... 132

Figure B-9: FRACGEN Output - Exponential Length Distribution $\quad$ ….... 134

Figure B-10: FRACGEN Output - Exponential Length Distribution $\quad$ …..... 135

Figure B-11: FRACGEN Output - Lognormal Length Distribution $\quad$ ….... 136

Figure B-12: FRACGEN Output - Lognormal Length Distribution $\quad$ ….... 137

Figure B-13: FRACGEN Output - Intersection Frequency Control $\quad$ ….... 138

Figure B-14: FRACGEN Output - Intersection Frequency Control $\quad$........ 139

Figure B-15: FRACGEN output - Fracture Density Control $\quad$......... 141

Figure B-16: FRACGEN output - Fracture Density Control $\quad$......... 142

Figure B-17: FRACGEN output - Fracture Density Control $\quad$........ 143

Figure B-18: FRACGEN output - Fracture Density Control $\quad$........ 144 


\section{List of Tables}

Table 3-1: Formation Picks for Wells with FMI Logs $\quad$........ 28

Table 3-2: Thickness of Sandstone A, Dolomite B, and Sandstone B $\quad \ldots . . . .28$

Table 3-3: Anticlinal Axis and Cooper's Theoretical Model $\quad . . . . . .33$

Table 3-4: Mean Dip Angle and Standard Deviation $\quad \ldots . \ldots . .40$

Table 3-5: Fracture Frequency and Layer Thickness $\quad \ldots . \ldots . .41$

Table 3-6: Mean Vertical Fracture Density and Standard Deviation $\quad \ldots . . . .442$

Table 3-7: Mean Fracture Aperture and Standard Deviation $\quad \ldots . . . .47$

Table 3-8: Fracture Cluster Strike and Aperture $\quad \ldots . . . .49$

Table 3-9: Statistics of Drill Induced Fractures $\quad \ldots . \ldots 52$

Table 4-1: Statistical Fracture Parameters for Length Minimum $\quad$....... 64

Table 4-2: Fracture Length from Power Law $\quad \ldots \ldots . . .67$

Table 4-3: Geometric Method - Horizontal Spacing $\quad \ldots . \ldots . .70$

Table 4-4: Geologic Method - Horizontal Spacing $\quad$........ 74

Table 4-5: Center Point Density $\quad \ldots \ldots . . .76$

Table 5-1: Fracture Cluster Parameters Strike and Length $\quad \ldots . \ldots 81$

Table 5-2: Fracture Cluster Parameters Aperture and Density $\quad \ldots \ldots . . .82$

Table 6-1: Mean Fracture Dip and Standard Deviation $\quad \ldots \ldots \ldots 101$ 


\section{Chapter 1: Introduction}

\subsection{Purpose}

Teapot Dome is a doubly-plunging anticline created during the Laramide Orogeny. Teapot Dome is located in Natrona County, Wyoming (Figure 1-1). Historical production from the Tensleep Formation in the Teapot Dome study area is largely water ( $\sim 99 \%)$ with less than $1 \%$ oil and consists of a strong water-drive (Milliken, 2005 and Stamp, 2005). Giangiacomo (2000) stated that groundwater flow through the fracture network limits the ability of the pumps to produce much of the oil from the matrix pore space. The matrix oil saturation in the Tensleep Formation is believed to be between $35 \%-61 \%$ and oil-wet (Giangiacomo 2000). Miscibility studies performed on reservoir fluid of the Tensleep Formation from wells 48-x-28 and 72-tpx-10 (Figure 1-2) indicate a decrease in reservoir fluid viscosity as the amount of $\mathrm{CO}_{2}$ solvent is injected into the reservoir fluid. $\mathrm{CO}_{2}$ injection could facilitate the production of matrix bound oil and be useful to enhance oil recovery (EOR) from for the Tensleep Formation.

Fractures and fracture networks in a tight reservoir can greatly enhance oil production (Lorenz, 1991). Intersecting fractures can increase the permeability in directions parallel to the connecting fracture trends. The increase in permeability may allow for better drainage of the reservoir rock which provides an increase in the recovery of reservoir fluids.

Schulte (2001) indicates that the performance of individual Tensleep wells is quite variable. Carr (1996) and Hurley (2003) have identified anisotropic permeability related to heterogeneities in the stratigraphic and depositional environments of reservoir intervals in the Tensleep Formation. Faults are also believed to provide a conduit 


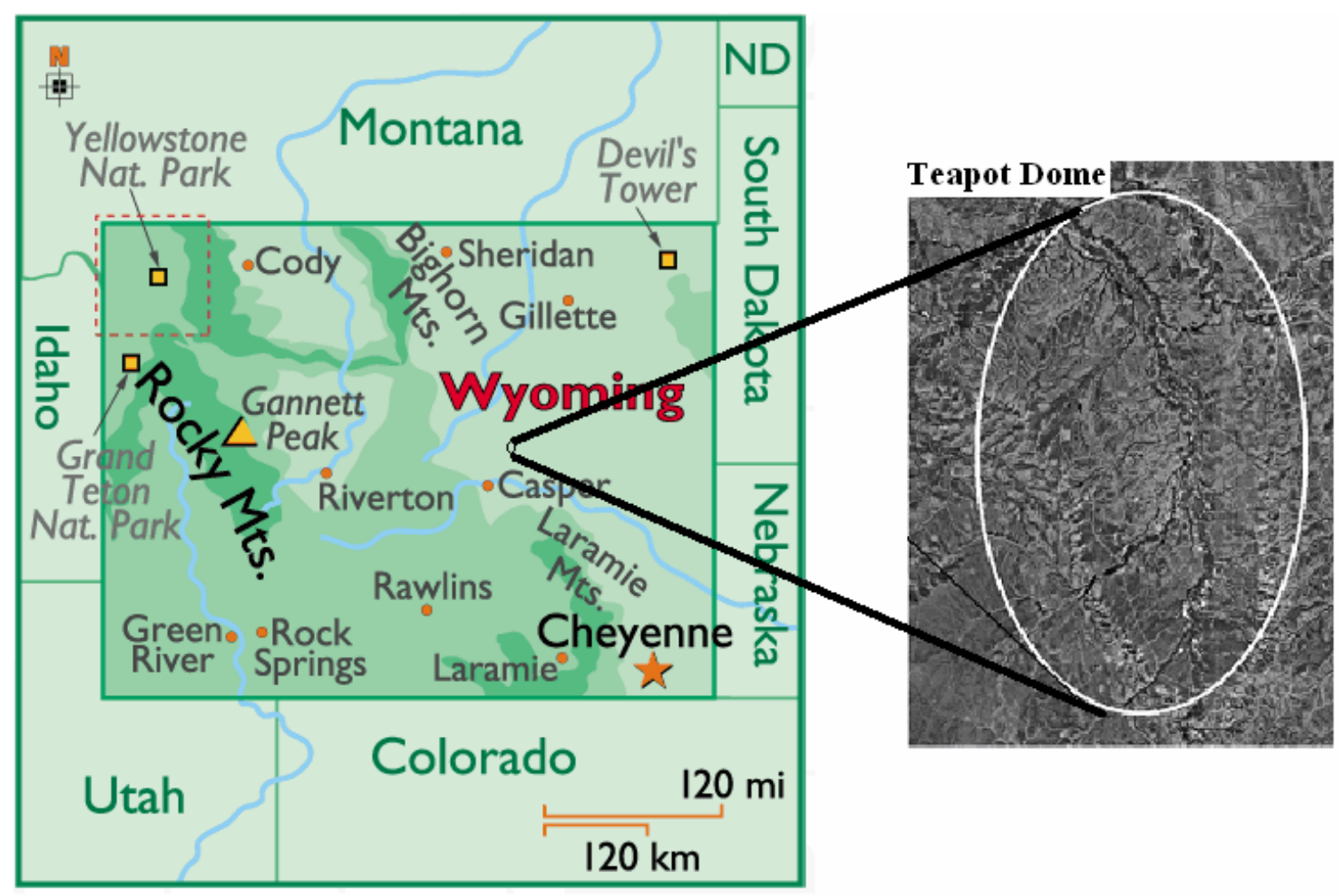

Figure 1-1: Location of Teapot Dome in the state of Wyoming. The left side image was taken from the World Atlas, http://worldatlas.com/webimage/countrys/namerica/usstates/largemap/wylarge.htm. The right side image was taken from TerraServer USA, http://www.terraserver.microsoft.com/. 


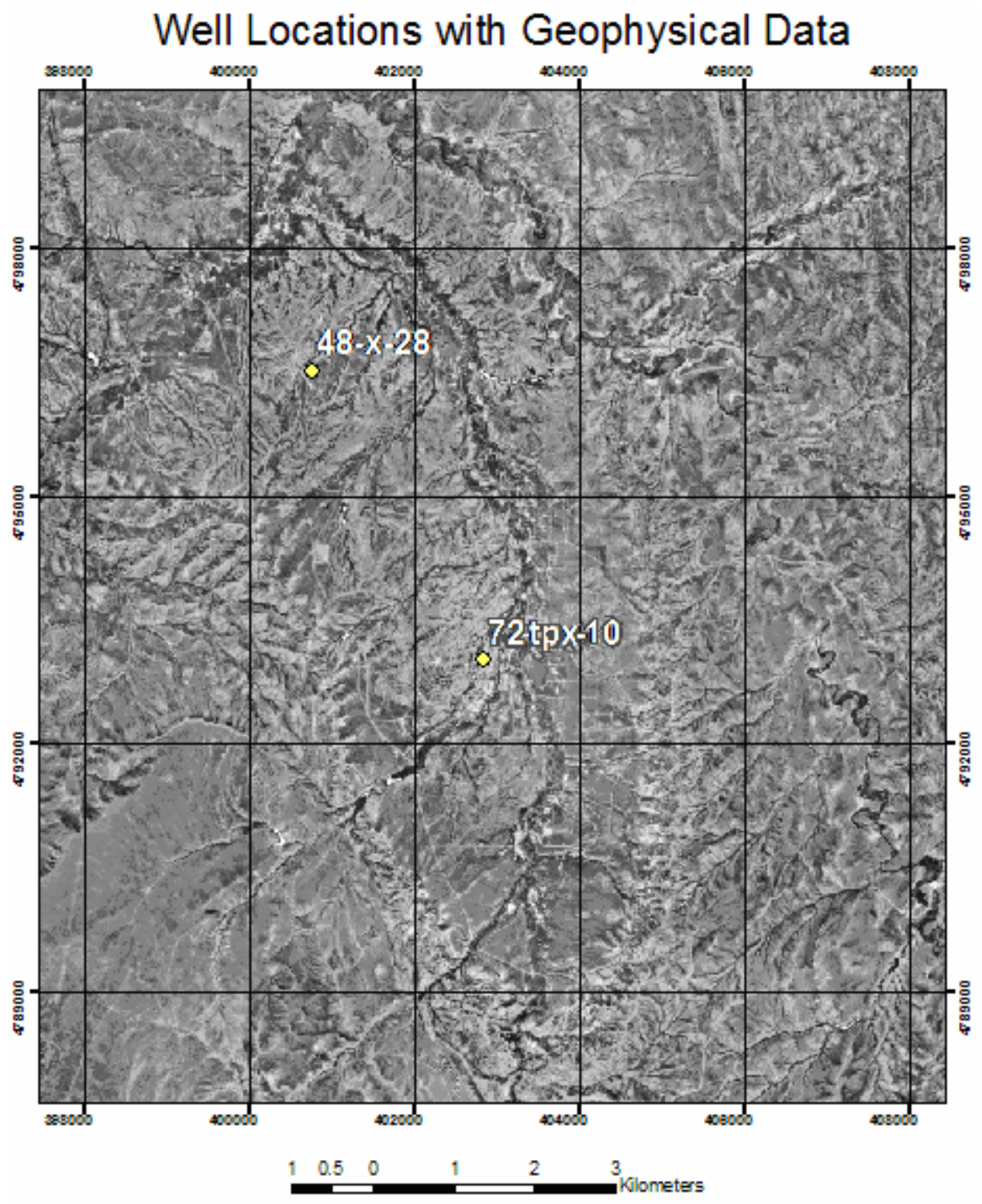

Figure 1-2: Location of wells where miscibility studies have been performed on reservoir fluids. Aerial photographs provided by the USDA's geospatial gateway http://datagateway.nrcs.usda.gov/. 
through permeability barriers in these eolian sandstone reservoirs. These complicated interrelationships have made it difficult to predict the performance of new wells and the optimum drilling locations.

In this study stochastic fracture models are derived by using an analysis of fracture orientations and spacings obtained from five Fullbore MicroImager (FMI) logs in wells located along the anticlinal axis of Teapot Dome (Figure 1-3). Stochastic models are developed using the Department of Energy: National Energy Technology Laboratory (NETL) program FRACGEN (McKoy, 2001). Fracture aperture, strike, fracture dip, and clustering of the fractures in the Tensleep Formation were determined from FMI log analysis. Fracture length minimums and fracture spacing were estimated using a variety of analysis techniques.

\subsection{Objectives}

Oil production at Teapot Dome from the Tensleep Formation is primarily waterdriven. Primary water and oil flow in the reservoir is through a high permeability fracture network. There are two main objectives of this research effort: 1) determine if fracture systems mapped at the surface (Cooper, 2000) relate to fracture networks in the oil producing Tensleep reservoir located approximately $5400 \mathrm{ft}$ beneath the surface; and 2) create $2 \mathrm{D}$ stochastic models of fracture networks within the Tensleep Formation at Teapot Dome based on the FMI log observations and any other available information.

These stochastic fracture models will be used to help evaluate the potential benefits of $\mathrm{CO}_{2}$ EOR methods in the Tensleep reservoir. $\mathrm{CO}_{2}$ swelling tests were conducted on the reservoir fluids from Section 10 at Teapot Dome at 


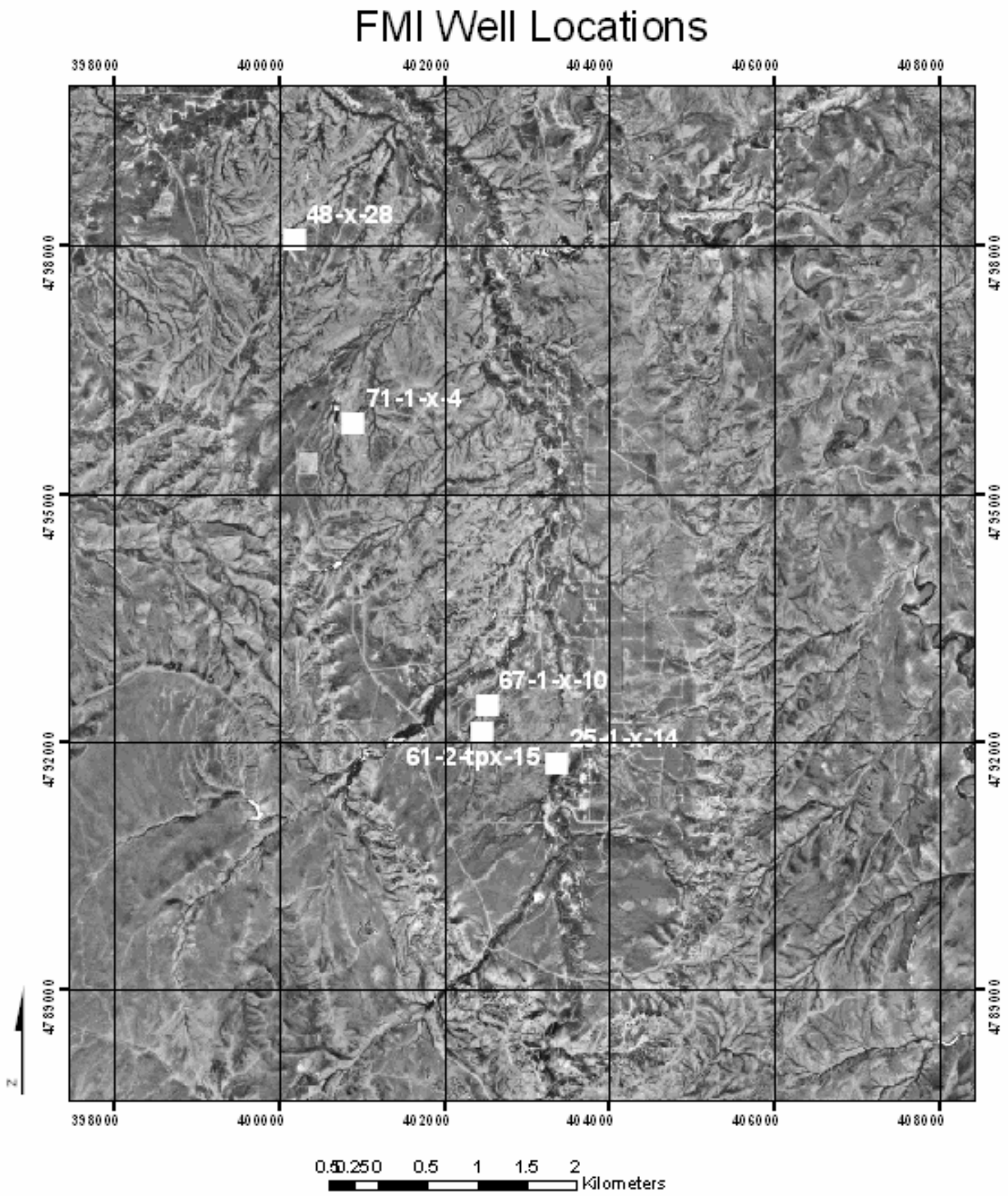

Figure 1-3: Location of wells containing FMI image logs. Aerial photographs were provided by the USDA's geospatial gateway http://datagateway.nrcs.usda.gov/. 


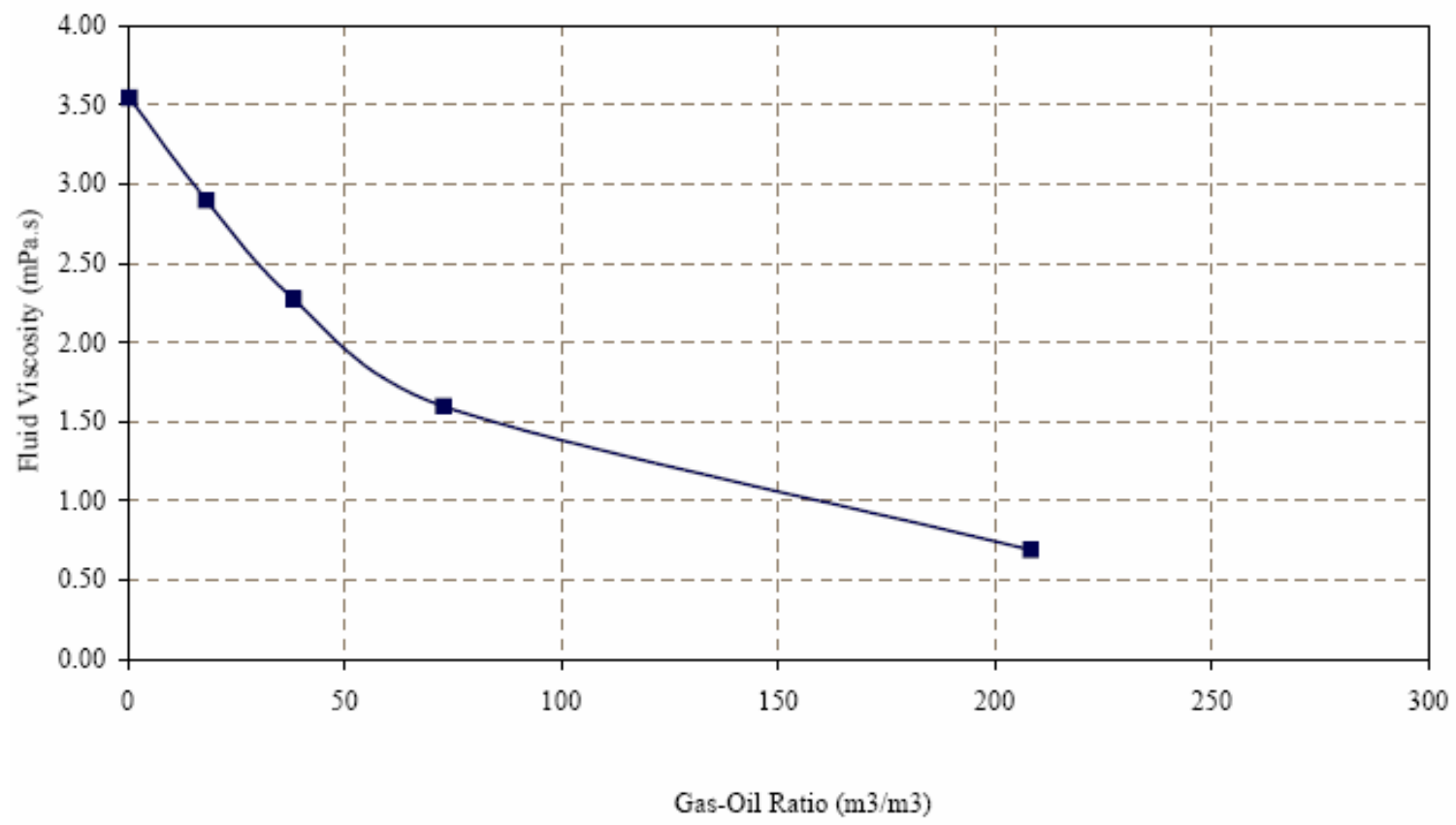

Figure 1-4: Viscosity of reservoir fluid from well 72-tpx-10. Introduction of $\mathrm{CO}_{2}$ decreases oil viscosity and increases production potential.

reservoir temperatures and pressures (Hycal, 2004). As the $\mathrm{CO}_{2}$ was sorbed, the viscosity and density of the reservoir fluids decreased (Figure 1-3) (Hycal, 2004). The results of this test suggest that increased oil production is possible from the Tensleep reservoir if significant quantities of $\mathrm{CO}_{2}$ can be forced into the reservoir to effectively lower the matrix bound oil viscosity. The fracture models developed in this thesis may help define the shapes of possible drainage areas and the likely distribution of injected $\mathrm{CO}_{2}$. 


\section{Chapter 2: Teapot Dome}

\subsection{Geologic Setting}

Teapot Dome is a doubly plunging basement-cored anticline of Laramide-age, and is located in central Wyoming (Figure 2-1). Teapot Dome is located about 35 miles north of Casper Wyoming in Natrona County. The field known as Naval Petroleum Reserve \#3 (NPR-3), is located on federal lands and is managed by the United States Department of Energy (DOE). Research and development activities conducted at the site are selected and supported through the site contractor, Rocky Mountain Oilfield Testing Center (RMOTC).

Oil was first produced at Teapot Dome in 1908. Historically, oil has been produced from 9 different reservoirs extending from the deeper Pennsylvanian age Tensleep Formation to the near-surface Upper Cretaceous Shannon Sandstone. Currently production comes from 3 different reservoirs: the Shannon, $2^{\text {nd }}$ Wall Creek, and Tensleep (http://www.rmotc.com/). Teapot Dome is part of a larger anticlinal system that includes the Salt Creek anticline to the north. The combined cumulative oil production from this anticlinal system was $675 \mathrm{MMBO}$ in 1990 (Dolton, 1990). Production during the last 15 years has added approximately $50 \mathrm{MMBO}$ to the total (see Figure 2-2). There was a steady decrease in production during the 90 s leveling off to approximately 2 MMBO per year from $1998-2005$.

Geologically, Teapot Dome is located along the southwestern margin of the Powder River Basin (Figure 2-3). The basement cored anticlinal system was created by the compressive forces of the Laramide Orogeny. Dolton (1990) suggests the folds developed predominantly through vertical basement uplift. However, fold asymmetry 


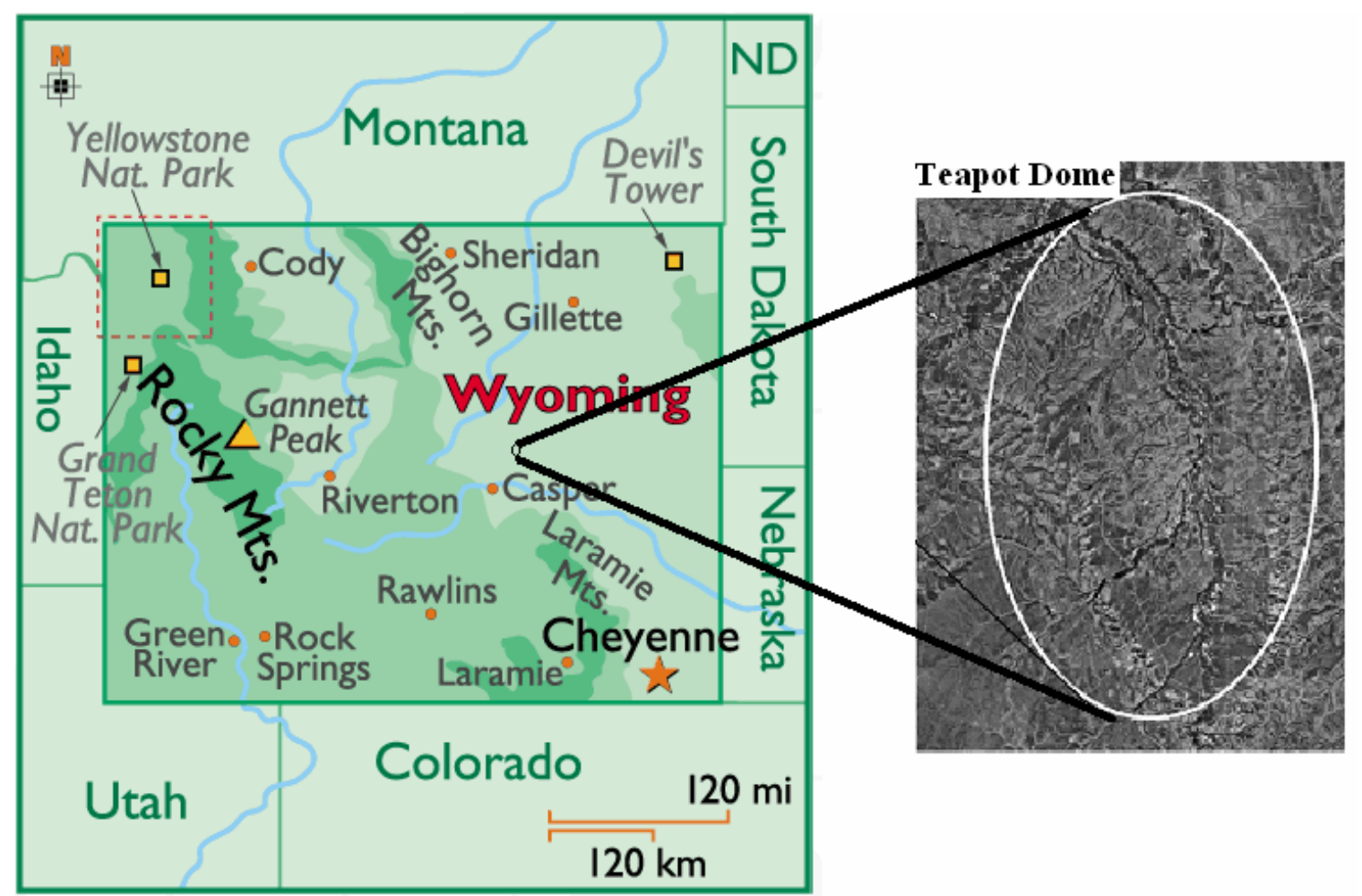

Figure 2-1: Location of Teapot Dome in the state of Wyoming. The left side image was taken from the World Atlas, http://worldatlas.com/webimage/countrys/namerica/usstates/largemap/wylarge.htm. The right side image was taken from TerraServer USA, http://www.terraserver.microsoft.com/. 


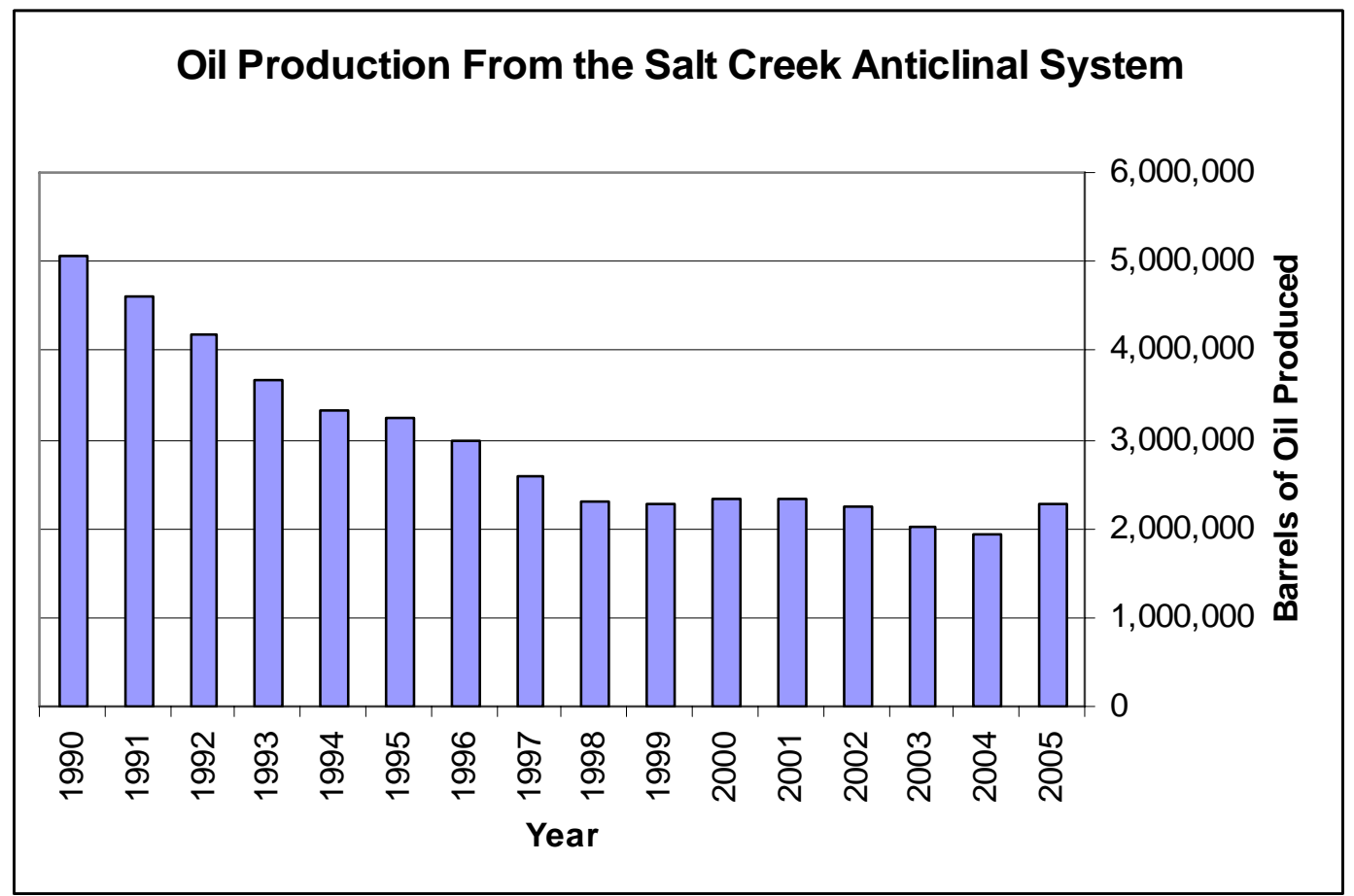

Figure 2-2: Oil Production from the Salt Creek Anticlinal System (Salt Creek and Teapot Dome Oil Fields) over the last 15 years. Declining oil production during the 1990s gives way to relatively constant production from 1998 to 2005 . Data are from the Wyoming Oil and Gas Commission. 


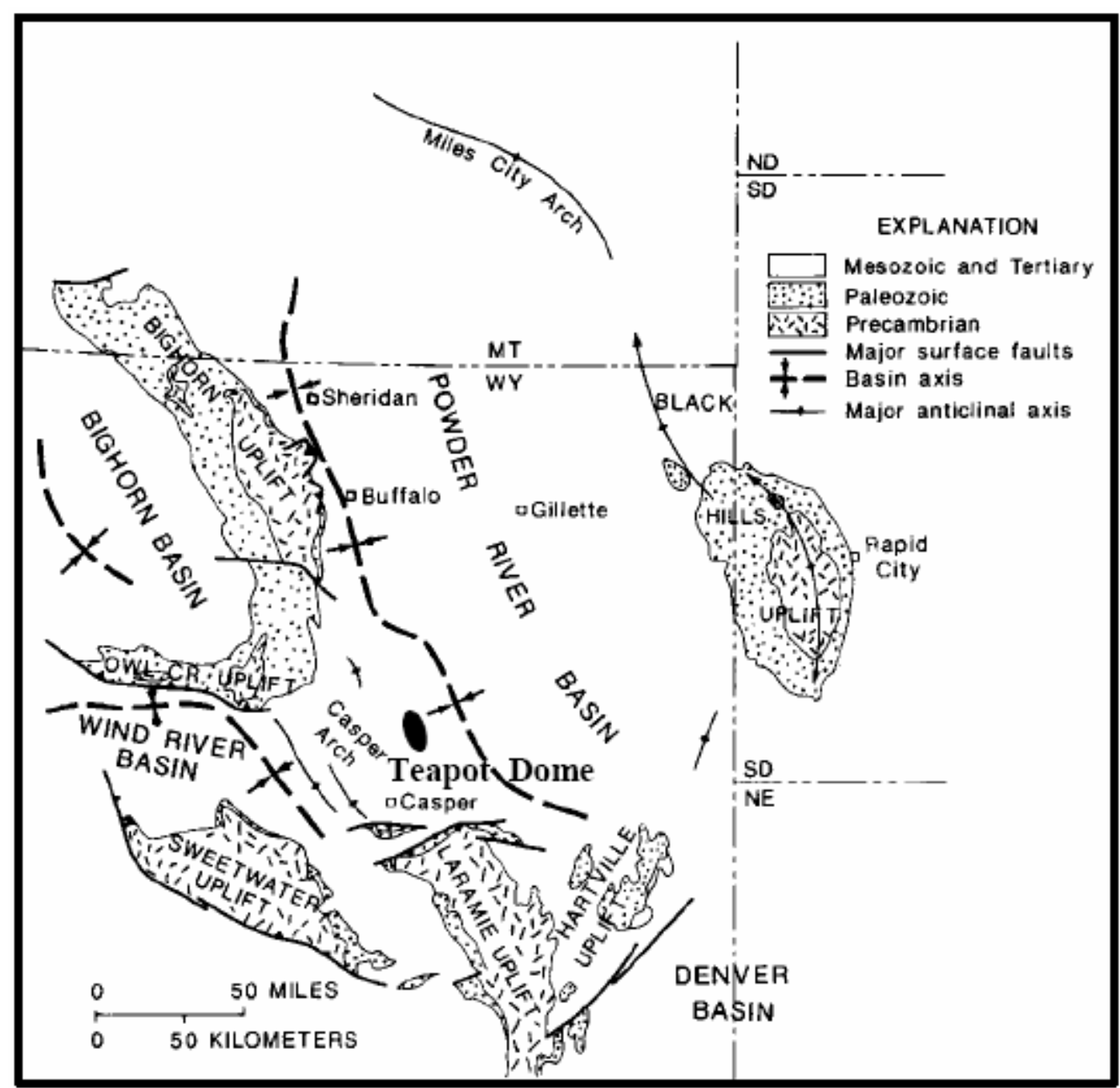

(2000).

Figure 2-3: Location of Teapot Dome. Figure is taken from Cooper 
indicates some horizontal displacement occurred along the basement thrust fault. Cooper (2000) also inferred the involvement of horizontal displacement along the deeper thrust that formed Teapot Dome based on the pattern of fractures mapped at the surface.

\subsection{Previous Work}

\section{Fracture Studies at Teapot Dome}

Cooper $(2000,2001)$ mapped fractures exposed at the surface in outcrops of the Parkman Sandstone of the Upper Cretaceous Mesaverde Group at Teapot Dome. Dominant fracture sets identified in the study consisted of hinge-parallel, hingeperpendicular, and hinge-oblique sets. The interrelationship between the three sets is illustrated in Cooper's structural model (Figure 2-4). Cooper (2000) also modeled the trend of the anticlinal fold hinge at Teapot Dome as N25W in the southern part of the structure. Midway along the length of the anticline, the trend of the fold hinge rotates westward to N40W. According to Cooper's (2000) model, the three sets of fractures encountered in the southern part of the anticline should consist of a dominant hingeparallel set that strikes $\mathrm{N} 25 \mathrm{~W}$, a hinge-perpendicular set with a strike of N65E, and a smaller hinge-oblique set with a strike of about N70W with an occurrence of 1.83:1.33:1.00, respectively. A data set was created to illustrate the appearance of Cooper's model in rose diagram and equal area projection form. This model illustrated fractures in the southern part of the oilfield and is displayed in Figure 2-5. The fold axis in the northern part of the field is rotated by $15^{\circ}$ to account for the change in the anticlinal axis. Thus generalized models will be used as a reference against which to compare fractures sets found in FMI logs of the Tensleep Formation. 


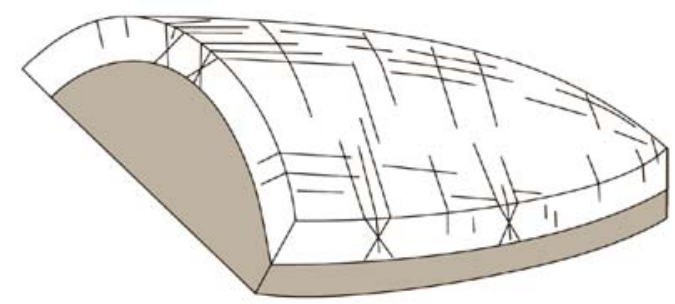

Figure 2-4: Teapot Dome surface fracture model proposed by Cooper (2000) represents the dominant fracture sets observed at the surface in the Mesaverde Formation. The dominant fracture sets are normal and parallel to the crest of the anticline.
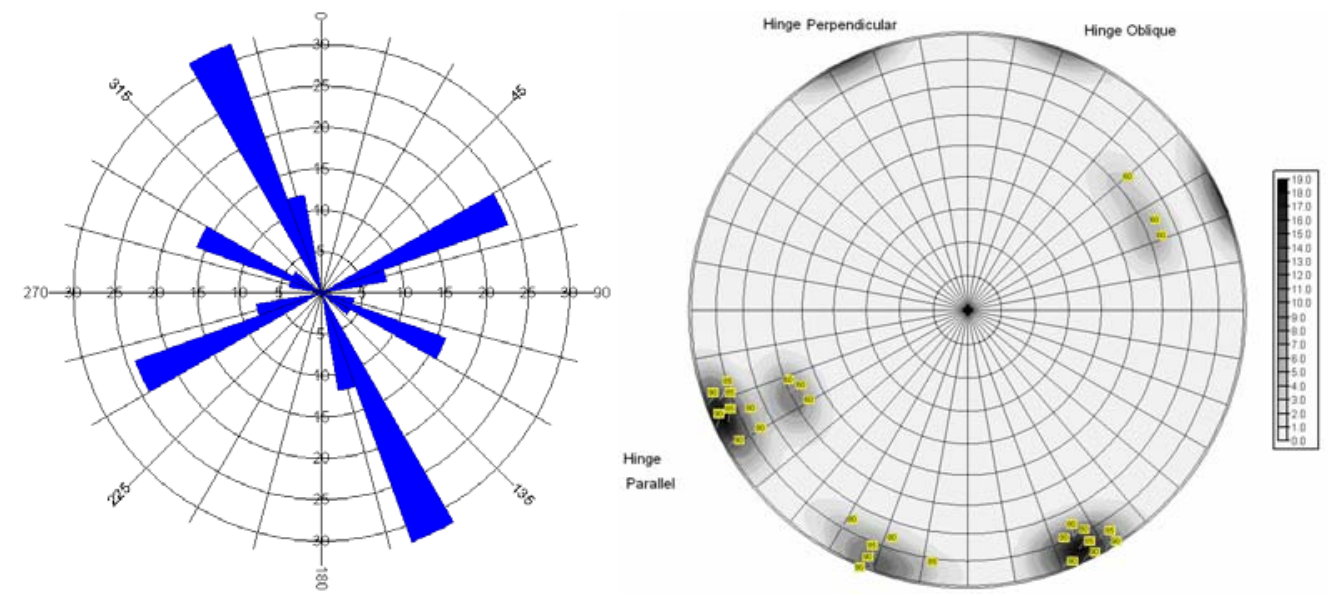

Figure 2-5: Idealized Rose diagram (left) and equal area projection (right) of the fractures shown in Cooper's Teapot Dome fracture model. The fracture data is an idealized fracture description based on Cooper's (2000) fracture description and frequency for the Mesaverde Formation shown in Figure 2-4. 
Cooper $(2000,2001)$ also identified fracture characteristics based on lithology. He noted that most fractures occurring in the Parkman Sandstone terminate at shale layers, have a greater fracture density with increased cementation, and form bands of deformation in poorly sorted, high porosity zones instead of fracturing. He also noted a higher density of fractures near fault zones and conjugate fracture sets striking subparallel to the axis of the anticline. Interpretation of a 3-D seismic data by Wilson (2005) shows a series of NE-SW striking normal faults and is displayed in Figure 2-6. The series of normal faults deviate by 10-20 degrees from surficially mapped faults observed by Cooper (2000) along the flanks of the dome in both the northern and southern part of the anticline.

\section{Structural History of Powder River Basin and Teapot Dome}

As noted earlier, Teapot Dome was formed during the Laramide orogeny. The Laramide orogeny extended from approximately $80-40 \mathrm{Ma}$ (i.e. late Cretaceous through Eocene) and resulted from the convergence of the Farallon Plate with the North American plate. The convergence angle produced NW-SE trending structures shortened in the NE-SW direction (Brown, 1993). The Laramide orogeny also produced structures interpreted to result from reactivation of older, possibly Precambrian age, linear zones of basement weakness (Dolton, 1990).

Several models have been proposed to explain how the structures of the Laramide orogeny formed. Stearns (1978) suggested that Teapot Dome formed as a simple drape fold created by differential vertical uplift. Cooper (2000) concluded that the fracture patterns seen in outcrops were more consistent with a basement cored anticline. Gries (1981) proposed a fold-thrust model caused by low-angle reverse faults. Brown (1993) 


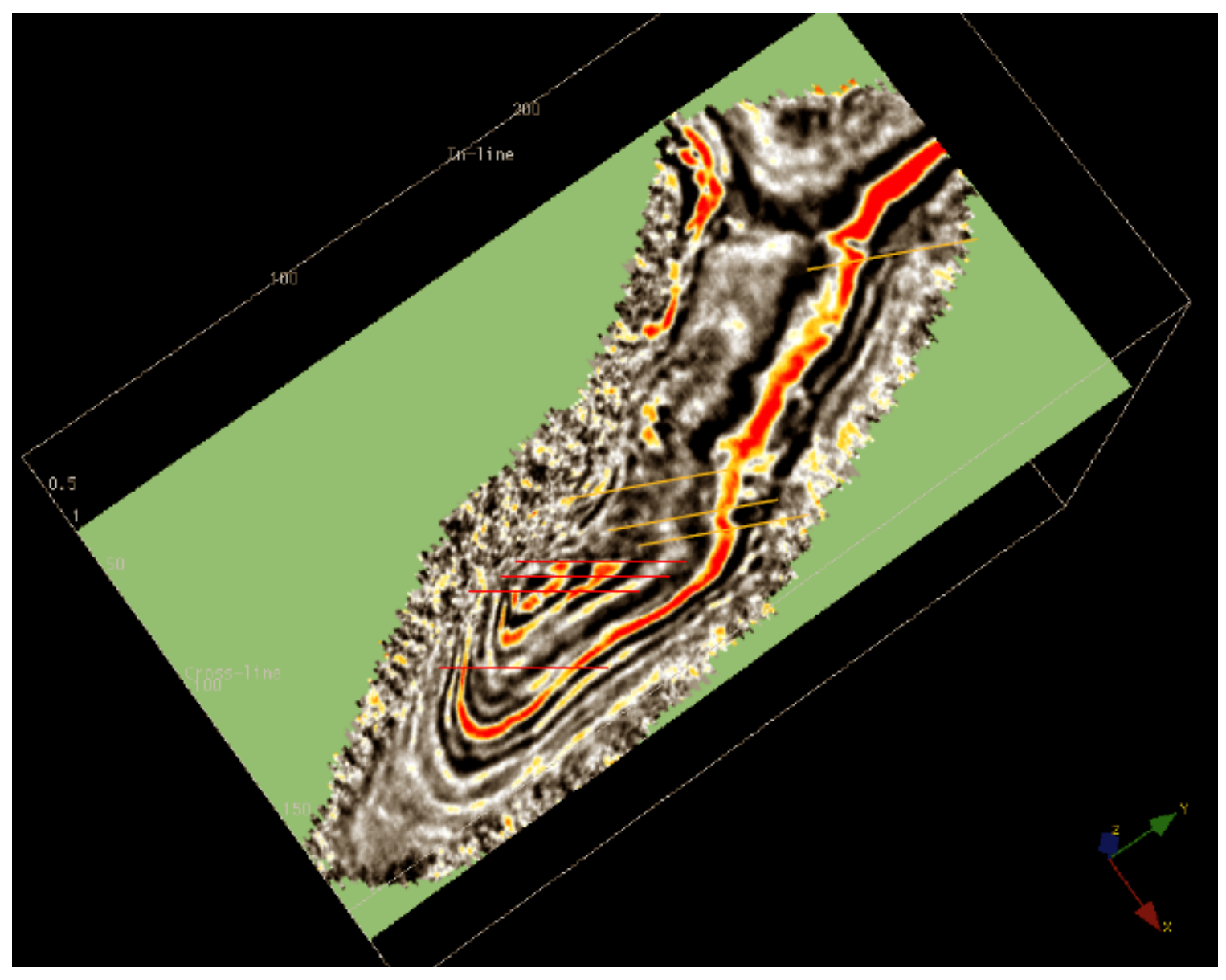

Figure 2-6: Timeslice from the 3D seismic survey over Teapot Dome. The Y direction indicated north. The figure was taken from Wilson (2005). 


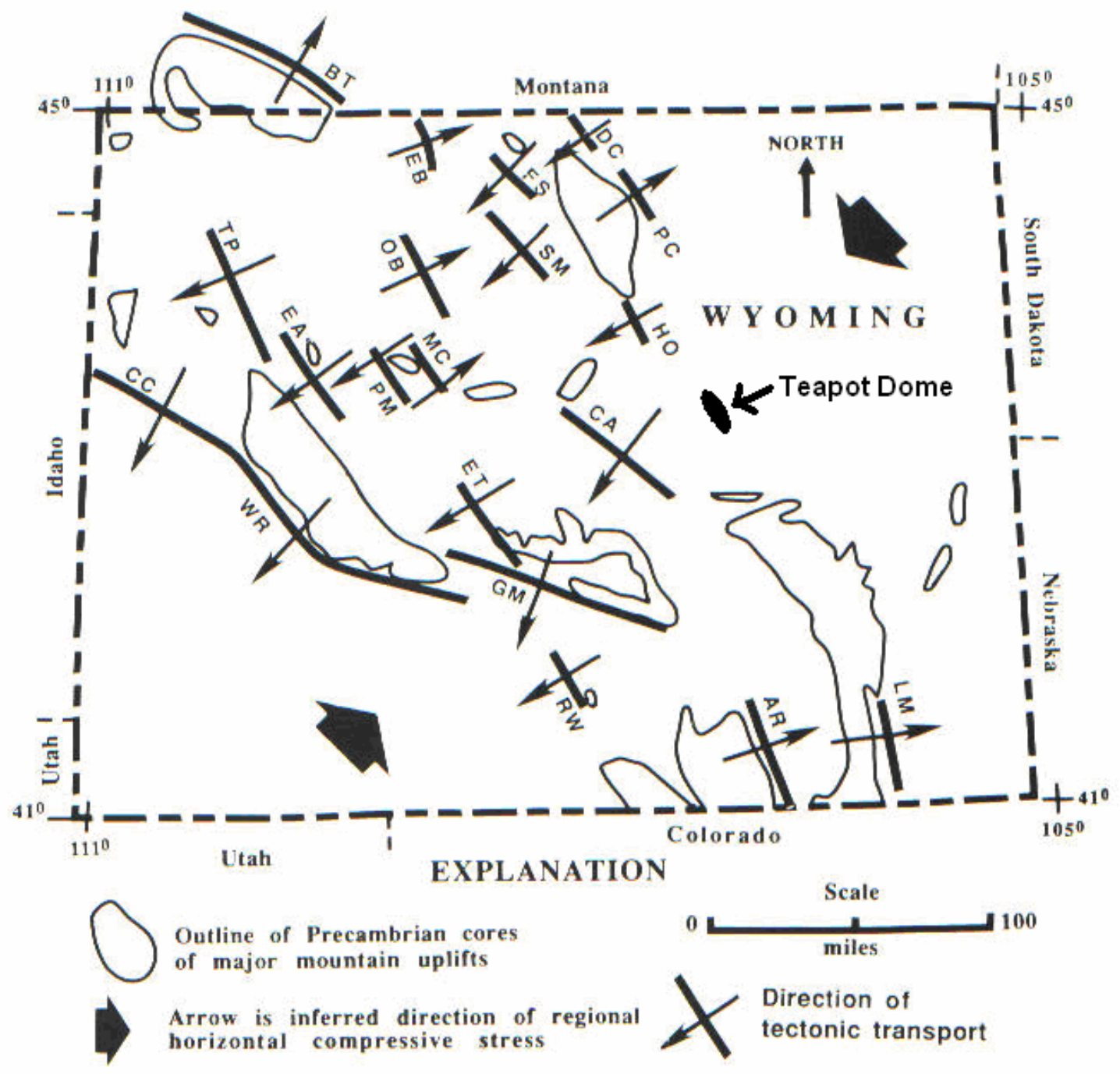

Figure 2-7: This map shows the locations of low angle reverse faults. This figure is modified from Brown (1993). 
indicates that deformation associated with the Laramide orogeny extended into the Precambrian basement rocks. A low angle reverse fault in proximity to Teapot Dome, shown in Figure 2-7, supports the basement cored anticline model proposed by Cooper (2000).

\section{Tensleep Formation}

The Tensleep Formation is an interbedded combination of eolian and marine deposits of Pennsylvanian age (Hurley, 2003; Carr, 1996, Nilsen, 2004). Core analysis of well 48-x-28 (the northernmost well) reveals the eolian sandstone to be fine to very fine grained well-sorted quartz arenite cemented primarily with dolomite (Nilsen, 2004). Nilsen (2004) also noted the presence of anhydrite nodules. Five major transgression/regression events have been identified in the core analysis undertaken by Nilsen (2004). He observed an increasing frequency of secondary parasequences toward the base of the Tensleep. The geophysical logs in Figure 2-8 show several early secondary parasequences in the lower part of the Tensleep Formation. The top of the Tensleep is an unconformity. Differential erosion along this surface leads to variable thickness of the Tensleep Formation. The Tensleep Formation has a thickness of about 250 feet at Teapot Dome based on interpreted geophysical logs (Figure 2-8).

The eolian sandstone facies of the Tensleep Formation was formed in a dry aerodynamically controlled system that was preserved by marine flooding events (Carr, 1996). The deposited carbonate unit was converted to the dolomite that is seen in outcrops and core samples. The Tensleep dolomites serve as major barriers to flow as described by Carr (1996) and Hurley (2003). Reduced porosity and permeability of the dolomite intervals is associated primarily with secondary dolomitic cementation (Carr, 


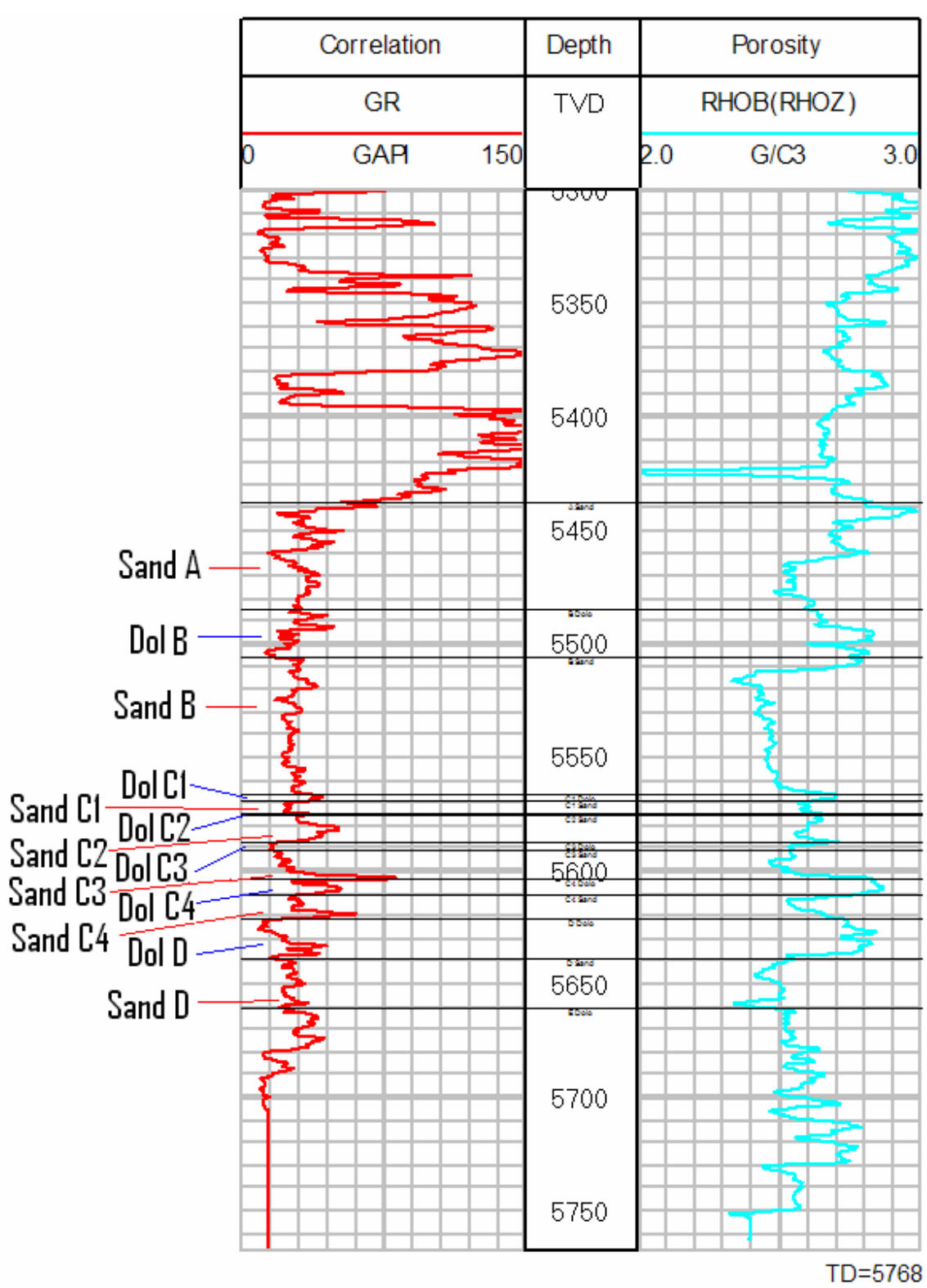

Figure 2-8: Stratigraphic subdivisions of the Tensleep Formation in well 48-x-28 as interpreted by core analysis (Nilsen, 2004). 


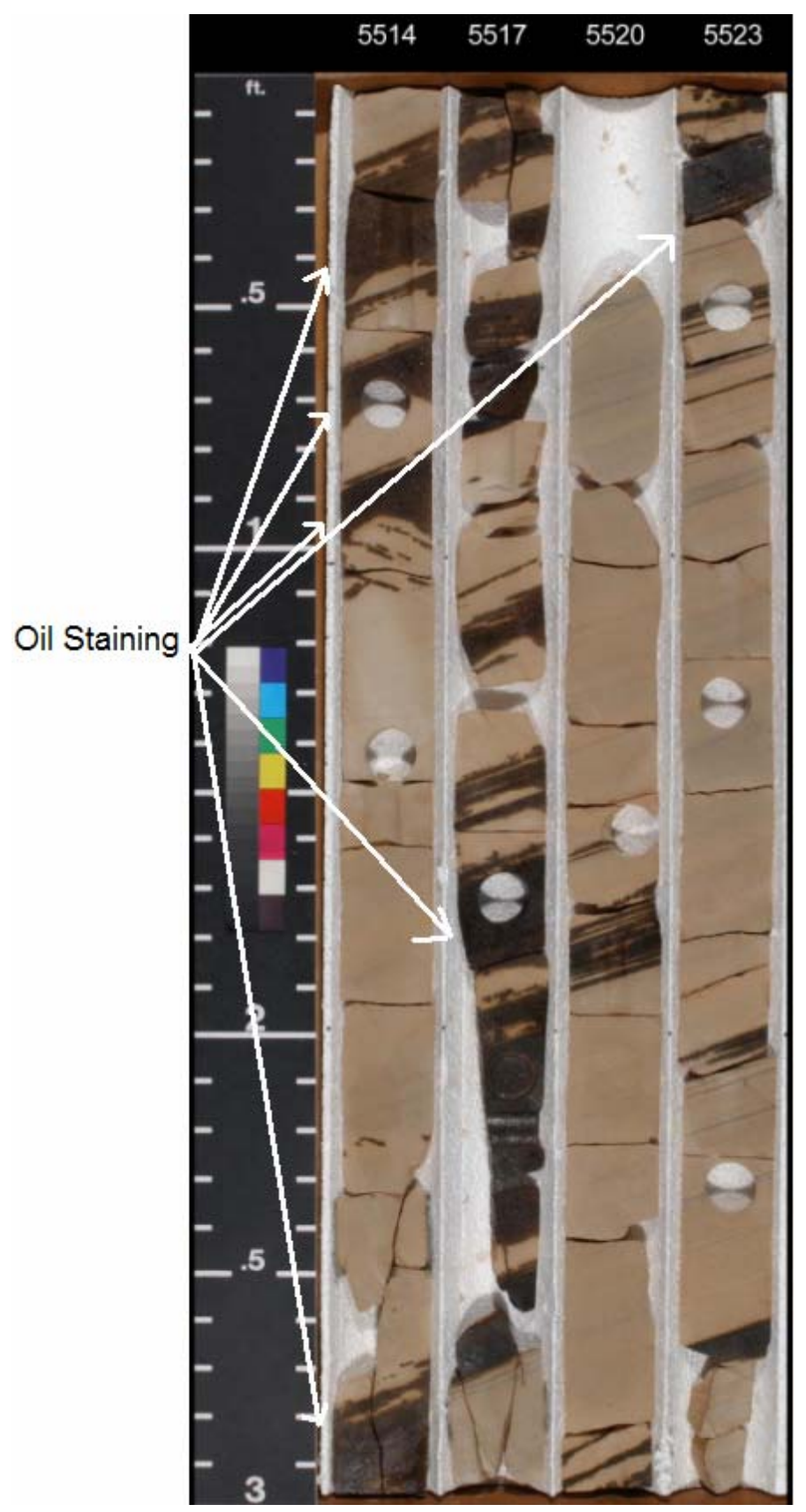

Figure 2-9: Core photo of the oil staining that occurs at the top 12 feet of the Sandstone B Reservoir for well 48-x-28. This core photo was provided by RMOTC. Arrows indicate some of the oil staining. 
1996). Evidence for the influence of these dolomite barriers can be inferred from the distribution of oil staining. Oil staining is confined to the tops of sandstones A and B. This suggests that oil at the top of Sandstone B is prevented from migrating into the base of Sandstone A by the intervening low permeability Dolomite B. Figure 2-9 shows the oil stain core for well 48-x-28. Nilsen (2004) detected fluorescence or partial fluorescence in the upper parts of Sandstone A and Sandstone B indicating the presence of oil. Carr (1996) suggests that there is a directional anisotropy in relative reservoir permeability associated with crossbeds in the eolian sands. Similar structures have been observed in outcrops of the Tensleep at Alcova, Wyoming (Figure 2-10). Hurley (2003) also suggests that dune compartmentalization of the Tensleep eolian layer would further inhibit the flow of fluids. This is further supported at Teapot Dome by the examination of core from well 48-x-28. Figure 2-11 indicates that the eolian cross-bedding will inhibit bed-parallel flow. This is supported by core observations which reveal oil is confined to the sandier more permeable intervals within the cross beds. Core observations (Figure 2-12) also reveal that fractures allow communication between cross beds. 


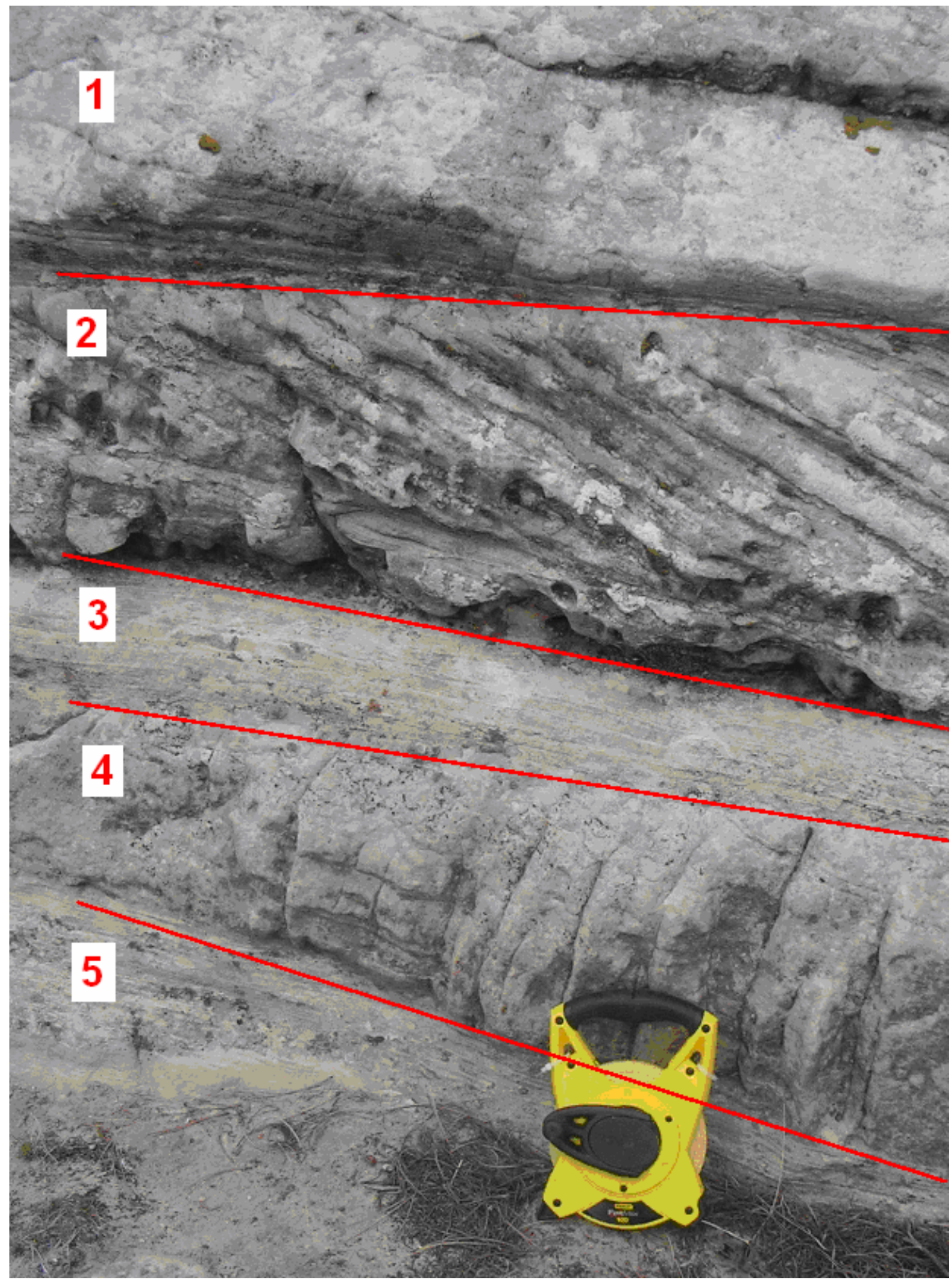

Figure 2-10: Photo taken at Alcova reservoir. This is about 60 miles southwest of Teapot Dome. Notice the compartmentalization of the eolian dune sand. Sequence 4 is highly fractured but is bound by sequences 3 and 5 that are relatively fracture free and may serve as relative permeability barriers. 


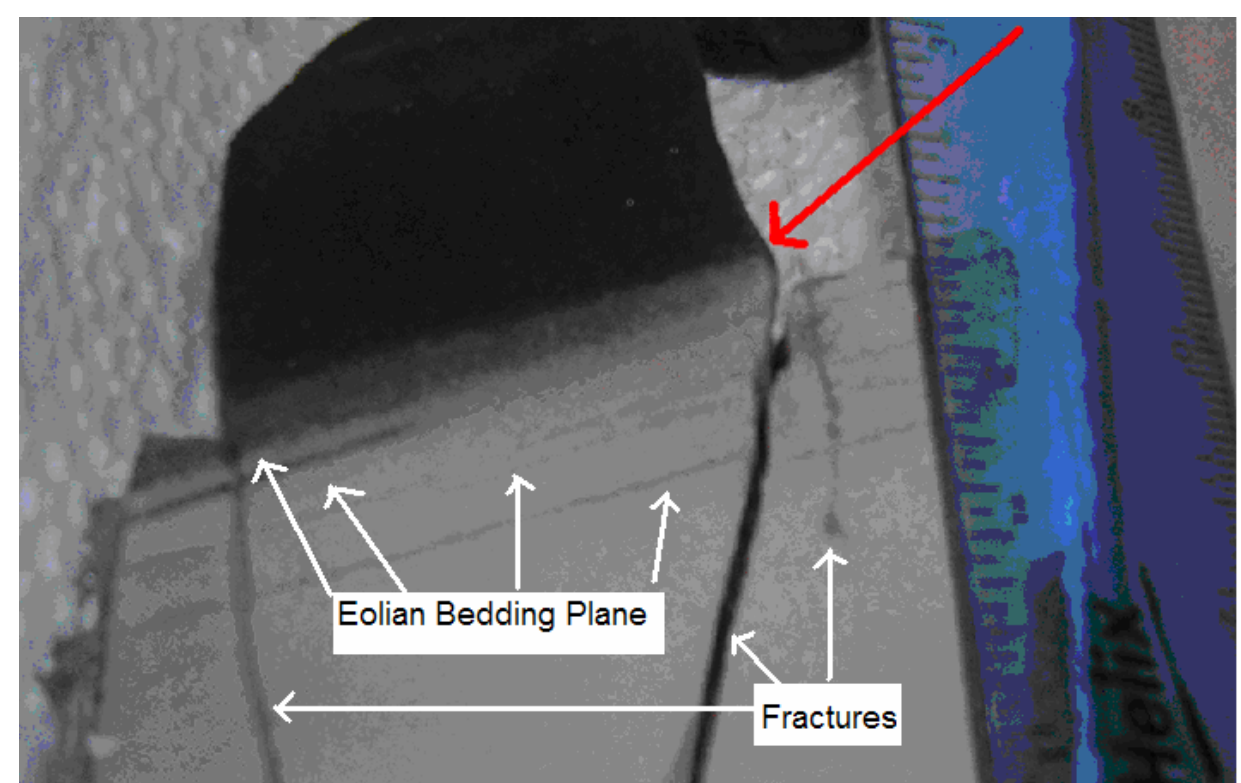

Figure 2-11: This is core photo from well 48-x-28 and is located in the Sandstone $\mathrm{B}$ unit of the Tensleep Formation. Notice how the oil staining does not penetrate the bedding plans of the eolian structure. The lithology is consistent across the bedding planes: Clean sandstone with grains that are well sorted, rounded, and very fine upper to fine lower in size.

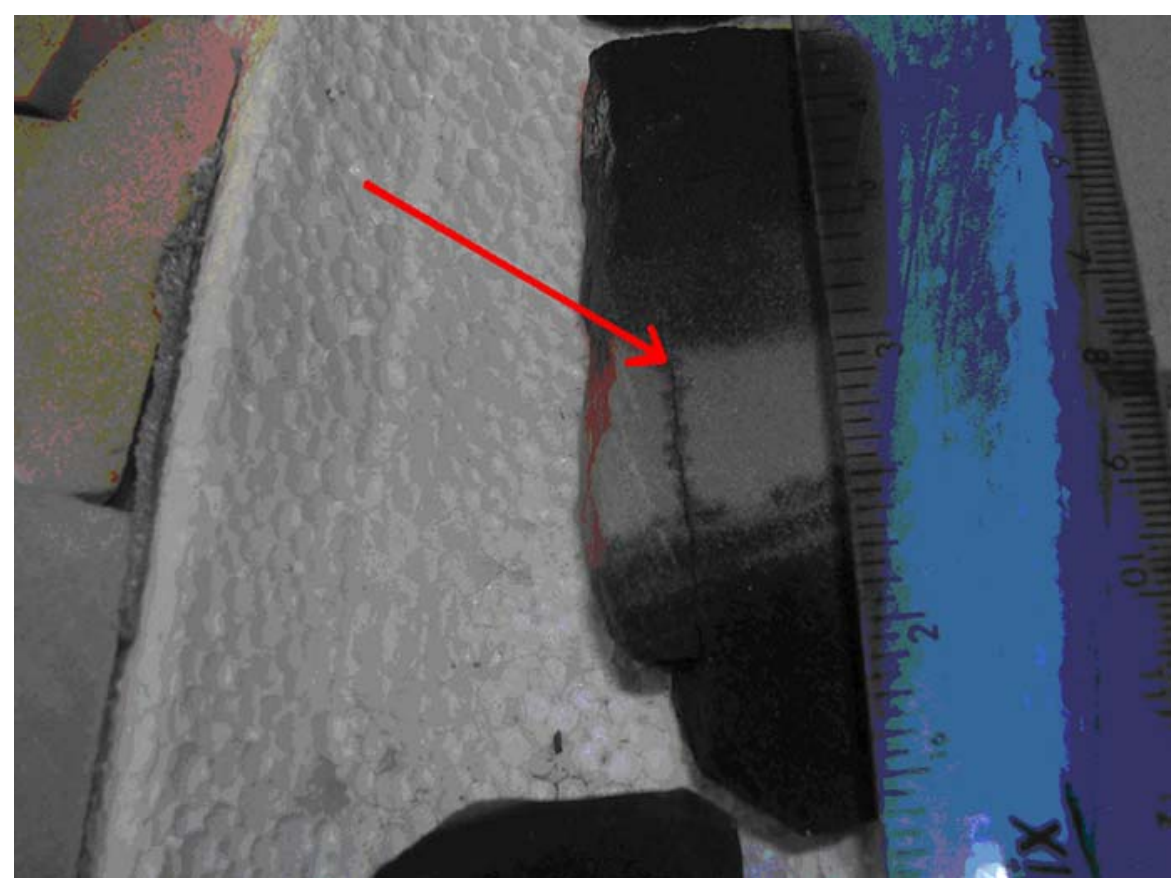

Figure 2-12: This is core photo from well 48-x-28 and is located in the Sandstone B unit of the Tensleep Formation. Note the small fracture in the core provides some intercommunication between two oil saturated intervals. 


\section{Chapter 3: Data Analysis}

\subsection{Geophysical Logs}

Geophysical logs are available from twenty-three wells that penetrate the Tensleep Formation. Most of the wells are in the structurally high area of the Tensleep Formation at Teapot Dome. Their locations are shown in Figure 3-1. Available log types vary from well to well but generally include gamma ray, neutron porosity, neutron density, and bulk density. Subdivisions of the Tensleep (i.e. Sandstone A, Sandstone B, etc.) were picked from the geophysical logs by Mark Milliken $(2002,2004)$ and Brian Black (2004) for these wells.

\section{Picks of Tensleep sequences}

Stratigraphic interpretations of the Tensleep Formation were based on gamma ray, bulk density, and neutron porosity logs from all wells with FMI logs. Formation top picks for well 48-x-28 were also supported by core observations. Initial picks for the top of Sandstone A, Dolomite B, and Dolomite C1 were derived from core interpretation of well 48-x-28. There was a core wash out zone at the base of the Dolomite B layer and the top of the Sandstone B layer. The depth of the top of Sandstone B was determined by using the bulk density log and the neutron porosity/bulk density crossover for well 48-x28. Figure 3-2 shows the gamma-ray, resistivity, neutron porosity, and bulk density curves for well 48-x-28. The top of the Dolomite B layer has a low bulk density of 2.6 $\mathrm{gm} / \mathrm{cm}^{3}$, but a core investigation indicates a lithologic change at this boundary to a sandy dolomite. Figure 3-3 shows an unmistakable visual change in appearance of the core at a 




Figure 3-1: This figure shows the location of wells with geophysical data. Square wells indicate FMI log data is available for this well. Aerial photographs provided by the USDA's geospatial gateway http://datagateway.nrcs.usda.gov/. 


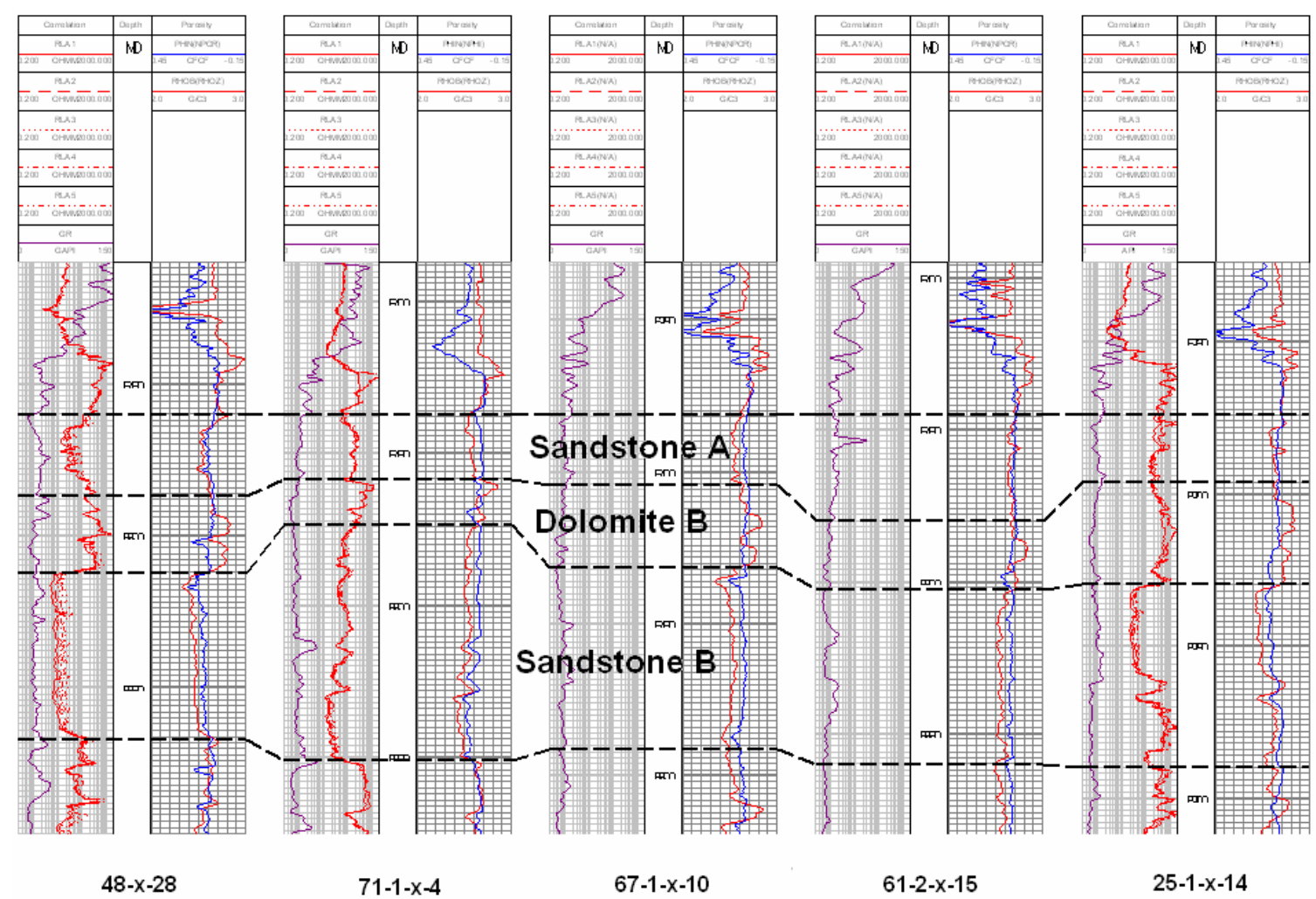

Figure 3-2: Geophysical log correlations are shown for the five wells with FMI logs. The display runs NW to SE along the axis of the Dome. The left track in each log contains the gamma ray and induction logs; the right track contains the bulk density and neutron porosity logs. 
core depth of $5479 \mathrm{ft}$ below surface. This core depth corresponds to a log depth of 5486ft below surface.

Well 48-x-28 was used as the standard to correlate the other 4 FMI wells. Figure 3-2 (gamma-ray, resistivity; neutron porosity, bulk density logs) shows the log correlations for the Sandstone A, Dolomite B, Sandstone B, and Dolomite C1 sequences in the Tensleep Formation. The tops of Sandstone A, Dolomite B, and Sandstone B were determined by matching log patterns. The top of the Dolomite $\mathrm{C} 1$ sequence was difficult to pick in wells $67-1-\mathrm{x}-10,61-2-\mathrm{x}-15$, and well $25-1-\mathrm{x}-14$. The core of well $48-\mathrm{x}-28$ (Figure 3-4) reveals that the $\mathrm{C} 1$ and $\mathrm{C} 2$ dolomite layers are about 1 foot and $1 / 2$ foot in thickness, respectively. Figure 3-2 indicates that the C1 Dolomite marker may not be evident from the bulk density logs. Without the Dolomite $\mathrm{C} 1$ marker, differentiation between the Sandstone B and Sandstone C1 layers is difficult. The lower Dolomite D and Dolomite C3 layers were interpreted from the well logs and a best estimate for the location of the Sandstone B and Sandstone C1 interface was marked as the top of C1 Dolomite.

Table 3-1 is a list of depths for the tops of Sandstone A, Sandstone B, and Dolomite B interpretations. This information was used to determine the thickness of the individual layers (Table 3-2). Figure 3-5 reveals that the combined thickness of Sandstone A, Dolomite B, and Sandstone B have a relatively consistent thickness along the axis of Teapot Dome that averages 112.2 feet with a standard deviation of $+/-3.7$ feet. There are some areas of thickening and thinning associated with the individual layers. Sandstone A shows its greatest thickness of 35 feet at well 61-2-x-15. Well 


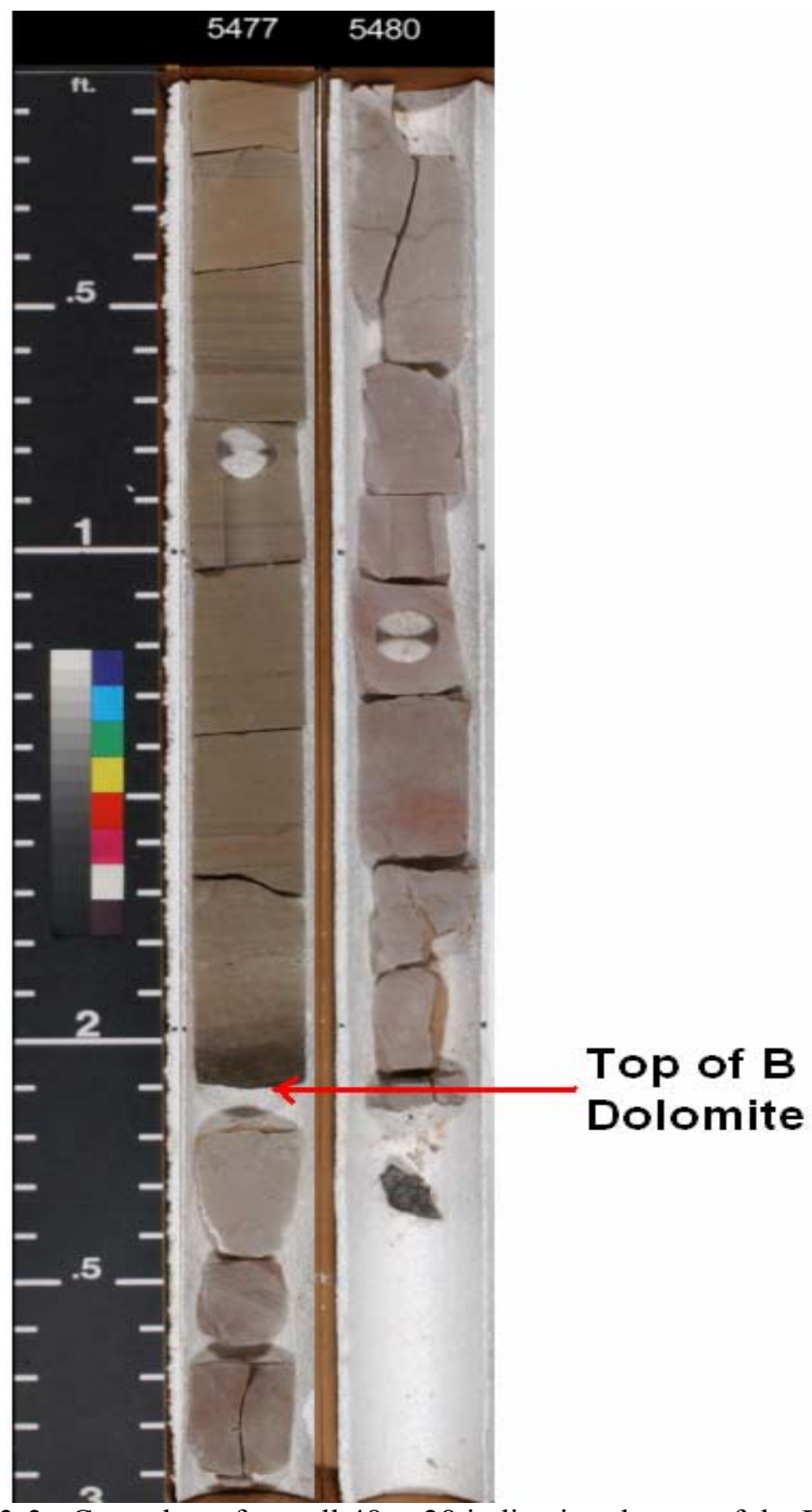

Figure 3-3: Core photo for well 48-x-28 indicating the top of the Dolomite B layer. Notice the change in character at the core depth of $5479 \mathrm{ft}$ below surface. This corresponds to a log depth of $5486 \mathrm{ft}$. 


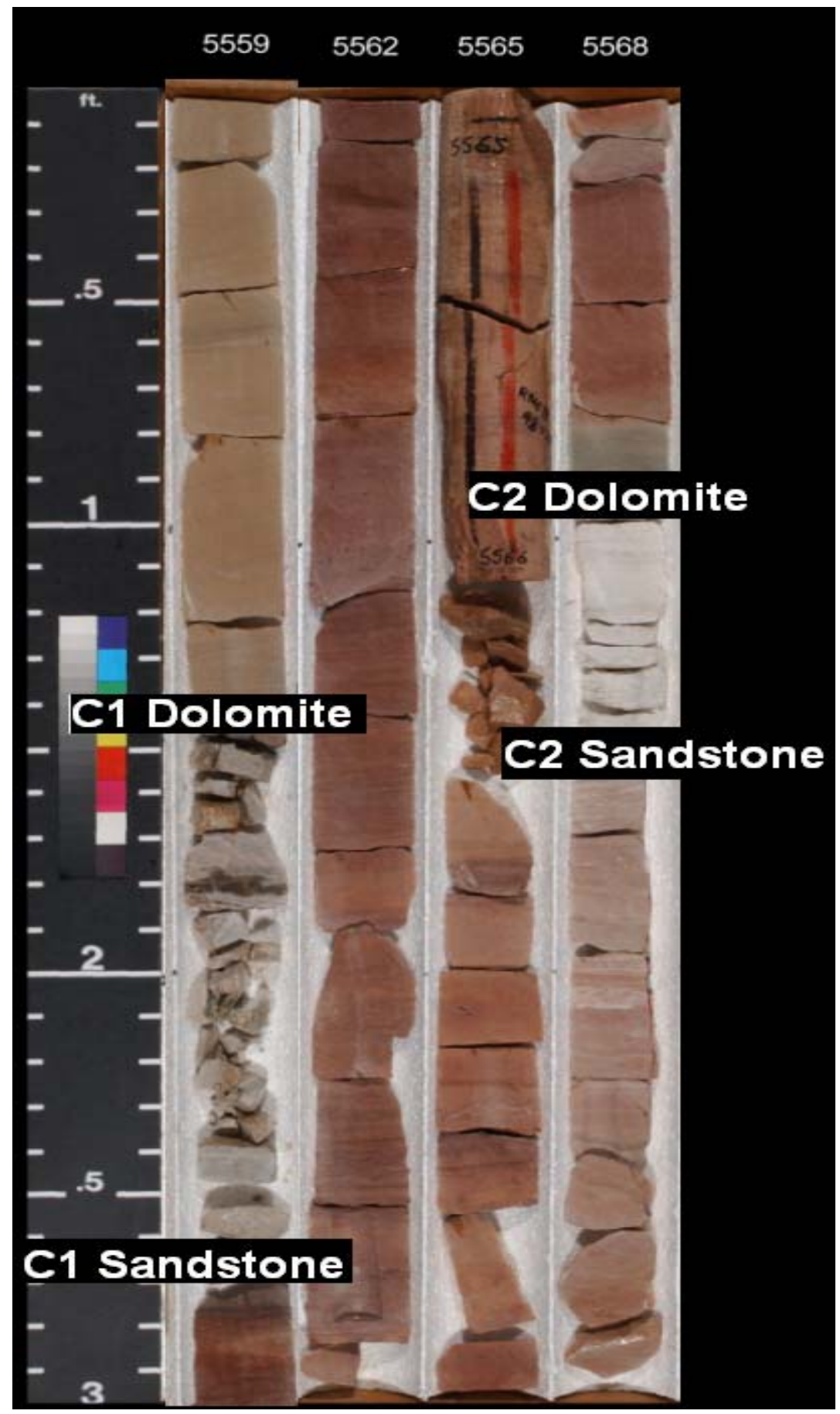

Figure 3-4: Core photo for well 48-x-28 indicting the tops of C1 Dolomite, C1 Sandstone, C2 Dolomite, and C2 Sandstone. Notice that the C1 and C2 Dolomites are about 1 foot and 1.2 foot, respectively. 


\begin{tabular}{|c|c|c|c|c|}
\hline Well & A Sandstone & B Dolomite & $\begin{array}{c}\text { B } \\
\text { Sandstone }\end{array}$ & $\begin{array}{c}\text { C1 } \\
\text { Dolomite }\end{array}$ \\
\hline $\mathbf{4 8 - x - 2 8}$ & -345 & -371 & -397 & -452 \\
\hline $\mathbf{7 1 - 1 - x - 4}$ & -241 & -262 & -277 & -354 \\
\hline $\mathbf{6 7 - 1 - x}-10$ & -175 & -198 & -226 & -285 \\
\hline $\mathbf{6 1 - 2 - x - 1 5}$ & -201 & -236 & -258 & -316 \\
\hline $\mathbf{2 5 - 1 - x - 1 4}$ & -549 & -571 & -605 & -665 \\
\hline
\end{tabular}

Table 3-1: Subsea depths to the tops of the major Tensleep subdivisions in wells with FMI logs..

\begin{tabular}{|c|c|c|c|c|}
\hline Well & $\begin{array}{c}\text { A } \\
\text { Sandstone }\end{array}$ & B Dolomite & B Sandstone & $\begin{array}{c}\text { A, B Sand B } \\
\text { Dol }\end{array}$ \\
\hline $\mathbf{4 8 - x - 2 8}$ & 26 & 26 & 55 & 107 \\
\hline $\mathbf{7 1 - 1 - x - 4}$ & 21 & 15 & 77 & 113 \\
\hline $\mathbf{6 7 - 1 - x - 1 0}$ & 23 & 28 & 59 & 110 \\
\hline $\mathbf{6 1 - 2 - x - 1 5}$ & 35 & 22 & 58 & 115 \\
\hline $\mathbf{2 5 - 1 - x - 1 4}$ & 22 & 34 & 60 & 116 \\
\hline
\end{tabular}

Table 3-2: Thicknesses of Sandstone A, Dolomite B, and Sandstone B in feet from geophysical log top picks. Combined thickness is also noted. 
71-1-x-4 displays the thickest Sandstone B layer at 77 feet thick but has the smallest

Sandstone A and Dolomite B layers. A cross section (Figure 3-6) through FMI Log wells (Figure 3-7) reveal that the Tensleep is at a structural high in the southern part of the field at well 67-1-x-10.

\subsection{FMI Data}

There are a total of five vertical wells at Teapot Dome that have FMI log coverage through the Tensleep Formation. These wells are located just to the east of the anticlinal axis and are displayed in Figure 3-7. Three of the wells with FMI data are located in or near section 10. The majority of oil production from the Tensleep Formation at Teapot Dome oilfield occurs in this section (Milliken, 2005). Detailed interpretations of the FMI logs were prepared by Koepsell (2002 and 2004) for fractures (open, closed, and induced) and sedimentary bedding planes. These interpretations include comprehensive fracture identification and classification along the length of the borehole covered by the FMI logs. These interpreted fractures are grouped into layers in the Tensleep by the depths in Table 3-1. Quantitative analysis undertaken by Koepsell was provided in several Excel and Schlumberger PDS files by RMOTC. These files include bed boundary, continuous fractures, drilling induced fractures, sedimentary bedding, lithologically bound fractures, partially-healed fractures, resistive fractures, and sedimentary bedding analysis. Additional information on fracture classifications is found in Appendix A. 


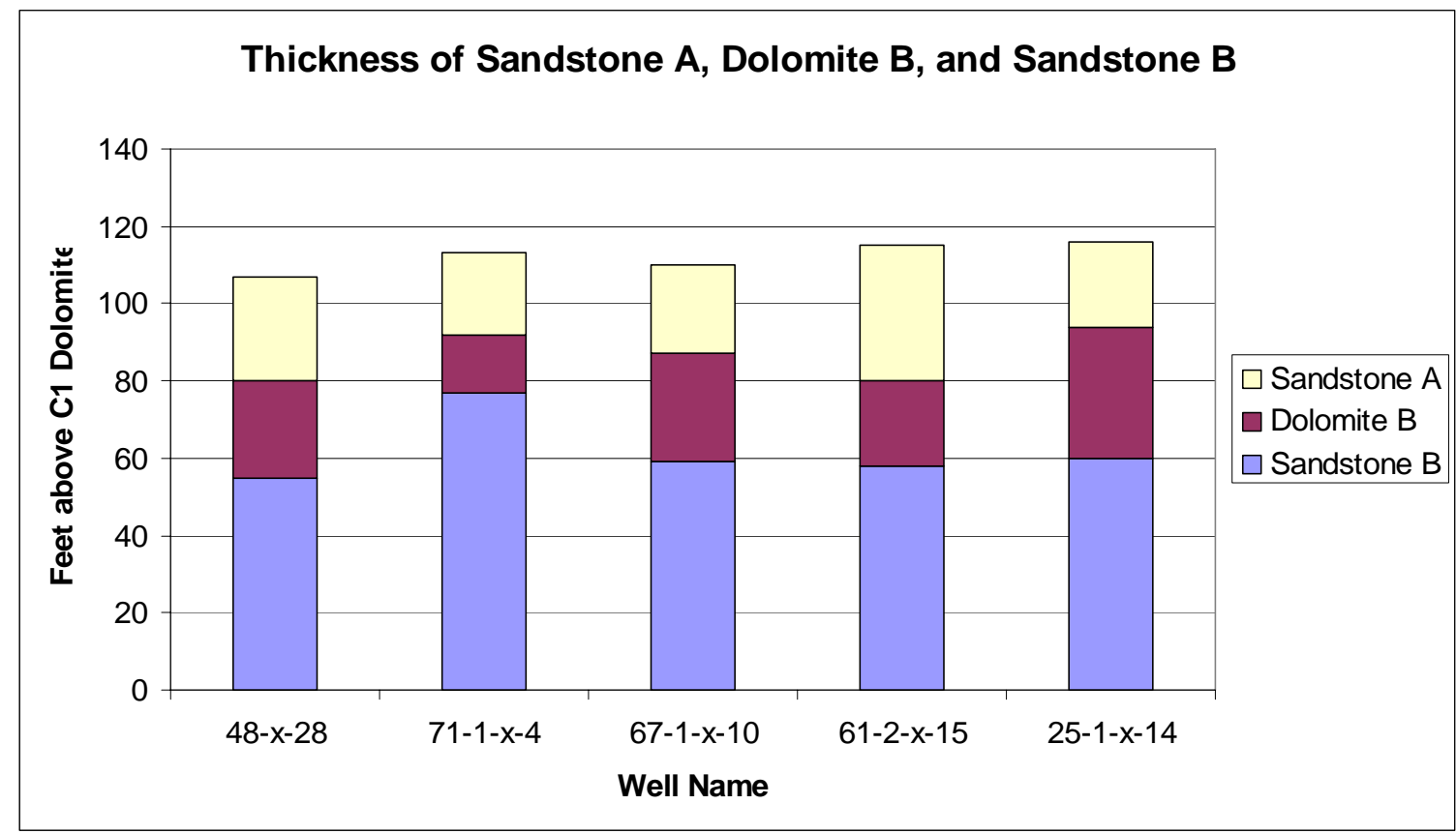

Figure 3-5: Thicknesses of Sandstone A and B and Dolomite B layers from the FMI log data. The base of Sandstone B was used as the datum for this Figure.

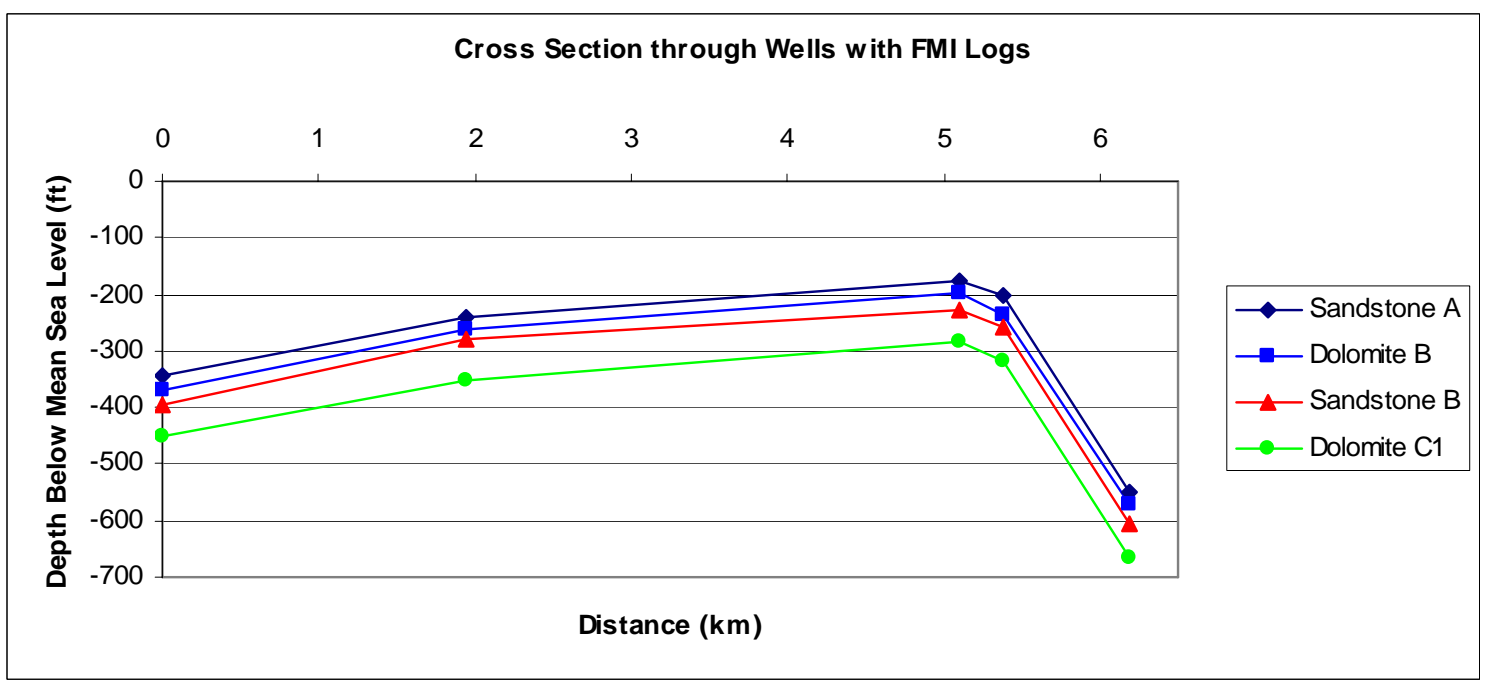

Figure 3-6: NW-SE oriented cross section formed from wells with FMI logs showing subsea depths to the tops of the units in the Tensleep. 


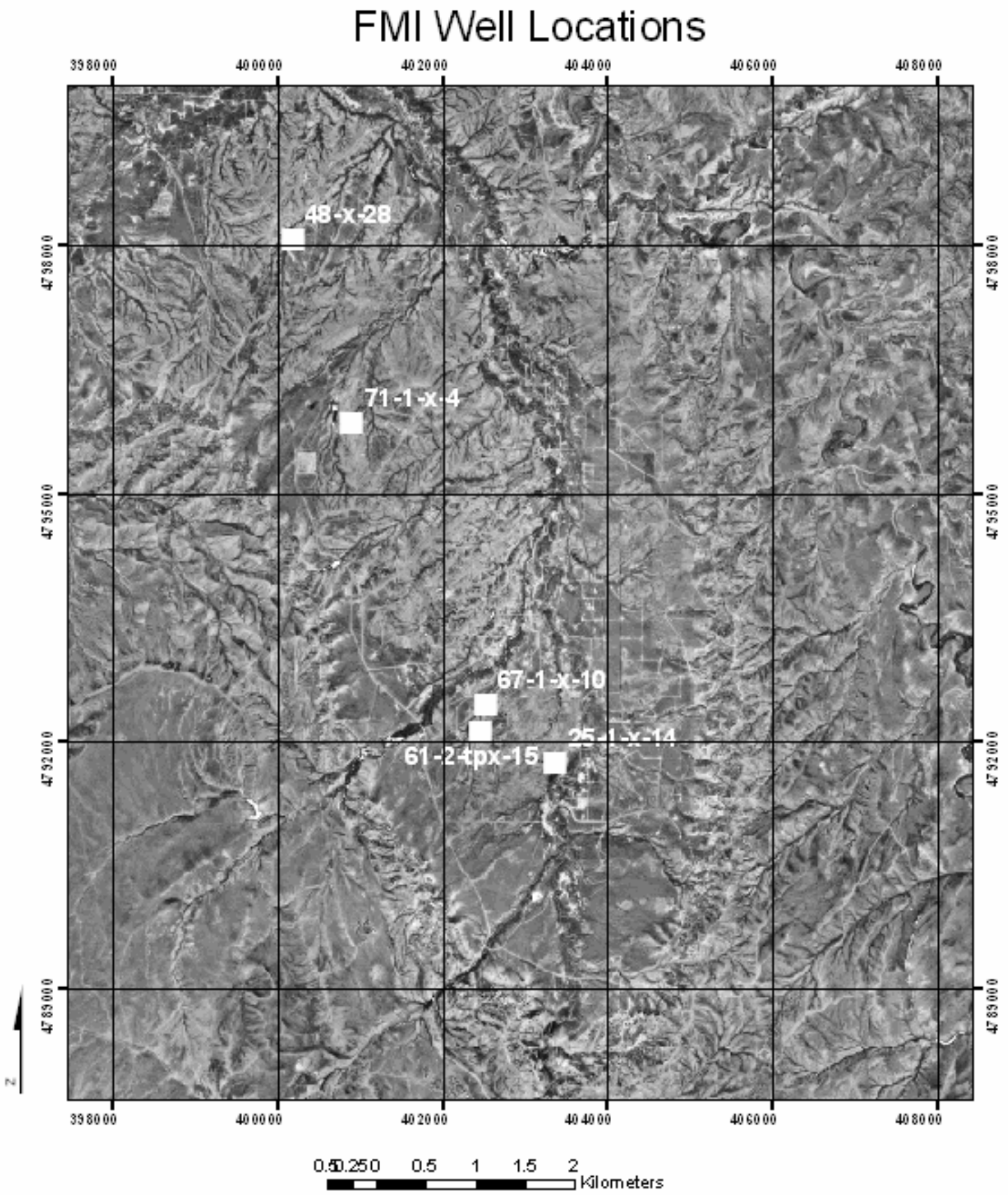

Figure 3-7: Location of wells containing FMI logs and core samples. Aerial photographs provided by the USDA's geospatial gateway http://datagateway.nrcs.usda.gov/. 


\section{Rose Diagrams and Equal Area Projections (Open Fractures)}

Rose diagrams and equal area projections of the open fractures, identified by

Koepsell, were constructed of individual stratigraphic subdivisions of the Tensleep Formation, and used to determine different groups of fractures. The primary oil producing Tensleep reservoirs at Teapot Dome are the A and B sandstones in Section 10. For this reason, rose diagrams and equal area projections were constructed of the open fractures in these 2 layers and also of the intervenning Dolomite B layer.

The axial hinge of the Teapot Dome was interpreted from an isochron map of the reflection event associated with the Tensleep Formation (Figure 3-8). The hinge line was divided into 5 linear sections. Table 3-3 lists the orientations of individual hinge segments, I -V. One of the major objectives of this study is to determine whether the fracture orientations observed at the surface coincide with the fracture orientations found at depth in the Tensleep Formation. The azimuth of hinge-parallel, hinge-perpendicular, and hinge-oblique fracture sets listed in the table are based on Cooper's (2000) surface fracture model. If Cooper's (2000) model serves as a good predictor of the fracture systems at depth, than fractures observed along the well bore in these areas should have trends similar to those predicted by the model (see Table 3-3). Notice that the trend of the dome hinge varies from southeast to northwest at Teapot Dome (Figure 3-8). Idealized fracture patterns based on Cooper's model were developed for each well with an FMI log. These idealized models are displayed in Figure 3-9 to illustrate hingeparallel, hinge-perpendicular, and hinge-oblique orientations predicted by Cooper (2000) from surface observations. Orientations of fracture sets inferred from Cooper's model are tabulated for each well location. 


\begin{tabular}{|c|c|c|c|c|}
\hline $\begin{array}{c}\text { Axial Hinge } \\
\text { Section }\end{array}$ & $\begin{array}{c}\text { Hinge } \\
\text { Parallel }\end{array}$ & $\begin{array}{c}\text { Hinge } \\
\text { Perpendicular }\end{array}$ & $\begin{array}{c}\text { Hinge } \\
\text { Oblique A }\end{array}$ & $\begin{array}{c}\text { Hinge } \\
\text { oblique B }\end{array}$ \\
\hline V & N34W & N56E & N79W & N11E \\
\hline IV & N24W & N66E & N69W & N21E \\
\hline III & N32W & N58E & N77W & N13E \\
\hline II & N5W & N85E & N50W & N40E \\
\hline I & N34W & N56E & N79W & N11E \\
\hline
\end{tabular}

Table 3-3: The trend of the Dome axis is noted for roughly linear segments shown in Figure 3-8. The oriented trends of fracture sets proposed by Cooper (2000) are located for each segment.

Fracture orientations observed in sandstones A and B and Dolomite B derived from FMI log analysis are presented as rose diagrams and equal area plots (see Figures 310, 3-11, 3-12, and 3-13). Figures 3-10, 3-11, and 3-12 reveal variations in the fracture orientations observed in Sandstone A, Dolomite B, and Sandstone B, respectively. These differences were not evaluated statistically. Composite rose diagrams and equal area projections of all open effective fractures observed in sandstones A and B and Dolomite B (Figure 3-13) reveal a predominance of Hinge Oblique fractures in the northern part of the field. The greatest scatter in the fracture orientations is observed in section 10 . The hinge oblique set again predominates in well 25-1-x-14.

All wells have a dominant hinge-oblique set of fractures. If you rotate the rose diagrams and stereonets for wells 48-x-28, 71-1-x-4, and 67-1-x-10 to align the anticlinal hinge, visual comparison suggests that the relationship of these fracture clusters to the fold trend is similar. Fracture cluster sets I, II, and III for these three wells (Figure 3-13) occur at similar angles from the anticlinal axis. The dip angles of the open-effective fractures observed in 


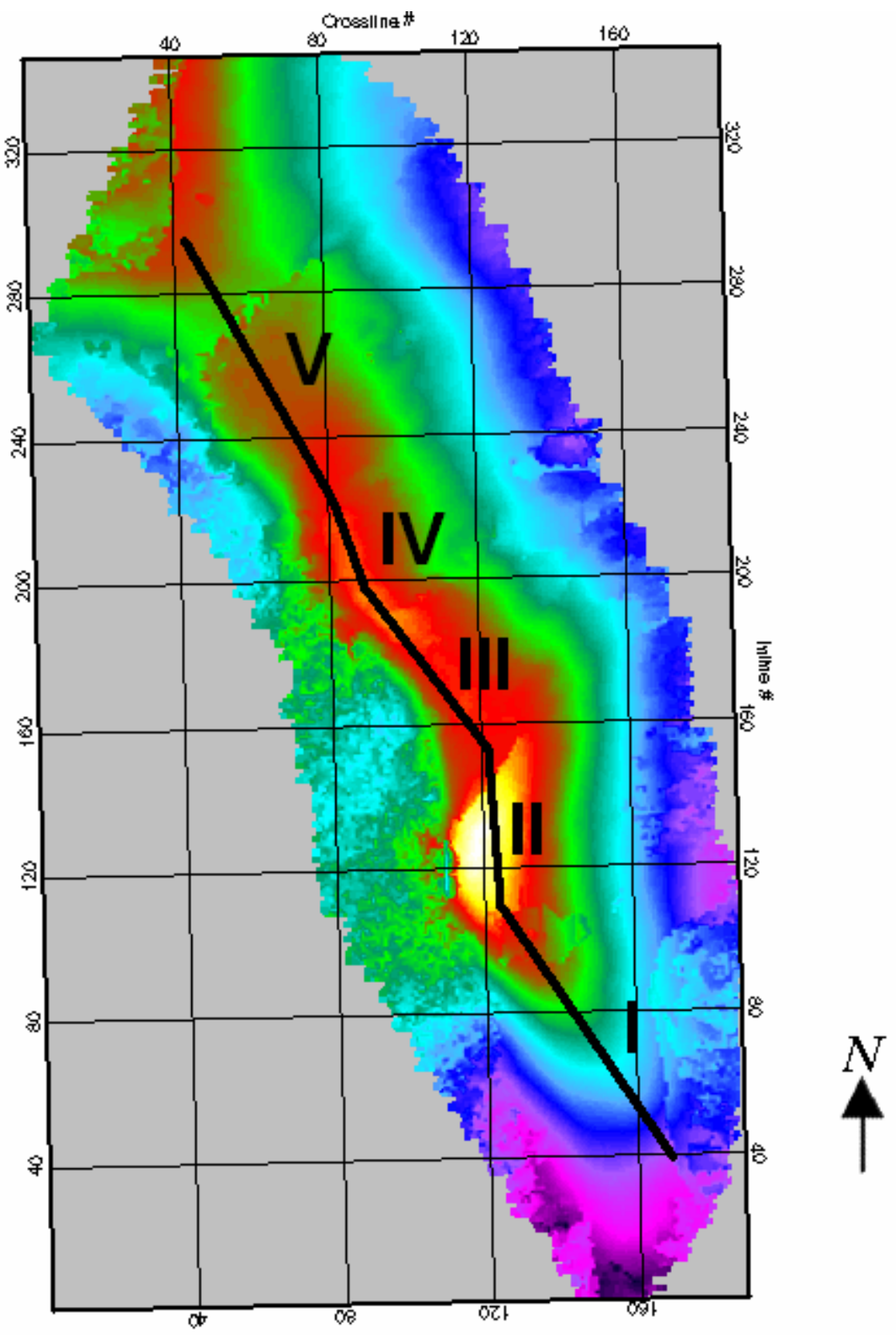

Figure 3-8: Isochron map of the Tensleep Formation reflector at Teapot Dome. The location of the axial hinge is interpreted as subdivided into linear segments of constant trend. 


\begin{tabular}{|c|c|c|c|}
\hline \multicolumn{3}{|c|}{ Idealized Fracture Grouping } & Well \\
\hline $\begin{array}{l}\mathrm{Hpl} \\
\text { Hob }\end{array}$ & $\begin{array}{l}\text { Hpl } \\
\text { Hpd } \\
\text { Hoa } \\
\text { Hob }\end{array}$ & $\begin{array}{l}\text { N34W } \\
\text { N56E } \\
\text { N79W } \\
\text { N11E }\end{array}$ & $48-x-28$ \\
\hline Hob & $\begin{array}{l}\text { Hpl } \\
\text { Hpd } \\
\text { Hoa } \\
\text { Hob }\end{array}$ & $\begin{array}{l}\text { N24W } \\
\text { N66E } \\
\text { N69W } \\
\text { N21E }\end{array}$ & $71-1-x-4$ \\
\hline $\begin{array}{l}\text { Hob } \\
\text { Hpd }\end{array}$ & $\begin{array}{l}\text { Hpl } \\
\text { Hpd } \\
\text { Hoa } \\
\text { Hob }\end{array}$ & $\begin{array}{l}\text { N5W } \\
\text { N66E } \\
\text { N50W } \\
\text { N40E }\end{array}$ & $67-1-x-10$ \\
\hline $\begin{array}{l}\text { Hob } \\
\text { Hpd }\end{array}$ & $\begin{array}{l}\text { Hpl } \\
\text { Hpd } \\
\text { Hoa } \\
\text { Hob }\end{array}$ & $\begin{array}{l}\text { N5W } \\
\text { N66E } \\
\text { N50W } \\
\text { N40E }\end{array}$ & $61-2-x-15$ \\
\hline $\begin{array}{l}\mathrm{Hpl} \\
\mathrm{Hob}\end{array}$ & $\begin{array}{l}\text { Hpl } \\
\text { Hpd } \\
\text { Hoa } \\
\text { Hob }\end{array}$ & $\begin{array}{l}\text { N34W } \\
\text { N56E } \\
\text { N79W } \\
\text { N11E }\end{array}$ & 25-1-x-14 \\
\hline
\end{tabular}

Figure 3-9: Idealized rose diagrams depicting the fracture sets mapped by Cooper (2000) at the surface and rotated to incorporate changes in the orientation of the fold hinge at individual well locations. 


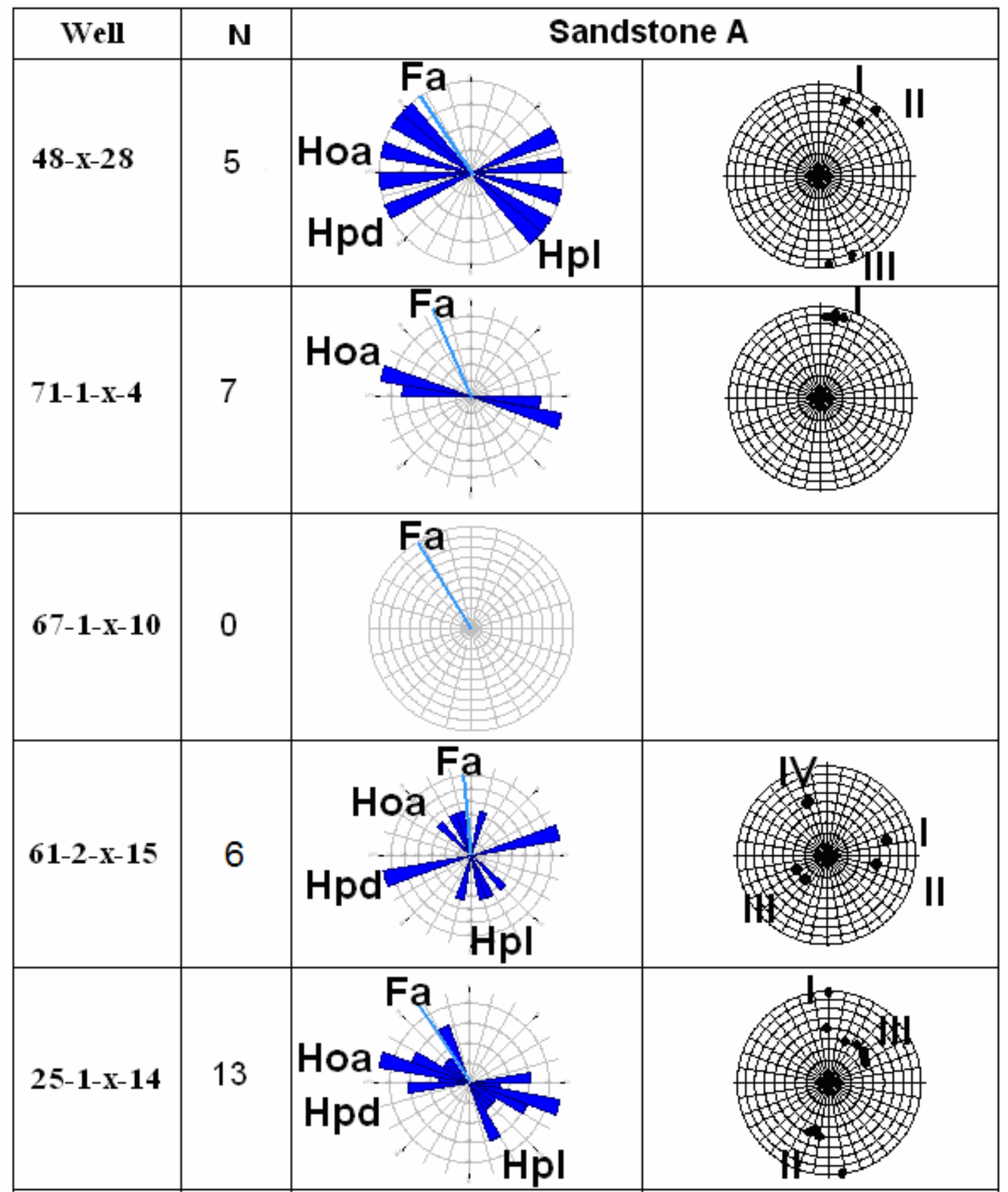

Figure 3-10: Rose diagrams and stereonets constructed from fractures observed in the FMI log through Sandstone A. Hinge-parallel (Hpl), hinge-perpendicular (Hpd), and hinge-oblique (Hao \& $\mathrm{Hob}$ ) are labeled on the rose diagrams. The fold axis ( $\mathrm{Fa}$ ) from Figure 3-6 is shown for reference. Fracture cluster sets are identified and labeled on the stereonet in Roman numerals. The Roman numeral cluster identifier does not correlate between wells or layers. 


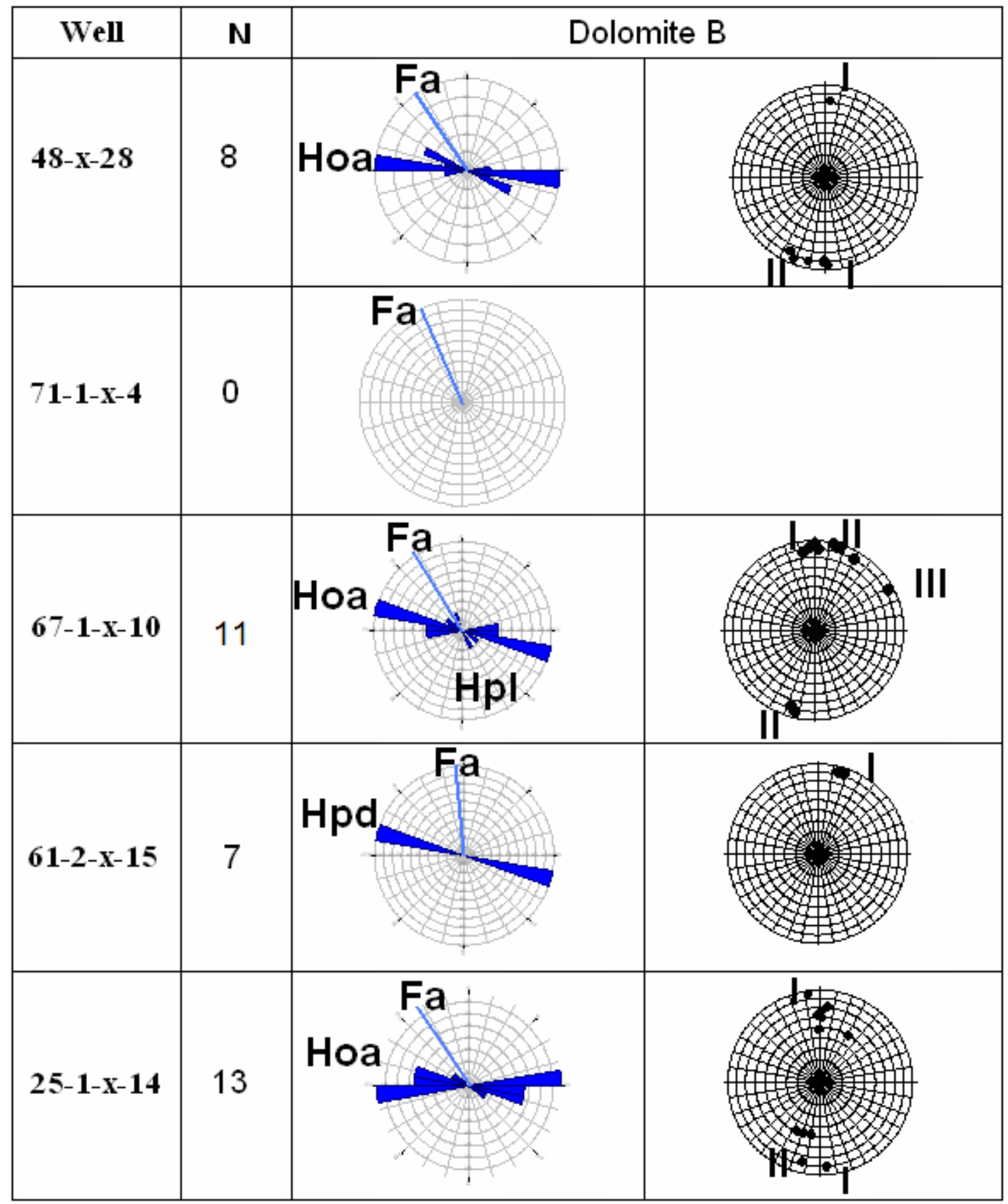

Figure 3-11: Rose diagrams and stereonets constructed from fractures observed in the FMI log through Dolomite B. Hinge-parallel (Hpl), hinge-perpendicular (Hpd), and hinge-oblique (Hao \& Hob) are labeled on the rose diagrams. The fold axis (Fa) from Figure 3-6 is shown for reference. Fracture cluster sets are labeled on the stereonet in Roman numerals. The Roman numeral cluster identifier does not correlate between wells or layers. 




Figure 3-12: Rose diagrams and stereonets constructed from fractures observed in the FMI log through Sandstone B. Hinge-parallel (Hpl), hinge-perpendicular (Hpd), and hinge-oblique (Hao \& $\mathrm{Hob}$ ) are labeled on the rose diagrams. The fold axis ( $\mathrm{Fa}$ ) from Figure 3-6 is shown for reference. Fracture cluster sets are labeled on the stereonet in Roman numerals. The Roman numeral cluster identifier does not correlate between wells or layers. 


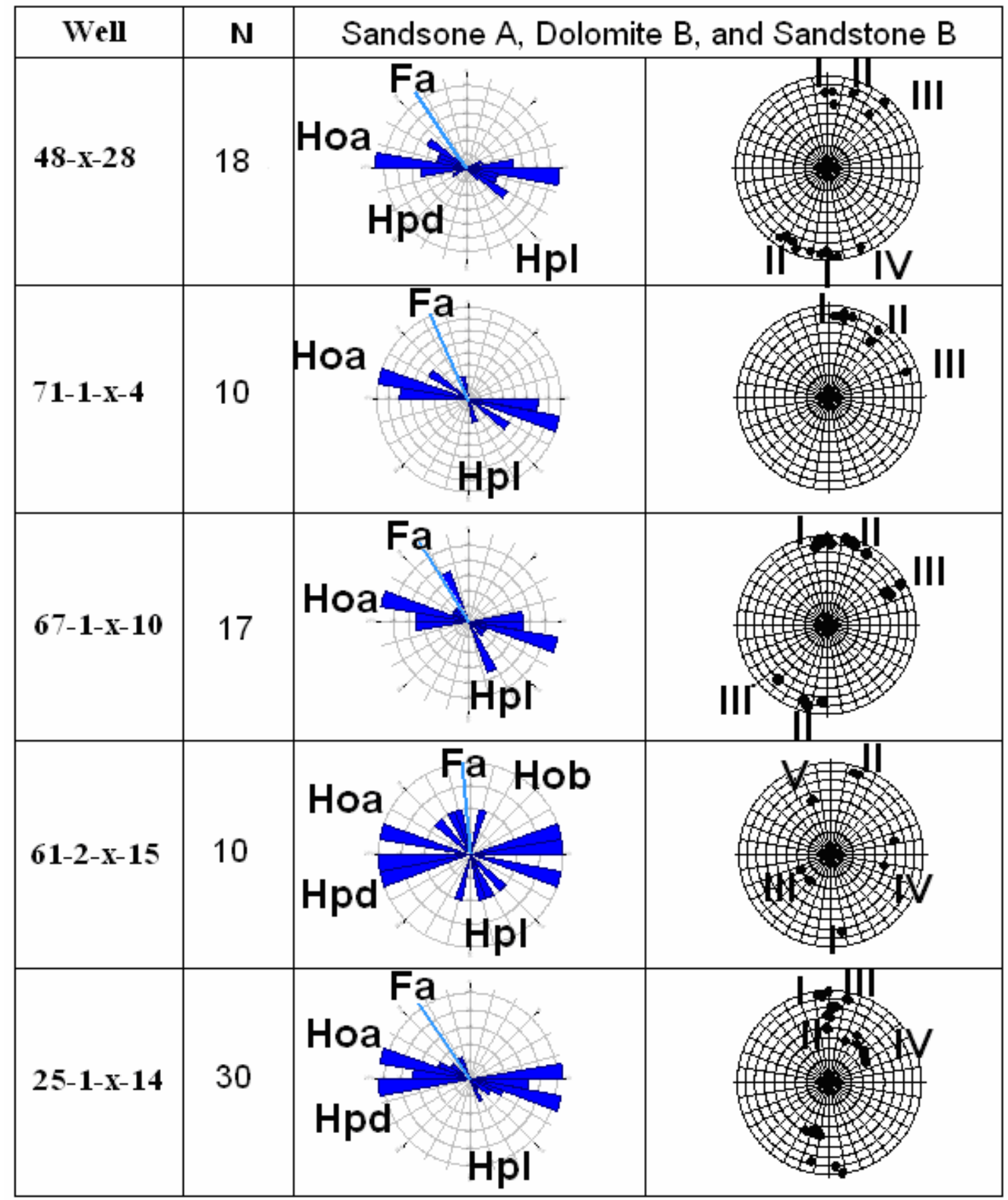

Figure 3-13: Rose diagrams and stereonets constructed from fractures observed in the FMI log through Sandstone A, Dolomite B, and Sandstone B. Hinge-parallel (Hpl), hinge-perpendicular (Hpd), and hinge-oblique (Hao \& Hob) are labeled on the rose diagrams. The fold axis (Fa) from Figure 3-6 is shown for reference. Fracture cluster sets are labeled on the stereonet in Roman numerals. The Roman numeral cluster identifier does not correlate between wells or layers. 
the FMI logs for wells 48-x-28, 71-1-x-4, and 67-1-x-10 (Table 3-4) for Sandstone A, Dolomite B, and Sandstone B average 77.4, 77.8 and 78.5 degrees with standard deviations of $+/-7.3,4.7$, and 6.7 degrees, respectively. The nearly vertical wells may undersample these steeply dipping fractures. Cluster IV of well $48-\mathrm{x}-28$ is represented by only 1 fracture in Figure 3-13. This fracture might belong to cluster 1, however, in isolation, its significance can not be determined.

\begin{tabular}{|c|c|c|c|c|c|}
\hline & $\mathbf{4 8 - x - 2 8}$ & $\mathbf{7 1 - 1 - x - 4}$ & $\mathbf{6 7 - 1 - x - 1 0}$ & $\mathbf{6 1 - 2 - x - 1 5}$ & 25-1-x-14 \\
\hline $\begin{array}{c}\text { Mean Dip } \\
\text { Angle }\end{array}$ & 77.4 & 77.8 & 78.2 & 60.2 & 59.0 \\
\hline $\begin{array}{c}\text { Standard } \\
\text { Deviation }\end{array}$ & 7.3 & 4.7 & 6.7 & 19.1 & 17.6 \\
\hline
\end{tabular}

Table 3-4: Mean fracture dip angle and standard deviation calculated for fractures observed in the FMI wells for Sandstone A, Dolomite B, and Sandstone B.

Wells $61-2-x-15$ and 25-1-x-14 do not have similar fracture characteristics when compared to wells 48-x-28, 71-1-x-4, and 67-1-x-10. Table 3-4 reveals that wells 61-2-x15 and 25-1-x-14 have fractures with a much lower mean dip angle (60.2 and 59.0 degrees, respectively) and a larger standard deviation (19.1 and 17.6 degrees, respectively) when compared to wells $48-\mathrm{x}-28,71-1-\mathrm{x}-4$, and 67-1-x-10. This variation in dip angles results in multiple fracture clusters with similar orientations for well 25-1-x14 (see Figure 3-13 Clusters I, II, and III for 25-1-x-14). If dip angle is ignored, the fractures clusters orientations for well $25-1-\mathrm{x}-14$ are similar to wells $48-\mathrm{x}-28,71-1-\mathrm{x}-4$, and 67-1-x-10. The low number of open fractures observed in well 61-2-x-15 does not reveal distinct fracture clusters (see Figure 3-13); instead, isolated fractures that trend along the fold axis, or at acute angles to it, suggest the possible presence of a hinge parallel cluster in section 10 . 


\subsection{Fracture Density}

The wells at Teapot Dome that have FMI logs are all vertical wells. A vertical well through nearly horizontal bedding provides a limited view of fracture density. The probability of observing vertical fractures in such a case is less than the probability of observing non-vertical fractures. The probability of intersection increases with decreasing fracture dip. Fractures detected in a vertical well provide a limited basis for estimating intersection frequency and fracture length. Vertical fracture density is defined as the number of open fractures intersected by a vertical well divided by the total thickness of the lithologic unit (Tables 3-5). Production histories from wells in the field may provide additional insight into the distribution of fractures in the surrounding area. During flow simulations, the characteristics of the reservoir fracture system such as fracture intersection, fracture length, and fracture density can be revised to obtain a good match between simulated and observed production history.

\begin{tabular}{|c|c|c|c|c|c|c|c|c|}
\hline Well & \multicolumn{2}{|c|}{ A Sandstone } & \multicolumn{2}{c|}{ B Dolomite } & \multicolumn{2}{c|}{ B Sandstone } & \multicolumn{2}{c|}{$\begin{array}{c}\text { A,B Sandstone } \\
\text { and B Dolomite }\end{array}$} \\
\hline & $\#$ & $\begin{array}{c}\text { Thickness } \\
(\mathrm{ft})\end{array}$ & $\#$ & $\begin{array}{c}\text { Thickness } \\
(\mathrm{ft})\end{array}$ & $\#$ & $\begin{array}{c}\text { Thickness } \\
(\mathrm{ft})\end{array}$ & $\#$ & $\begin{array}{c}\text { Thickness } \\
(\mathrm{ft})\end{array}$ \\
\hline $\mathbf{4 8 - x - 2 8}$ & 5 & 26 & 8 & 26 & 5 & 55 & 18 & 107 \\
\hline $\mathbf{7 1 - 1 - x - 4}$ & 7 & 21 & 0 & 15 & 3 & 77 & 10 & 113 \\
\hline $\mathbf{6 7 - 1 - x - 1 0}$ & 0 & 23 & 11 & 28 & 6 & 59 & 17 & 110 \\
\hline $\mathbf{6 1 - 2 - x - 1 5}$ & 6 & 35 & 2 & 22 & 2 & 58 & 10 & 115 \\
\hline $\mathbf{2 5 - 1 - x - 1 4}$ & 13 & 22 & 13 & 34 & 4 & 60 & 30 & 116 \\
\hline
\end{tabular}

Table 3-5: Fracture frequency (\#) along the length of the wellbore and thicknesses of Sandstone A and B and Dolomite B layers from FMI log data.

The vertical open fracture density is calculated (Table 3-6) and plotted for Sandstone A, Dolomite B, and Sandstone B in Figures 3-16, 3-17, and 3-18, respectively. An average density for the three layers is displayed in Figure 3-19 with the average vertical fracture density and standard deviation shown in Table 3-6. At first there does 
not seem to be a correlation between vertical fracture density and well location or stratigraphic layer in the Tensleep. The mean fracture density for the three layers, Table 3-6, reveals that on average Sandstone A has the highest vertical fracture density. However, note that its fracture density is similar to the vertical fracture density observed in the Dolomite B layer. Perhaps the similar fracture density is associated with the similar thicknesses in the Sandstone A and Dolomite B layers (Table 3-5).

\begin{tabular}{|c|c|c|c|c|}
\hline Well & Sandstone A & Dolomite B & Sandstone B & $\begin{array}{c}\text { A,B Sandstone } \\
\text { and } \\
\text { Dolomite B }\end{array}$ \\
\hline $\mathbf{4 8 - x - 2 8}$ & 0.19 & 0.31 & 0.09 & 0.17 \\
\hline $\mathbf{7 1 - 1 - x - 4}$ & 0.33 & - & 0.04 & 0.09 \\
\hline $\mathbf{6 7 - 1 - x - 1 0}$ & - & 0.39 & 0.10 & 0.15 \\
\hline $\mathbf{6 1 - 2 - x - 1 5}$ & 0.17 & 0.09 & 0.03 & 0.09 \\
\hline $\mathbf{2 5 - 1 - x - 1 4}$ & 0.59 & 0.38 & 0.07 & 0.26 \\
\hline Mean All Wells & 0.26 & 0.23 & 0.07 & 0.15 \\
\hline St Dev All Wells & 0.22 & 0.18 & 0.03 & 0.07 \\
\hline
\end{tabular}

Table 3-6: Vertical fracture density (in units of fractures per foot) for A Sandstone, B Dolomite, and B Sandstone calculated for fractures observed in the FMI wells. The mean vertical fracture density and standard deviation were also calculated.

The inverse of fracture density is fracture spacing. Bai (2000) suggest there is a linear relationship between fracture spacing and bed thickness. Cooper (2000) concluded that fracture spacing observed in beach sandstones at the surface broadly follow this relationship (Figure 3-14). Comparison of fracture density in Table 3-6 to thickness in Table 3- 5 reveals that this relationship may also hold for the A and B sandstone layers. An attempt was made to evaluate the bed thickness, fracture spacing relationship for sandstones A and B and Dolomite B (see Figure 3-15). The results suggest a linear relationship with positive slope between fracture spacing and bed thickness for Sandstone A and Sandstone B. 


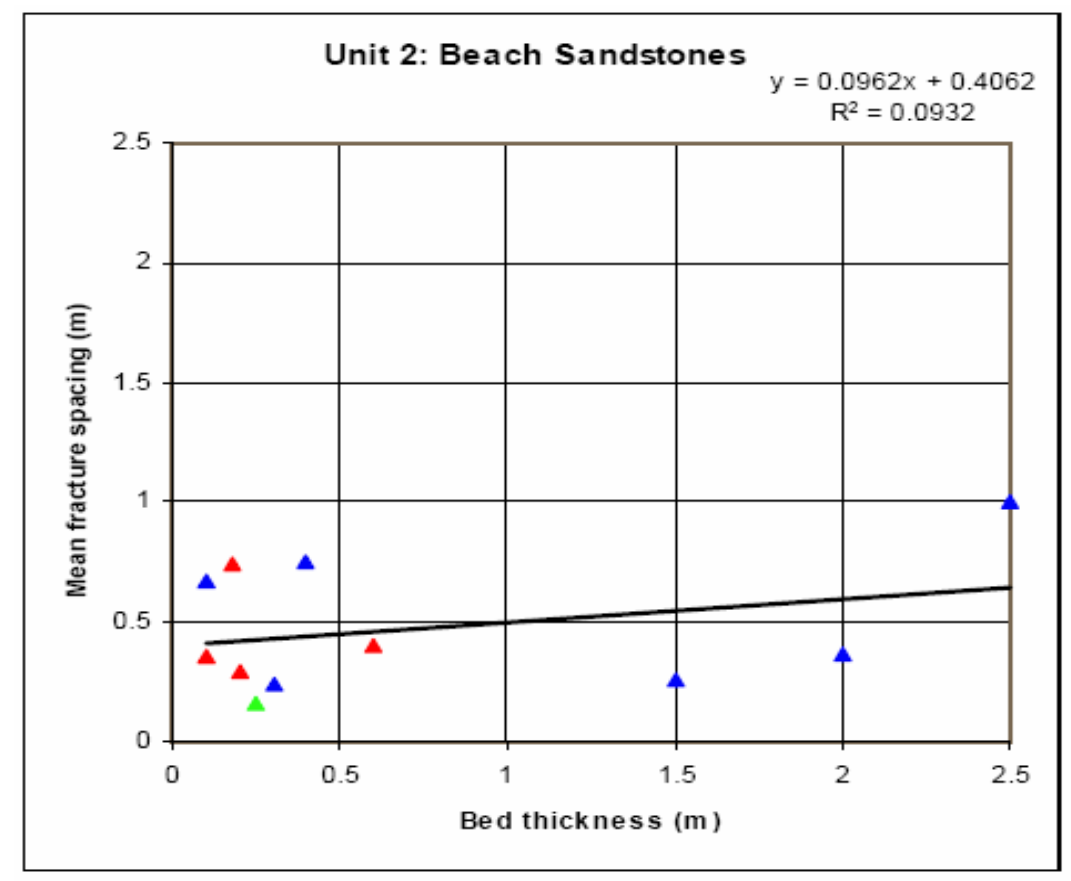

Figure 3-14: Cooper's (2001) bed thickness vs. fracture spacing for surface beach sandstones at Teapot Dome. Fracture spacing was measured perpendicular to the through going fracture set and averaged for each location. This figure is taken from Cooper (2001).

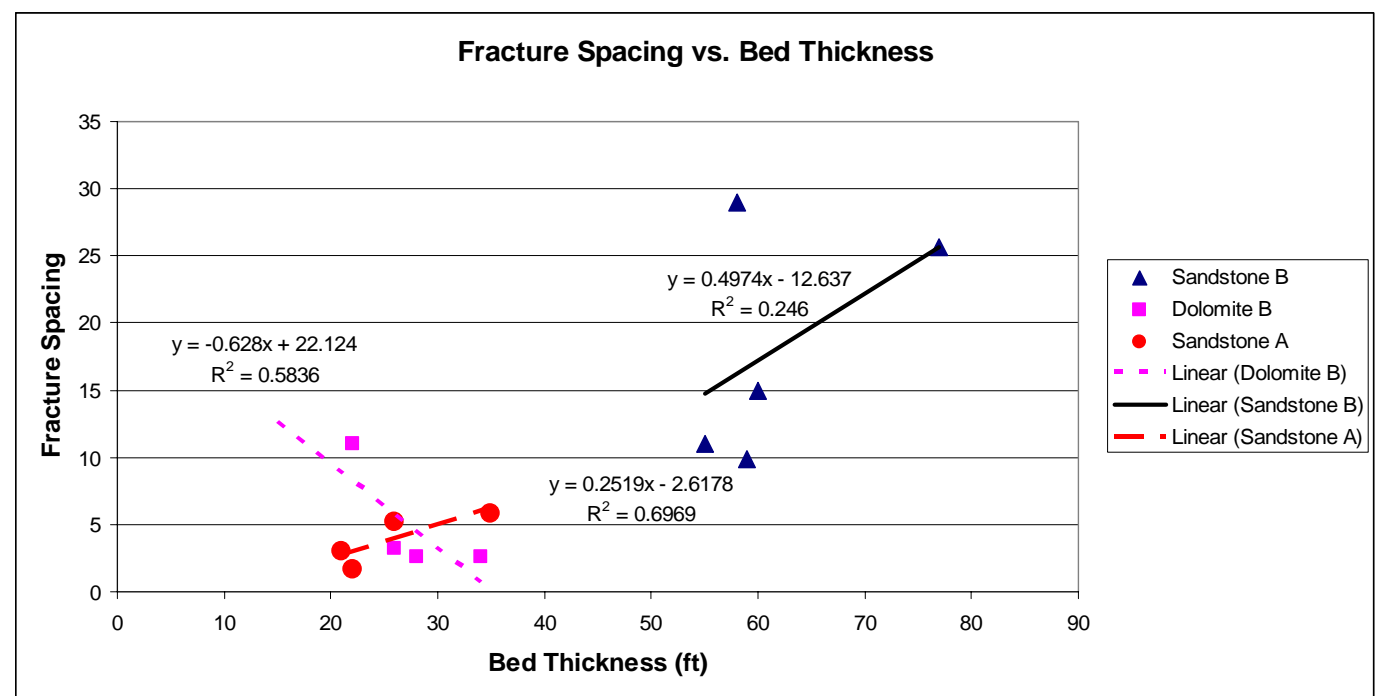

Figure 3-15: Vertical fracture spacing vs. bed thickness as interpreted from all wells with FMI logs in the Tensleep Formation. 


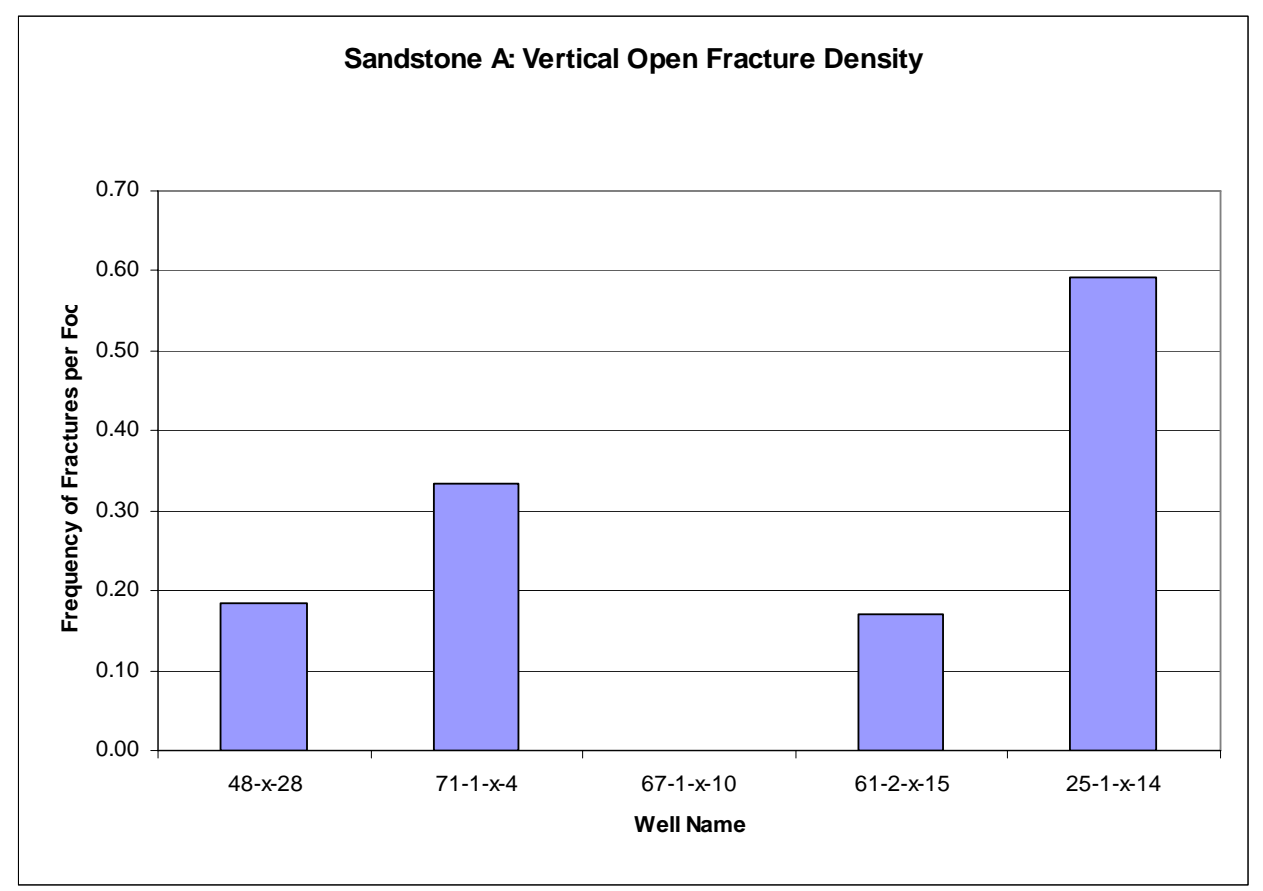

Figure 3-16: Vertical Fracture density (frequency of fractures per foot) derived from FMI logs for Sandstone A shown for each FMI log well.

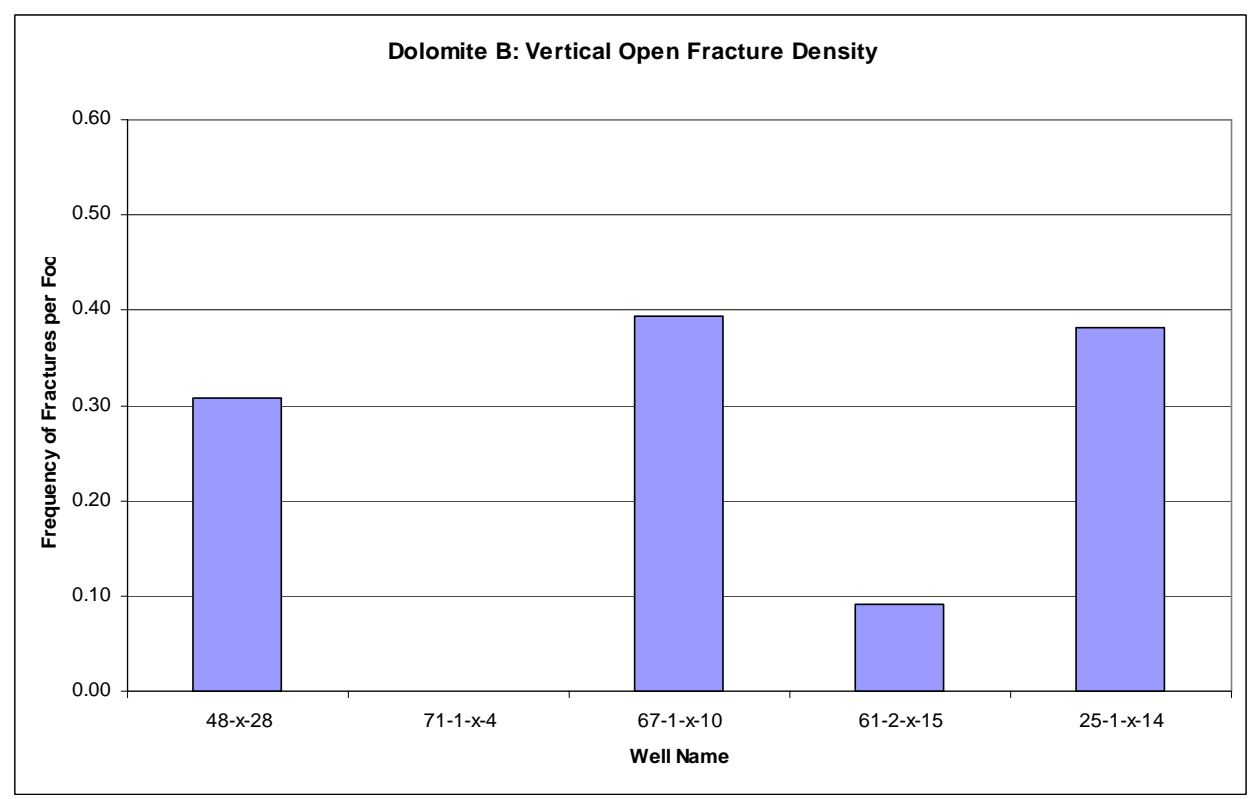

Figure 3-17: Vertical fracture density (frequency of fractures per foot) derived from FMI logs for Dolomite B shown for each FMI log well. 


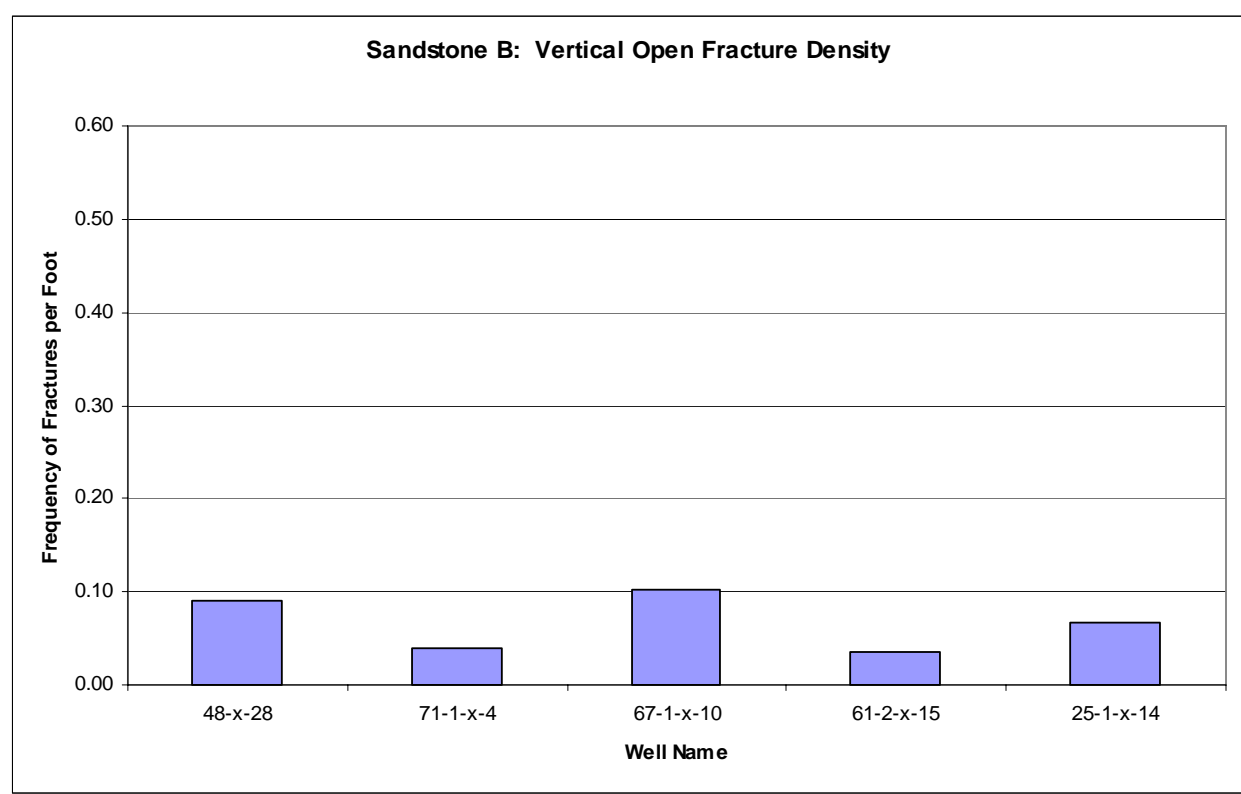

Figure 3-18: Vertical fracture density (frequency of fractures per foot) derived from FMI logs for Sandstone B shown for each FMI log well.

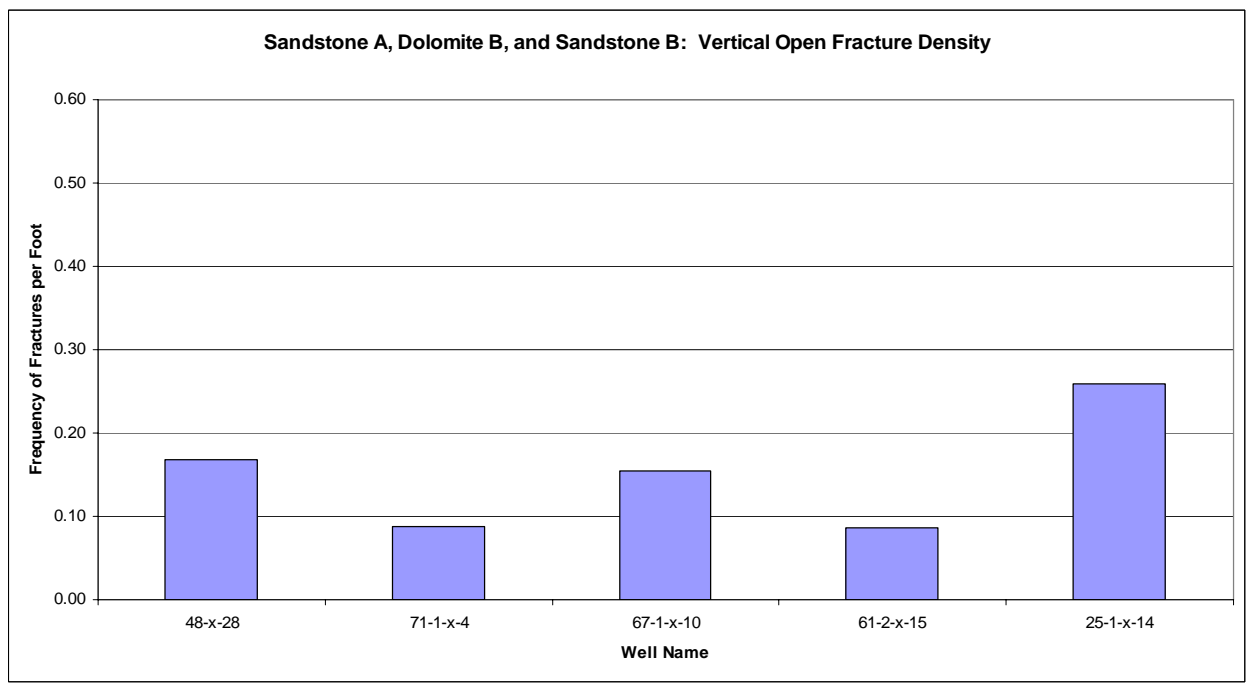

Figure 3-19: Vertical fracture density (frequency of fractures per foot) derived from FMI logs for Sandstone A, Dolomite B, and Sandstone B shown for each FMI log well. 


\subsection{Fracture Aperture}

The effective aperture is one of the most important properties controlling flow in tight fracture reservoirs such as the Tensleep Formation. Parallel plate fracture models indicate that the total fluid flow is proportional to the cube of the fracture's aperture (e.g., Sakar, 2002). Some relationships have been obtained between fracture aperture, length, spacing, and layer thickness based on empirical studies (e.g., Vermilye, 1995; Park, 1997; Perez, 2002; and Ji, 1998). One difficulty with fracture apertures determined through FMI log analysis is that measured apertures may have been distorted by the drilling process. These alterations would cause errors in the relationships between fracture aperture and fracture length, spacing, and layer thickness.

Aperture data, presented in Table 3-7, indicate that dolomitic layers of the Tensleep Formation have a smaller fracture aperture than the sandstone layers.

Sandstone A and Dolomite B layers have a relatively similar thickness throughout Teapot Dome, but the fracture aperture of the Dolomite B layer is roughly $1 / 2$ that found Sandstone A. If these apertures are representative of their initial value when formed, then fractures in Dolomite B would have smaller lengths and spacing than those in Sandstone A.

When comparing the apertures of fractures in sandstones $\mathrm{A}$ and $\mathrm{B}$, fracture aperture appears roughly proportional to the thickness of the layer (Figure 3-20). The mean thickness of the Sandstone A and Sandstone B are $25.4 \mathrm{ft}$ and $61.8 \mathrm{ft}$, respectively (Table 3-2). The mean aperture for Sandstone A and Sandstone B are 0.001135 in and 0.00272 , respectively (Table 3-6). Calculating the mean thickness ratio and mean aperture ratio for Sandstone B to Sandstone A yields values of 2.43 and 2.40, 
respectively, and suggests a proportional relationship between unit thickness and fracture aperture in these sandstone intervals.

The distribution of mean fracture apertures are divided into three groups: those with apertures less than 0.00098 inches, between 0.00098 and 0.0012 inches, and apertures between 0.0012 and 0.0066 inches. Figure 3-21 shows a relatively equal frequency of mean apertures in each aperture group.

\begin{tabular}{|c|c|c|c|c|c|c|}
\hline Well & Layer & Frequency & $\begin{array}{c}\text { Mean } \\
\text { Aperture } \\
\text { (in) }\end{array}$ & $\begin{array}{c}\text { Standard } \\
\text { Deviation }\end{array}$ & $\begin{array}{c}\text { Mean } \\
\text { Aperture } \\
\text { (mm) }\end{array}$ & $\begin{array}{c}\text { Standard } \\
\text { Deviation }\end{array}$ \\
\hline $\mathbf{4 8 - x - 2 8}$ & SS A & 5 & 0.001356 & 0.000502 & 0.034442 & 0.012744 \\
\hline & Dol B & 8 & 0.000700 & 0.000689 & 0.017780 & 0.017504 \\
\hline & SS B & 5 & 0.003024 & 0.001547 & 0.076810 & 0.039296 \\
\hline $\mathbf{7 1 - 1 - x - 4}$ & SS A & 7 & 0.001164 & 0.000479 & 0.029573 & 0.012171 \\
\hline & Dol B & 0 & - & - & - & - \\
\hline & SS B & 3 & 0.004977 & 0.002288 & 0.126407 & 0.058112 \\
\hline $\mathbf{6 7 - 1 - x - 1 0}$ & SS A & 0 & - & - & - & - \\
\hline & Dol B & 11 & 0.000701 & 0.000438 & 0.017803 & 0.011132 \\
\hline & SS B & 6 & 0.001547 & 0.000443 & 0.039285 & 0.011262 \\
\hline $\mathbf{6 1 - 2 - x - 1 5}$ & SS A & 6 & 0.000343 & 0.000165 & 0.008721 & 0.004194 \\
\hline & Dol B & 2 & 0.000170 & 0.000113 & 0.004318 & 0.002874 \\
\hline & SS B & 2 & 0.001765 & 0.001237 & 0.044831 & 0.031431 \\
\hline $\mathbf{2 5 - 1 - x - 1 4}$ & SS A & 13 & 0.001399 & 0.000657 & 0.03554 & 0.016694 \\
\hline & Dol B & 13 & 0.000388 & 0.000151 & 0.009867 & 0.003824 \\
\hline & SS B & 4 & 0.002920 & 0.003083 & 0.074168 & 0.078306 \\
\hline All Wells & SS A & 20 & 0.002827 & 0.002014 & 0.069266 & 0.051151 \\
\hline & Dol B & 34 & 0.000550 & 0.000447 & 0.013970 & 0.011349 \\
\hline & SS B & 31 & 0.001135 & 0.000649 & 0.028825 & 0.016476 \\
\hline
\end{tabular}

Table 3-7: Fracture aperture from FMI logs shown for Sandstone A, Dolomite B, and Sandstone B from each of the FMI log wells. 


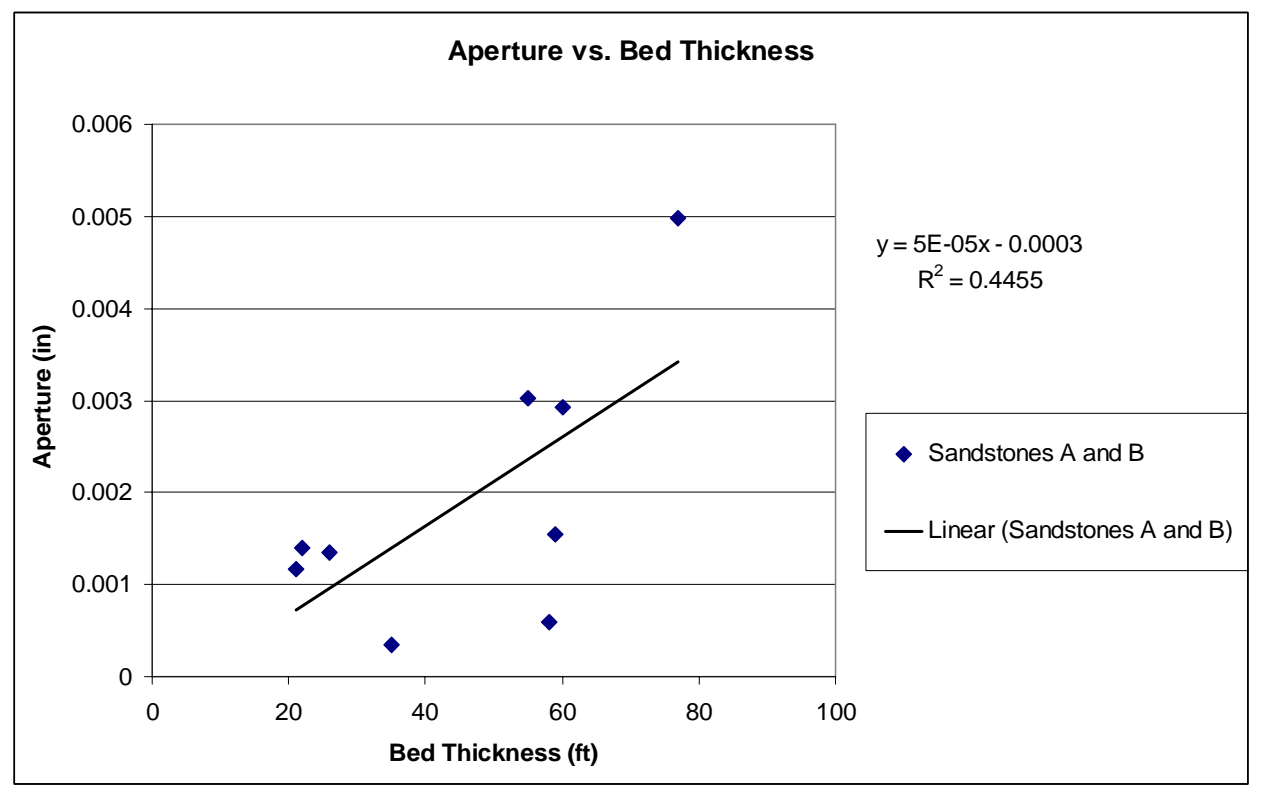

Figure 3-20: Fracture aperture vs. bed thickness for Sandstone A and Sandstone B layers of the Tensleep Formation. Notice the broad linear relationship between aperture and bed thickness.

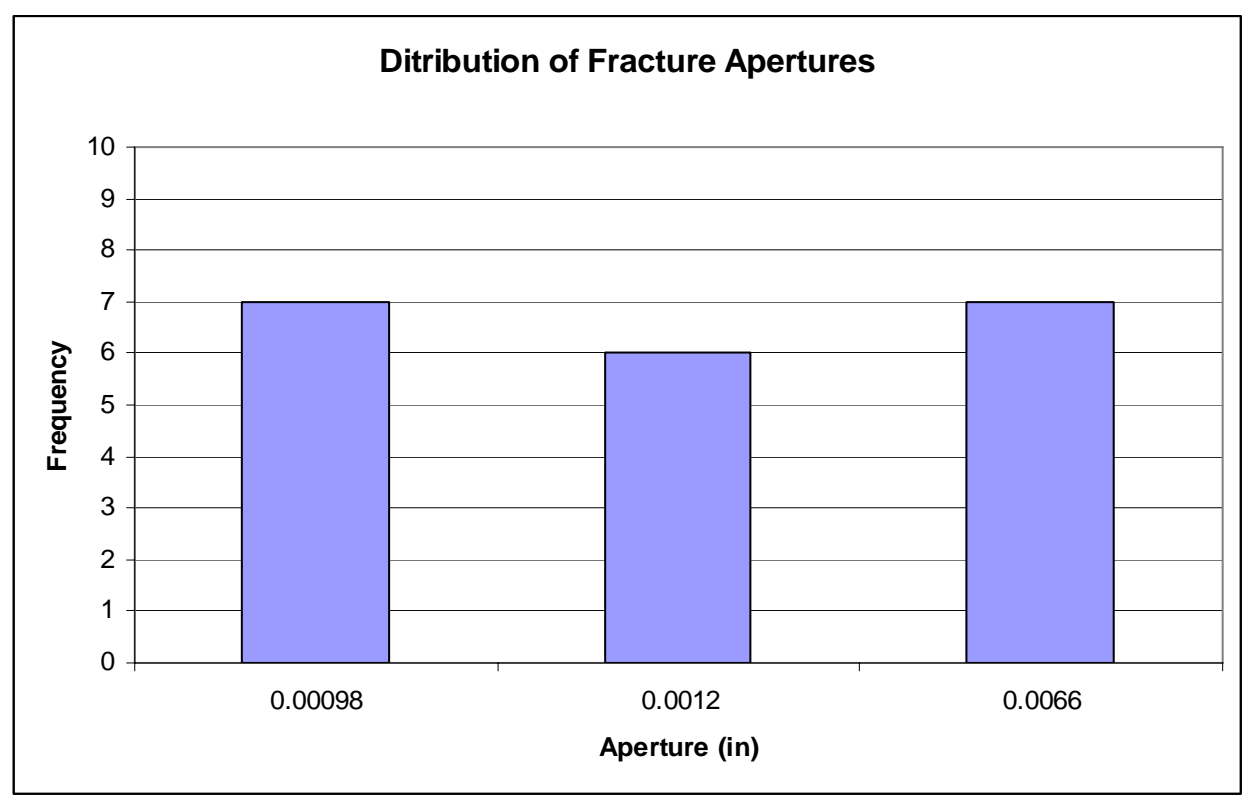

Figure 3-21: Histogram of fracture apertures to show an equal bin number of fractures with apertures less than 0.00098 inches, between 0.00098 and 0.0012 inches, and apertures greater then between 0.0012 inches. See Figure 4.7 for a distribution of fracture apertures with a smaller bin size. 
Well 48-x-28

\begin{tabular}{|l|l|l|l|l|l|l|l|}
\hline Cluster & Frequency & $\begin{array}{l}\text { Mean } \\
\text { Strike } \\
(\text { degrees })\end{array}$ & $\begin{array}{l}\text { St Dev } \\
\text { Strike } \\
(\text { degrees })\end{array}$ & $\begin{array}{l}\text { Mean } \\
\text { Aperture } \\
\text { (in) }\end{array}$ & $\begin{array}{l}\text { St Dev } \\
\text { Aperture } \\
\text { (in) }\end{array}$ & $\begin{array}{l}\text { Mean } \\
\text { Aperture } \\
\text { (mm) }\end{array}$ & $\begin{array}{l}\text { St Dev } \\
\text { Aperture } \\
(\mathrm{mm})\end{array}$ \\
\hline I & 10 & 91.66 & 5.04 & 0.001288 & 0.001309 & 0.032715 & 0.033253 \\
\hline II & 5 & 116.48 & 6.49 & 0.002194 & 0.001686 & 0.055728 & 0.042832 \\
\hline III & 2 & 129.54 & 1.83 & 0.001280 & 0.000905 & 0.032512 & 0.022989 \\
\hline IV & 1 & 66.94 & - & 0.001090 & - & 0.027686 & - \\
\hline
\end{tabular}

Well 71-1-X-4

\begin{tabular}{|l|l|l|l|l|l|l|l|}
\hline Cluster & Frequency & $\begin{array}{l}\text { Mean } \\
\text { Strike } \\
\text { (degrees) }\end{array}$ & $\begin{array}{l}\text { St Dev } \\
\text { Strike } \\
\text { (degrees) }\end{array}$ & $\begin{array}{l}\text { Mean } \\
\text { Aperture } \\
\text { (in) }\end{array}$ & $\begin{array}{l}\text { St Dev } \\
\text { Aperture } \\
\text { (in) }\end{array}$ & $\begin{array}{l}\text { Mean } \\
\text { Aperture } \\
(\mathrm{mm})\end{array}$ & $\begin{array}{l}\text { St Dev } \\
\text { Aperture } \\
(\mathrm{mm})\end{array}$ \\
\hline I & 7 & 100.01 & 4.82 & 0.001164 & 0.000479 & 0.029573 & 0.012171 \\
\hline II & 2 & 126.15 & 0.01 & 0.004165 & 0.002553 & 0.105791 & 0.064837 \\
\hline III & 1 & 161.57 & - & 0.006600 & - & 0.167640 & - \\
\hline
\end{tabular}

Well 67-1-x-10

\begin{tabular}{|l|l|l|l|l|l|l|l|}
\hline Cluster & Frequency & $\begin{array}{l}\text { Mean } \\
\text { Strike } \\
(\text { degrees })\end{array}$ & $\begin{array}{l}\text { St Dev } \\
\text { Strike } \\
(\text { degrees })\end{array}$ & $\begin{array}{l}\text { Mean } \\
\text { Aperture } \\
\text { (in) }\end{array}$ & $\begin{array}{l}\text { St Dev } \\
\text { Aperture } \\
\text { (in) }\end{array}$ & $\begin{array}{l}\text { Mean } \\
\text { Aperture } \\
(\mathrm{mm})\end{array}$ & $\begin{array}{l}\text { St Dev } \\
\text { Aperture } \\
(\mathrm{mm})\end{array}$ \\
\hline I & 6 & 88.75 & 4.57 & 0.000933 & 0.000588 & 0.023701 & 0.014940 \\
\hline II & 6 & 106.52 & 2.93 & 0.000950 & 0.000614 & 0.024130 & 0.015589 \\
\hline III & 5 & 125.47 & 7.37 & 0.001200 & 0.001160 & 0.030480 & 0.029455 \\
\hline IV & 3 & 153.10 & 2.24 & 0.001097 & 0.000535 & 0.027855 & 0.013596 \\
\hline
\end{tabular}

Well 61-2-x-15

\begin{tabular}{|l|l|l|l|l|l|l|l|}
\hline Cluster & Frequency & $\begin{array}{l}\text { Mean } \\
\text { Strike } \\
\text { (degrees) }\end{array}$ & $\begin{array}{l}\text { St Dev } \\
\text { Strike } \\
\text { (degrees) }\end{array}$ & $\begin{array}{l}\text { Mean } \\
\text { Aperture } \\
\text { (in) }\end{array}$ & $\begin{array}{l}\text { St Dev } \\
\text { Aperture } \\
\text { (in) }\end{array}$ & $\begin{array}{l}\text { Mean } \\
\text { Aperture } \\
\text { (mm) }\end{array}$ & $\begin{array}{l}\text { St Dev } \\
\text { Aperture } \\
(\mathrm{mm})\end{array}$ \\
\hline I & 2 & 81.92 & 0.04 & 0.001765 & 0.001237 & 0.044831 & 0.031431 \\
\hline II & 2 & 107.22 & 2.16 & 0.000170 & 0.000113 & 0.004318 & 0.002874 \\
\hline III & 2 & 141.54 & 16.45 & 0.000470 & 0.000141 & 0.011938 & 0.003592 \\
\hline IV & 2 & 179.62 & 16.86 & 0.000260 & 0.000042 & 0.006604 & 0.001078 \\
\hline V & 2 & 70.73 & 1.19 & 0.000300 & 0.000255 & 0.007620 & 0.006466 \\
\hline
\end{tabular}

Well 25-1-X-14

\begin{tabular}{|l|l|l|l|l|l|l|l|}
\hline Cluster & Frequency & $\begin{array}{l}\text { Mean } \\
\text { Strike } \\
(\text { degrees })\end{array}$ & $\begin{array}{l}\text { St Dev } \\
\text { Strike } \\
(\text { degrees })\end{array}$ & $\begin{array}{l}\text { Mean } \\
\text { Aperture } \\
\text { (in) }\end{array}$ & $\begin{array}{l}\text { St Dev } \\
\text { Aperture } \\
(\mathrm{in})\end{array}$ & $\begin{array}{l}\text { Mean } \\
\text { Aperture } \\
(\mathrm{mm})\end{array}$ & $\begin{array}{l}\text { St Dev } \\
\text { Aperture } \\
(\mathrm{mm})\end{array}$ \\
\hline I & 5 & 84.96 & 3.29 & 0.002026 & 0.001578 & 0.051460 & 0.040089 \\
\hline II & 16 & 98.94 & 10.06 & 0.001093 & 0.001610 & 0.027749 & 0.040907 \\
\hline III & 3 & 102.78 & 0.695 & 0.000413 & 0.000240 & 0.010497 & 0.006087 \\
\hline IV & 6 & 137.57 & 12.56 & 0.001012 & 0.000215 & 0.025696 & 0.005453 \\
\hline
\end{tabular}

Table 3-8: Cluster frequency, strike, and aperture observations for all five wells with FMI logs for the fracture clusters shown in Figure 3-13. 


\subsection{Present Day Principal Stress}

The present day maximum compressive principal stress orientation can be estimated from the average strike of drilling induced fractures if the dips are consistent throughout the well bore. As mentioned earlier, stress released into the borehole produces fractures that strike in the maximum compressive stress direction. Rose diagrams and equal area projections of the drilling induced fractures interpreted in the five FMI logs at Teapot Dome reveal that they form a relatively compact fracture set with a mean vector strike of N75.54W (Figure 3-22, Table 3-9) and a standard deviation of 11.94 degrees. The strike of the drilling induced fractures is consistent throughout all five wells (Table 3-9) with a R-Mag value of 0.98 and a 95\% confidence interval of 1.54 degrees. The R-Mag and confidence interval indicate a strong correlation between the direction of the drilling induced fractures and the location of each well. A visual comparison confirms this strong correlation and suggests that small variations in fold azimuth do not produce similar changes in the orientations of the drilling induced fractures. The principal compressive stress reported by Heidelberg Academy of Sciences and Humanities' World Stress Map Project (Figure 3-23) of N60W for the area closest to the Teapot Dome area is within 1.3 standard deviations of the stress direction calculated from the drilling induced fractures. As noted, the present-day principal stress orientation serves as a good prediction of fracture orientations likely to be produced by hydraulic stimulation. The present-day maximum compressive stress orientations will also tend to close fractures that strike oblique to the maximum compressive stress direction and will tend to hold open the fractures that are parallel to the maximum principal stress. However, fractures oriented at high angle to the maximum compressive stresses may be held open by partial mineralization. 


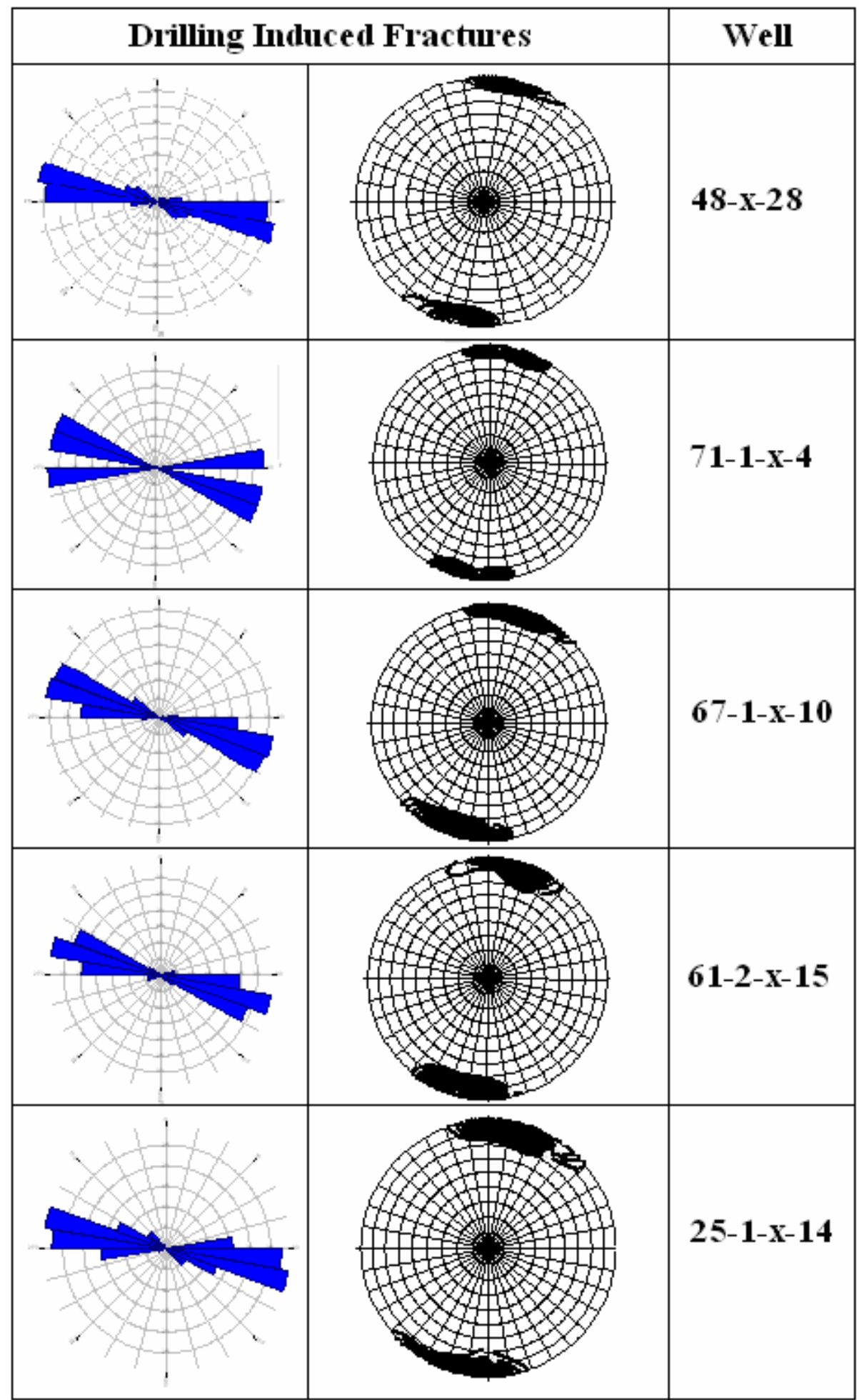

Figure 3-22: Rose diagrams and stereonets of drilling induced fractures observed in the FMI logs for each FMI well. 


\begin{tabular}{|c|c|c|c|c|c|}
\hline Well & $\begin{array}{c}\text { Frequency } \\
\text { (n) }\end{array}$ & $\begin{array}{c}\text { Vector } \\
\text { Mean } \\
\text { Strike (deg) }\end{array}$ & $\begin{array}{c}\text { Standard } \\
\text { Deviation } \\
\text { (deg) }\end{array}$ & R-Mag & $\begin{array}{c}\text { 95 \% } \\
\text { Confidence } \\
\text { Interval (deg) }\end{array}$ \\
\hline $\mathbf{4 8 - x - 2 8}$ & 38 & 101.2 & 14.16 & 0.98 & 4.82 \\
\hline $\mathbf{7 1 - 1 - x - 4}$ & 3 & 101.7 & 0.00 & 0.98 & 17.1 \\
\hline $\mathbf{6 7 - 1 - x - 1 0}$ & 190 & 106.35 & 12.8 & 0.98 & 2.15 \\
\hline $\mathbf{6 1 - 2 - x - 1 5}$ & 49 & 104.02 & 13.5 & 0.98 & 4.23 \\
\hline $\mathbf{2 5 - 1 - x - 1 4}$ & 94 & 102.55 & 10.85 & 0.97 & 3.76 \\
\hline All Wells & 374 & 104.54 & 11.94 & 0.98 & 1.54 \\
\hline
\end{tabular}

Table 3-9: Statistical parameters of the Rose Diagrams associated with drilling induced fractures. 


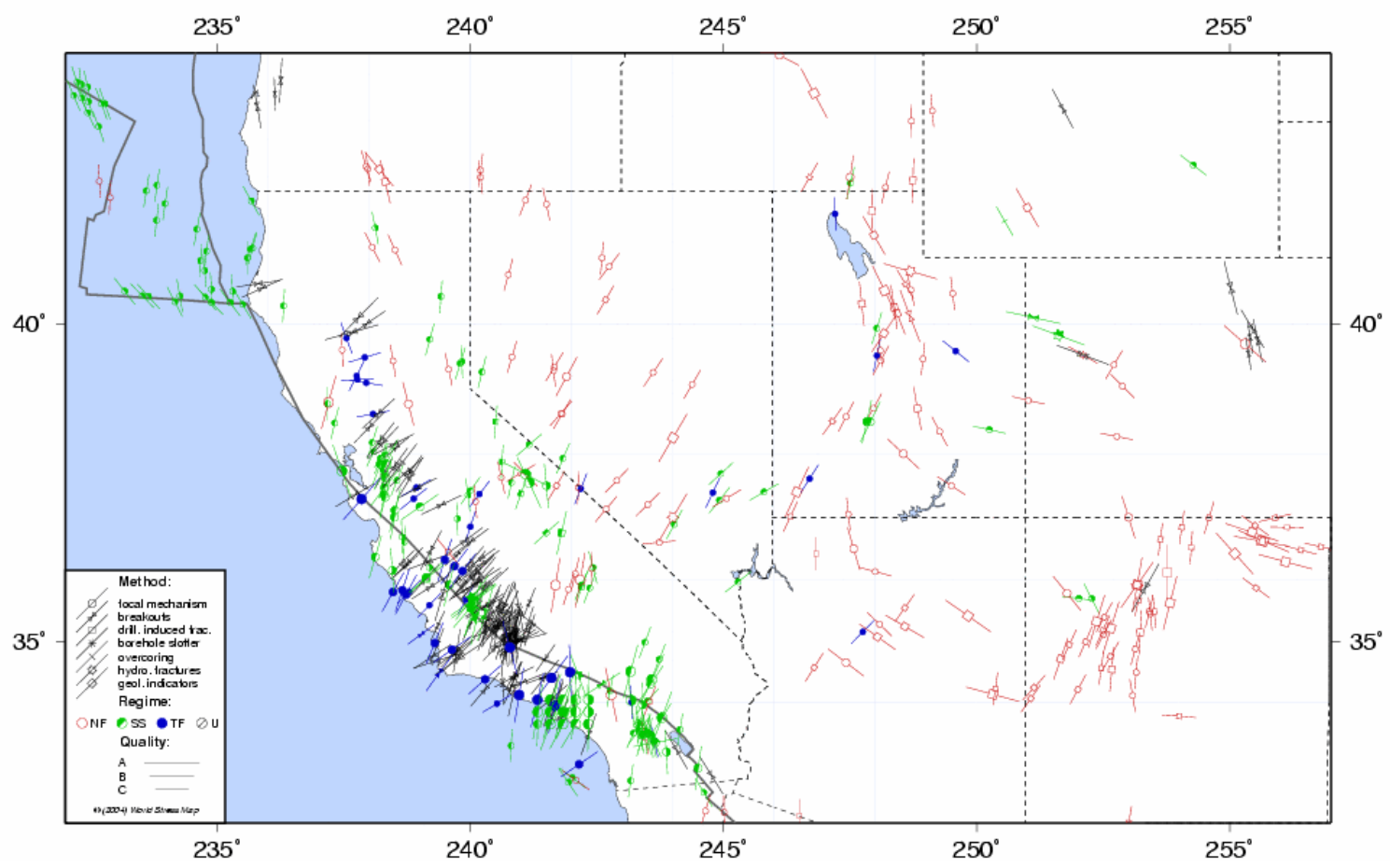

Figure 3-23: The world stress map (Reinecker, 2004) above indicates the maximum principal compressive stress to be about $\mathrm{N} 60 \mathrm{~W}$ at the location of Teapot Dome. The world stress map is located here: http://www-wsm.physik.unikarlsruhe.de/pub/introduction/introduction_frame.html 


\section{Chapter 4 Estimation of Fracture Length and Spacing from Borehole Images}

\subsection{Fracture Length}

\section{Minimum Fracture Length}

Ozkaya (2003a) derived a geometric method to determine minimum fracture length from the ratio of fully intersecting fractures to the total number of fractures intersecting the borehole. This geometric method makes a number of assumptions: all fractures are circular in shape, the image analyst has eliminated all drilling induced fractures, and fractures with lengths smaller than the borehole diameter are not detectable. Ozkaya's (2003b) statistical method has the criteria that a fracture trace covers at least $1 / 3$ of the borehole to accurately determine a fracture's parameters. This model does not incorporate mechanical and geologic properties of the fractured interval. The reliability of Ozkaya's method is dependent upon the number of fractures penetrated by the borehole and the assumption that fractures are circular in shape. Ozkaya suggests that the uncertainty in the estimate can be minimized when a large number of fractures are used and the fractures have an approximately circular shape, consistent with the model's assumptions.

An intersecting fracture is any fracture that can be identified in the borehole. Ozkaya (2002a), defines a fully intersecting fracture as one in which the entire fracture trace is seen in the borehole. The intersecting fracture is projected onto a plane normal to the borehole (Figure 4-1). The projected fracture will have an elliptical in shape with length $\frac{L}{2}$ along the major axis, and length $\frac{L \cos \theta}{2}$ along the minor axis. $\Theta$ is the dip of the fracture relative to a reference plane normal to the borehole (Figure 4-2) 

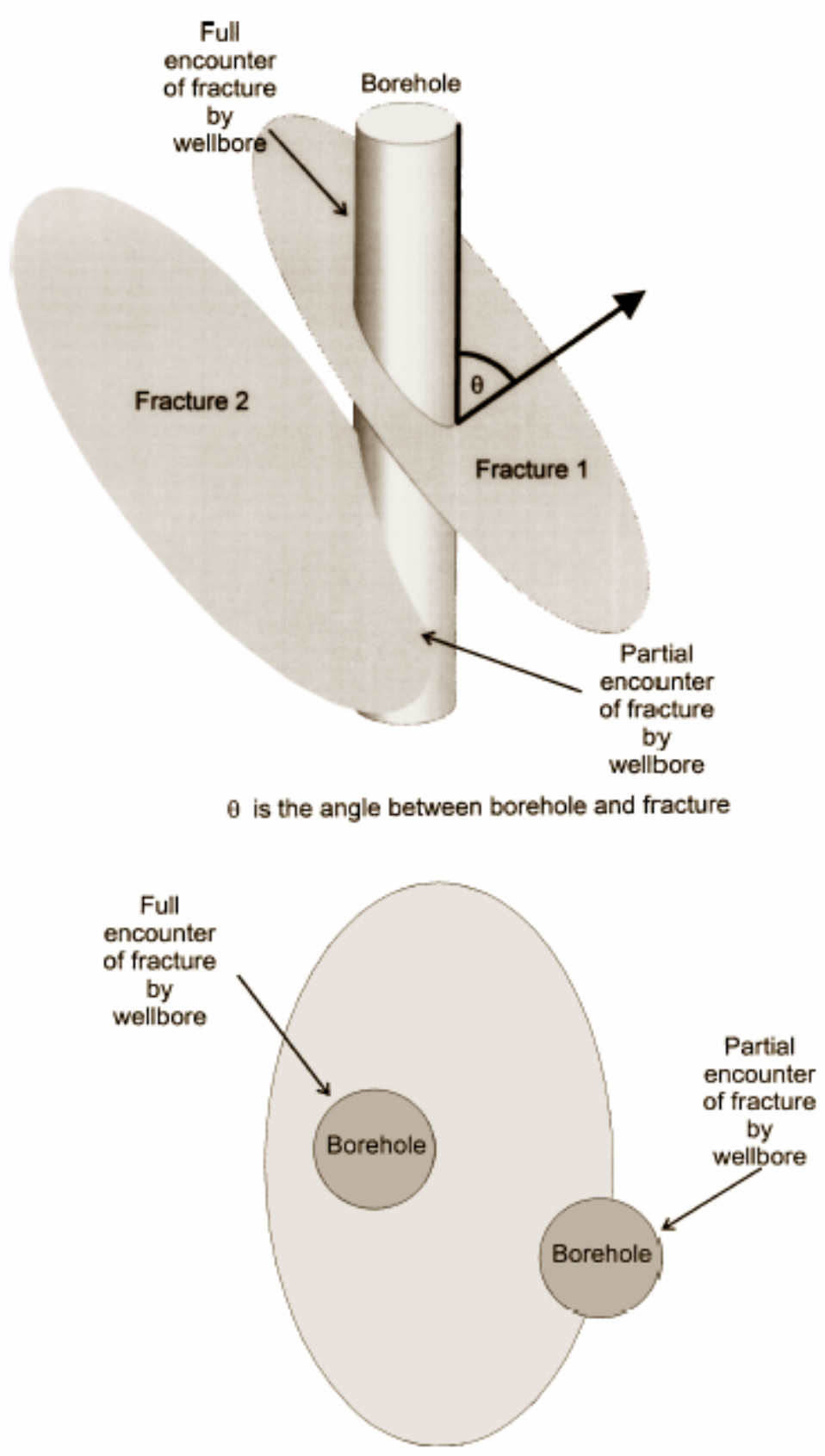

Figure 4-1: This figure is taken from Ozkaya (2003). The top diagram shows fracture intersections with the borehole. The bottom diagram illustrates the fracture projection normal to the borehole. 


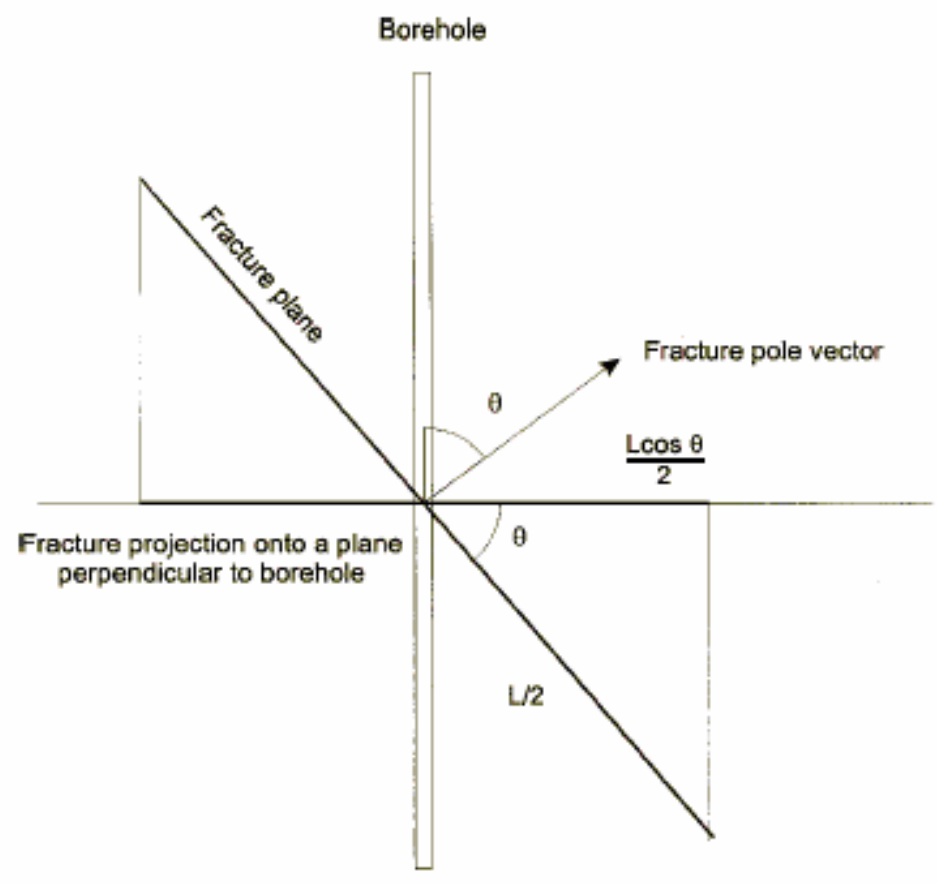

Figure 4-2: Pole to the fracture plane makes an angle $\Theta$ with the borehole (taken from Ozkaya, 2003). 
(Ozkaya, 2003a). The area of this projection is defined as $\frac{\pi L^{2} \cos \theta}{4}$. If a smaller circular fracture with diameter $(L-D)$ is considered (Figure 4-3), the area of that fracture projection will be

$$
A=\frac{\pi(L \cos \theta-D)(L-D)}{4} .
$$

In this case $\mathrm{L}$ is the diameter of the circular fracture, $\mathrm{D}$ is the borehole diameter, and $\mathrm{A}$ is the total area of the elliptical projection of that fracture. Ozkaya, also, introduces an outer fracture projection (Figure 4-3) with the major and minor axis of

$$
\begin{aligned}
& w_{1}=L+D, \text { and } \\
& w_{2}=L \cos \theta+D,
\end{aligned}
$$

respectively. The area of this fracture projection is defined as

$$
A^{\prime}=\frac{\pi(L+D)(L \cos \theta+D)}{4}
$$

Ozkaya (2003b) statistically equates the ratio of the frequency of intersecting fractures to the total number of fractures, $r$, to the ratio of the projection area for fracture 1 to the ratio of the second fracture. This given relationship is defined as

$$
r=\frac{A}{A^{\prime}}
$$

Substitution of equations 4.1 and 4.4 into equation 4.5 yields the relationship

$$
r_{k}=\frac{\left(L_{k}-D\right)\left(L_{k} \cos \theta_{k}-D\right)}{\left(L_{k}+D\right)\left(L_{k} \cos \theta_{k}+D\right)}
$$




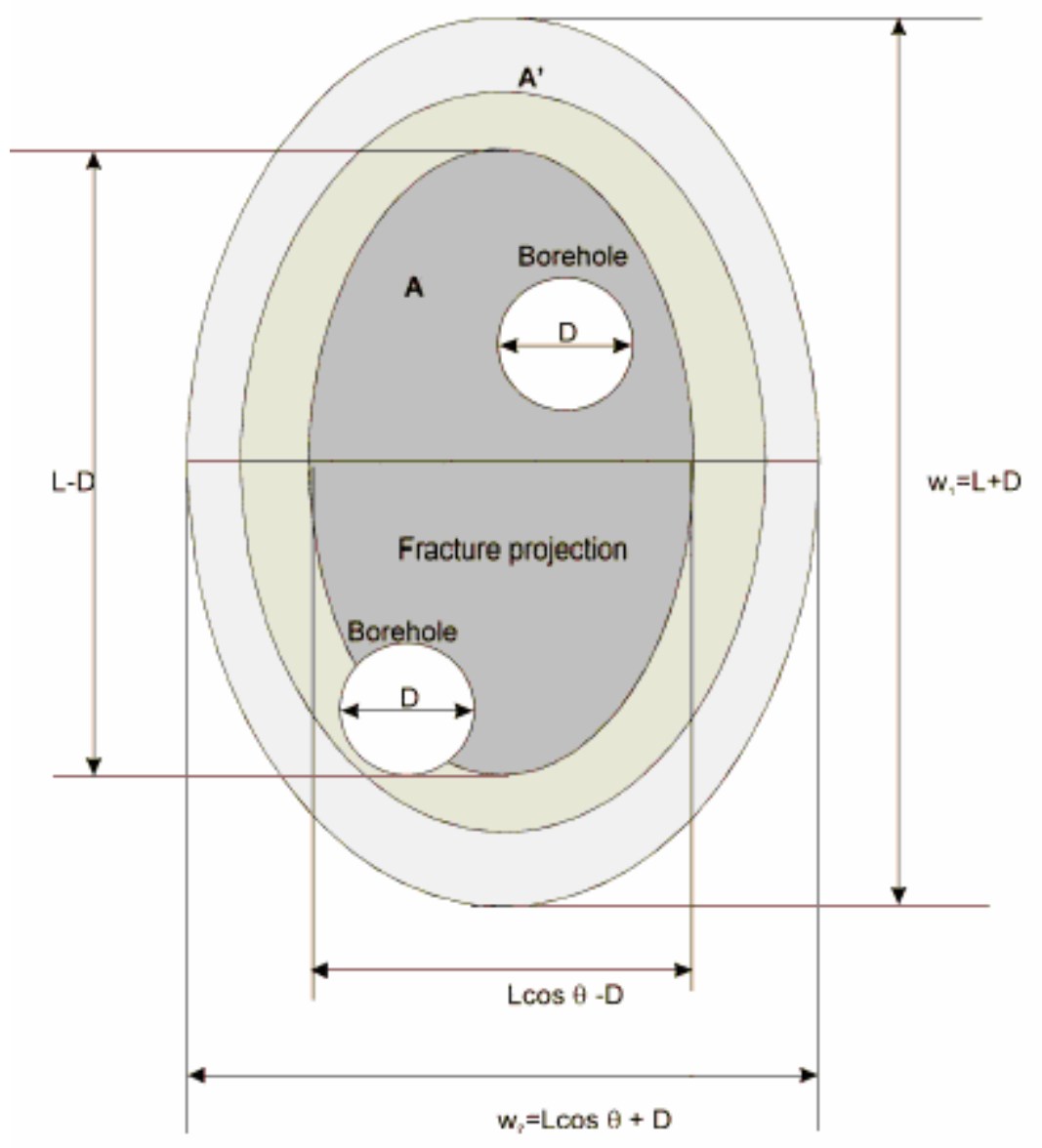

Figure 4-3: This figure illustrates the dimensions and shape of a dipping a circular fracture plane projected onto a plane oriented normal to the borehole. This would correspond to a horizontal projection for a vertical well. This figure is modified from Ozkaya (2003a). 
where the minimum fracture length $L_{k}$ is defined for fracture set k (Ozkaya, 2003a).

Solving this quadratic equation for $\mathrm{L}_{\mathrm{k}}$ will yield the minimum fracture length. Also note that this quadratic equation has two solutions with one value of $\mathrm{L}_{\mathrm{k}}$ being smaller than the borehole diameter and the other larger than the borehole diameter. The smaller length is discarded as it is assumed that fractures smaller than the borehole diameter will not be observed. (see Section 4.3 for length calculations at Teapot Dome)

\section{Fracture Aperture vs. Fracture Length}

FMI logs produce a limited view of fracture properties. Direct analysis of FMI images will provide fracture strike, dip, aperture, and an approximation of fracture density. Information about fracture length and spacing must be inferred from the limited scope of the borehole. According to elastic fracture theory, fracture aperture will scale linearly with fracture length (Pollard, 1987) when formed. Pollard's theoretical model is for opening mode fractures without any shear displacement. Vermilye (1994) concluded that an isolated fracture's aperture varies linearly with length for veins in different sedimentary and igneous rocks, following the relationship:

$$
A=C L
$$

where A the aperture, $\mathrm{C}$ is a scaling factor, and $\mathrm{L}$ is the length. Vermilye (1994) defined a vein's length and width as the maximum dimensions measured parallel and perpendicular to the earth's surface, respectively during the formation of the opening mode fracture.

Additional analysis undertaken by Park (1997) and Perez (2002) indicates that mechanically connected fractures do not exhibit a linear relationship between fracture aperture and fracture length as described by Vermilye (1994). For interconnected or 
coupled fractures, fracture length and fracture aperture were observed to follow a power law relationship (Marrett, 1996):

$$
A=C L^{m}
$$

where $\mathrm{A}$ is the fracture aperture, $\mathrm{L}$ is the fracture length, $\mathrm{C}$ is a scaling factor and $\mathrm{m}$ is the exponent of the power law relationship. Aperture-length relationships can be divided into three categories based on the value of the exponent $m: m=1, m<1$, or $m>1$. When $\mathrm{m}=1$, aperture increases linearly with length. When $\mathrm{m}<1$, aperture continues to increase with length but with decreasing gradient. For $\mathrm{m}>1$, aperture increases exponentially with positive gradient. Figures 4-4 and 4-5 illustrate the relationship in equation 4.8 when $\mathrm{C}=1$ and $\mathrm{m}$ is greater than, less than, and equal to 1.

Perez (2002) studied microfractures, fractures seen only with magnification, with a petrographic microscope and a hand lens for samples of the Ozona Sandstone beds located in the Ozona and Sonora gas fields in Crockett County Texas. He concluded that fracture length $(\mathrm{mm})$ and apertures $(\mathrm{mm})$ for the Ozona Sandstone follow the relationship of Aperture $=0.012 *$ Length $^{0.884}$, where aperture and length are measured in $\mathrm{mm}$. Typically microfracture apertures are between $0.001-0.1 \mathrm{~mm}$. The data collected by Perez (2002) (Figure 4-6) suggest that this power law relationship is a good approximation of fracture apertures that range from $0.001 \mathrm{~mm}$ to $0.3 \mathrm{~mm}$. Moros (1999) conducted an additional study comparing fracture aperture vs. fracture length for multiple sandstones and determined the power law exponent to be approximately 0.75 for microfractures. Moros (1999) indicates that the power law relationship will scale out to fracture lengths of about $1000 \mathrm{~mm}$ and aperture values of $10 \mathrm{~mm}$. It is unknown how the 


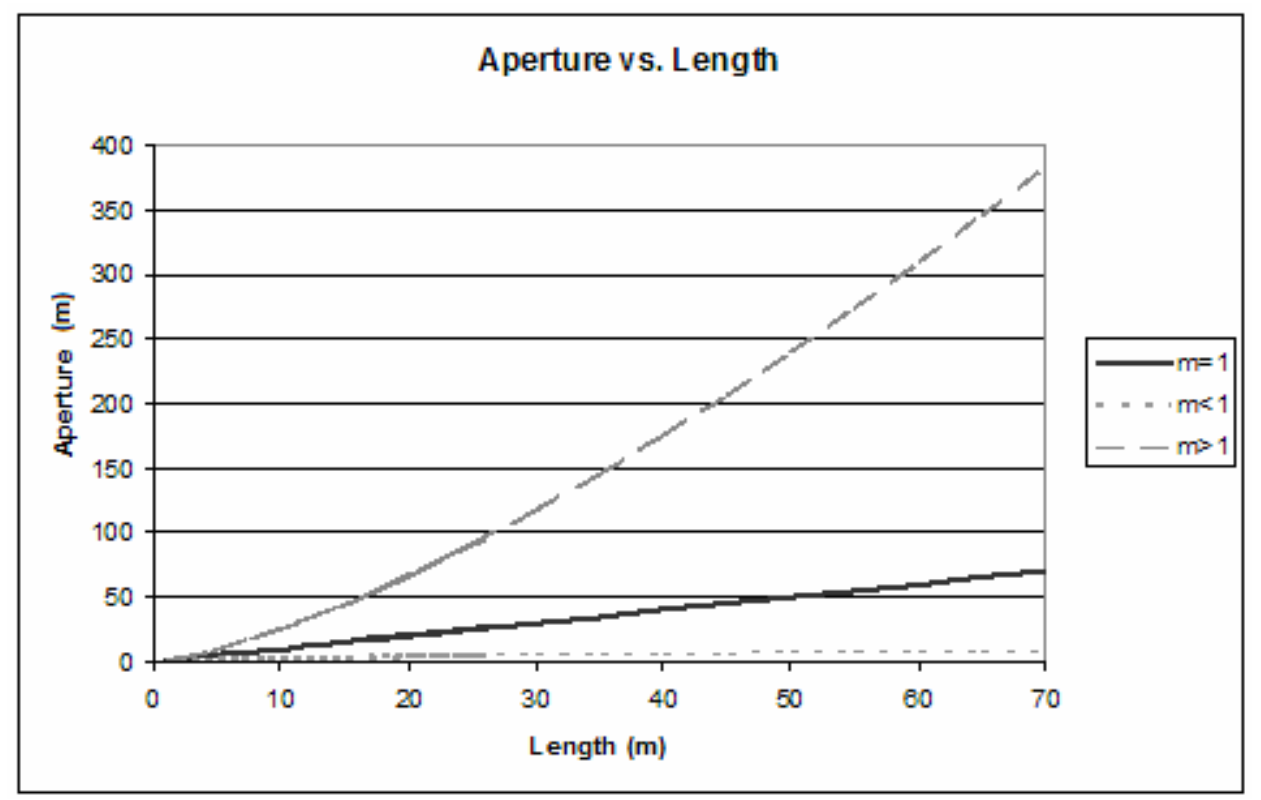

Figure 4-4: The relationship between fracture aperture vs. fracture length as defined by equation 4.8 when the scaling factor, c, equals 1 .

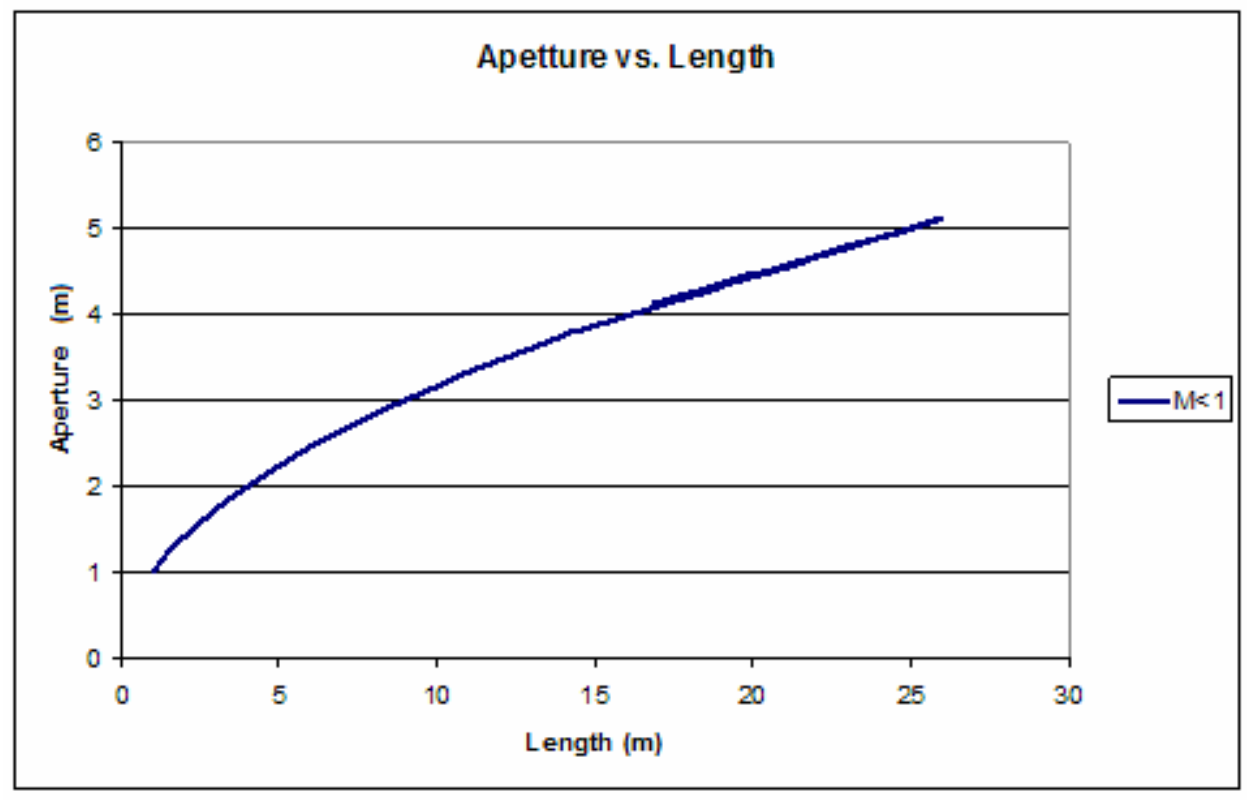

Figure 4-5: The relationship between fracture aperture vs. fracture length as defined by equation 4.8 when $\mathrm{m}<1$ and the scaling facture equals 1 . 


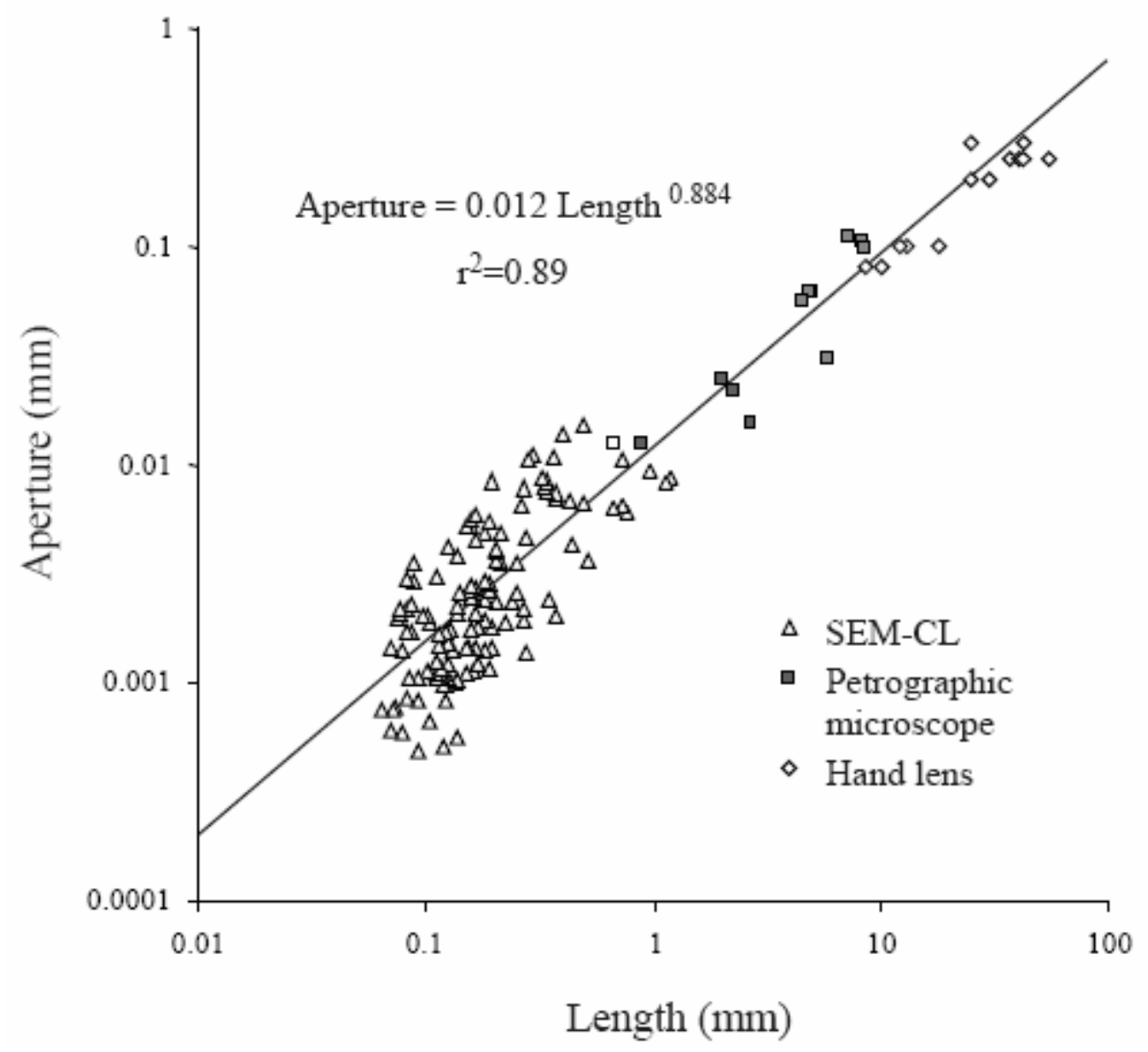

Figure 4-6: Aperture-length data and log-log relationship derived for fractures in the Ozona Sandstone core (taken from Perez, 2002). 
power law relationship determined from microfractures will scale to much larger lengths and aperture values.

\section{Fracture Length Determination at Teapot Dome}

Pavement fracture maps from Cooper's (2000) surface fracture study indicate a minimum fracture length at Teapot Dome to be approximately $0.82 \mathrm{ft}(0.25 \mathrm{~m})$ in length with a fracture maximum length greater than the $16.40 \mathrm{ft}(5 \mathrm{~m})$ of exposed pavement. His study did not include analysis or observation of fracture aperture data. Perez (2002) derived a power law relationship based on observations from the Ozona Sandstone core to be Aperture $=0.012 *$ Length $^{0.884}$, when aperture and length are measured in $\mathrm{mm}$. The aperture values for the open fractures in the Tensleep range between $0.00009-0.00682$ inches $(0.002286-0.173288 \mathrm{~mm})$. Aperture values span about two orders of magnitude and their frequency distribution drops almost exponentially with increased aperture (Figure 4-7). Use of Perez's formula to estimate fracture lengths in the Tensleep yields lengths ranging from $0.006033-0.80708$ inches $(0.15325-20.4998 \mathrm{~mm})$. This yields fracture lengths less than the diameter of the borehole and highlights that the formula, in its current form, does not provide realistic estimates of fracture length in the Tensleep. Increasing the constant $(\mathrm{C})$ and/or the exponent $(\mathrm{m})$ in the power law relationship would yield lengths more representative of the macroscopic fractures observed in the Tensleep.

A possible alternative method to determine minimum fracture length in the Tensleep Formation is to use the minimum fracture length method proposed by Ozkaya (2003) and modify the estimates in the power law relationship to approximate minimum fracture length from average aperture. The parameters for using Ozkaya's (2003) statistical method are provided in Figure 4-1. The ratio, $r$, of the intersecting fractures to 
all fractures is $r=\frac{1}{30}=0.032$. Substituting this ratio, fracture pole angle, and borehole diameter $(155.575 \mathrm{~mm})$ into equation 4.6 yields the relationship

$$
0.032=\frac{\left(L_{k}-155.575 \mathrm{~mm}\right)\left(L_{k} \cos (78.5)-155.575 \mathrm{~mm}\right)}{\left(L_{k}+155.575 \mathrm{~mm}\right)\left(L_{k} \cos (78.5)+155.575 \mathrm{~mm}\right)}
$$

Solving this quadratic equation for $\mathrm{L}_{\mathrm{k}}$ yields two possible solutions for the minimum fracture length: $2.82 \mathrm{ft}$ or $0.45 \mathrm{ft}(0.86 \mathrm{~m}$ or $0.14 \mathrm{~m})$. As $0.45 \mathrm{ft}$ is smaller than the borehole diameter, it is ignored and the minimum fracture length derived from Ozkaya's method is $2.82 \mathrm{ft}(0.86 \mathrm{~m})$. This is similar to the minimum fracture length observed in Cooper's (2000) 0.82ft $(0.25 \mathrm{~m})$ surface fracture maps.

\begin{tabular}{|l|l|}
\hline Parameters & Values \\
\hline Borehole Diameter $(\mathrm{mm})$ & 155.575 \\
\hline Fracture Pole Angle (degrees) & 78.5 \\
\hline Number Intersecting Fractures & 30 \\
\hline Number Fully Intersecting Fractures & 1 \\
\hline r & 0.032 \\
\hline Length $(\mathrm{m})$ & 0.86 \\
\hline
\end{tabular}

Table 4-1: Parameters used for evaluation of the minimum fracture length using the method described by Ozkaya (2003)

The minimum fracture length determined through Ozkaya's (2003) method was compared to the average fracture aperture for the cluster used in the length calculation. The constant $\mathrm{C}$ in Marret's relationship was modified to obtain another estimate of length given the aperture A. Perez's value for the exponent was retained. Given these values for $\mathrm{A}(0.001283 \mathrm{in}$ or $0.03512 \mathrm{~mm})$ requires $\mathrm{C}=0.000041$

It is possible to relate the values of $\mathrm{A}$ and $\mathrm{L}$ in the above by varying $\mathrm{C}, \mathrm{m}$, or both. However, in the absence of actual lengths corresponding to fractures observe in the FMI 
logs it is impossible to derive a separate power law or determine the validity of the power law relationship between apertures and lengths of fractures in the Tensleep sandstones. Ozkaya's method is the only method encountered thus far that allows one to estimate fracture lengths from the distribution of fracture intersections. The minimum average fracture length was calculated for each cluster Ozkaya's approach (Table 4-2). These fracture length estimates serve as an initial starting point for fracture modeling and refinement through future iterative flow simulations. 


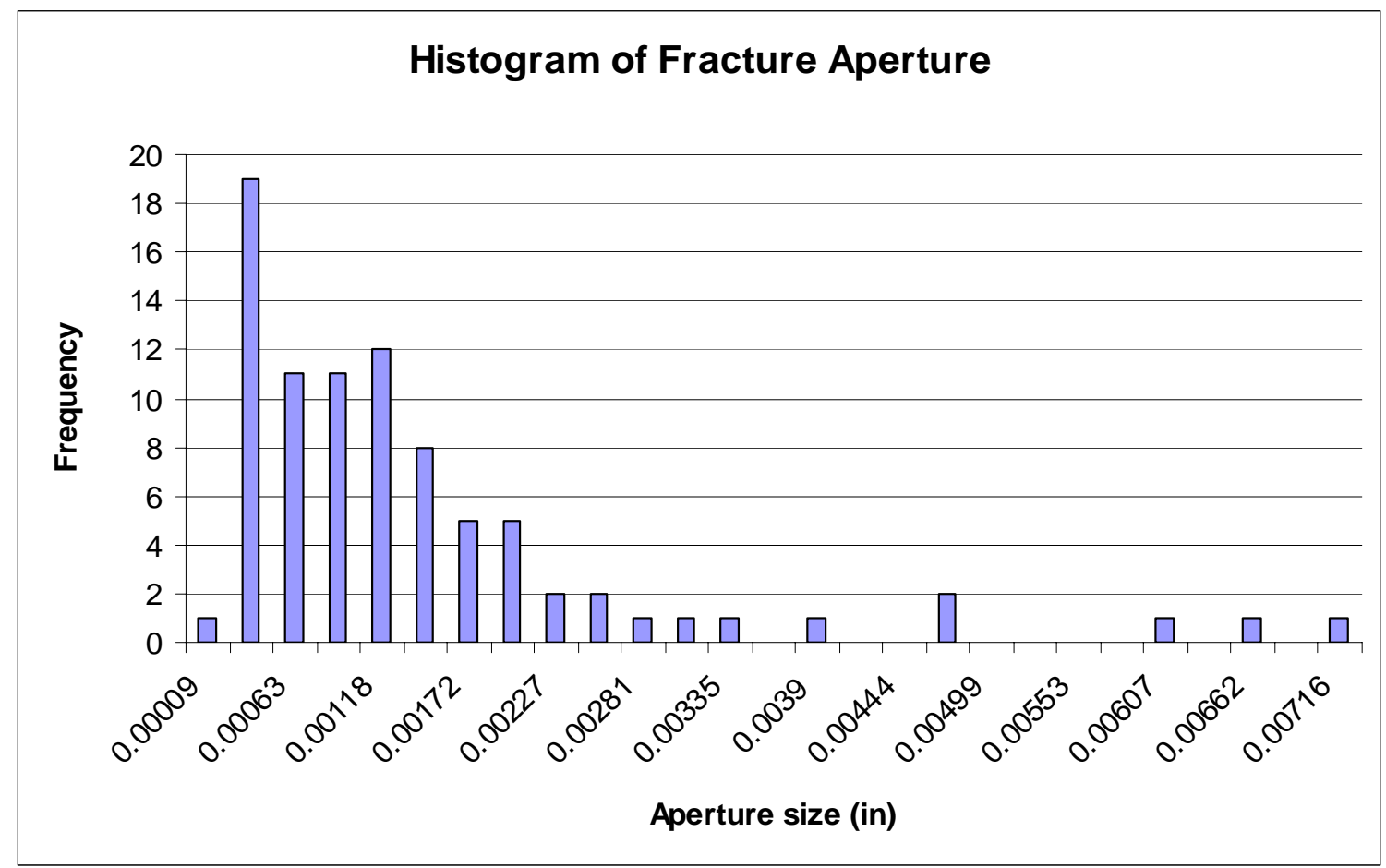

Figure 4-7: Histogram of fracture apertures encountered in the borehole in the Tensleep Formation. 
48-x-28

\begin{tabular}{|c|c|c|c|c|}
\hline Layer & Cluster & Frequency & Min Mean L (ft) & St Dev Length \\
\hline Sandstone A & I & 1 & 3.99 & - \\
\hline & II & 2 & 4.29 & 2.90 \\
\hline & III & 2 & 4.29 & 0.73 \\
\hline Dolomite B & I & 5 & 1.20 & 1.31 \\
\hline & II & 3 & 3.89 & 6.69 \\
\hline Sandstone B & I & 3 & 9.09 & 6.11 \\
\hline & II & 2 & 1.48 & 3.73 \\
\hline
\end{tabular}

71-1-X-4

\begin{tabular}{|c|c|c|c|c|}
\hline Layer & Cluster & Frequency & Min Mean L (ft) & St Dev Length \\
\hline Sandstone A & I & 7 & 3.85 & 1.41 \\
\hline Dolomite B & - & 0 & - & - \\
\hline Sandstone B & I & 2 & 16.29 & 9.37 \\
\hline & II & 1 & 27.42 & - \\
\hline
\end{tabular}

67-1-X-10

\begin{tabular}{|c|c|c|c|c|}
\hline Layer & Cluster & Frequency & Min Mean L (ft) & St Dev Length \\
\hline Sandstone A & - & 0 & - & - \\
\hline Dolomite B & I & 4 & 2.09 & 1.33 \\
\hline & II & 6 & 2.25 & 1.85 \\
\hline & III & 1 & 1.99 & - \\
\hline Sandstone B & I & 2 & 4.92 & 1.73 \\
\hline & II & 1 & 6.03 & - \\
\hline & III & 2 & 4.44 & 1.56 \\
\hline & IV & 1 & 7.19 & - \\
\hline
\end{tabular}

$61-2-\mathrm{x}-15$

\begin{tabular}{|c|c|c|c|c|}
\hline Layer & Cluster & Frequency & Min Mean L (ft) & St Dev Length \\
\hline Sandstone A & I & 1 & 0.62 & - \\
\hline & II & 1 & 0.80 & - \\
\hline & III & 2 & 1.38 & 0.35 \\
\hline & IV & 2 & 0.83 & 0.69 \\
\hline Dolomite B & I & 2 & 0.47 & 0.28 \\
\hline Sandstone B & I & 2 & 6.17 & 4.13 \\
\hline
\end{tabular}

25-1-x-14

\begin{tabular}{|c|c|c|c|c|}
\hline Layer & Cluster & Frequency & Min Mean L (ft) & St Dev Length \\
\hline Sandstone A & I & 3 & 7.93 & 3.36 \\
\hline & II & 5 & 4.19 & 0.73 \\
\hline Dolomite B & III & 5 & 3.47 & 0.51 \\
\hline & I & 7 & 1.12 & 0.25 \\
\hline Sandstone B & II & 6 & 1.11 & 0.54 \\
\hline
\end{tabular}

Table 4-2: The mean minimum fracture length and standard deviation for the fracture clusters were determined using the statistical approach for finding the minimum fracture length and the power law relationship. 


\subsection{Horizontal Fracture Spacing}

Determining horizontal fracture spacing presents difficulties similar to those encountered with fracture length determination. Two methods for determining fracture spacing are compared: the first is a geometric approach that uses a trigonometric correction; the second calculates the average horizontal fracture spacing by comparing the core volume to the volume of the fracture voids. Each method has similar but distinct assumptions and produce similar results.

\section{Geometric Approach}

The geometric approach is a straight forward technique that uses a trigonometric correction to determine horizontal spacing of fractures. In order to use this technique it is assumed that the image log contains a representative sampling of fractures, the average derived spacing represents spacing perpendicular to the borehole, fracture spacing is less than layer thickness, and all fractures are naturally occurring opening mode fractures without shear displacement.

Figure 4-8 illustrates the geometric approach by showing the relationship between the vertical spacing to the horizontal spacing. For this approach, the average vertical spacing is defined as the relationship

$$
S_{\text {vertical }}=\frac{\text { Frequency_of _Fractures }}{\text { Thickness_of_Layer }}
$$

where $S_{\text {vertical }}$ is the average vertical spacing for a fracture set encountered in the borehole. In Figure 4-8, the average dip of the fracture set is denoted by the letter $\mathrm{X}$ and can be calculated directly from the FMI log interpretation. Using the tangent trigonometric identity, the average horizontal spacing is determined by the relationship 


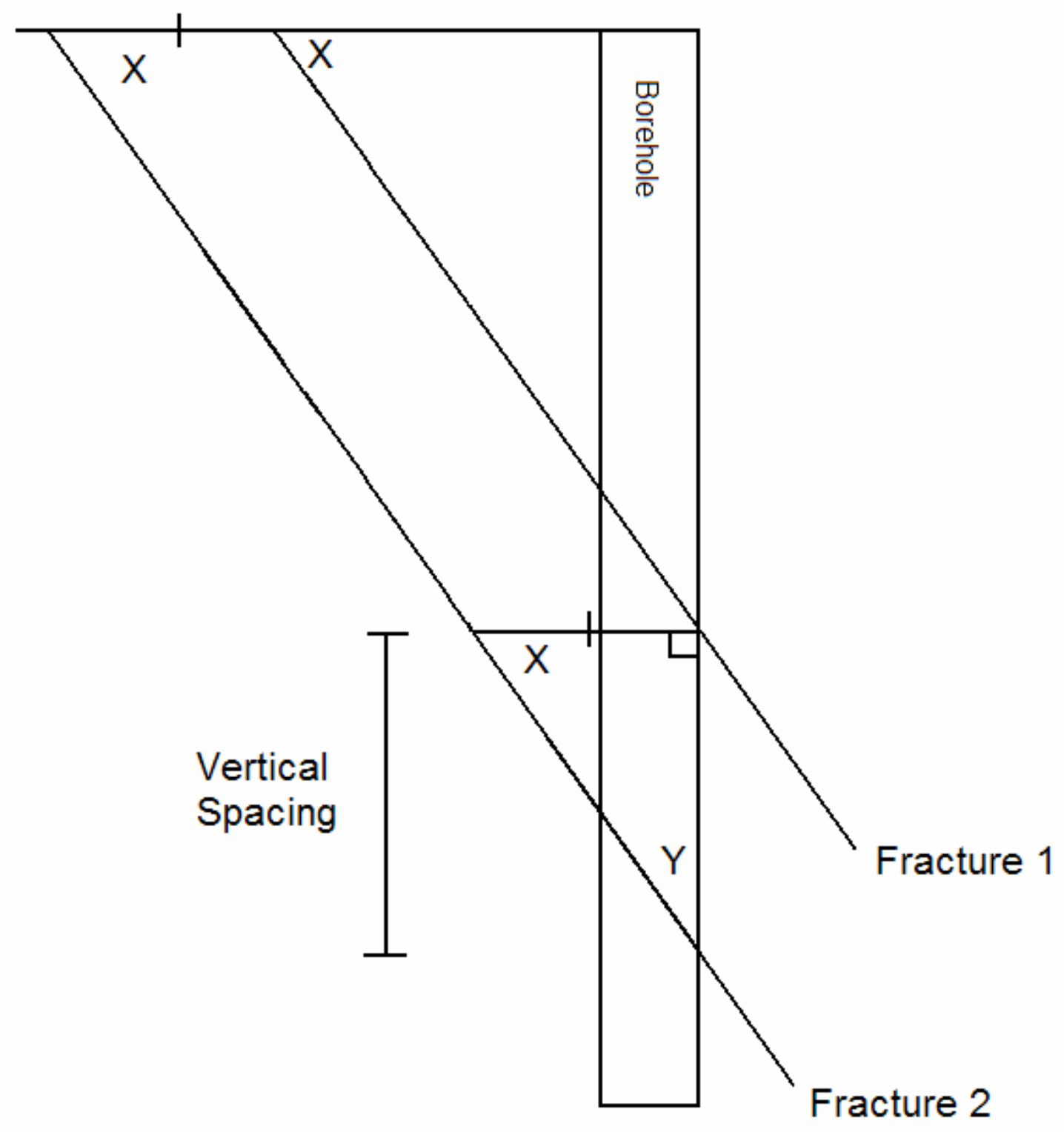

Figure 4-8: The geometric approach determines horizontal fracture spacing based on the dip of the fracture (x) and the vertical fracture spacing. It is assumed that the fractures spacing is not larger than the thickness of the layer. 
48-x-28

\begin{tabular}{|c|c|c|c|c|c|}
\hline Layer & Cluster & Frequency & $\mathrm{S}_{\text {vertical }}(\mathrm{ft})$ & Dip $\left(^{\circ}\right)$ & $\mathrm{S}_{\text {horizontal }}(\mathrm{ft})$ \\
\hline Sandstone A & I & 1 & 26.00 & 75.12 & 6.91 \\
\hline & II & 2 & 13.00 & 73.60 & 3.82 \\
\hline & III & 2 & 13.00 & 84.31 & 1.30 \\
\hline Dolomite B & I & 5 & 5.20 & 79.11 & 1.00 \\
\hline Sandstone B & II & 3 & 8.67 & 80.77 & 1.41 \\
\hline & I & 3 & 18.33 & 71.20 & 6.24 \\
\hline
\end{tabular}

71-1-x-4

\begin{tabular}{|c|c|c|c|c|c|}
\hline Layer & Cluster & Frequency & $\mathrm{S}_{\text {vertical }}(\mathrm{ft})$ & Dip ( $\left.{ }^{\circ}\right)$ & S $_{\text {horizontal }}(\mathrm{ft})$ \\
\hline Sandstone A & I & 7 & 3.00 & 79.51 & 0.56 \\
\hline Dolomite B & - & 0 & - & - & - \\
\hline Sandstone B & I & 2 & 38.50 & 72.53 & 12.12 \\
\hline & II & 1 & 77 & 76.59 & 18.36 \\
\hline
\end{tabular}

$67-1-\mathrm{x}-10$

\begin{tabular}{|c|c|c|c|c|c|}
\hline Layer & Cluster & Frequency & $\mathrm{S}_{\text {vertical }}(\mathrm{ft})$ & Dip $\left(^{\circ}\right)$ & S $_{\text {horizontal }}(\mathrm{ft})$ \\
\hline Sandstone A & - & 0 & - & - & - \\
\hline Dolomite B & I & 4 & 13.75 & 80.17 & 1.00 \\
\hline & II & 6 & 34.31 & 83.04 & 0.47 \\
\hline & III & 1 & 4.70 & 83.80 & 2.50 \\
\hline Sandstone B & I & 2 & 5.91 & 78.98 & 5.75 \\
\hline & II & 1 & 4.03 & 82.78 & 7.47 \\
\hline & III & 2 & 2.31 & 66.07 & 13.09 \\
\hline & IV & 1 & 1.45 & 70.66 & 20.70 \\
\hline
\end{tabular}

61-2-x-15

\begin{tabular}{|c|c|c|c|c|c|}
\hline Layer & Cluster & Frequency & $\mathrm{S}_{\text {vertical }}(\mathrm{ft})$ & $\operatorname{Dip}\left(^{\circ}\right)$ & $\mathrm{S}_{\text {horizontal }}(\mathrm{ft})$ \\
\hline Sandstone A & I & 1 & 35 & 59.42 & 20.68 \\
\hline & II & 1 & 35 & 49.30 & 30.10 \\
\hline & III & 2 & 17.5 & 30.08 & 30.21 \\
\hline & IV & 2 & 17.5 & 52.54 & 13.41 \\
\hline Dolomite B & I & 2 & 11 & 81.52 & 1.64 \\
\hline Sandstone B & I & 2 & 29 & 72.76 & 9.00 \\
\hline
\end{tabular}

25-1-x-14

\begin{tabular}{|c|c|c|c|c|c|}
\hline Layer & Cluster & Frequency & $\mathrm{S}_{\text {vertical }}(\mathrm{ft})$ & $\operatorname{Dip}\left(^{\circ}\right)$ & $\mathrm{S}_{\text {horizontal }}(\mathrm{ft})$ \\
\hline Sandstone A & I & 3 & 7.33 & 76.28 & 1.79 \\
\hline & II & 5 & 4.40 & 45.79 & 4.28 \\
\hline & III & 5 & 4.40 & 39.82 & 5.28 \\
\hline Dolomite B & I & 7 & 4.86 & 64.48 & 2.32 \\
\hline Sandstone B & II & 6 & 5.67 & 57.18 & 3.65 \\
\hline
\end{tabular}

Table 4-3: The average horizontal cluster spacing determined from the geometric approach. 


$$
S_{\text {horizontal }}=\frac{S_{\text {vertical }}}{\tan (x)}
$$

where $\mathrm{S}_{\text {horizontal }}$ is the average horizontal spacing.

Table 4-3 shows average vertical spacing, average dip, and average horizontal spacing for the fracture clusters identified by rose diagrams and equal-area plots in Chapter 3. The thicker Sandstone B has a larger average horizontal fracture spacing when compared to the thinner Sandstone A layer. The low dip angle associated with some fracture sets in wells $61-2-\mathrm{x}-15$ and $25-1-\mathrm{x}-14$ are treated as naturally occurring opening mode fractures for the purposes of fracture spacing, but the low angle maybe more indicative of shear fractures. Further study may show that these fracture sets do not meet the assumptions for this model.

\section{Geologic Method}

The geologic model for finding fracture spacing was developed by Wayne Narr (1984 and 1996). This model is based on having fractures that are opening mode fractures, the fractures form parallel to one another, the fractures are perpendicular to bedding, and the fractures are much longer than the core length (Narr, 1996). This model calculates fracture spacing from fracture porosity. Fracture porosity is defined by the relationship

$$
\phi_{f}=\frac{\text { void_space_in_fractures }}{\text { Total_Core_Volume }}=\frac{\sum_{i=1}^{n} A_{i} H_{i} L_{i}}{W_{c} H_{c} L_{c}},
$$

where $\mathrm{A}_{\mathrm{i}}=$ aperture of fractures, $\mathrm{H}_{\mathrm{i}}=$ height of fractures, $\mathrm{L}_{\mathrm{i}}=$ Length of fractures, $\mathrm{n}=$ total number of fractures, $\mathrm{W}_{\mathrm{c}}=$ core width, $\mathrm{H}_{\mathrm{c}}=$ core height, and $\mathrm{L}_{\mathrm{c}}=$ length of core and is 
shown in Figure 4-9 (Narr, 1996). Based on the assumption that fractures lengths are much longer than the core length, the lengths will reduce out. Narr (1996) further defines fracture porosity to be

$$
\phi_{f}=\frac{A_{a v}}{S_{a v}},
$$

where $\mathrm{A}_{\mathrm{av}}$ is equal to the average aperture and $\mathrm{S}_{\mathrm{av}}$ is the average horizontal spacing of the fractures. Equating Equations 4-10 and 4-11 and solving for the average spacing yields the relationship

$$
S_{a v}=\frac{A_{a v} W_{c} H_{c}}{\sum_{i=1}^{n} A_{i} H_{i}} .
$$

To further simply this relationship, the average aperture can be used to yield

$$
S_{a v}=\frac{A_{a v} W_{c} H_{c}}{A_{a v} \sum_{i=1}^{n} H_{i}}=\frac{W_{c} H_{c}}{\sum_{i=1}^{N} H_{i}} .
$$

This reduces the average fracture spacing to the ratio of the quantity of the core diameter multiplied by core height to the sum of the fracture heights.

The accuracy of this method requires accurate measurements of core diameter, core height, and fracture height. When working with FMI images to determine fracture height, the resolution of FMI logs is a limiting factor as fracture endpoints may not be clearly delineated on the FMI image. The stringent set of assumptions for use of this model limits the application of this technique to find fracture spacing. Fractures that are not conforming to these assumptions will cause errors to be introduced into the calculation. 


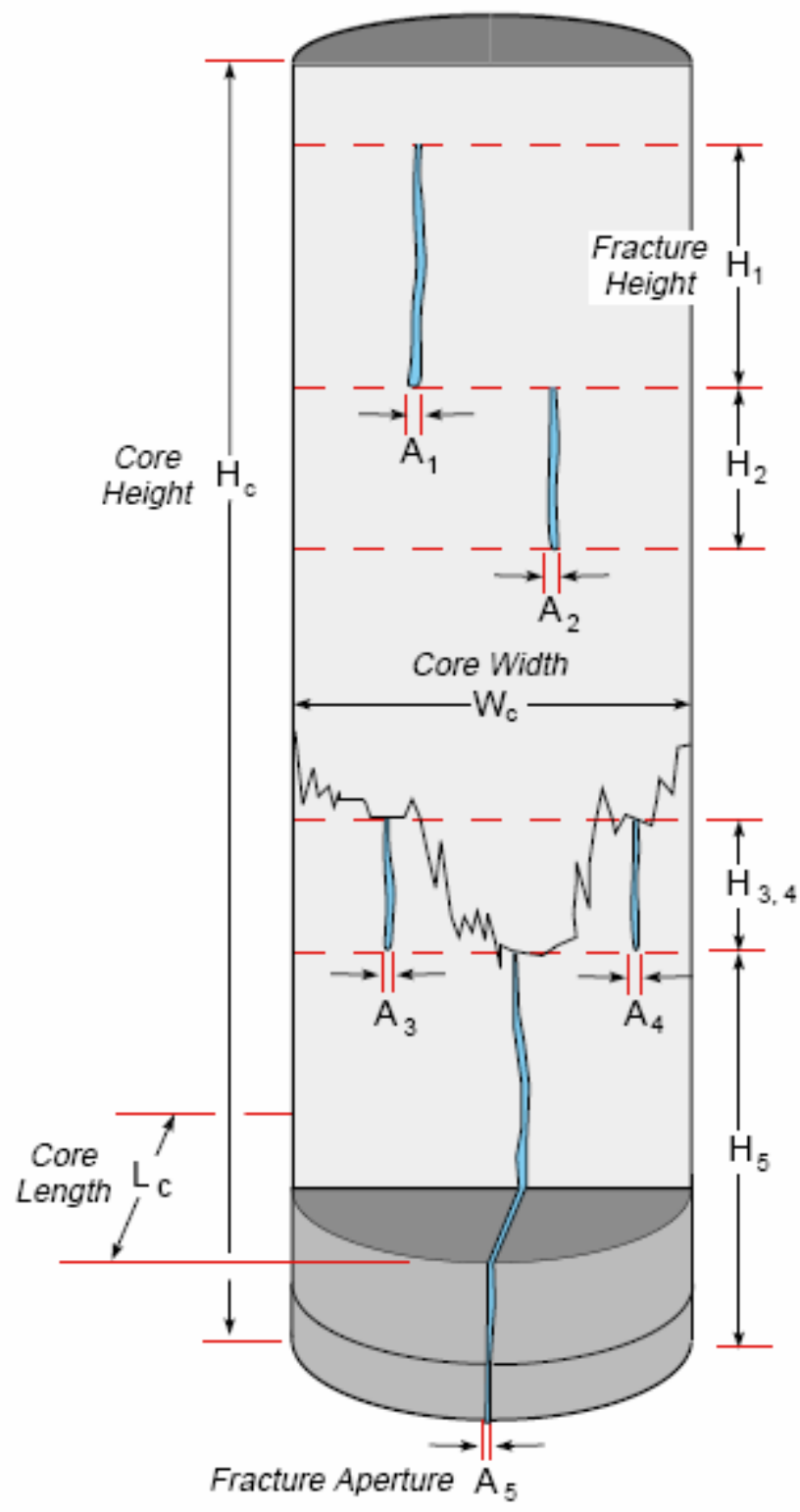

Figure 4-9: Schematic of fractures core lacking regular, mechanically significant layering. The jagged line along the core width represents the boundary between two unique mechanical layers (taken from Narr, 1996). 
48-x-28

\begin{tabular}{|c|c|c|c|c|c|}
\hline Layer & Cluster & Frequency & Thickness (ft) & $\Sigma$ Hi (ft) & S $_{\text {horizontal }}(\mathrm{ft})$ \\
\hline Sandstone A & I & 1 & 26 & 1.92 & 6.91 \\
\hline & II & 2 & 26 & 6.04 & 2.20 \\
\hline & III & 2 & 26 & 11.14 & 1.19 \\
\hline Dolomite B & I & 5 & 26 & 15.13 & 0.88 \\
\hline & II & 3 & 26 & 10.27 & 1.29 \\
\hline Sandstone B & I & 3 & 55 & 6.61 & 4.24 \\
\hline & II & 2 & 55 & 4.98 & 5.63 \\
\hline
\end{tabular}

71-1-x-4

\begin{tabular}{|c|c|c|c|c|c|}
\hline Layer & Cluster & Frequency & & & \\
\hline Sandstone A & I & 7 & 21 & 20.01 & 0.54 \\
\hline Dolomite B & - & 0 & 15 & - & - \\
\hline Sandstone B & I & 2 & 77 & 3.91 & 10.06 \\
\hline & II & 1 & 77 & 2.14 & 18.36 \\
\hline
\end{tabular}

67-1-x-10

\begin{tabular}{|c|c|c|c|c|c|}
\hline Layer & Cluster & Frequency & & & \\
\hline Sandstone A & - & 0 & 23 & - & - \\
\hline Dolomite B & I & 4 & 28 & 13.75 & 1.04 \\
\hline & II & 6 & 28 & 26.83 & 0.53 \\
\hline & III & 1 & 28 & 4.70 & 3.04 \\
\hline Sandstone B & I & 2 & 59 & 5.91 & 5.09 \\
\hline & II & 1 & 59 & 4.03 & 7.47 \\
\hline & III & 2 & 59 & 1.45 & 13.02 \\
\hline & IV & 1 & 59 & 2.31 & 20.70 \\
\hline
\end{tabular}

61-2-x-15

\begin{tabular}{|c|c|c|c|c|c|}
\hline Layer & Cluster & Frequency & & & \\
\hline Sandstone A & I & 1 & 35 & 0.86 & 20.68 \\
\hline & II & 1 & 35 & 0.60 & 30.10 \\
\hline & III & 2 & 35 & 0.59 & 30.21 \\
\hline & IV & 2 & 35 & 1.33 & 13.41 \\
\hline Dolomite B & I & 2 & 22 & 6.86 & 1.64 \\
\hline Sandstone B & I & 2 & 58 & 3.29 & 9.00 \\
\hline
\end{tabular}

25-1-x-14

\begin{tabular}{|c|c|c|c|c|c|}
\hline Layer & Cluster & Frequency & & & \\
\hline Sandstone A & I & 3 & 22 & 10.61 & 1.05 \\
\hline & II & 5 & 22 & 2.64 & 4.25 \\
\hline & III & 5 & 22 & 2.13 & 5.26 \\
\hline Dolomite B & I & 7 & 34 & 12.11 & 1.43 \\
\hline Sandstone B & II & 6 & 34 & 6.13 & 2.80 \\
\hline
\end{tabular}
model. 


\subsection{Center Point Density}

Fracture center point density as defined by McKoy (2001), is the number of fracture or fracture zone center points per unit representative area $\left(\mathrm{pts} / \mathrm{ft}^{2}\right)$. The fracture center point density for each cluster is calculated from the relationship

$$
D_{i}=\frac{\Lambda_{i}}{b_{i} l_{i}}
$$

where $\mathrm{D}_{\mathrm{i}}$ is the density of the fracture center points $\left(\mathrm{pts} / \mathrm{ft}^{2}\right), \Lambda_{\mathrm{i}}$ is the linear density of fractures (fractures/ft), $b_{i}$ is the correction factor for variance in fracture orientation, and $l_{i}$ is the mean fracture length (ft) (Mckoy, 2001). The length used for this calculation is the average minimum fracture length determined in Section 4-1. This will cause the calculated center point density to be systematically large. The linear density (fractures/ft) is the inverse of the horizontal spacing. The horizontal spacing obtained from the Geometric Method was used to determine the center point density for each fracture cluster (set) observed. The correction factor is defined by the relationship

$$
b_{i}=\int_{\theta_{\min }}^{\theta_{\max }} \cos (\theta) p(\theta) d \theta
$$

where $\mathrm{p}$ is a probability function and $\theta$ is the fracture orientation, assumed to be a Gaussian Distribution. Table 4-5 displays the results of the center point density calculations. 
$48-\mathrm{x}-28$

\begin{tabular}{|c|c|c|c|c|}
\hline Layer & Cluster & $\begin{array}{c}\text { Linear } \\
\text { Density }\end{array}$ & $\begin{array}{c}\text { Length } \\
(\mathrm{ft})\end{array}$ & $\mathrm{CPD}\left(\mathrm{pts} / \mathrm{ft}^{2}\right)$ \\
\hline Sandstone A & I & 0.14 & 3.99 & 0.017309 \\
\hline & II & 0.26 & 4.29 & 0.041216 \\
\hline & III & 0.77 & 4.29 & 0.123218 \\
\hline Dolomite B & I & 1.00 & 1.20 & 0.539837 \\
\hline & II & 0.71 & 3.89 & 0.121790 \\
\hline Sandstone B & I & 0.16 & 9.09 & 0.011867 \\
\hline & II & 0.17 & 1.48 & 0.007883 \\
\hline
\end{tabular}

\begin{tabular}{|c|c|c|c|c|}
\hline $71-1-\mathrm{x}-4$ & Cluster & $\begin{array}{c}\text { Linear } \\
\text { Density }\end{array}$ & $\begin{array}{c}\text { Length } \\
(\mathrm{ft})\end{array}$ & CPD (pts/ft2) \\
\hline Layer & I & 1.79 & 3.85 & 0.315949 \\
\hline Sandstone A & - & & - & \\
\hline Solomite B & I & 0.08 & 16.29 & 0.003441 \\
\hline & II & 0.05 & 27.42 & 0.001369 \\
\hline
\end{tabular}

\begin{tabular}{|c|c|c|c|c|}
\hline \multicolumn{5}{|l|}{$67-1-x-10$} \\
\hline Layer & Cluster & $\begin{array}{c}\text { Linear } \\
\text { Density }\end{array}$ & $\begin{array}{l}\text { Length } \\
\text { (ft) }\end{array}$ & $\mathrm{CPD}(\mathrm{pts} / \mathrm{ft} 2)$ \\
\hline Sandstone A & - & & - & \\
\hline \multirow[t]{3}{*}{ Dolomite B } & I & 1.00 & 2.09 & 0.320321 \\
\hline & II & 2.13 & 2.25 & 0.632212 \\
\hline & III & 0.40 & 1.99 & 0.138019 \\
\hline \multirow[t]{4}{*}{ Sandstone B } & I & 0.17 & 4.92 & 0.024189 \\
\hline & II & 0.13 & 6.03 & 0.015281 \\
\hline & III & 0.08 & 4.44 & 0.011769 \\
\hline & IV & 0.05 & 7.19 & 0.004629 \\
\hline
\end{tabular}

$61-2-\mathrm{x}-15$

\begin{tabular}{|c|c|c|c|c|}
\hline Layer & Cluster & $\begin{array}{c}\text { Linear } \\
\text { Density }\end{array}$ & $\begin{array}{c}\text { Length } \\
(\mathrm{ft})\end{array}$ & CPD (pts/ft2) \\
\hline Sandstone A & I & 0.05 & 0.62 & 0.053962 \\
\hline & II & 0.03 & 0.80 & 0.028534 \\
\hline & III & 0.03 & 1.38 & 0.016422 \\
\hline & IV & 0.07 & 0.83 & 0.059981 \\
\hline Dolomite B & I & 0.61 & 0.47 & 0.942222 \\
\hline Sandstone B & I & 0.11 & 6.17 & 0.012172 \\
\hline
\end{tabular}

25-1-x-14

\begin{tabular}{|c|c|c|c|c|}
\hline Layer & Cluster & $\begin{array}{c}\text { Linear } \\
\text { Density }\end{array}$ & $\begin{array}{c}\text { Length } \\
(\mathrm{ft})\end{array}$ & CPD (pts/ft2) \\
\hline Sandstone A & I & 0.56 & 7.93 & 0.047961 \\
\hline & II & 0.23 & 4.19 & 0.038261 \\
\hline & III & 0.19 & 3.47 & 0.037473 \\
\hline Dolomite B & I & 0.43 & 1.12 & 0.263779 \\
\hline & II & 0.27 & 1.11 & 0.167268 \\
\hline Sandstone B & I & 0.37 & 10.90 & 0.021775 \\
\hline
\end{tabular}

Table 4-5: Center point density determined from minimum average fracture

lengths and the horizontal linear density determined from the geometric spacing method. 


\section{Chapter 5: FRACGEN Fracture Models}

\subsection{Description of FRACGEN}

FRACGEN is a stochastic fracture modeling program developed by Mark McKoy (2001). The program is capable of creating a 2D fracture network representation for fracture distribution patterns that range from regular to random to clustered. Multiple layer fracture models can be created by stacking the 2D models to simulate a multilayer reservoir. Fractures can extend between layers. If specific fracture locations are available from seismic methods or FMI logs, FRACGEN allows the addition of known fractures by specifying the fracture's length, width, and aperture (McKoy, 2001). FRACGEN assumes that all fractures are strata bound and perpendicular to bedding. It also assumes bed thickness is relatively constant (McKoy, 2001). The 2D fracture model provides an adequate representation of most fracture networks that are strata-bound (McKoy, 1999).

FRACGEN models are based on statistical descriptions of the reservoir fracture network, including statistics on fracture orientation, effective clustering, effective fracture aperture and fracture center point densities (McKoy, 2001). FRACGEN is capable of modeling multiple sets of fractures by allowing the input of stochastic fracture parameters for each set. Each fracture set can be modeled by different distribution patterns: random, swarm, and non-overlapping swarm (See Appendix B) (McKoy, 2001). Figure 5-1, shows the graphical output generated for an Oriskany Sandstone gas reservoir. This sample input data file for the fracture network is provided with the program FRACGEN (McKoy, 2001). The simulated fracture network has five different fracture sets that 


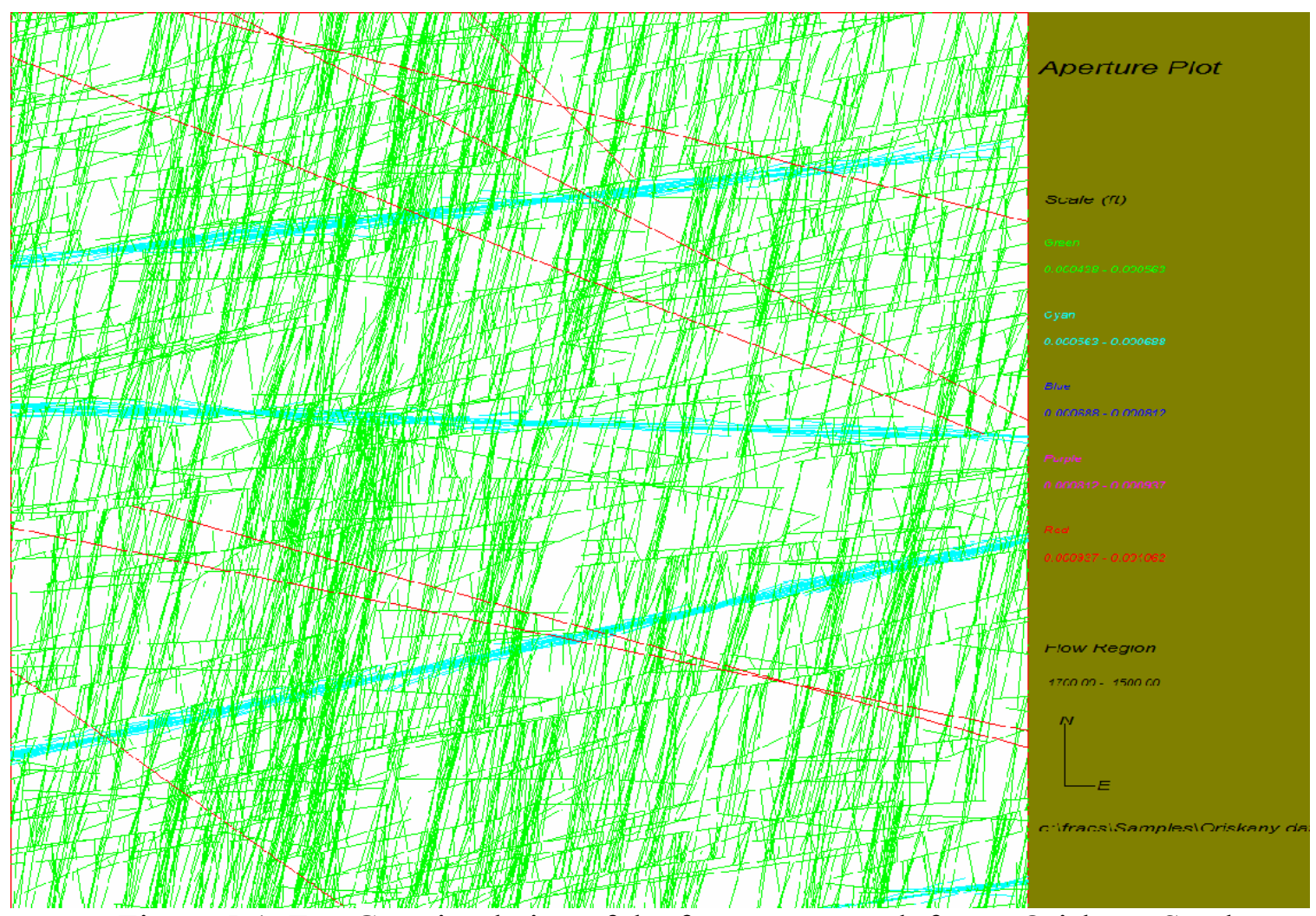

Figure 5-1: FracGen simulation of the fracture network for an Oriskany Sandstone gas reservoir at an undisclosed location. This simulation is taken from FRACGEN samples. 
honor the orientations, spacing distributions, and observed fracture intersections with a horizontal well. This particular example was part of a study of a storage field where knowledge of the interconnected fracture trends will help design a drilling program to optimize storage and production of natural gas. Fracture network realizations developed by FRACGEN can be input into the NETL developed flow simulator NFFLOW. FRACGEN's output file contains a serial listing of fracture endpoint coordinates, apertures, height, depth, and an identification number for each fracture (McKoy, 2001). The output file can be used to create rose diagrams of fracture trends generated by FRACGEN to compare fracture parameters specified in the input.

\subsection{Model Limitations}

An FMI log provides a limited view of fractures penetrated by the borehole. FMI $\log$ interpretations provide fracture orientation, dip, fracture aperture and fracture spacing in the direction of the borehole. Actual fracture spacing can be computed given the fracture dip. Some information about fracture length can also be inferred from the aperture of fractures encountered in the wellbore (see Chapter 4). Fracture spacing and length have been directly related to fracture aperture for fractures that have not been altered since their initial formation (Perez, 2002; Marrett, 1999; Park, 1997; Vermilye, 1995). Estimates of fracture length and spacing for fractures in the Tensleep, discussed in Chapter 4, are rough approximations at best for these parameters. The FMI log provides little direct evidence for fracture intersection frequency. However, fracture lengths and spacing can also be inferred indirectly by examining the effects of varying 
fracture length, fracture intersection frequency, and fracture spacing on production in a reservoir simulator.

Three assumptions are made by FRACGEN in the process used to generate a stochastic fracture model: 1) all layers have a near constant thickness, 2) all fractures are near vertical, and 3) all fractures extend through the entire thickness of the layer. If layer thickness varies considerably, if the fractures have a relatively low dip angle, or if the fractures do not go through the entire layer, the models created with FRAGEN may have significant systematic error. See section 5.4 for methods to improve the fracture model's accuracy.

\subsection{FRACGEN Models for Teapot Dome}

FRACGEN models were created for the fractures interpreted for the Sandstone A, Dolomite B, and Sandstone B layers at Teapot Dome. The FMI logs for wells 48-x-28, 71-1-x-4, 67-1-x-10, 61-2-x-15, and 25-1-x-14, interpreted by Koepsell (2001, 2002a, 2002b, 2004a, and 2004b) were analyzed for fracture clusters or sets (Chapters 3 and 4). The cluster or set statistics determined in Chapters 3 and 4 (fracture aperture, minimum length, orientation, and center point density) are shown in Table 5-1 and Table 5-2 for the Sandstone A, Dolomite B, and Sandstone B layers. This stochastic fracture information was entered as a fracture description for FRACGEN to create a stochastic model for the area around the wellbore.

In this study, the FRACGEN modeling area is defined as $50 \mathrm{ft}$ by $50 \mathrm{ft}$ with a thickness corresponding to the thickness of the individual layers found in Table 3-2. Fracture clusters were input into FRACGEN based on the mean of the minimum fracture 


\begin{tabular}{|c|c|c|c|c|c|c|c|}
\hline Well & Layer & Cluster & Frequency & $\begin{array}{c}\text { Strike } \\
\text { Mean }\end{array}$ & $\begin{array}{c}\text { Strike St } \\
\text { Dev }\end{array}$ & $\begin{array}{c}\text { Length } \\
\text { Mean } \\
(\mathrm{ft})\end{array}$ & $\begin{array}{c}\text { Length } \\
\text { St Dev } \\
(\mathrm{ft})\end{array}$ \\
\hline $48-\mathrm{x}-28$ & SSA & I & 1 & 109.13 & - & 8.36 & - \\
\hline & & II & 2 & 129.54 & 1.83 & 6.35 & 4.95 \\
\hline & & III & 2 & 75.18 & 11.66 & 6.24 & 1.48 \\
\hline & DOLB & I & 5 & 90.67 & 2.08 & 1.85 & 2.25 \\
\hline & & II & 3 & 109.74 & 7.22 & 5.82 & 4.45 \\
\hline & SSB & I & 3 & 92.66 & 3.99 & 13.50 & 10.66 \\
\hline & & II & 2 & 122.97 & 1.83 & 21.57 & 7.17 \\
\hline $71-1-\mathrm{x}-4$ & SSA & I & 7 & 100.21 & 4.82 & 5.65 & 2.69 \\
\hline & DOLB & - & 0 & - & - & - & - \\
\hline & SSB & I & 2 & 126.15 & 0.01 & 23.98 & 16.31 \\
\hline & & II & 1 & 161.57 & - & 39.78 & - \\
\hline $67-1-\mathrm{x}-10$ & SSA & - & 0 & - & - & & - \\
\hline & DOLB & I & 4 & 88.69 & 5.12 & 3.12 & 2.26 \\
\hline & & II & 6 & 108.10 & 2.09 & 3.37 & 2.28 \\
\hline & & III & 1 & 151.57 & - & 2.90 & - \\
\hline & SSB & I & 2 & 88.89 & 5.12 & 7.19 & 3.20 \\
\hline & & II & 1 & 110.77 & - & 8.76 & - \\
\hline & & III & 2 & 153.87 & 2.54 & 6.49 & 2.89 \\
\hline & & IV & 1 & 130.68 & - & 10.44 & - \\
\hline $61-2-x-15$ & SSA & I & 1 & 167.70 & - & 0.90 & - \\
\hline & & II & 1 & 11.54 & - & 1.16 & - \\
\hline & & III & 2 & 141.54 & 16.44 & 2.02 & 0.68 \\
\hline & & IV & 2 & 70.73 & 1.19 & 1.24 & 1.15 \\
\hline & DOLB & I & 2 & 107.22 & 2.16 & 0.65 & 0.48 \\
\hline & SSB & I & 2 & 81.92 & 0.04 & 9.13 & 7.06 \\
\hline & SSA & I & 3 & 86.44 & 4.19 & 11.65 & 6.00 \\
\hline & & II & 5 & 107.51 & 4.99 & 6.11 & 1.44 \\
\hline & & III & 5 & 141.03 & 10.38 & 5.06 & 1.06 \\
\hline & DOLB & I & 7 & 87.70 & 3.11 & 1.63 & 0.49 \\
\hline & SSSB & II & 6 & 107.26 & 9.39 & 1.64 & 0.98 \\
\hline & & 4 & 95.53 & 8.61 & 16.85 & 18.96 \\
\hline
\end{tabular}

Table 5-1: Fracture cluster parameters, fracture strike and length, for FMI log wells for each sublayer. 


\begin{tabular}{|c|c|c|c|c|c|c|}
\hline Well & Layer & Cluster & Frequency & $\begin{array}{c}\text { Aperture } \\
\text { Mean } \\
\text { (in) }\end{array}$ & $\begin{array}{c}\text { Aperture } \\
\text { St Dev } \\
\text { (in) }\end{array}$ & $\begin{array}{c}\text { Center } \\
\text { Point } \\
\text { Density }\end{array}$ \\
\hline $48-\mathrm{x}-28$ & SSA & I & 1 & 0.00120 & - & 0.017309 \\
\hline & & II & 2 & 0.00128 & 0.00091 & 0.041216 \\
\hline & & III & 2 & 0.00128 & 0.00027 & 0.123218 \\
\hline & DOLB & I & 5 & 0.00042 & 0.00045 & 0.539837 \\
\hline & & II & 3 & 0.00117 & 0.00085 & 0.121790 \\
\hline & SSB & I & 3 & 0.00249 & 0.00175 & 0.011867 \\
\hline & & II & 2 & 0.00383 & 0.00113 & 0.007883 \\
\hline $71-1-x-4$ & SSA & I & 7 & 0.00116 & 0.00048 & 0.315949 \\
\hline & DOLB & - & 0 & - & - & \\
\hline & SSB & I & 2 & 0.00417 & 0.00255 & 0.003441 \\
\hline & & II & 1 & 0.00660 & - & 0.001369 \\
\hline $67-1-x-10$ & SSA & - & 0 & - & - & \\
\hline & DOLB & I & 4 & 0.000678 & 0.00045 & 0.320321 \\
\hline & & II & 6 & 0.00073 & 0.00061 & 0.632212 \\
\hline & & III & 1 & 0.00065 & - & 0.138019 \\
\hline & SSB & I & 2 & 0.00145 & 0.00057 & 0.024189 \\
\hline & & II & 1 & 0.00173 & - & 0.015281 \\
\hline & & III & 2 & 0.00132 & 0.00052 & 0.011769 \\
\hline & & IV & 1 & 0.00202 & - & 0.004629 \\
\hline $61-2-x-15$ & SSA & I & 1 & 0.00023 & - & 0.053962 \\
\hline & & II & 1 & 0.00290 & - & 0.028534 \\
\hline & & III & 2 & 0.00047 & 0.00014 & 0.016422 \\
\hline & & IV & 2 & 0.00030 & 0.00026 & 0.059981 \\
\hline & DOLB & I & 2 & 0.00017 & 0.00011 & 0.942222 \\
\hline & SSB & I & 2 & 0.00177 & 0.00124 & 0.012172 \\
\hline & SSA & I & 3 & 0.00220 & 0.00103 & 0.047961 \\
\hline & & II & 5 & 0.00125 & 0.00027 & 0.038261 \\
\hline & & III & 5 & 0.00106 & 0.00020 & 0.037473 \\
\hline & DOLB & I & 7 & 0.00039 & 0.00010 & 0.263779 \\
\hline & SSSB & I & 6 & 0.00039 & 0.00020 & 0.167268 \\
\hline & & 4 & 0.00292 & 0.00308 & 0.021775 \\
\hline
\end{tabular}

Table 5-2: Fracture cluster parameters, aperture and center point density, for FMI log wells for each sublayer. 
set length from Table 5-1: fracture cluster 1 has the longest mean cluster length; fracture cluster 2 has the next longest mean cluster length; and so forth. The FRACGEN models display fracture aperture in five different groupings based on size. Size ranges are shown by color for easy identification in the output. Fracture lengths are shown to scale in the output model. North is shown in the side panel.

The FRACGEN models for well 48-x-28 as displayed in Figures 5-2, 5-3, 5-4 and correspond to the fracture network of Sandstone A, Dolomite B, and Sandstone B, respectively. Notice the dominant WNW-ESE trend of the fractures for all three layers. Figure 5-4 shows that the Sandstone B layers has a lower fracture density than the other two layers, but has much longer fractures on average.

Figures 5-5 and 5-6 display the FRACGEN model fracture networks for created Sandstone A and Sandstone B layers of well 71-1-x-4. The Dolomite B layer of well 711-x-4 was not modeled since no open fractures were interpreted to have intersected the borehole in this layer. The overall general orientation of the fractures in Sandstone A and Sandstone B strike NW-SE. The Sandstone A layer has a much higher fracture density than Sandstone B (Figure 5-6) or Dolomite B (No open fractures detected).

There were no open fractures interpreted for Sandstone A in well 67-1-x-10. Dolomite B and Sandstone B are modeled in Figures 5-7 and 5-8. The models for these layers reveal that the Dolomite B has a much higher fracture density than Sandstone B but has a smaller average fracture length.

Well 61-2-x-15 has the smallest fracture density of all the FMI wells at Teapot Dome. Figures 5-9, 5-10 and 5-11 display the Sandstone A, Dolomite B, and Sandstone B layers, respectively. The fracture density for Sandstone A and Dolomite B are higher 




Figure 5-2: FRACGEN model for well 48-x-28 Sandstone A. FMI log analysis and fracture cluster statistic are found in Table 5-1 and Table 5-2. 


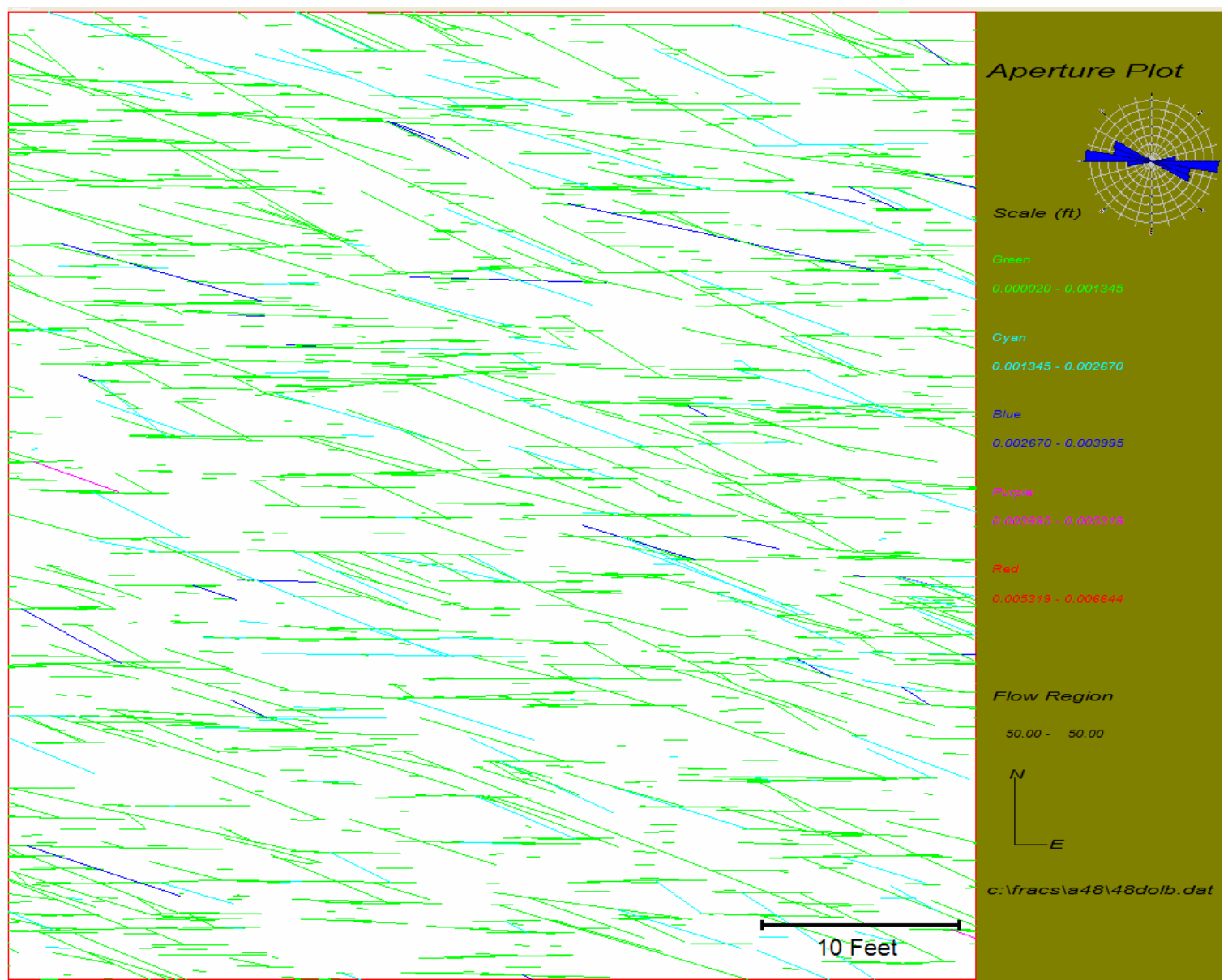

Figure 5-3: FRACGEN model for well 48-x-28 Dolomite B. FMI log analysis and fracture cluster statistic are found in Table 5-1 and Table 5-2. 


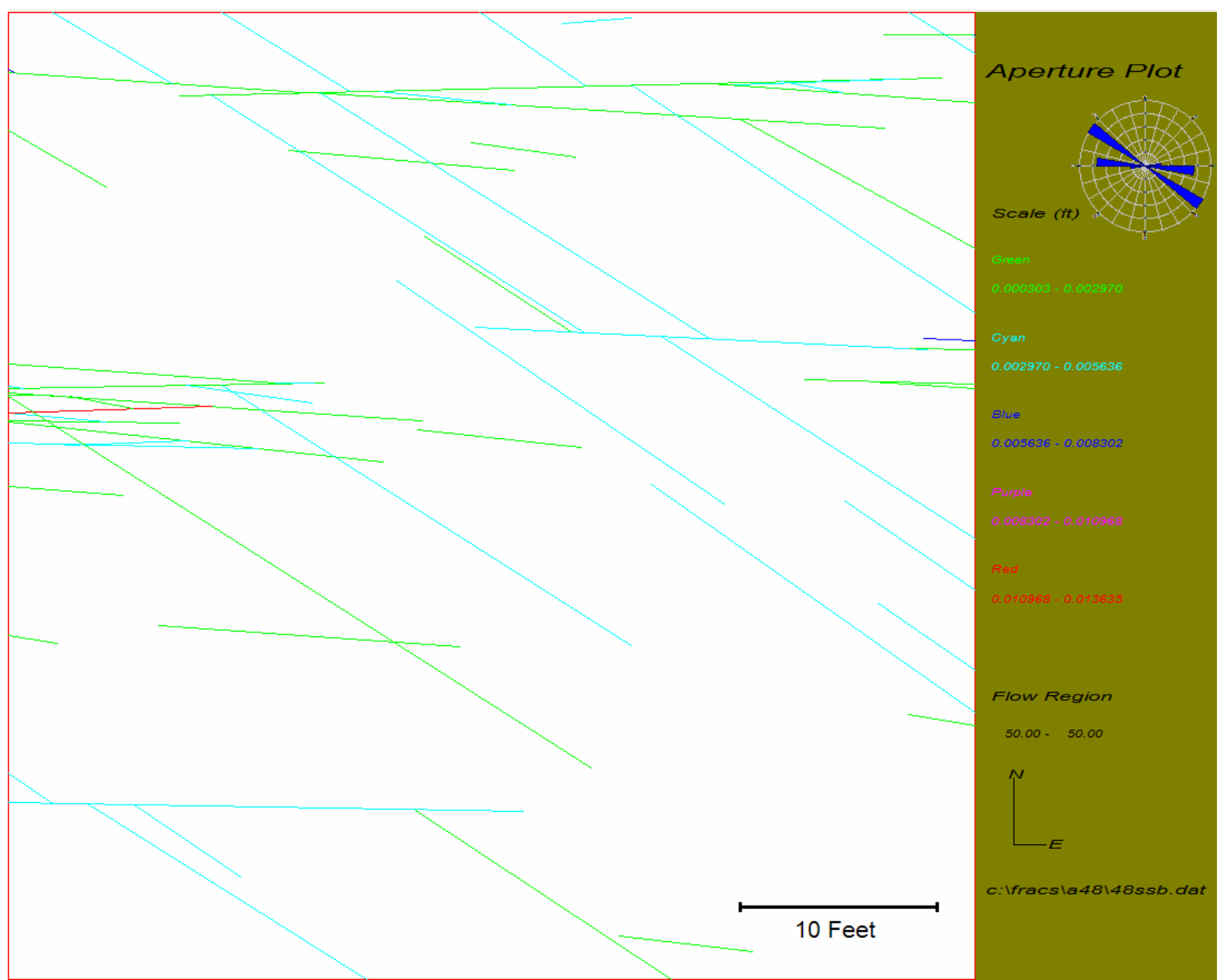

Figure 5-4: FRACGEN model for well 48-x-28 Sandstone B. FMI log analysis and fracture cluster statistic are found in Table 5-1 and Table 5-2. 


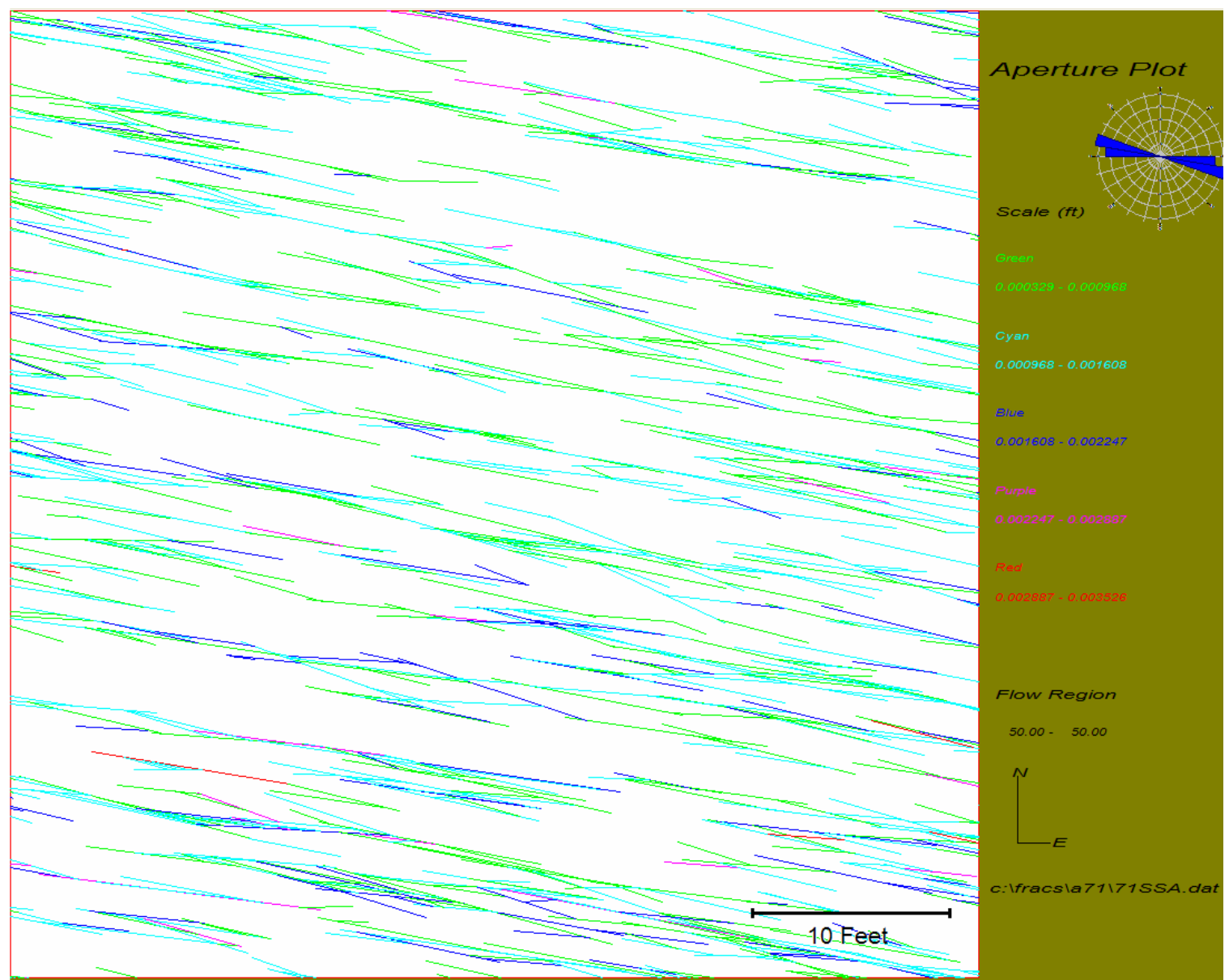

Figure 5-5: FRACGEN model for well 71-1-x-4 Sandstone A. FMI log analysis and fracture cluster statistic are found in Table 5-1 and Table 5-2. 


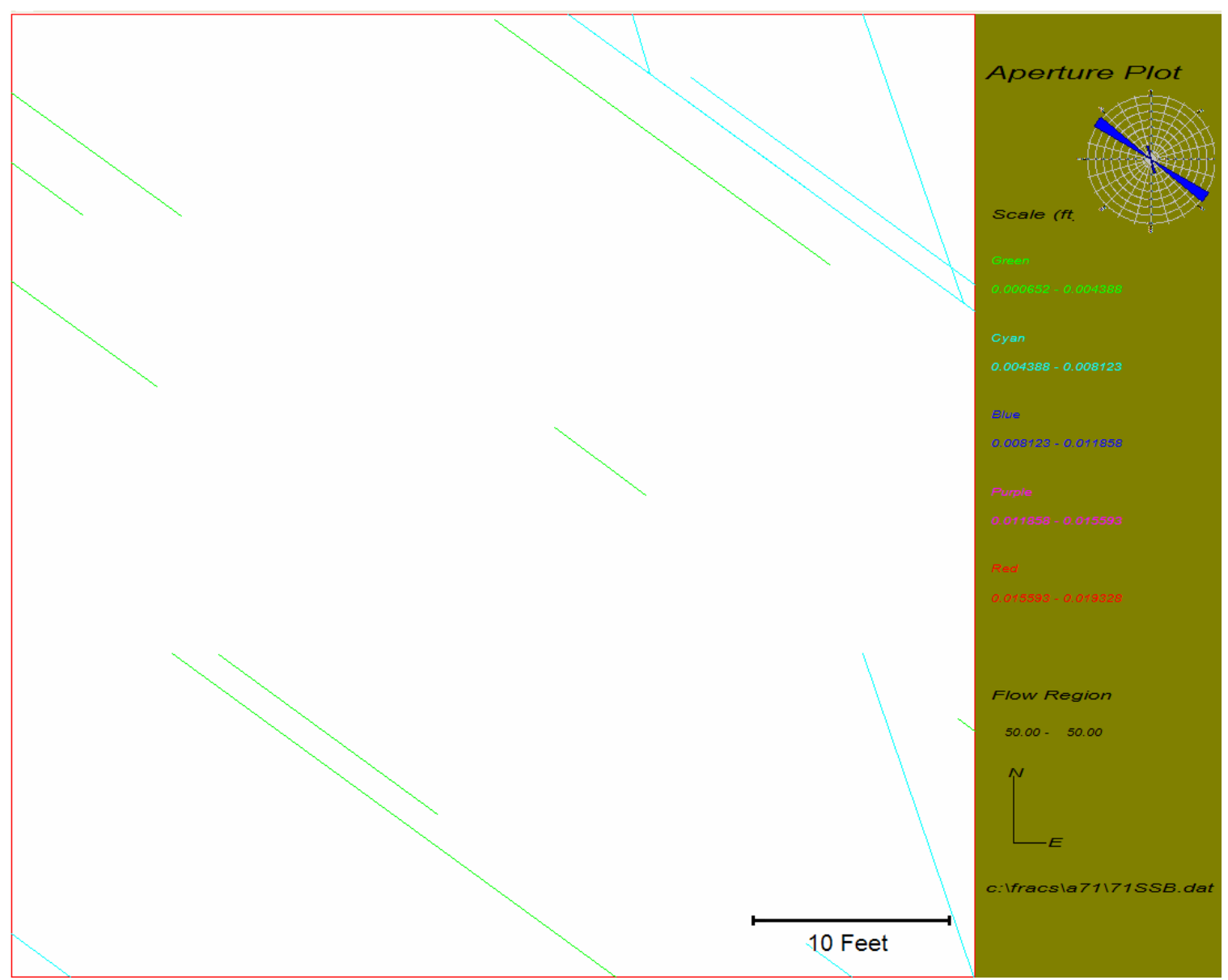

Figure 5-6: FRACGEN model for well 71-1-x-4 Sandstone B. FMI log analysis and fracture cluster statistic are found in Table 5-1 and Table 5-2. 


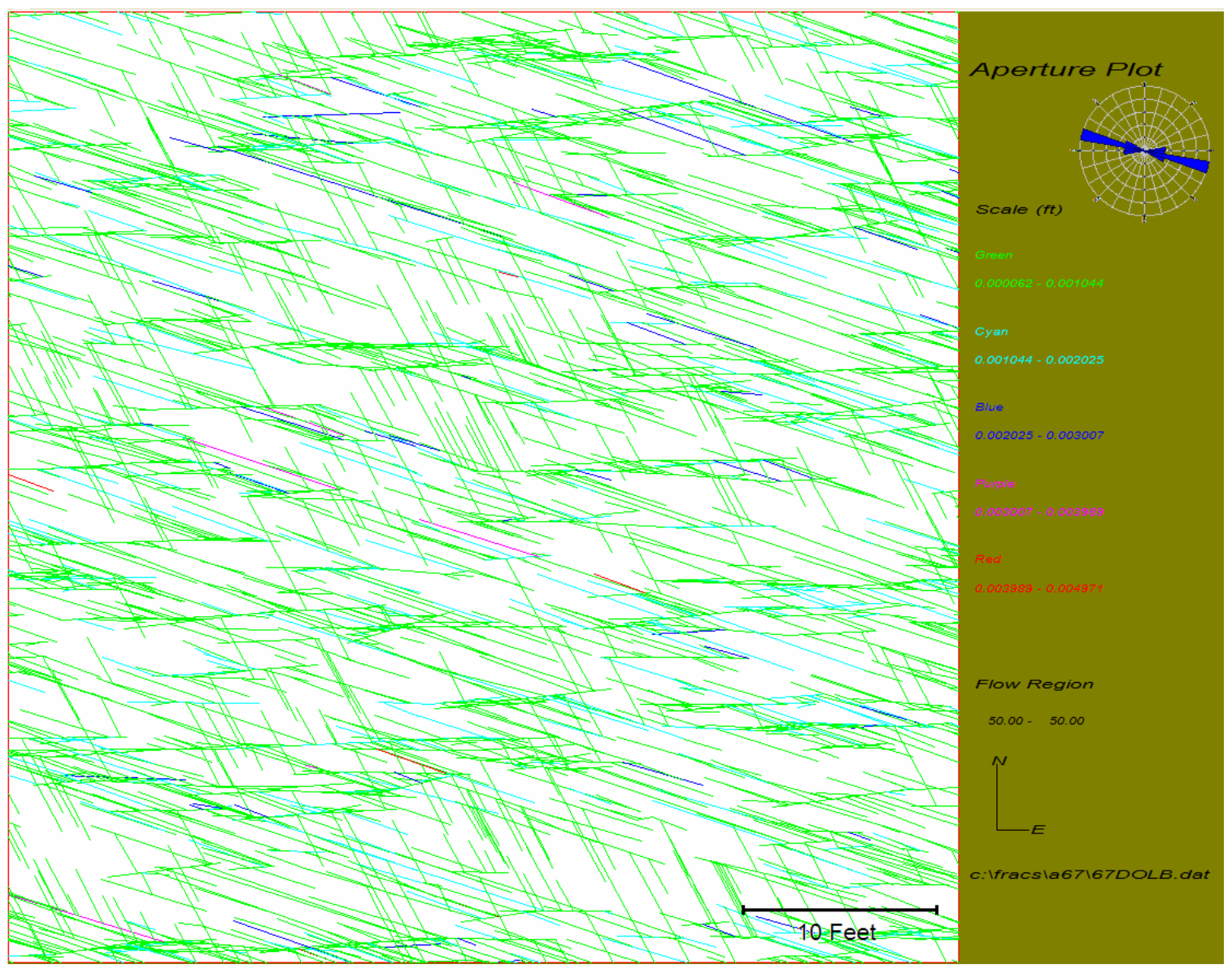

Figure 5-7: FRACGEN model for well 67-1-x-10 Dolomite B. FMI log analysis and fracture cluster statistic are found in Table 5-1 and Table 5-2. 


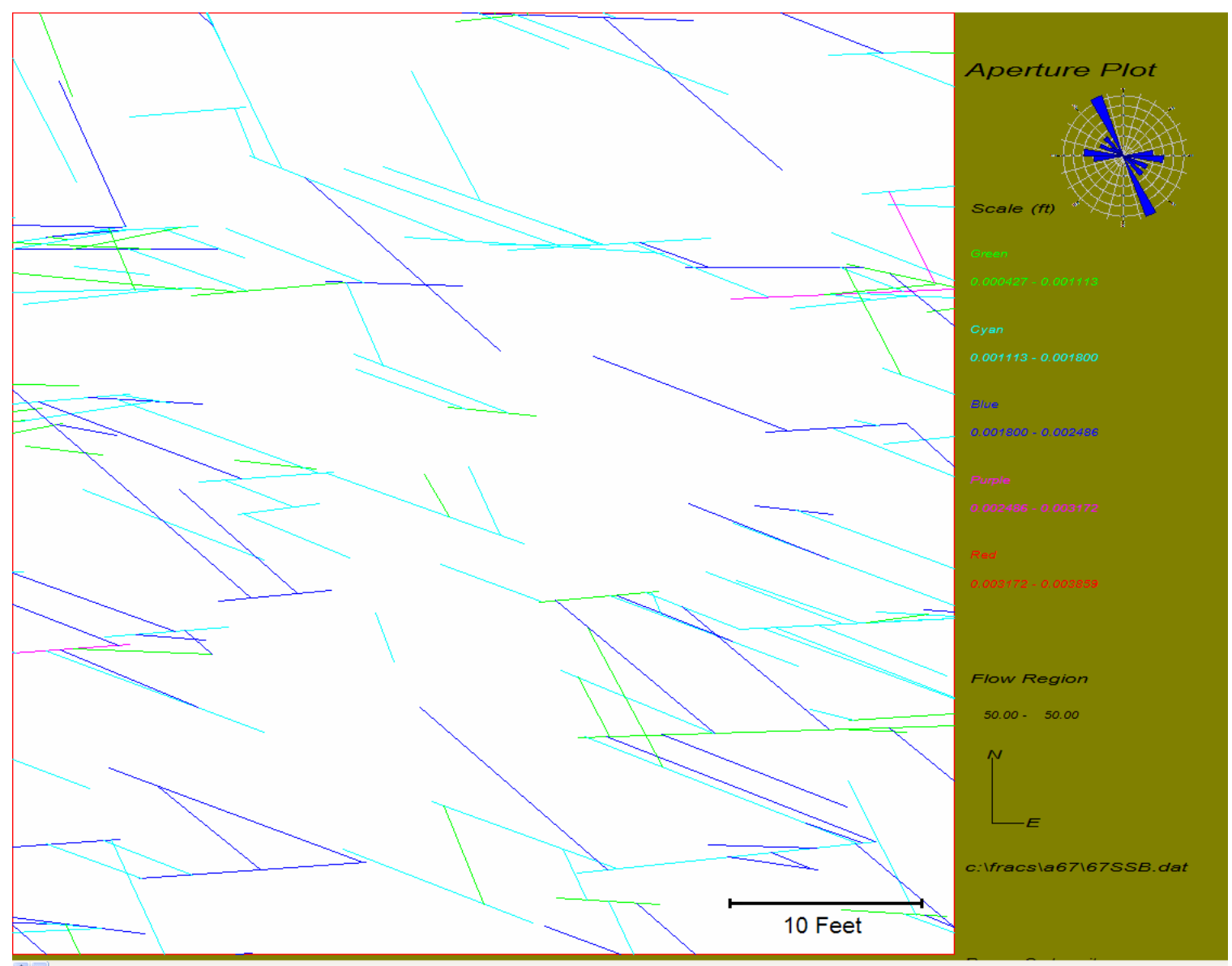

Figure 5-8: FRACGEN model for well 67-1-x-10 Sandstone B. FMI log analysis and fracture cluster statistic are found in Table 5-1 and Table 5-2. 


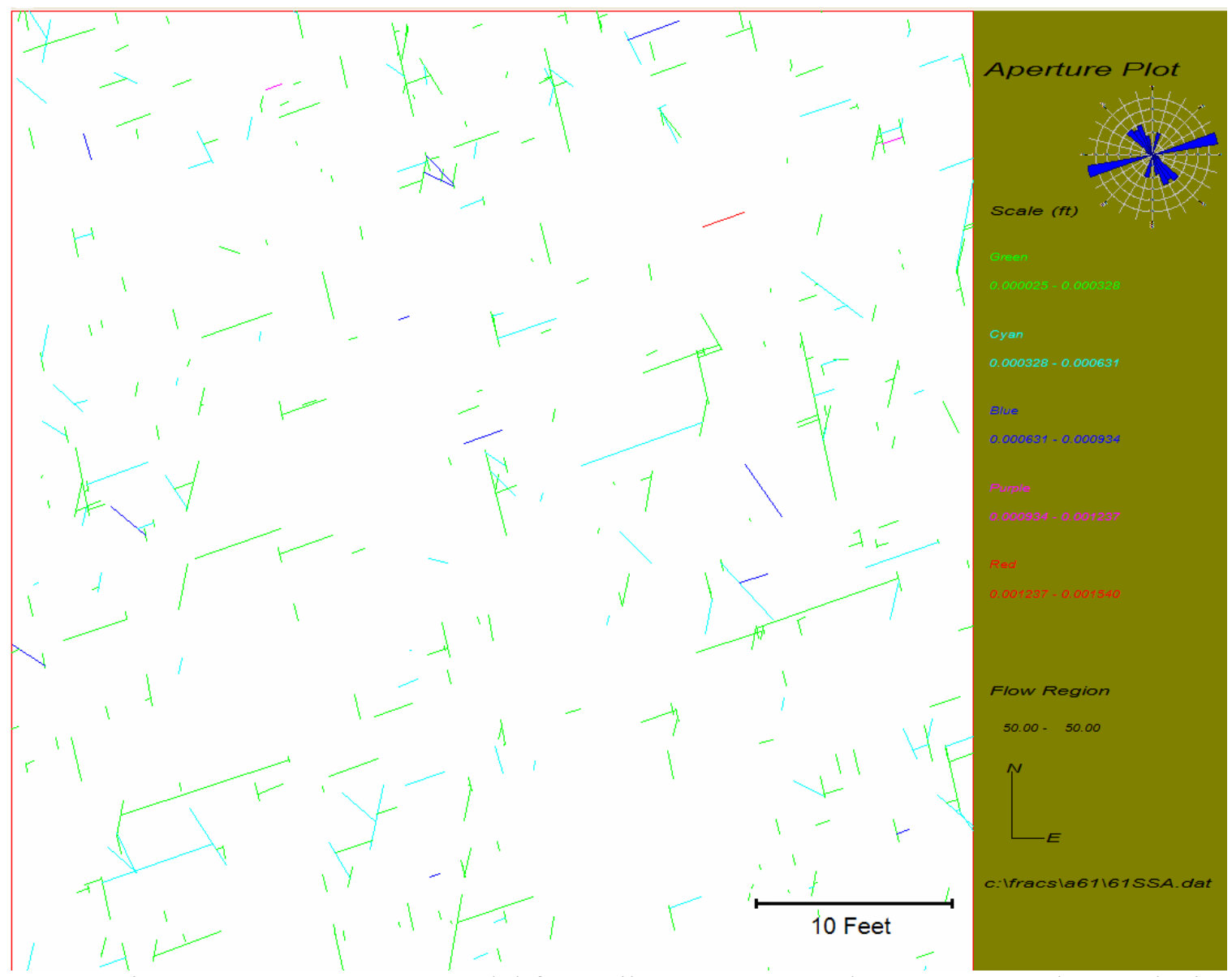

Figure 5-9: FRACGEN model for well 61-2-x-15 Sandstone A. FMI log analysis and fracture cluster statistic are found in Table 5-1 and Table 5-2. 


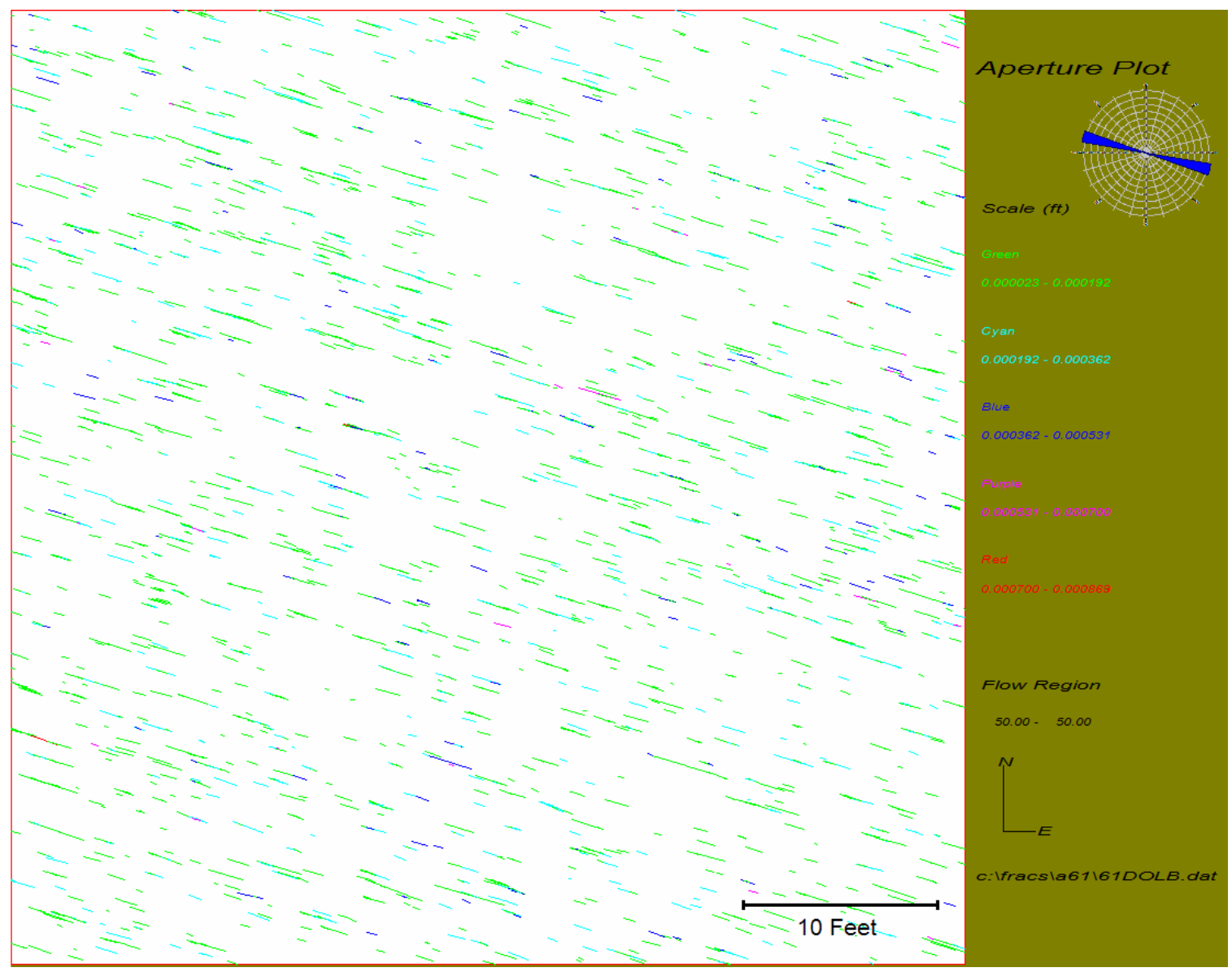

Figure 5-10: FRACGEN model for well 61-2-x-15 Dolomite B. FMI log analysis and fracture cluster statistic are found in Table 5-1 and Table 5-2. 


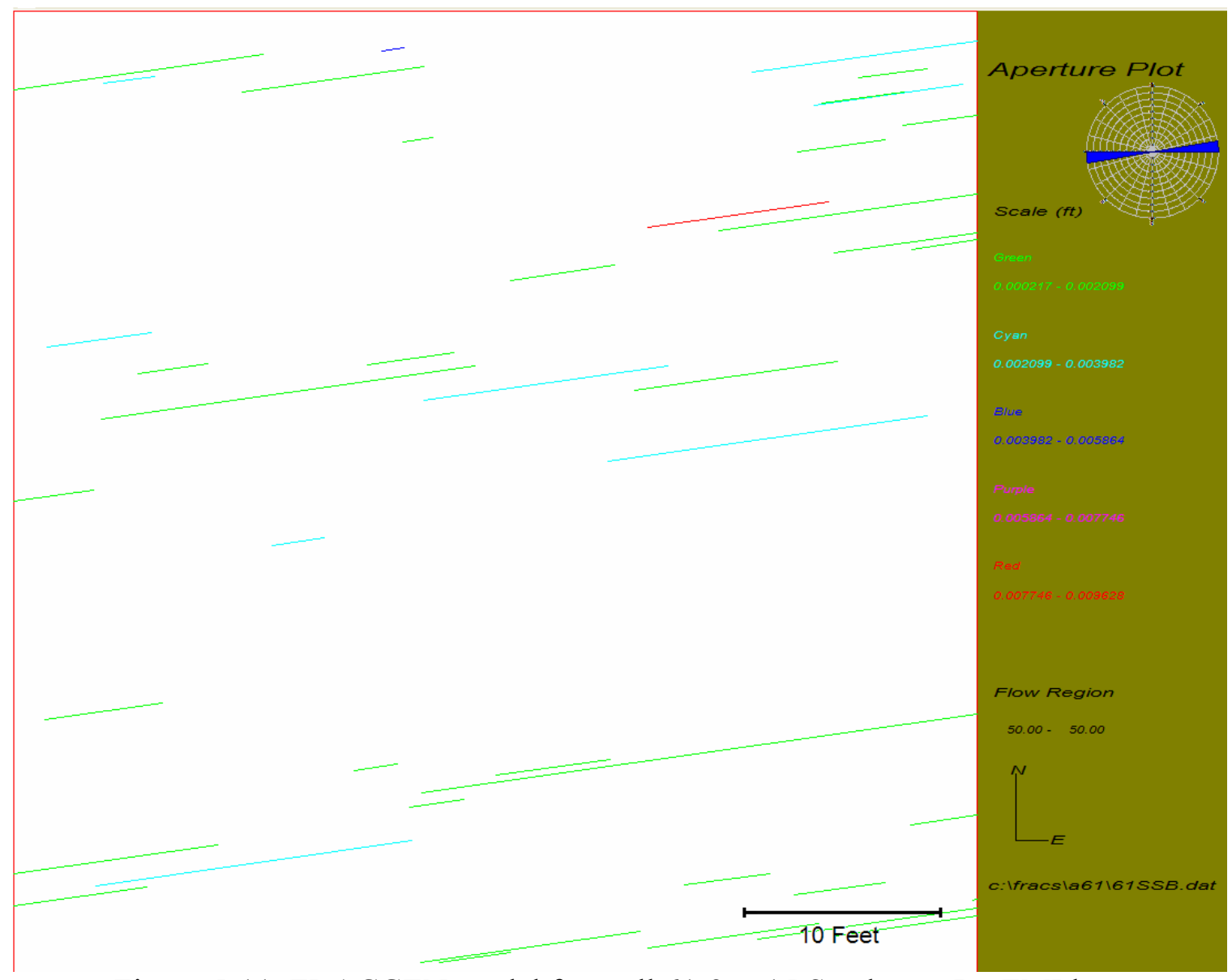

Figure 5-11: FRACGEN model for well 61-2-x-15 Sandstone B. FMI log analysis and fracture cluster statistic are found in Table 5-1 and Table 5-2. 
than Sandstone B but they have considerably smaller fracture lengths. The Sandstone A layer (Figure 5-9) appears to display a random orientation of fractures. The low frequency of open fractures interpreted for the Dolomite B and Sandstone B layers limits the orientations to only 1 trend.

The FRACGEN models for well 25-1-x-14 as displayed in Figures 5-12, 5-13, 514 and correspond to the fracture network of Sandstone A, Dolomite B, and Sandstone B, respectively. These models reveal similar W-E striking fracture orientations among all three layers. These models primarily differ in the density of center points for fracture clusters and the mean fracture length. Sandstone A and Dolomite B layers have a high fracture density ( 0.349 and 0.146 fractures per $\mathrm{ft}^{2}$, respectively) compared to the Sandstone B layer $\left(0.004\right.$ fractures per $\left.\mathrm{ft}^{2}\right)$. The mean fracture lengths show that the Dolomite B fractures are the shortest (3.67ft). Sandstone B's mean fracture length is the longest (35.98ft), and Sandstone A mean fracture length is in the middle (15.76). This may indicate fracture intensity and length are depended on layer thickness and rheology.

\subsection{Improving Model Accuracy}

The models discussed in section 5.3 use estimates of fracture length and spacing derived from FMI logs analysis (Chapter 3 and 4). However, as noted, the ability to accurately assess fracture density, spacing, and length from wellbore characterization is limited. Additional insights into the nature of fracture systems controlling production can be obtained through flow simulations that incorporate discrete fracture networks as the primary reservoir flow path. Using past reservoir production and pressure data, the fracture spacing, density, length, intersection frequency and aperture are varied until a match is obtained between the model and actual production history data. Note the past 
successes reported by McKoy $(1997,2005)$ and Sams (2005). Fracture models derived through history matching yield nonunique results. Many combinations of the above parameters can be used to match given production history and pressure data. Additional production and well data within a developing field may help refine fracture networks associated with the reservoir.

The opportunity to extrapolate fracture systems defined by the FMI log analysis into the surrounding reservoir using the flow simulator NFFLOW is currently not possible (Sams, 2006). Additional fracture studies on the Tensleep Formation will also increase the accuracy of the fracture simulations. Additional fracture length vs fracture aperture study would provide a more accurate coefficient $(\mathrm{C})$ and exponent $(\mathrm{m})$ for the power law relationship (Equation 4-8) specifically for the Tensleep Formation sublayers This could be provided by microfracture studies using core or from surface fracture studies, provided accurate aperture measurements could be obtained. Surface studies of the Tensleep Formation may also provide a more accurate method to determine horizontal fracture spacing and intersection frequency. 


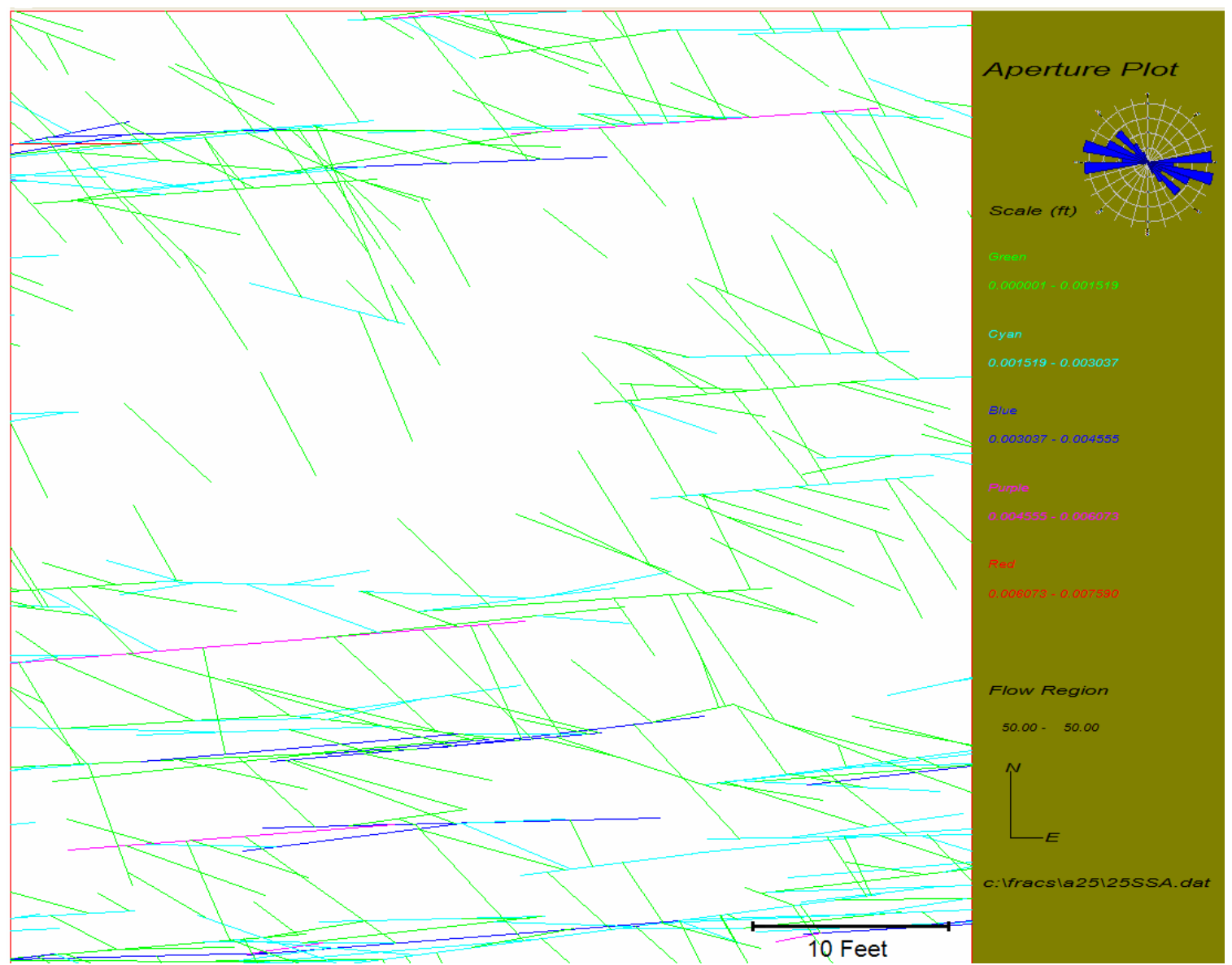

Figure 5-12: FRACGEN model for well 25-1-x-14 Sandstone A. FMI log analysis and fracture cluster statistic are found in Table 5-1 and Table 5-2. 


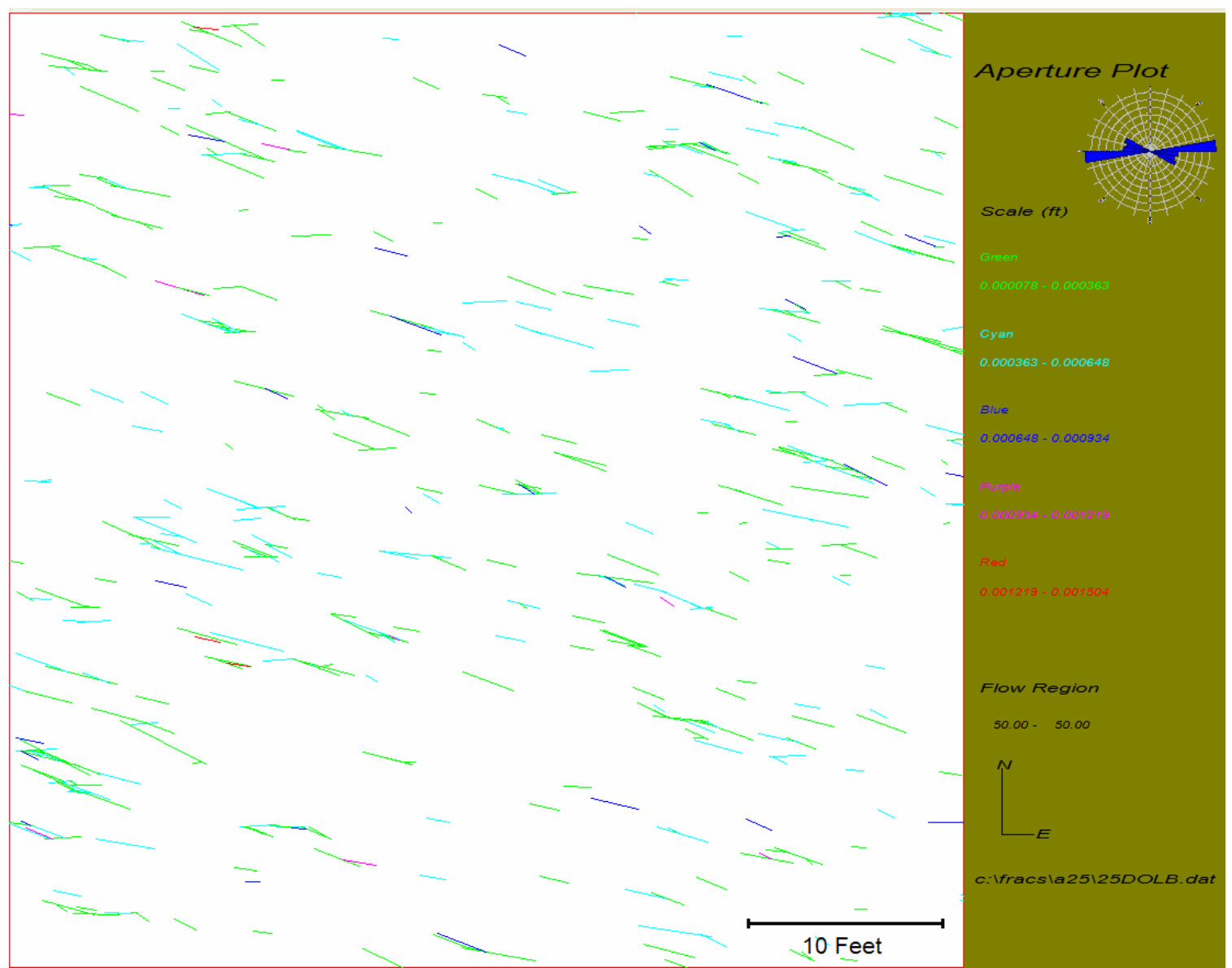

Figure 5-13: FRACGEN model for well 25-1-x-14 Dolomite B. FMI log analysis and fracture cluster statistic are found in Table 5-1 and Table 5-2. 


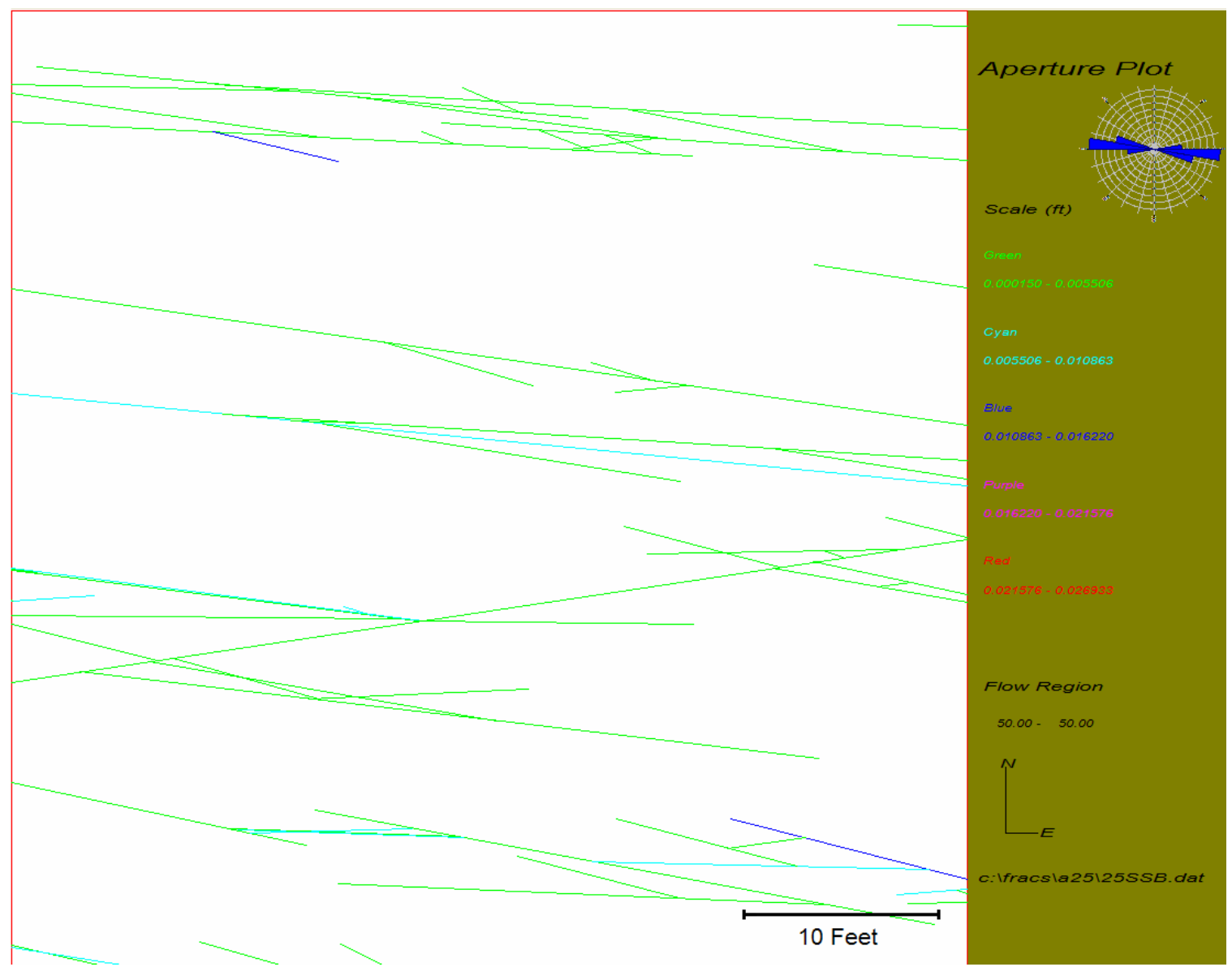

Figure 5-14: FRACGEN model for well 25-1-x-14 Sandstone B. FMI log analysis and fracture cluster statistic are found in Table 5-1 and Table 5-2. 


\section{Chapter 6: Conclusions}

This study was conducted primarily to determine the characteristics of natural fracturing within the oil producing Tensleep Formation at Teapot Dome in Wyoming. Teapot Dome is a doubly plunging anticline formed during the Laramide orogeny. The Teapot Dome field is also known as the Naval Petroleum Reserve \#3. Oil has been produced from nine reservoirs in the field that extend from depths of about 500 feet to more than 5000 feet beneath the surface. The deepest oil producing zones in the field lie in the Tensleep Formation at depths of approximately 5400 feet in the area. The field is government owned and operated by the U. S. Department of Energy and the Rocky Mountain Oil Testing Center (RMOTC). Much of the research currently being undertaken through the center is focused on the development and testing of carbon sequestration technologies. The present study is motivated by the need to better understand the fracture networks controlling oil production in the Tensleep reservoir and the potential to enhance oil recovery and sequester $\mathrm{CO}_{2}$ within these networks.

The Tensleep Formation consists of a sequence of sand and dolomite intervals deposited in eolian and marine environments during the Pennsylvanian. The Tensleep sands and dolomites are referred to as sandstones A through D and dolomites B through D. Oil is produced primarily from sandstones A and B. The Tensleep reservoirs are located at a depth of approximately 5400 feet beneath the surface in the area. Prior to this work, examination of fracture systems associated with the Dome were restricted to field studies conducted at the surface by Cooper (2000) in the Parkman Sandstone Member of the Cretaceous Mesaverde Formation. The Parkman Sandstone was deposited in fluvial, beach and shallow marine environments. 
Hydrocarbon traps in the field are dominantly structural, associated with closure across the NW trending axial hinge of the dome. The fracture model developed by Cooper (see Figure 2.13) consists of bed-normal hinge-parallel and hinge perpendicular sets, and a third bed-normal set oriented obliquely (WNW to NW) to the axis of the dome. Cooper observed a smaller number of oblique fractures oriented NNE, normal to the dominant oblique set. The hinge-parallel and hinge perpendicular sets are complex and each include a subset of fractures oriented at an acute angle to bed normal.

\section{Comparison of Fracture Models}

In this study, a fracture model was developed of fracture systems in the deep Tensleep reservoir intervals using FMI logs. The general characteristics of this model are compared to that developed by Cooper (2000) for younger Cretaceous age formations exposed at the surface.

The Tensleep model was developed using only the open fractures observed in Sandstone A, Dolomite B, and Sandstone B in FMI logs from 5 wells along the anticlinal axis. Open fractures, interpreted in the FMI logs from wells 48-x-28, 71-1-x-4, 67-1-x10, 61-2-x-15, and 25-1-x-14 (Figure 3-7) appear to consist of a dominant hinge oblique fracture set and minor hinge parallel and hinge perpendicular fracture sets (see Figures 3$10,3-11,3-12$, and 3-13). These sets appear to maintain a consistent relationship to the axis of the dome as its orientation changes north to south along its length. Fractures observed in the northern part of the field (wells 48-x-28, 71-1-x-4) and just south of the S1 fault (67-1-x-10) have a similar mean dip angle and standard deviation as indicated in 


\begin{tabular}{|l|l|l|}
\hline \multicolumn{1}{|c|}{ Well } & \multicolumn{1}{|c|}{$\begin{array}{c}\text { Mean Dip Angle } \\
\text { (degrees) }\end{array}$} & \multicolumn{1}{|c|}{$\begin{array}{c}\text { Standard Deviation } \\
\text { (degrees) }\end{array}$} \\
\hline $48-\mathrm{x}-28$ & 77.69 & 7.37 \\
\hline $71-1-\mathrm{x}-4$ & 77.82 & 4.74 \\
\hline $67-1-\mathrm{x}-10$ & 79.19 & 6.67 \\
\hline $61-2-\mathrm{x}-15$ & 58.25 & 18.97 \\
\hline $25-1-\mathrm{x}-14$ & 59.01 & 17.57 \\
\hline \multicolumn{2}{|l|}{ Table 6-1: Mean fracture dip angle and standard deviation layers } \\
Sandstone A, Dolomite B, and Sandstone B in the wells with FMI logs. \\
\hline
\end{tabular}

Table 6-1. In the southern part of the field (wells $61-2-x-15$, and 25-1-x-14), the mean fracture dip drops while the standard deviation increase (Table 6-1).

The southern part of the field is separated from the northern part of the field by a large normal fault (the S1 fault in Figure 6-1) that cuts SW-NE across the dome (see Friedmann, 2004). A shift in the orientation of the axis of the dome from NW to NS (to the south across the fault) suggests that movement across the fault included a right-lateral strike-slip component. Since this fault offsets the fold, it appears to have followed or occurred late in the episode of deformation that produced the dome. Additional faults farther south may have rotated earlier formed fractures in wells $61-2-x-15$ and 25-1-x-14. The greater standard deviation in their dip suggests that the events that formed them led to less uniform dip than is found along the dome to the north.

The results of this study suggest that the model proposed by Cooper is not an accurate predictor of fracture systems at depth within the Tensleep Formation. Although Cooper's model suggests that dipping fractures will be present, fractures in his model are dominantly bed-normal. His model also does not suggest the presence of variations in the fracture network along the length of the dome observed in this study. 


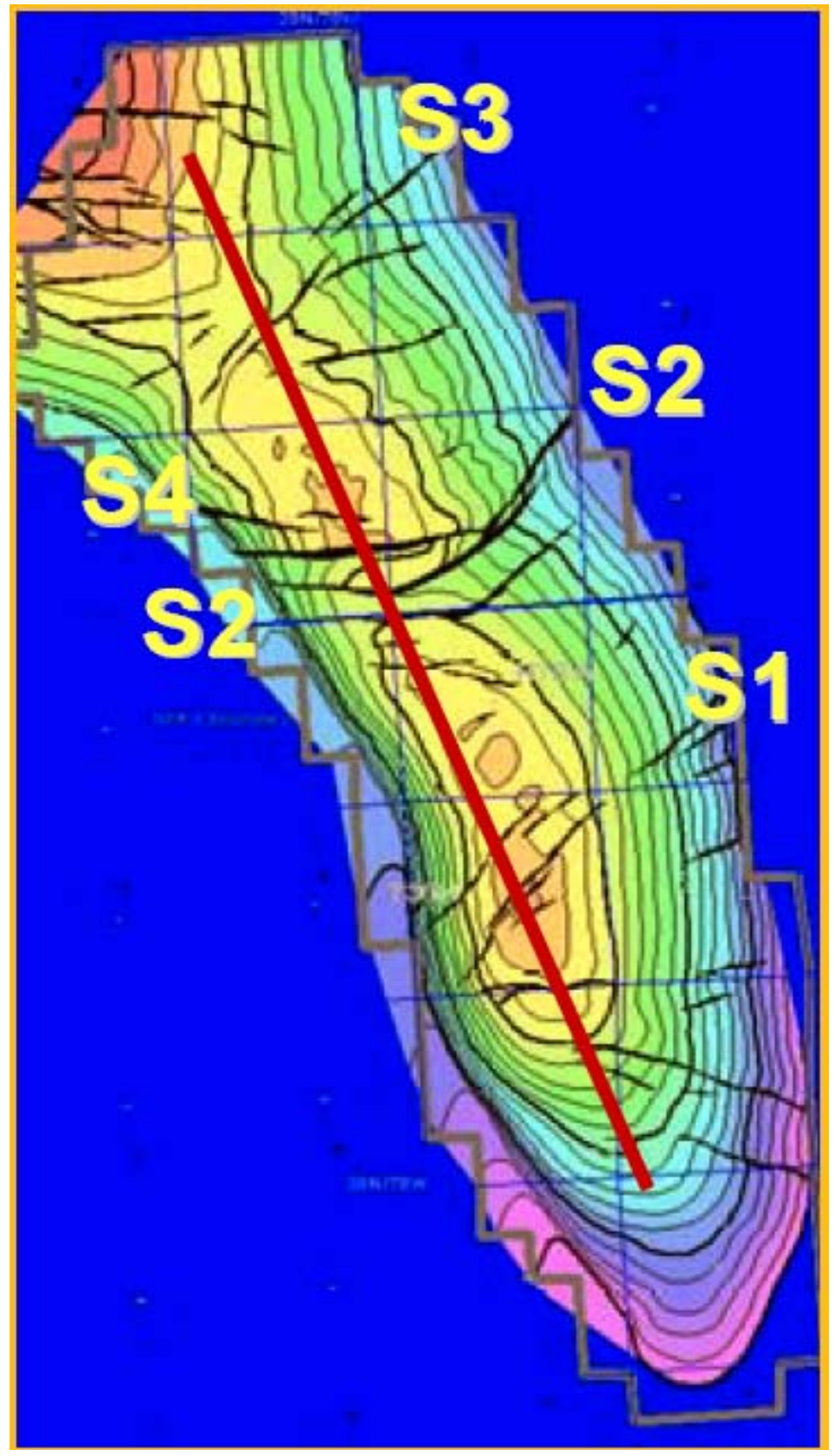

Figure 6-1: Distribution of the interpreted faults along Teapot Dome. The S1 fault separates the NS trending southern part of the field form the NW trending northern part. The figure is taken from Friedmann (2004) . 
In addition, fracture systems in the Tensleep inferred from the FMI log analysis are dominated by a WNW hinge-oblique set. The relative frequency between hinge-parallel, hinge perpendicular, and oblique fractures in the Tensleep does not match that observed at the surface. Cooper (2000) indicated that hinge-parallel, hinge perpendicular, and oblique fractures occur with a relative frequency of 1.83:1.33:1.00, where as fracture sets observed in the FMI logs have relative frequencies of 0.30:0.21:1.00. Cooper (2000) observed the WNW set of fractures at locations surrounding Teapot Dome and indicated that these fractures may predate the fractures formed during the Laramide uplift that formed Teapot Dome. If this is correct, the present day maximum principal compressive stress may keep the WNW set of Tensleep fractures open while effectively closing most of the hinge parallel and hinge perpendicular fractures.

Observations in Cooper's (2000) study were concentrated primarily on the southern and central flanks along the dome, while FMI logs on which this study is based are distributed along the axis of the dome. In addition, the model developed here relies on observations made within vertical boreholes penetrating nearly horizontal strata. These observations provide a limited view of actual fracture systems within the reservoir interval and it is possible that the hinge parallel and hinge perpendicular fracture sets are underrepresented in the Tensleep. Fracture sets that dip at significant angles from the vertical will be penetrated in greater numbers than those with near-vertical dip. Additional fracture study of the pavement along the anticlinal axis at the surface, or of additional FMI logs from inclined wells may yield results suggesting greater similarity between the two models. 


\section{Fracture Models}

The second objective of this study was to create 2D stochastic models of fracture networks within the Tensleep Formation using the NETL program FRACGEN (McKoy, 2000). In the future, these or similar stochastic models of the aerial distribution of fracture systems observed in the logs will be used to help evaluate the potential benefits of $\mathrm{CO}_{2}$ EOR methods in the Tensleep reservoir. The fracture models are based on fracture descriptions presented in Chapters 3 and 4 of open fractures interpreted in the FMI logs. FRACGEN models were created for the Sandstone A, Dolomite B, and Sandstone B layers of the Tensleep Formation. The FRACGEN models provide a 2D map view of fracture intersections on a bedding surface. These aerial views are equivalent to pavement views and assume that all fractures are bed-normal.

The aerial distributions of fractures generated by FRACGEN are consistent with orientation, density, and length data inferred from the FMI log analysis. 2D fracture maps yield fracture distributions, for example, that reveal greater fracture density for Sandstone A and Dolomite B than for Sandstone B. Likewise, consistent with log observations, the fracture lengths are smaller in Sandstone A and Dolomite B and the apertures are smaller. 2D fracture networks simulated by FRACGEN provide insights into conditions that must exist for significant oil production to occur. For example, the smaller lengths of fractures inferred for Sandstone A and Dolomite B will require greater numbers of intersecting fractures to facilitate significant production from the reservoir.

The FRACGEN models can be tested and refined through flow simulations that allow discrete fracture networks to be incorporated as the primary reservoir flow pathways. The fracture models can be iteratively adjusted until a match between 
predicted and actual production history is obtained. With significant log and production data, it may be possible using such an approach to develop a field scale model of the fracture networks that can than be used to design $\mathrm{CO}_{2} \mathrm{EOR}$ flooding and sequestration operations that optimize oil recovery and $\mathrm{CO}_{2}$ storage.

\section{Suggestions for Future Work}

The work in this study will provide a basis for future studies of the Tensleep Formation fracture networks. Because the FMI log provides a limited view of the fracture networks in the vicinity of the borehole, the models generated by FRACGEN are at best rough approximations. To improve the fracture characterization of the Tensleep Formation, I recommend the following research:

- A surface study of the Tensleep Formation to better determine horizontal fracture spacing, fracture lengths, and fracture intersection frequencies.

- Additional surface studies at the surface of Teapot Dome along the anticlinal axis to refine Cooper's (2000) fracture model. This will allow a comparison of fracture patterns found above and below each other.

- Additional study of the Tensleep Formation to determine fracture aperture vs fracture length to derive a more accurate power law relationship. This could be through a microfracture study such as those conducted by Perez (2002) and Moros (1999).

- Simulating past reservoir production and pressure tests to better define fracture spacing, density, length, and intersection frequency. Although this was an 
original goal for this study, limitations in NFFLOW prevented carrying out this work. 


\section{Appendix A: FMI Log Analysis}

\section{A.1 FMI Tool}

The Formation MicroImager (FMI) tool (Figure A-1) provides a detailed view of stratigraphic, lithologic, and structural information along the wall of the well bore. The FMI tool produces a high-resolution electrical current image of the borehole wall using 192 current monitoring electrodes (high resolution fullbore imaging mode). The electrode distribution provides $80 \%$ coverage of the borehole wall in an 8 inch diameter borehole (Schlumberger, 2002). The spacing of the electrodes offers a maximum resolution of 0.2 inches in the azimuthal and vertical directions and a detection limit of 50 microns (about 0.002 inches) in the horizontal direction. This limit is achieved through quantifying the current flow of the electrodes (Schlumberger, 2002). The FMI tool uses an alternating current $(\mathrm{AC})$ to produce a current map that minimizes the effects of a formation's spontaneous potential (SP) and the direct current (DC) flow between the electrodes on the surface of the borehole (Schlumberger, 2002). The current is emitted through the lower electrodes and received by the upper electrodes after it has passed through the formation. The amount of current received is recorded and digitized. Current values are recorded at points along the borehole wall. Variations of measured current flow are portrayed as variations in the borehole color scheme to produce an resistivity image of the borehole (Figure A-2). The current map color ranges from white to black with the lighter colors corresponding to relatively low conductivity zones and the darker colors to higher conductivity zones. Lower conductivity generally indicates a rock type such as a carbonate, and a higher conductivity is often indicative of shale or sandstone. The FMI tool also uses direct current induction to determine formation 


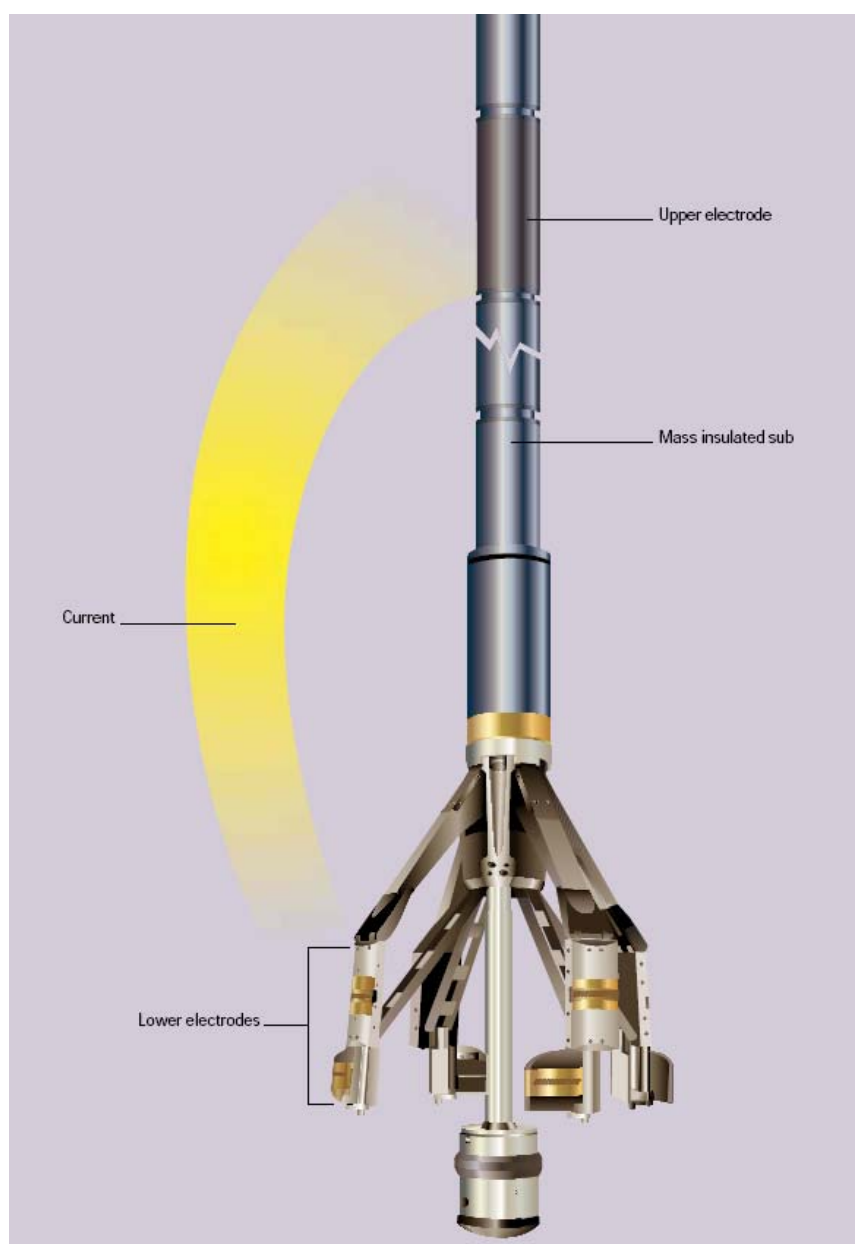

Figure A-1: The FMI tool (image was taken from Schlumberger, 2002). 


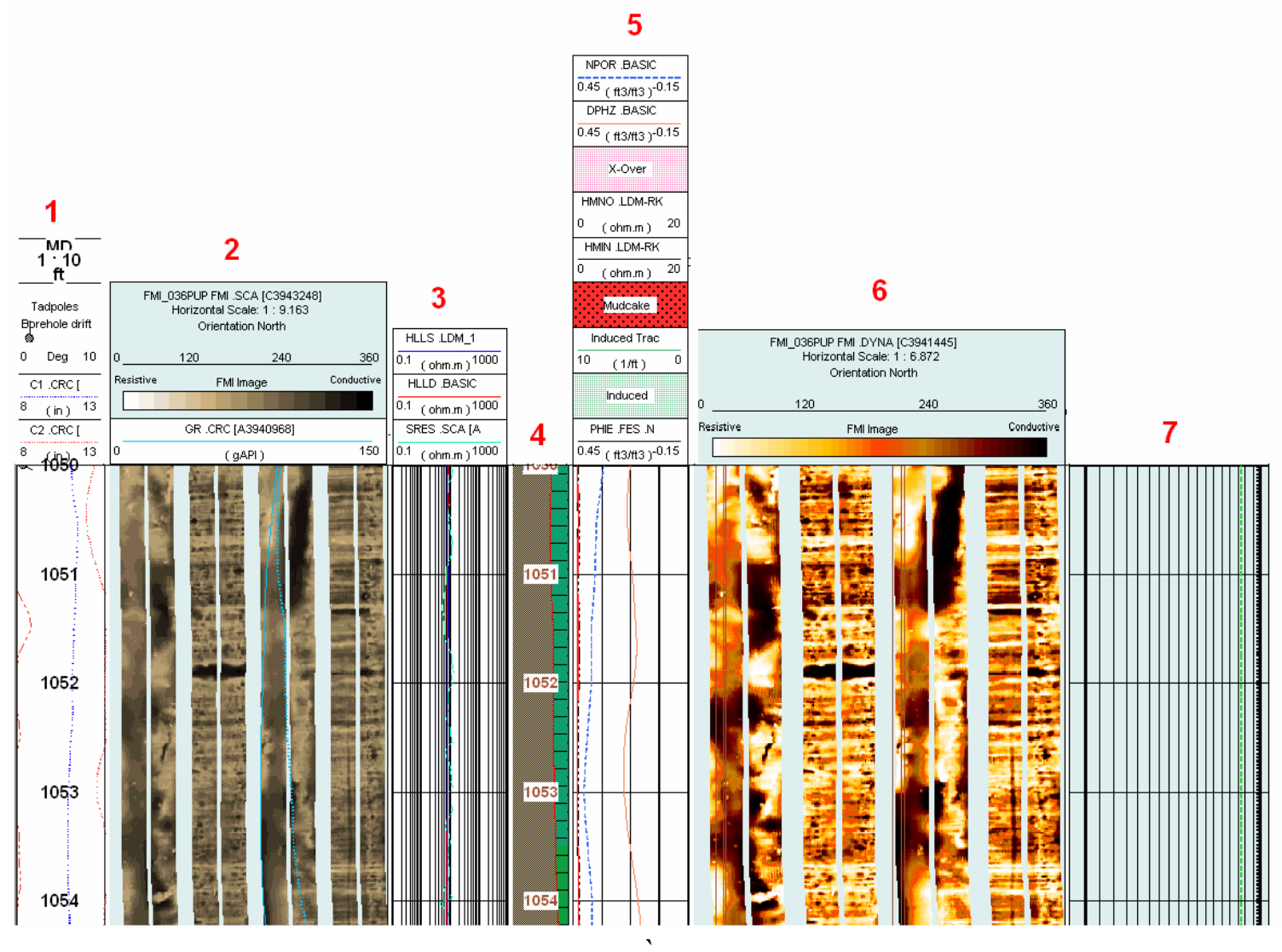

Figure A-2: Typical FMI header information and log tracks. This log is from well 67-1-X-10 at Teapot Dome, Wyoming. 
resistivity. The FMI tool can only be used in boreholes that are filled with conductive drilling muds (Schlumberger, 2002).

Interpretation of the FMI log image can be used to estimate fracture dip, strike, and aperture. The fracture aperture is determined by the equation A-1,

$$
W=a A R_{m}^{b} R_{x_{0}}^{1-b} \quad(\mathrm{~A}-1)
$$

where $\mathrm{W}$ is the fracture aperture, $A$ is the extra current flowing through the fracture (measured with FMI tool), $a$ is the tool constant, $R_{m}$ and $R_{x o}$ are the mud and shallow rock resistivity, and $b$ is a constant slightly less than 1 (Luthi, 2001). Lithology interpretation obtained from other logs and combined with the measured current provides the basis for fracture classification. FMI interpreters generally classify fractures as open, healed, or drilling induced.

\section{A.2 Reading FMI Log}

A typical FMI log header is shown in Figure A-2. This header is divided into 7 vertical columns labeled in red. Column 1 provides depth and caliper readings. In a smooth borehole, the caliper readings will generally indicate a constant borehole width. Widening of the borehole shown in Figure A-2 indicates the possible presence of a washout zone or a drilling induced fracture. Column 1 of the FMI log display generally included the gamma ray log for general correlation purposes. Column 2 of Figure A-2 displays a static current map image. The static current map is displayed in grey scale and represents the relative current at any position in the borehole compared to the absolute highest and lowest current values obtained in the logging session. The static image is used to determine the major lithologic features surrounding the borehole. Column 3 shows the output of multiple induction logs. Generally a shallow induction, medium 
induction, and a deep induction $\log$ are run with the FMI tool. These logs provide direct correlation to other logging tools and are used for troubleshooting during interpretation and $\log$ acquisition. Column 4 is a depth and lithology indicator. The lithology indicator is obtained by combining the gamma ray, induction, and photoelectric effect of the rock being tested. This section provides a first approximation of formation lithology. The neutron and density porosity readings are plotted in Column 5 . The neutron-density porosity cross-over is noted by the color pink. When the neutron porosity reading is much less than the density porosity, presence of natural gas is suspected. The log display also shows the amount of mudcake present in the borehole in Column 5. Column 6 displays the dynamic current map. Unlike the static current map, the dynamic current map recalculates the discrete current values every inch. This allows small scale features to stand out in the FMI's dynamic current map image. Finally, column 7 displays the tadpole plots for the planar features interpreted in the FMI log. The circle of the tadpole plot is located at the depth and dip of the planar features. The dip scale is nonlinear and increases from 0 degrees (on left) to 90 degrees (on right).

The projection of a planar feature on borehole images will be represented by a sine wave as seen in Figure A-3. Because the borehole is very small in relation to stratigraphic and structural features, when they intersect the borehole, they are nearly planar and assumed to be planar feature. The trough of the sine wave indicates the azimuthal angle (dip trend angle) of the planar feature. Figure A-3 indicates how the trough value of the sine wave corresponds to the azimuthal angle of the planar feature on the FMI image. The dip of the planar feature can be directly calculated from the amplitude of the sine wave and the diameter of the borehole. 


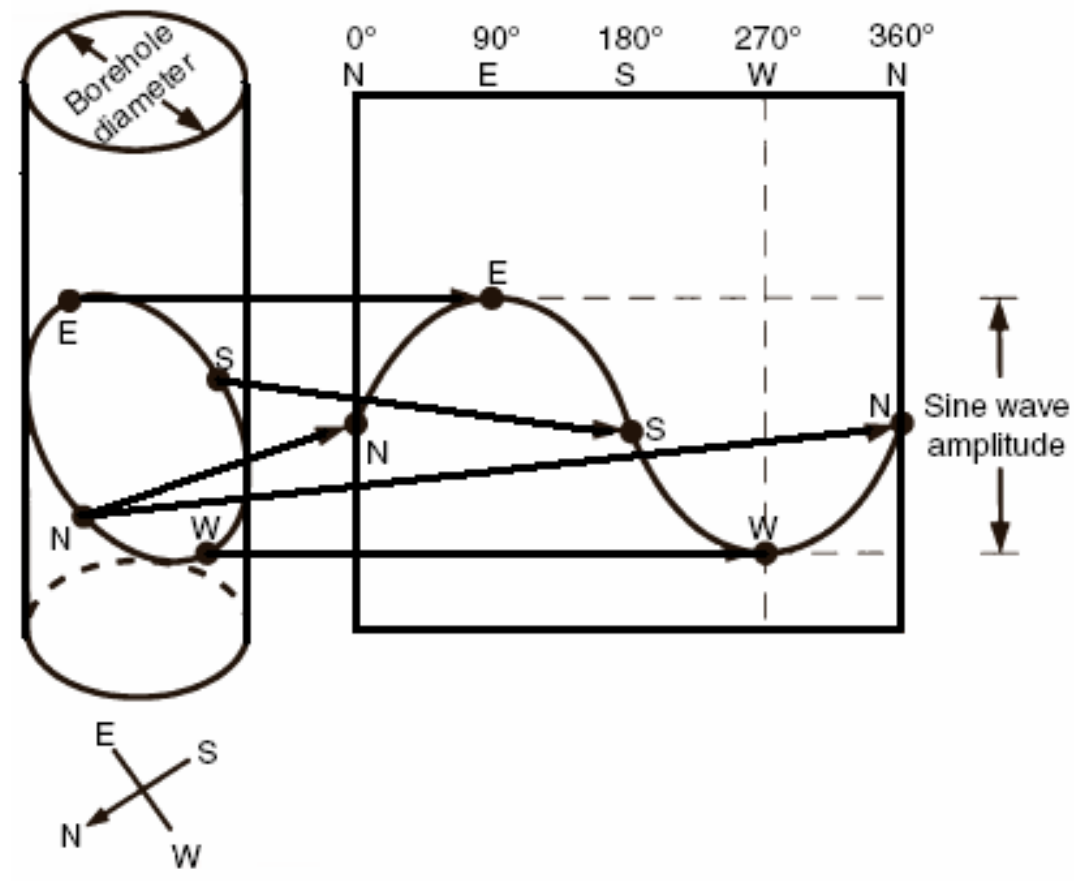

Figure A-3: This indicated how directional information is displayed on the FMI $\log$. The trend is indicated at the top of the chart. This figure was taken from (Donselaar, 2005) 
If the entire sine wave is not seen in the borehole image, a series of curves can be fitted to the points that are visible. Figure A-4, shows how line segments A and B are visible in the image and the curve of best fit is chosen to represent the plane on which they both lie. This process has been greatly enhanced through the use of computer algorithms that compute best fit sinusoids to interpret fracture planes.

The FMI image displays the strike and dip of a feature as tadpole plots. The color of the tadpole corresponds to a specific planar feature: fracture, bedding plan, etc. Looking at the header of the FMI log will indicate which color represents that specific feature. Figure A-5 indicates that yellow tadpoles represent the strike and dip of the sedimentary bedding planes. The yellow sinusoids are also used on the static and dynamic images to depict sedimentary bedding planes. Figure A-5 shows that sinusoid 1 has a larger amplitude than sinusoid 2 and therefore it is plotted farther to the right on the dip chart. For example sinusoid 1, of Figure A-5, has a dip of about 23 degrees and an trend of about 135 degrees.

\section{A.3 Fracture Types}

There are three major classifications of fractures associated with an FMI image. These include open fractures, closed fractures, and drilling induced fractures. Open fractures may have been partially cemented but retain some permeability. Closed fractures were open at one time but may have been sealed through cementation or changes in the local stress orientation. Closed fractures generally will inhibit fluid flow. The third classification of fractures is referred to as drilling induced fractures. These fractures are produced by stress release accommodated by the borehole opening and are useful in determining the present day maximum principle compressive stress. Drilling 
induced fractures are a good prediction of the opening mode of the fractures produced by hydraulic fracing.

\section{Open Fractures}

Open fractures are identified by an apparent low resistivity associated infiltration of drilling mud, formation waters, or clay within the aperture. Although it is not possible to determine if the fractures are truly open to flow or filled with clay, it is assumed that all conductive fractures are open (Koepsell, 2004). Hydrocarbon production is often greatly enhanced by open fracture interconnections.

\section{Continuous Fractures}

Continuous fractures have fracture traces that cross the entire circumference of the well bore. In the FMI log they appear as complete sinusoids across the image.. The FMI image identifies a continuous fracture by a red sinusoid in the image trace. Figure A-6, shows a typical continuous fracture as seen in the FMI dynamic image.

\section{Lithologically Bound Fractures}

Lithologically bound fractures appear as truncated or partial sinusoids in the FMI log (Figure A-7). The discontinuity occurs because these fractures truncate against lithologic bed boundaries. In the FMI log they are represented by a light blue sinusoid. Lithologically bound fractures might significantly inhibit production within multilayer reservoirs. However if fractures are confined to the reservoir they will enhance productivity without jeopardizing the reservoir seal. 

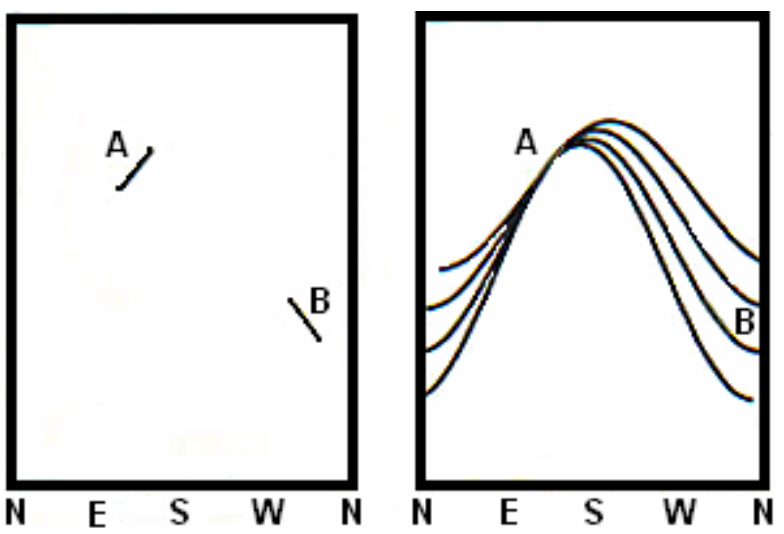

Figure A-4: The left hand figure shows two line segments identified on an FMI $\log$ that are used for analysis. The right hand side indicates how sine waves are fitted to these line segments so that dip and azimuth direction can be quantified. This figure was taken from (Luthi, 2001).
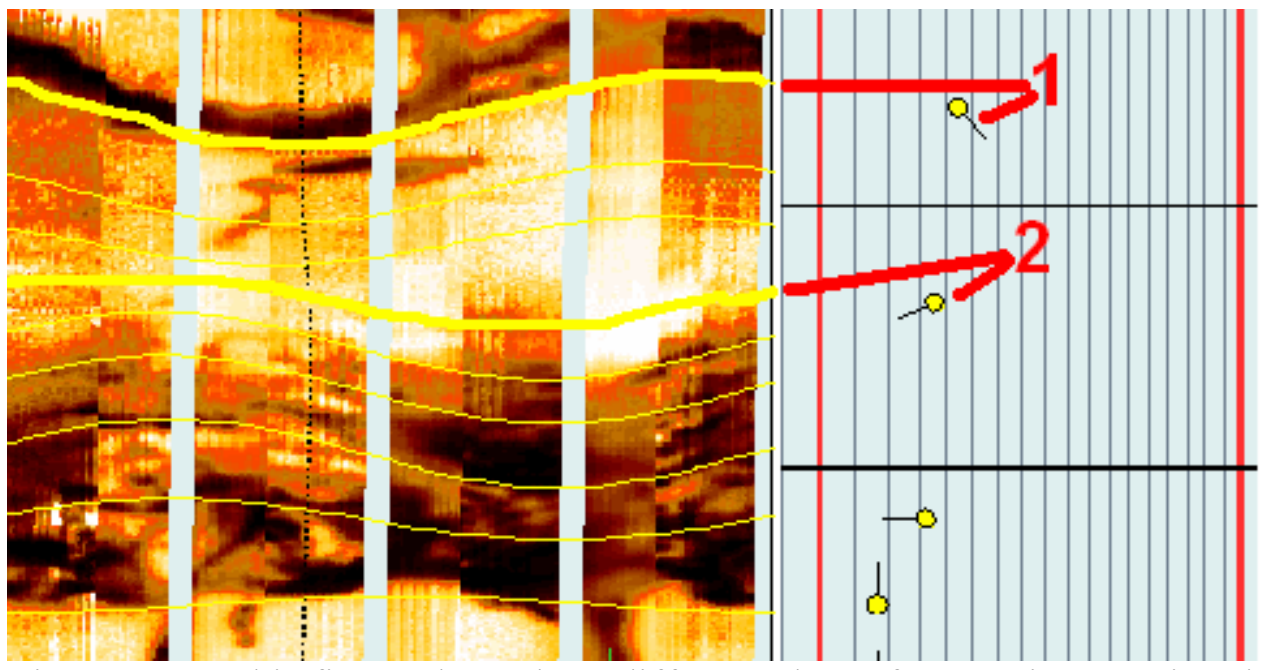

Figure A-5: This figure shows how different planar features intersecting the borehole are displayed in both the dynamic FMI image (Left) and the tadpole plot (Right). This image was taken from well 67-1-X-10 at Teapot Dome and was interpreted by Koepsell (2002). 


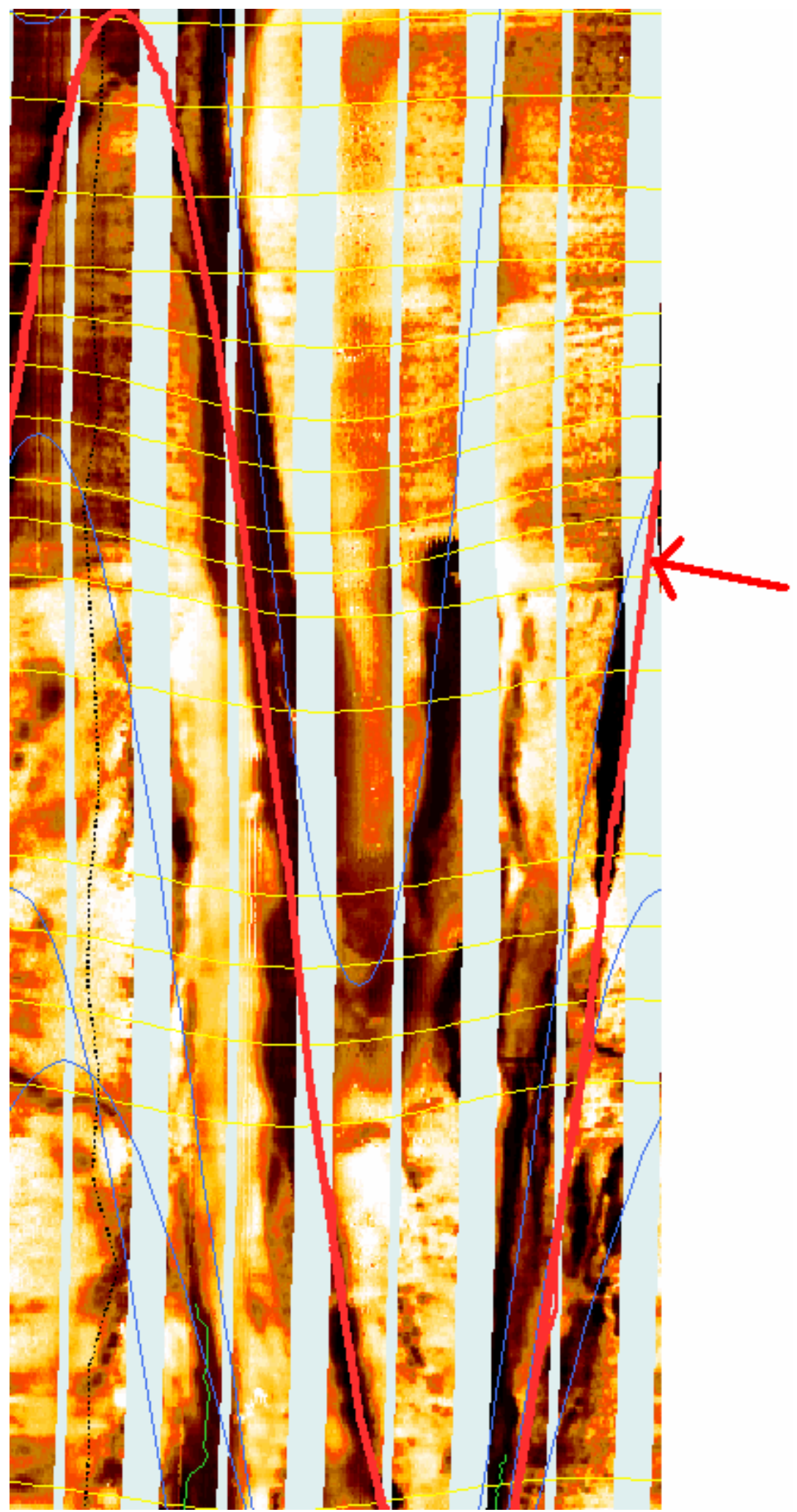

Figure A-6: A continuous fracture as seen in the FMI log for well 48-X-28 from Teapot Dome. This log was interpreted by Koepsell (2002). 


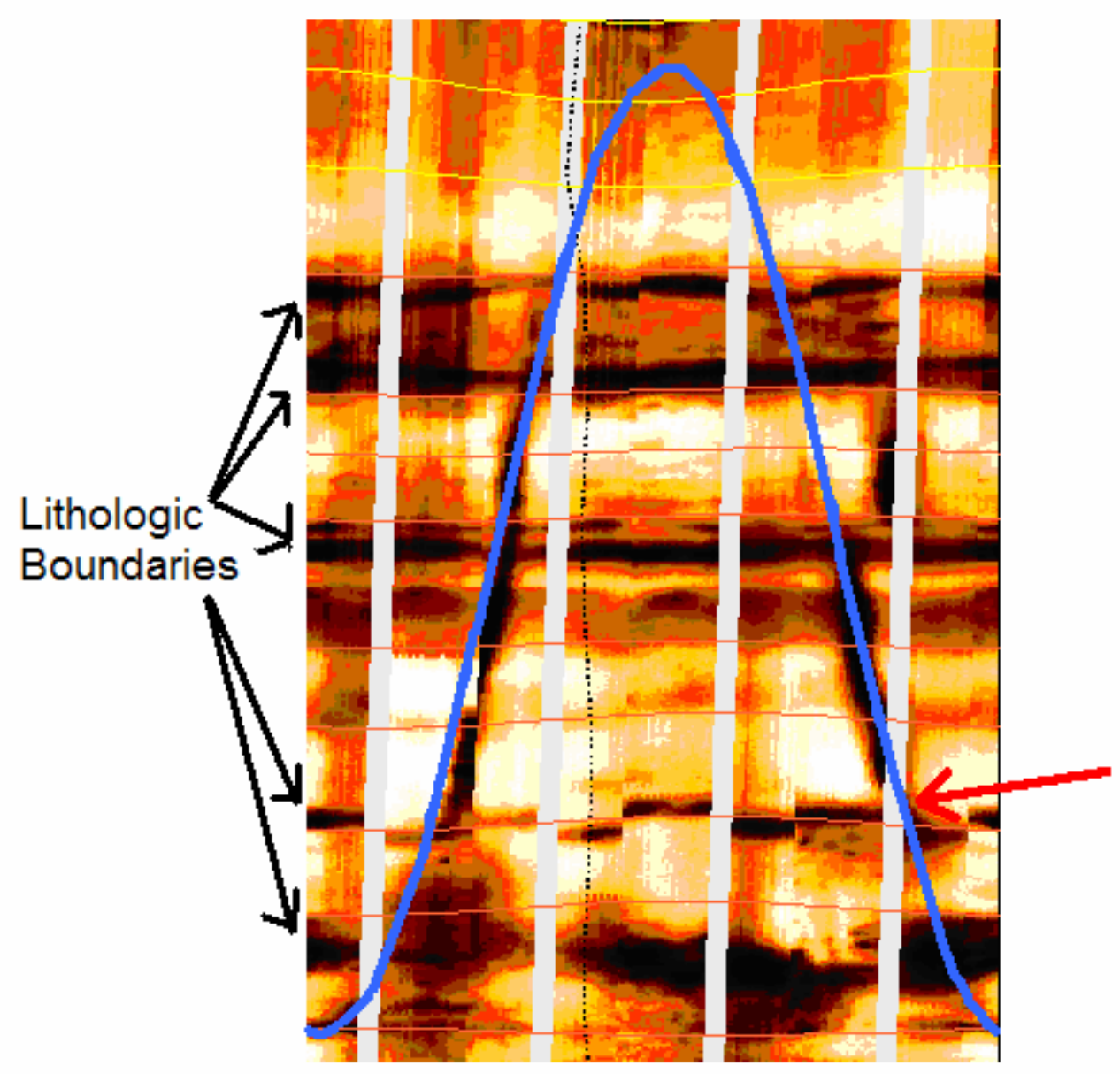

Figure A-7: A lithologically bound fracture as seen in the FMI log for well 48-X28 from Teapot Dome. This log was interpreted by Koepsell, 2002 


\section{Partially Healed Fractures}

Partially healed fractures are open fractures that are partially filled by cement. The degree of filling may vary and there is also the possibility the fractures could have been opened by the drilling process. If these fractures were completely healed, they will not serve as conduits for fluid flow. Figure A-8 shows a typical partially healed fracture as seen in the FMI dynamic image.

\section{Healed Fractures}

Resistive fractures appear as a light or white sinusoidal feature in the FMI image. These fractures were once open, but have been cemented with the resistive cements quartz or calcium carbonate. These fractures will often appear to have a halo effect around the fracture due to an interruption of the current flow to the tool. Healed fractures represent permeability barriers to fluid flow. Figure A-9, shows a typical resistive fracture as seen in the FMI dynamic image.

\section{Drilling Induced Fractures}

Drilling induced fractures occur through strain release into the borehole opening. These fractures strike in the direction of the present day maximum principal compressive stress and open in the direction of the present day minimum principal compressive stress. The orientation of induced fractures is a good prediction of the orientation of open fractures formed by hydraulic fracturing treatments. These fractures have nearly vertical orientation and therefore do not appear as sine waves in the FMI image. Instead they will appear like railroad tracks running vertically up and down in the FMI log image. Figure 
A-11 shows a typical drilling induced fracture as seen in the FMI log. Notice the fractures have a parallel railroad track-like appearance. 


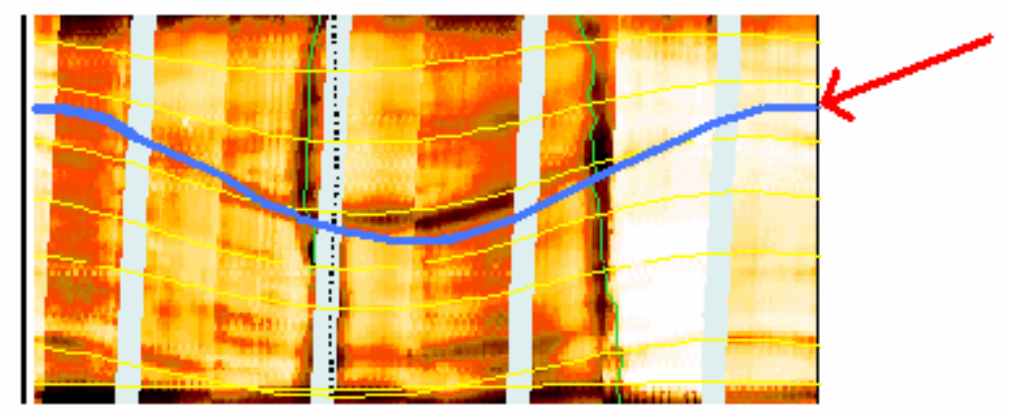

Figure A-8: A partially healed bound fracture as seen in the FMI log for well 48X-28 from Teapot Dome. This log was interpreted by Koepsell (2002).

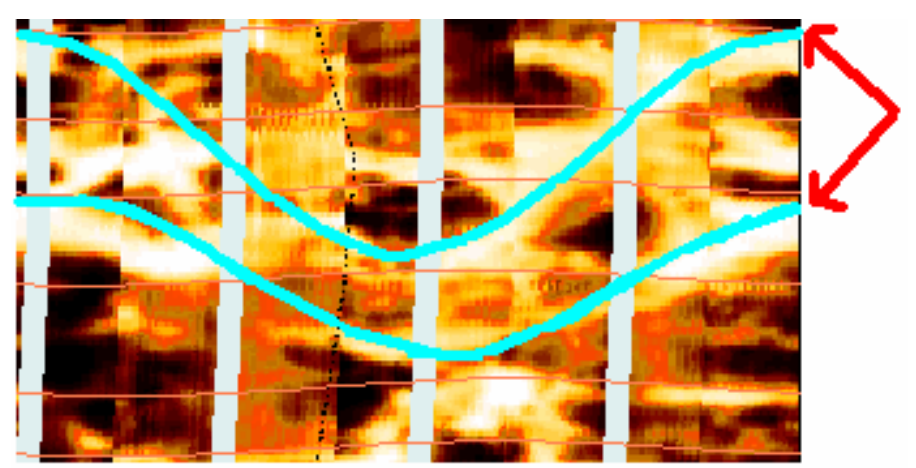

Figure A-9: Two healed fractures as seen in the FMI log for well 48-X-28 from Teapot Dome. This log was interpreted by Koepsell (2002). 


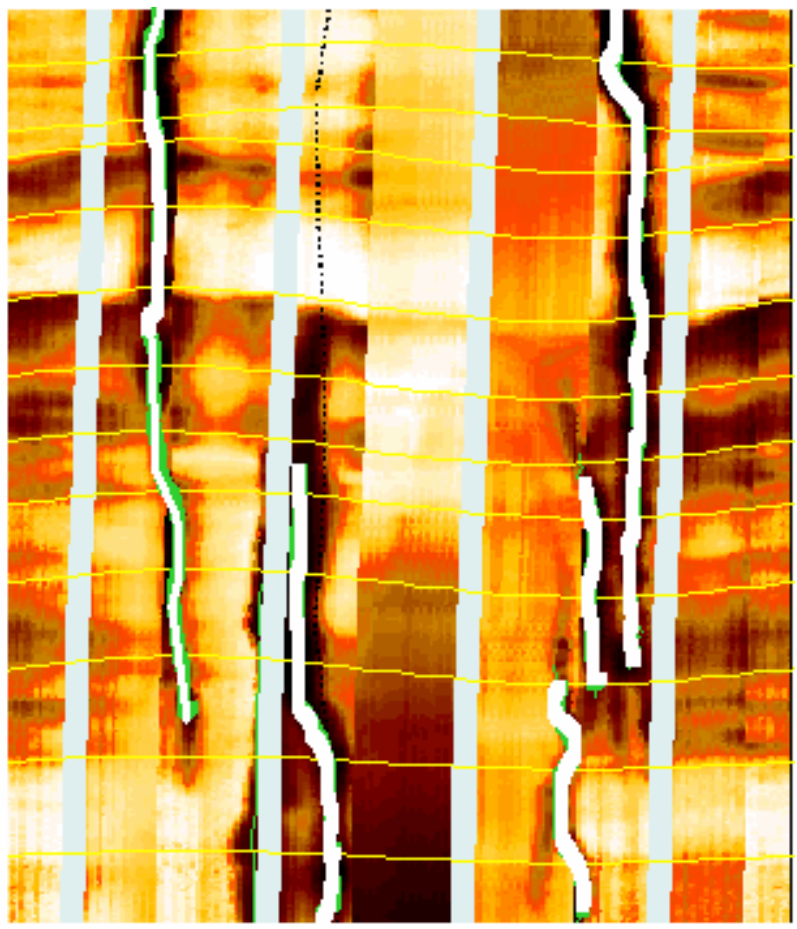

Figure A-10: A drilling induced fracture as seen in the FMI log for well 48-X-28 from Teapot Dome. This log was interpreted by Koepsell, 2002. 


\section{Appendix B: FracGen Modeling}

\section{B.0 Introduction}

This appendix provides some basic information about the operation of FracGen to generate fracture models based on known fracture network statistics. This appendix is not designed to be a complete guide to fracture modeling with FracGen, but instead is designed to allow the reader to gain insight into the process of using FracGen to create fracture models. For a complete description of FracGen modeling procedures please see the User's Guide For The Naturally-Fractured Natural Gas Reservoir Simulator (McKoy, 2001).

\section{B.1 FracGen Fracture Sets}

FracGen allows a user to define up to ten fracture sets in a single stochastic fracture model. These fracture sets are based on three different models types: model 1, model 2, and model 3. The variety of models help the user design a fracture network that is representative of those observed in their study area.

\section{Model 1}

The model 1 fracture set is the type of fracture model used throughout this thesis. These fracture models generate randomly located fractures that can be clustered together with connectivity controls (McKoy, 2001). Figure B-1 shows an example of the input file for model 1 fractures. This model uses the mean and standard deviation of a fracture network to produce a representative fracture set. The fracture lengths can be defined by using one of four different modeling approaches. See Section B.2 for additional information on modeling fracture length. The number of fractures is determined by the 
density of fracture center points. This value is defined as the number of points per $\mathrm{ft}^{2}$ (McKoy, 2001). See Section B.3 for additional information on fracture density. This model type will allow user defined fractures to be entered as necessary. The rest of the modeling parameters in Figure B-1 define the annealing and connectivity properties of the fracture network. Figure B-2 is an example of Model 1 fracture sets.

\section{Model 2}

The model 2 fracture set is used to define randomly located or overlapping fracture swarms (McKoy, 2001). The mean and standard deviation of the fracture strike, fracture cluster length, cluster density, inter-cluster fracture spacing, and the mean and standard deviation of the intra-cluster density are specified. This information generates fracture clusters based on the statistical fracture and fracture clustering characteristics. Figure B-3 displays an input file for Model 2 fracture sets. Figure B-4 is the graphical representation of the fractures network created by FracGen to represent these fractures.

\section{Model 3}

The model 3 fracture set is used to generate regularly located, non-overlapping swarms (McKoy, 2001). Fractures are only placed within specified cluster locations. Figure B-5 shows how information on cluster length, width, and orientation are entered into FracGen to simulate a clustered fracture network. Figure B-6 is the graphical representation of the fracture cluster created by using the model 3 approach. Notice the regular location of the fracture clusters and absence of overlapping fractures. 


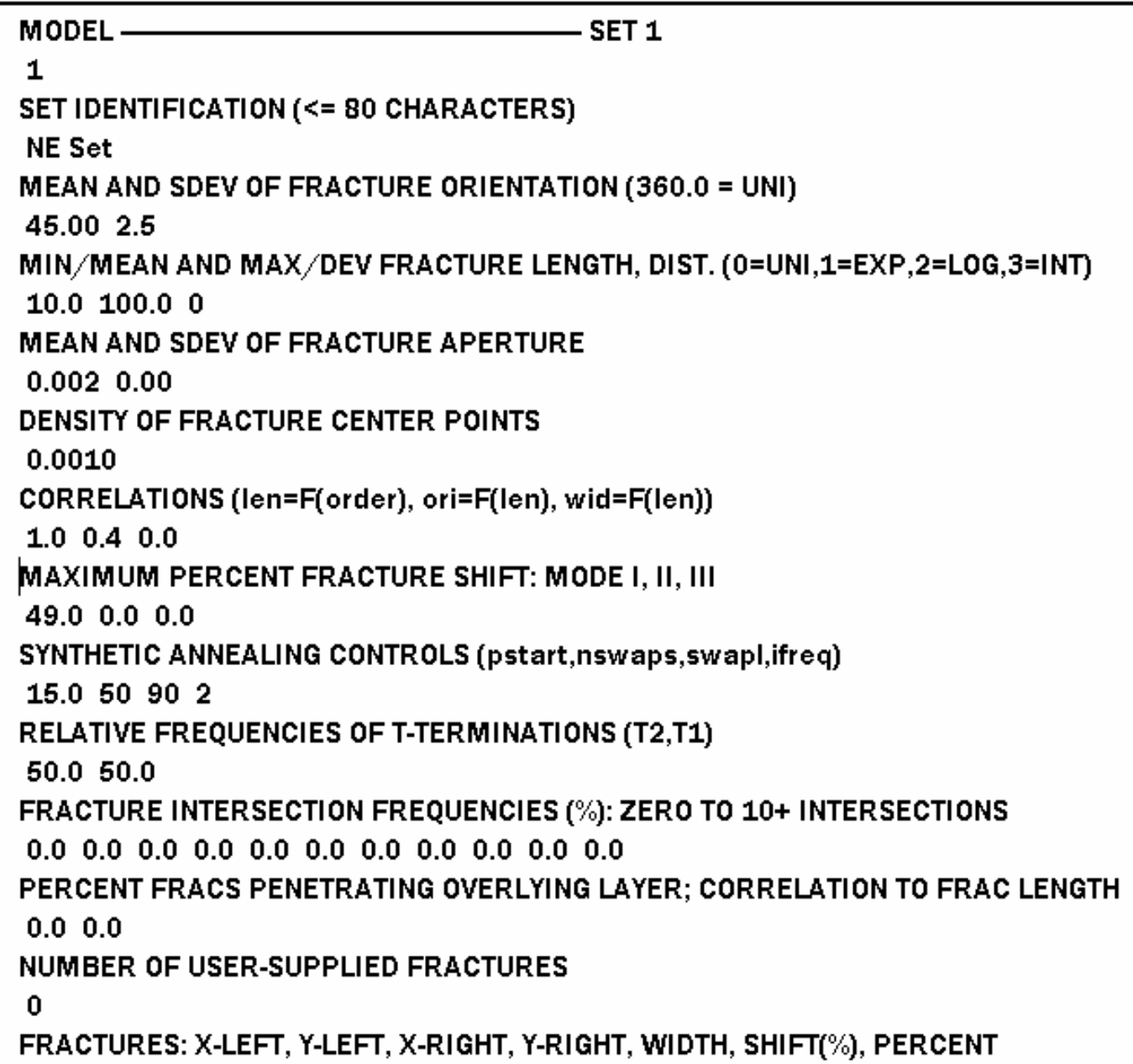

Figure B-1: Input file for Model 1 fracture sets for FracGen. This file allows the fracture orientation and standard deviation to be specified along with other fracture characteristics. 


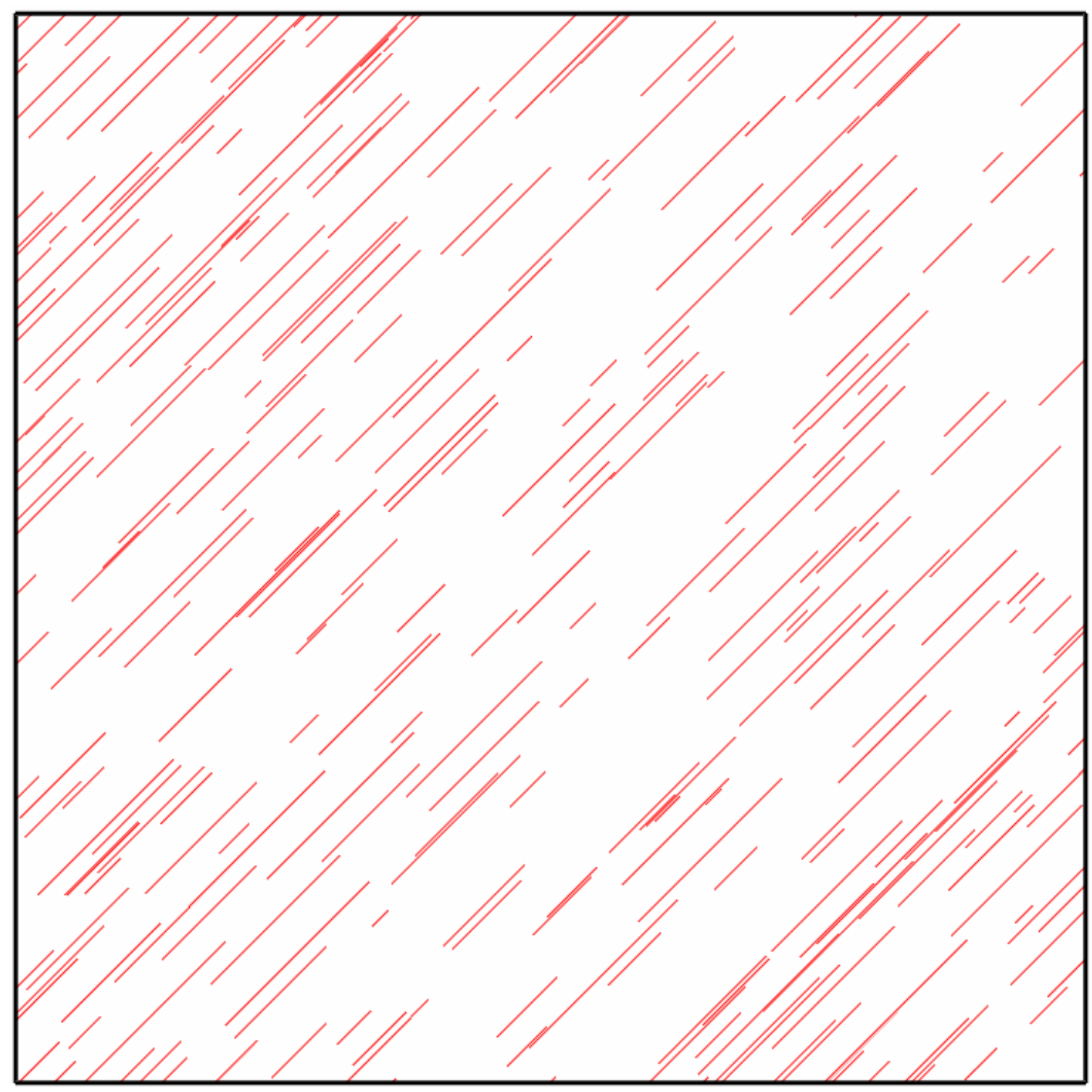

Figure B-2: This is an example of the Model 1 fracture set defined by the input values shown in Figure B-1. The modeling area is $500 \mathrm{ft} \times 500 \mathrm{ft}$. 


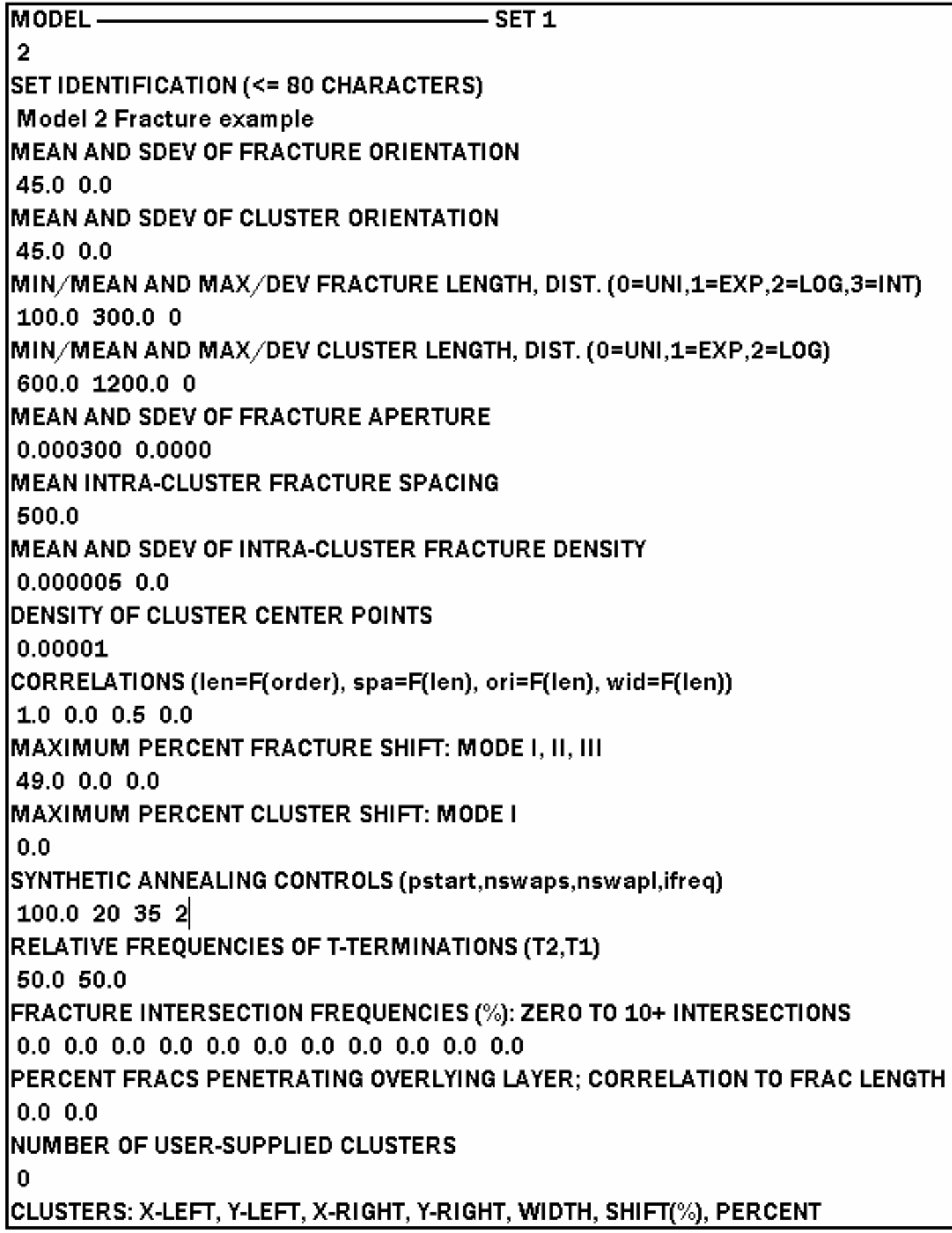

Figure B-3: Input file for Model 2 fracture sets for FracGen. This file allows the fracture orientation and standard deviation of both the fracture and the fracture swarm to be defined. 


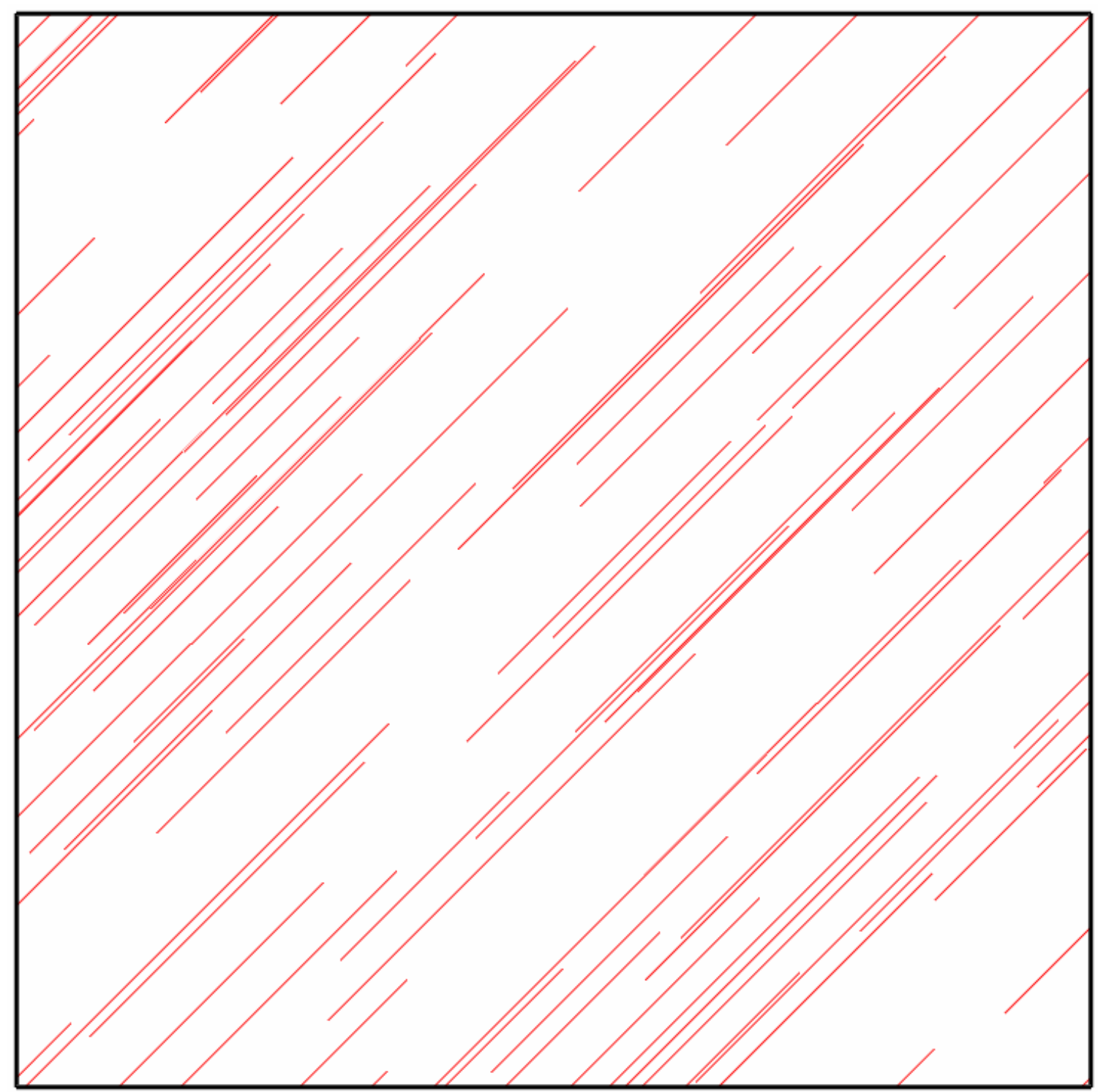

Figure B-4: This is an example of the Model 2 fracture set defined in Figure B-3. The modeling area is $500 \mathrm{ft} \times 500 \mathrm{ft}$ 


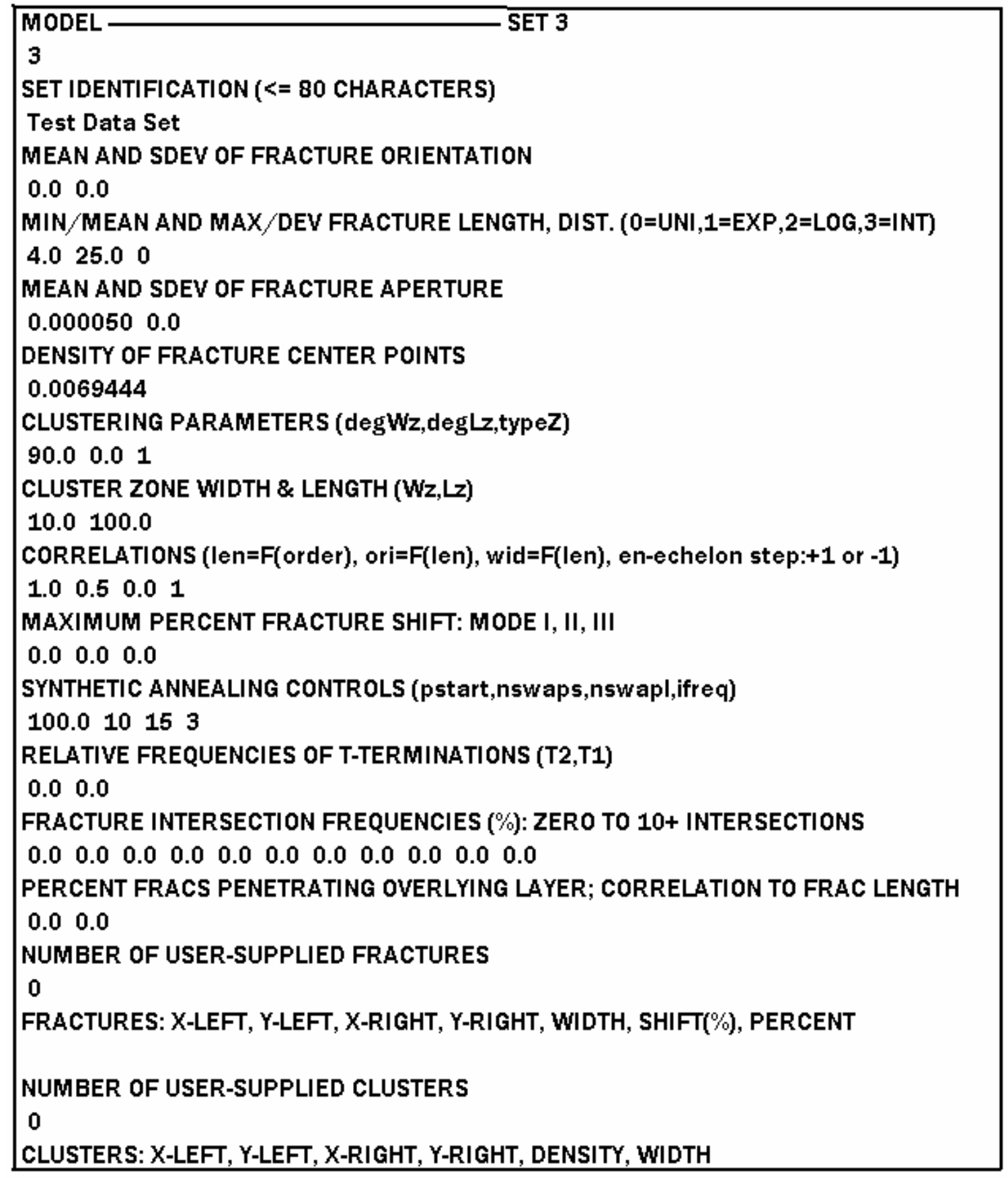

Figure B-5: Input file for Model 3 fracture sets for FracGen. This file is an sample provided with the FracGen software. This file defines the specific swarm location and width. 


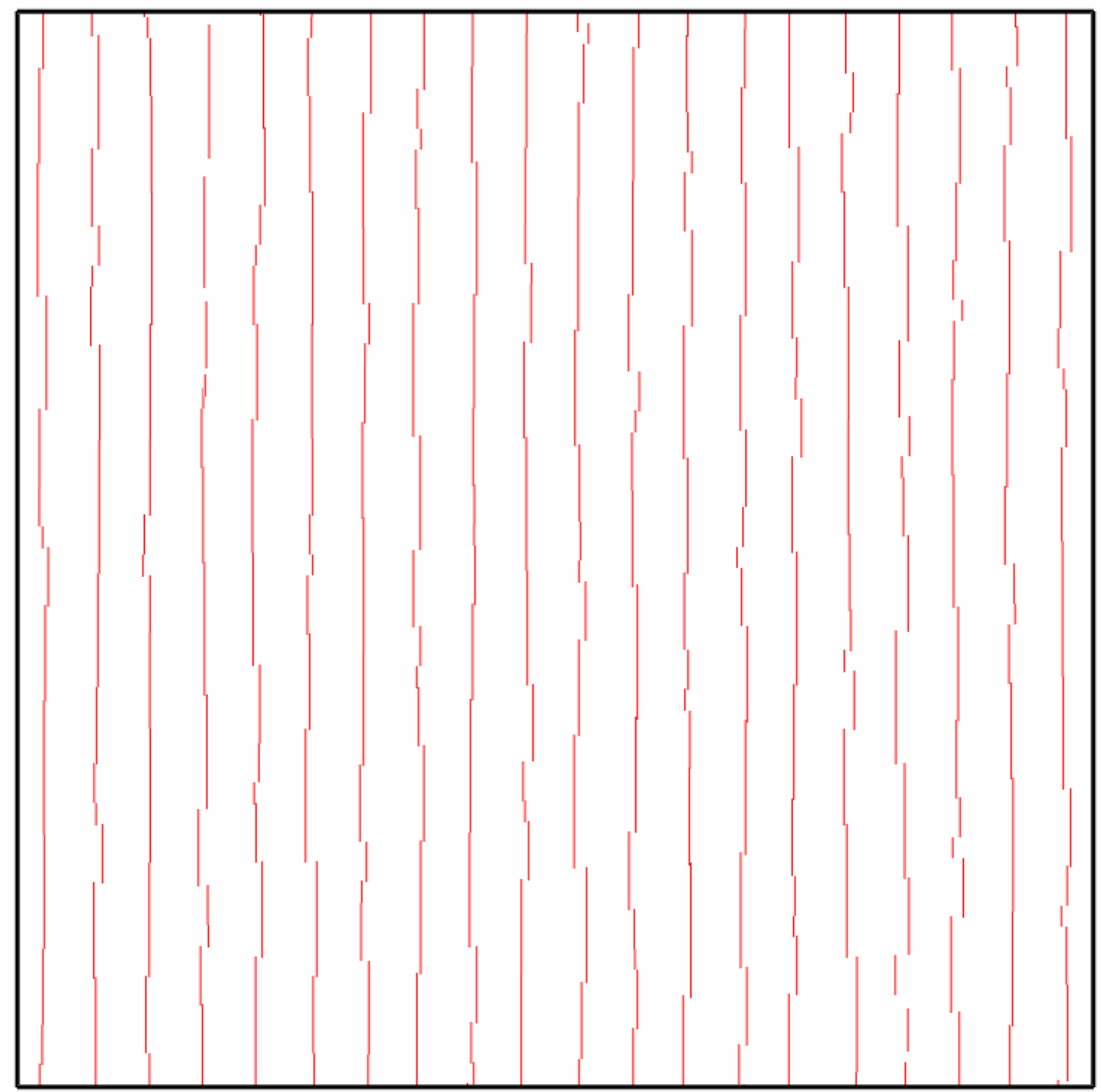

Figure B-6: This is an example of the Model 3 fracture set defined by the control values specified in Figure B-5. The modeling area is $200 \mathrm{ft} \times 200 \mathrm{ft}$ 


\section{B.2 Modeling Fracture Length}

FracGen has the ability to stochastically define fracture length distributions as uniform, exponential, lognormal, and intersection frequency controlled (McKoy, 2001). These parameters will determine the type of distribution and intersection control FracGen will use to determine fracture length. The fracture length parameter will be the same for all three fracture model types (I, II, or III). For this reason the examples in the fracture length section were produced using only type I fracture intersection control. Fracture set 1 has a mean fracture orientation of 45 degrees with a standard deviation of 2.5 degrees, and fracture set two has mean fracture orientation of 135 degrees with a standard deviation of 2.5 degrees. The density of fracture center points was set to 0.0010 points per $\mathrm{ft}^{2}$ to provide an adequate fracture coverage in the $500 \times 500$ foot modeling area. Two runs were done for each fracture length modeling scheme to show the subtle differences between two equivalent statistical models.

\section{Uniform Length Distribution}

The uniform length model creates a uniform distribution of fracture lengths between a given minimum and maximum length (McKoy, 2001). The distribution will be a uniform distribution meaning there is an equal probability that a fracture will have a given length with a specified range of possible lengths. The minimum fracture length is 10 feet and the maximum fracture length is 100 feet in the example shown here (Figures B-7 and B-8). Figures B-7 and B-8 reveal the uniform distribution of fracture lengths generated in the model. 


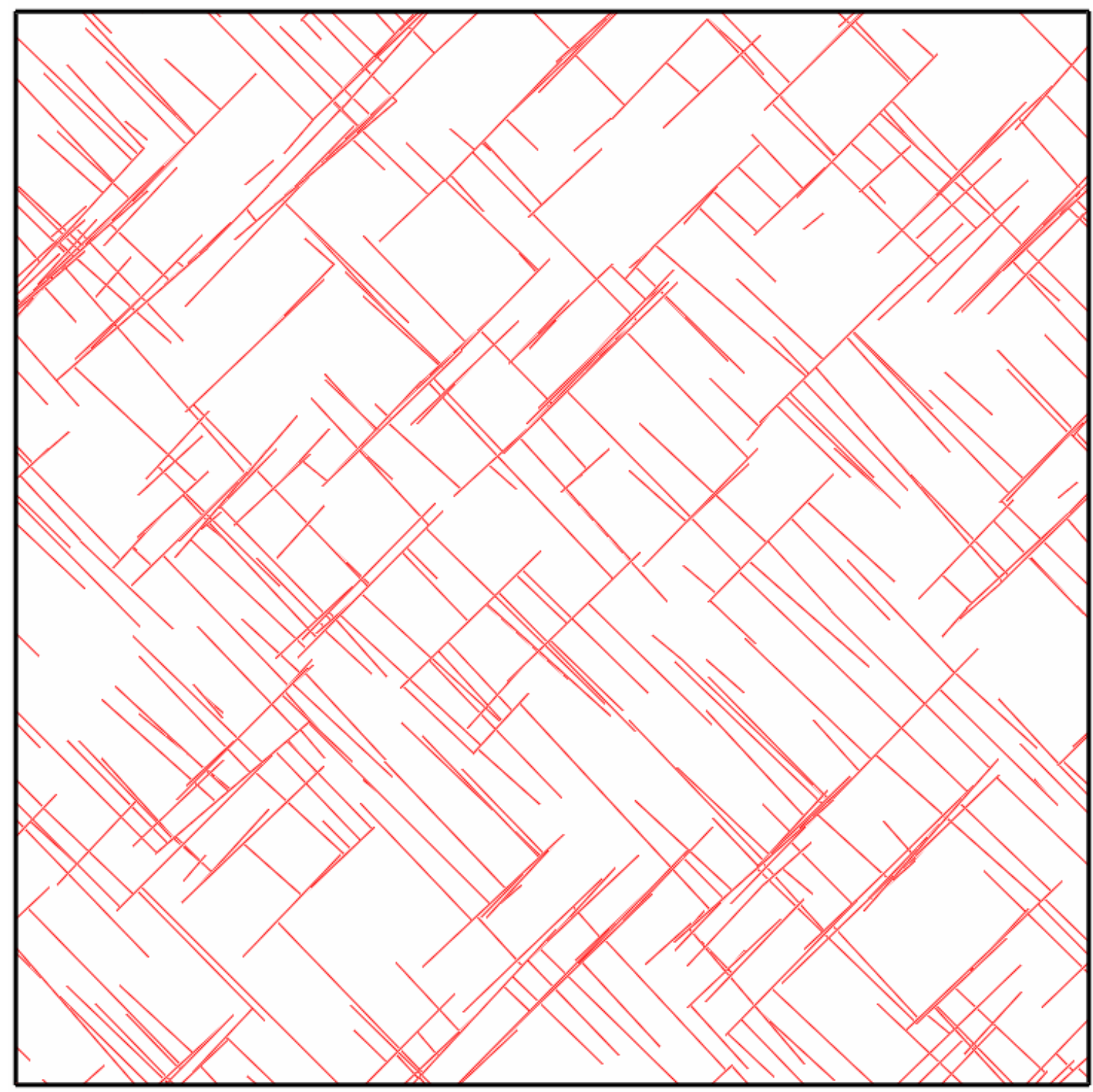

Figure B-7: This type 1 model fracture set has a model length and width of 500 $\mathrm{ft}$. Note that there is a similar number of fractures of different lengths. 


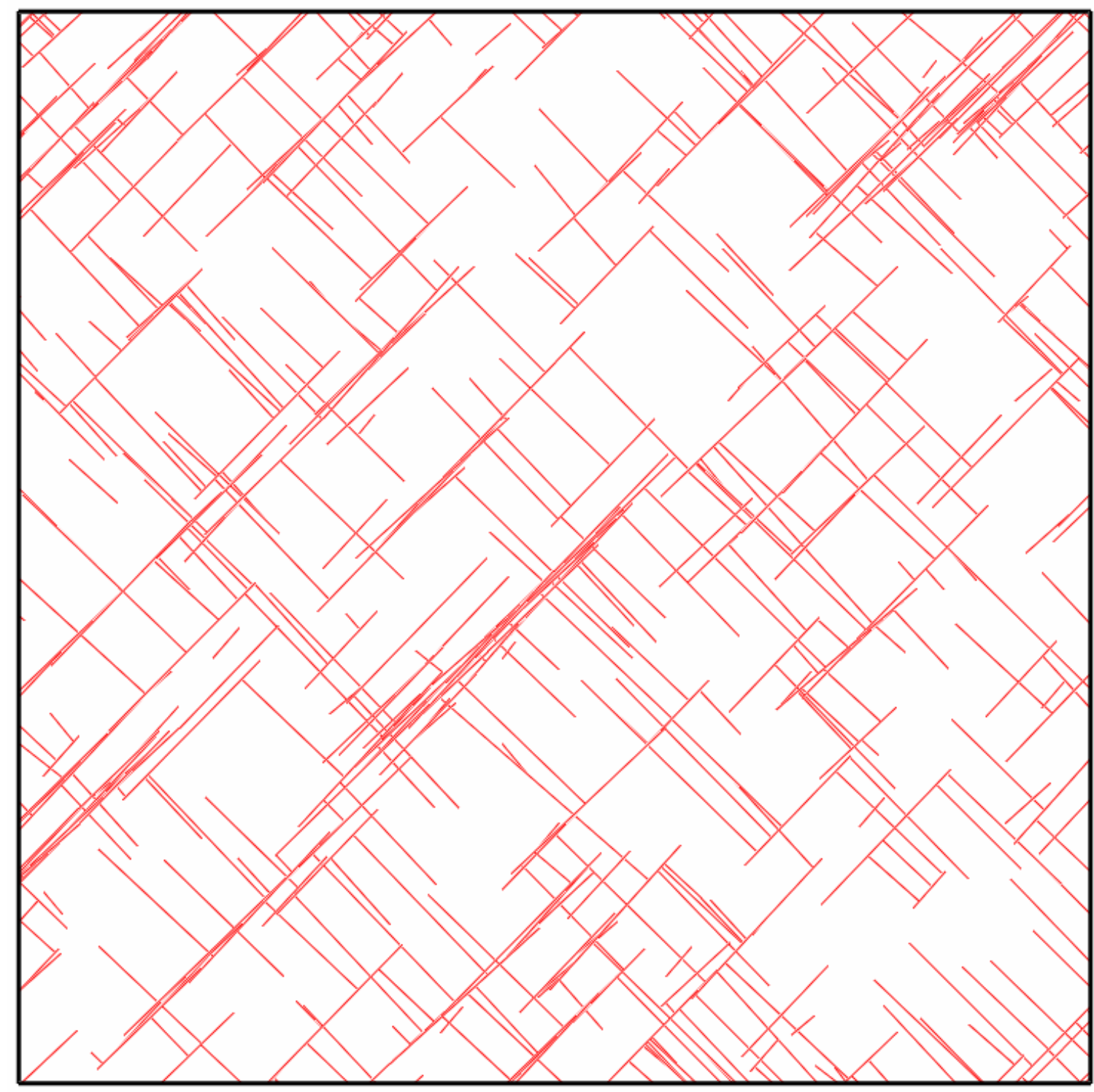

Figure B-8: This type 1 model fracture set has a model length and width of 500 $\mathrm{ft}$. Note that there is a similar number of fractures of different lengths. 


\section{Exponential}

The exponential length model will generate fracture lengths between a given minimum and maximum fracture length. The exponential control yields a small number of large fractures and a much greater number of shorter fractures. In the example model (Figures B-9 and B-10), the minimum fracture length is 10 feet and the maximum fracture length is 100 feet. Figures B-9 and B-10 reveal much greater abundance of smaller fractures relative to the larger fractures.

\section{Lognormal}

The lognormal model uses the natural logarithm of the normal distribution of fracture lengths (McKoy, 2001). This modeling option will truncate the tails of the lognormal distribution to \pm 3 standard deviations (McKoy, 2001). The mean facture length in Figures B-11 and B-12 is 50 feet with a standard deviation of 20 feet. The model output (Figure B-11 and B-12) show the normally distributed fracture lengths.

\section{Intersection Frequency Controlled}

The intersection-frequency controlled fracture length model controls the fracture intersection frequency, and uses the lognormal mean and standard deviation of the fracture length distribution (McKoy, 2001). The lognormal model may cause fracture clustering to occur if multiple fracture intersections are desired. Figure B-13 and B-14 show an intersection frequency controlled length model with the same parameters for length as the lognormal models shown in Figures B-11 and B-12. Notice in these figures how the fractures tend to create clustering when compared to the lognormal fracture length model. 


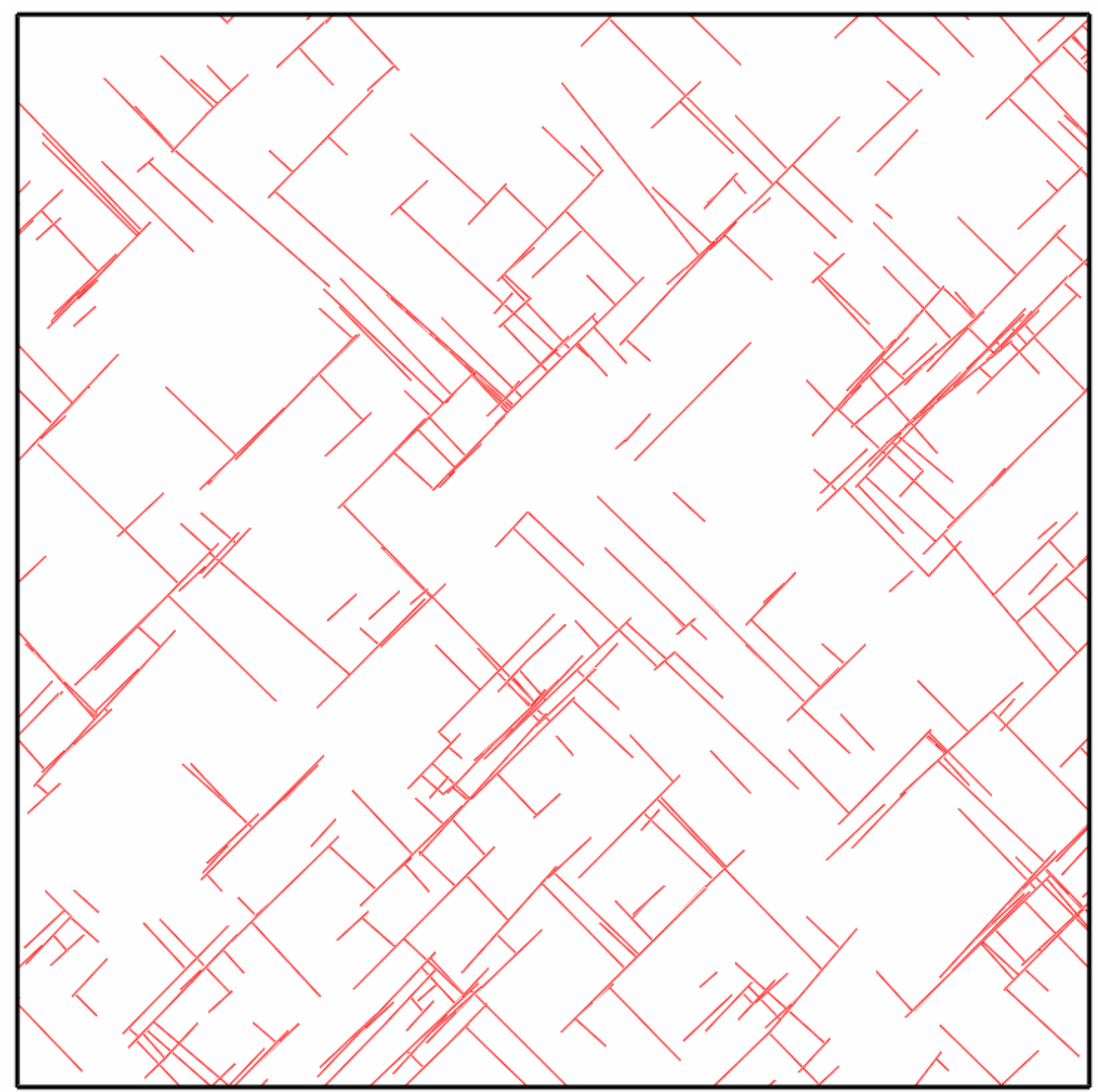

Figure B-9: This type 1 model fracture set has a model length and width of 500 $\mathrm{ft}$. Note that there is a small number of larger fractures and a much greater value of smaller fractures. 


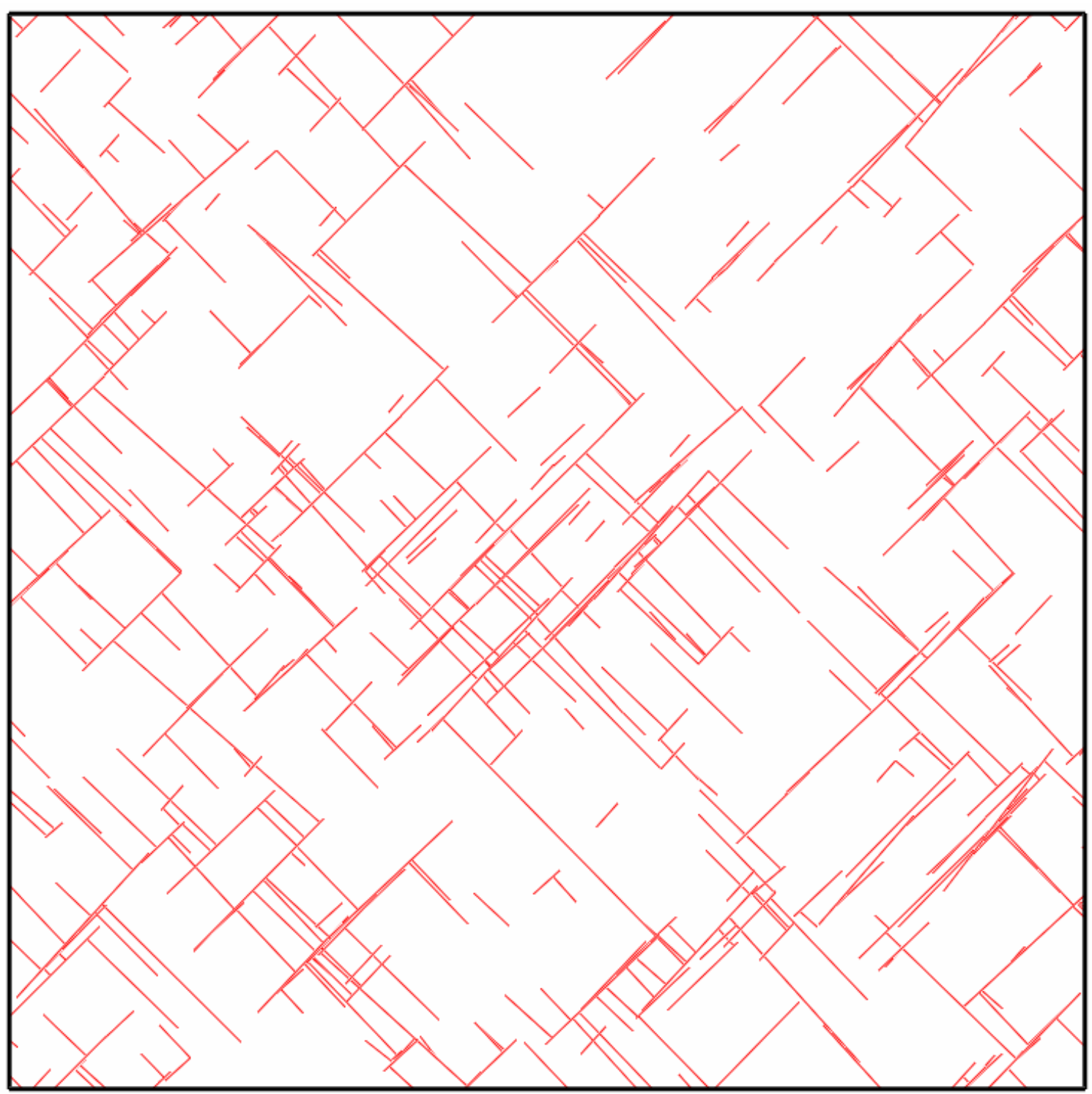

Figure B-10: This type 1 model fracture set has a model length and width of 500 $\mathrm{ft}$. Note that there is a small number of larger fractures and a much greater value of smaller fractures. 


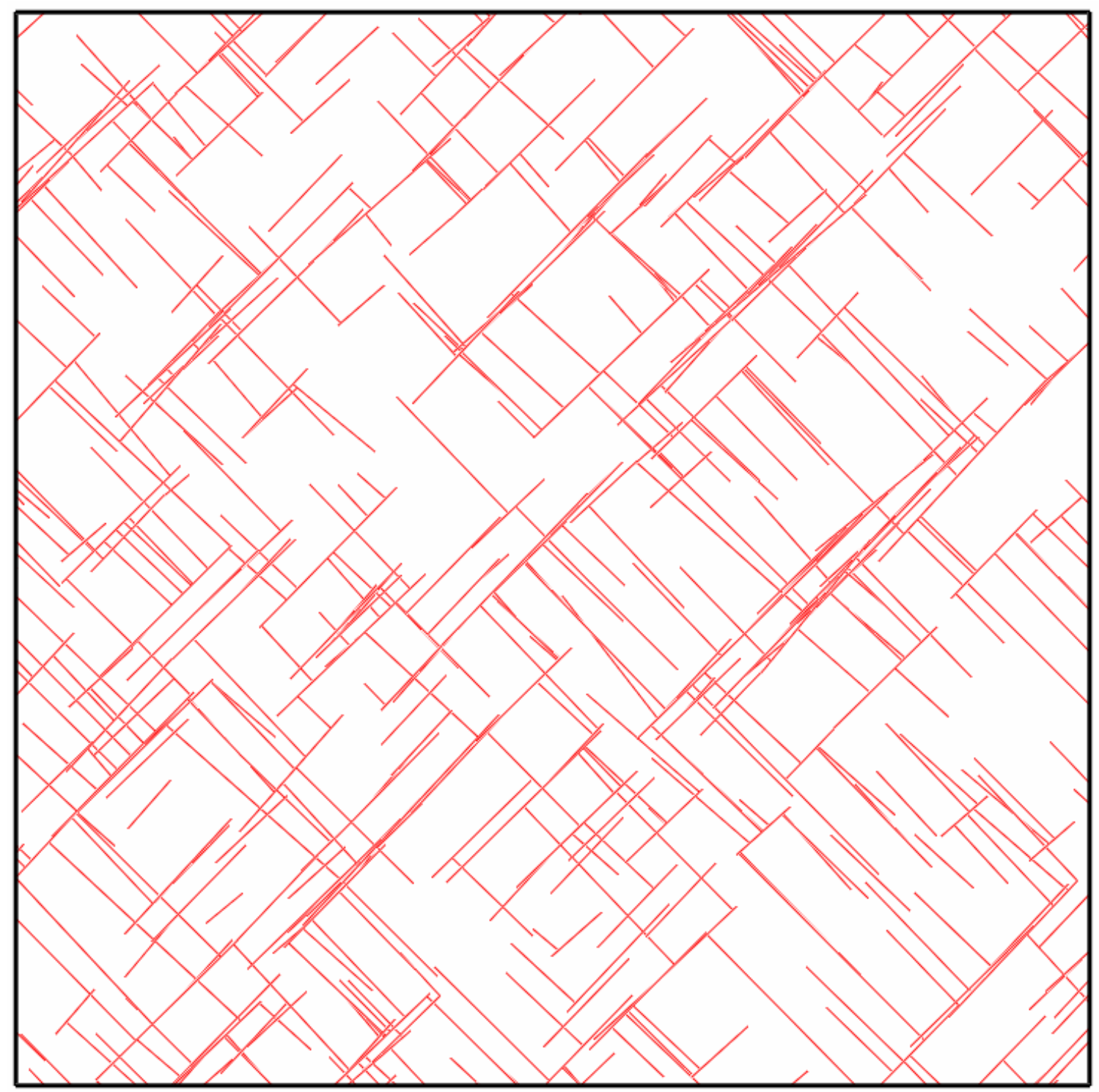

Figure B-11: This type 1 model fracture set has a model length and width of 500 $\mathrm{ft}$. Note that the fracture length is normally distributed around 50 feet. 


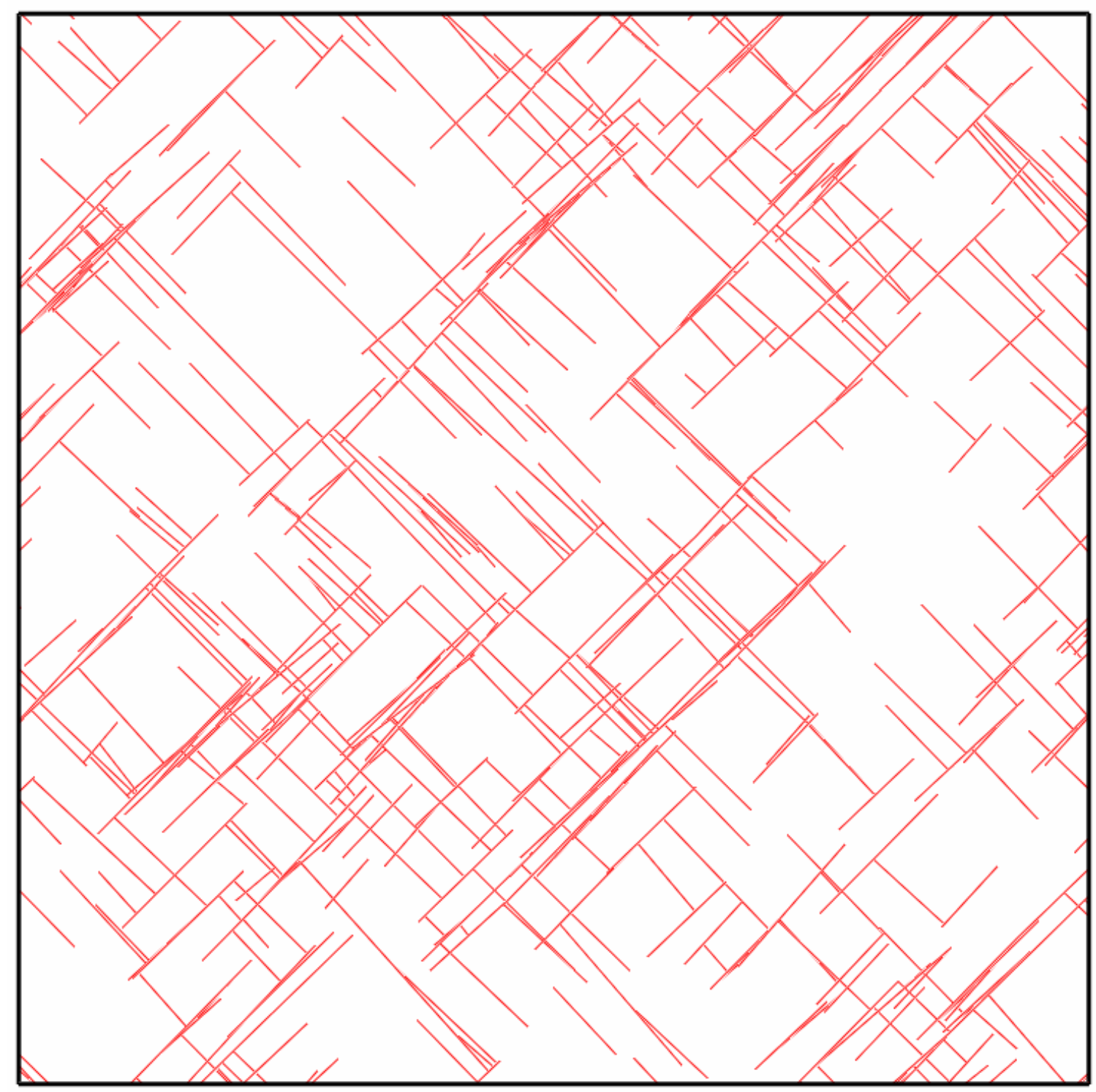

Figure B-12: This type 1 model fracture set has a model length and width of 500 $\mathrm{ft}$. Note that the fracture length is normally distributed around 50 feet. 


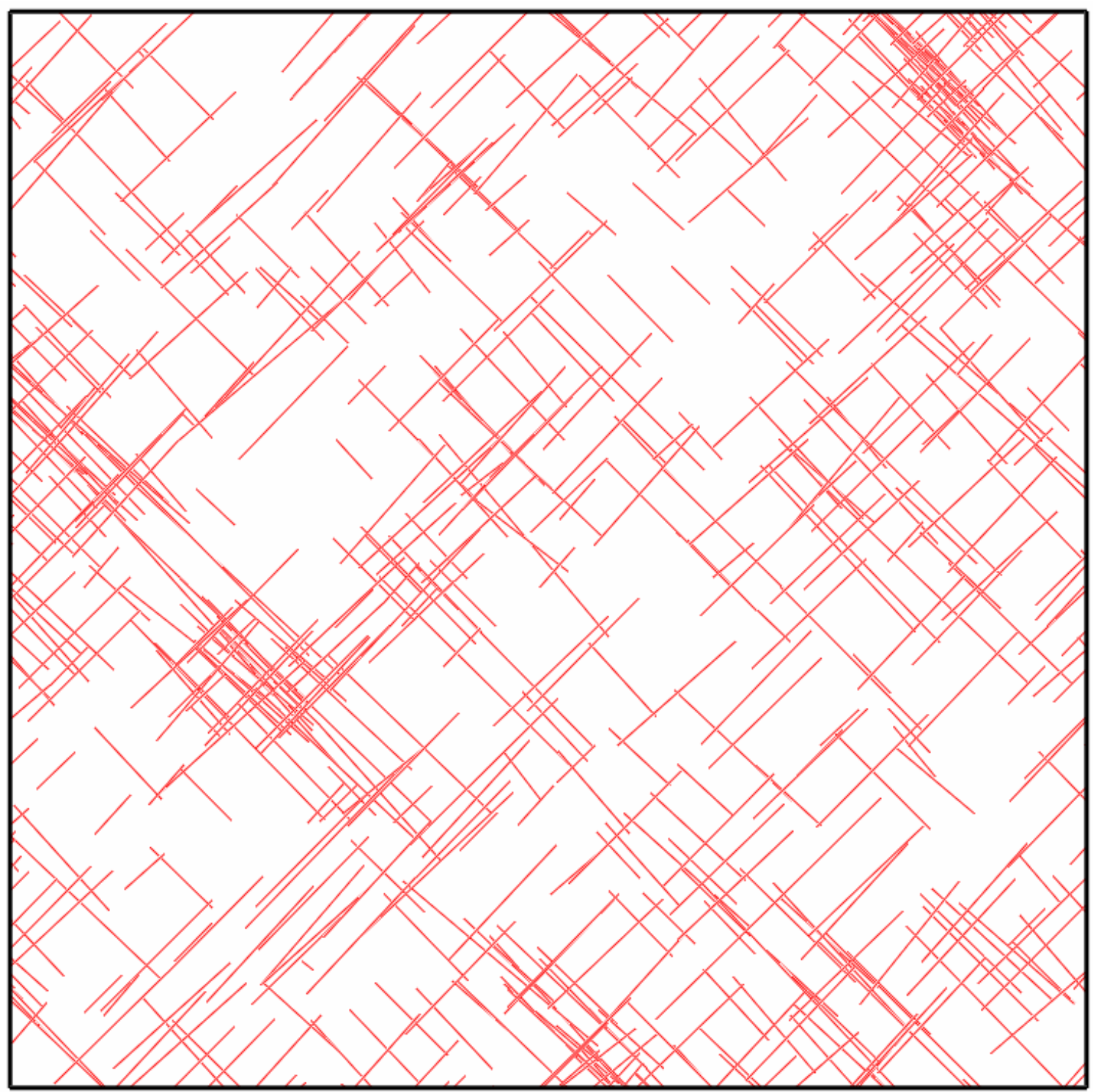

Figure B-13: This type 1 model fracture set has a model length and width of 500 $\mathrm{ft}$. Note that the fracture length is normally distributed around 50 feet in length but the fractures appear to become clustered as a result of matching the frequency of fracture intersection. 


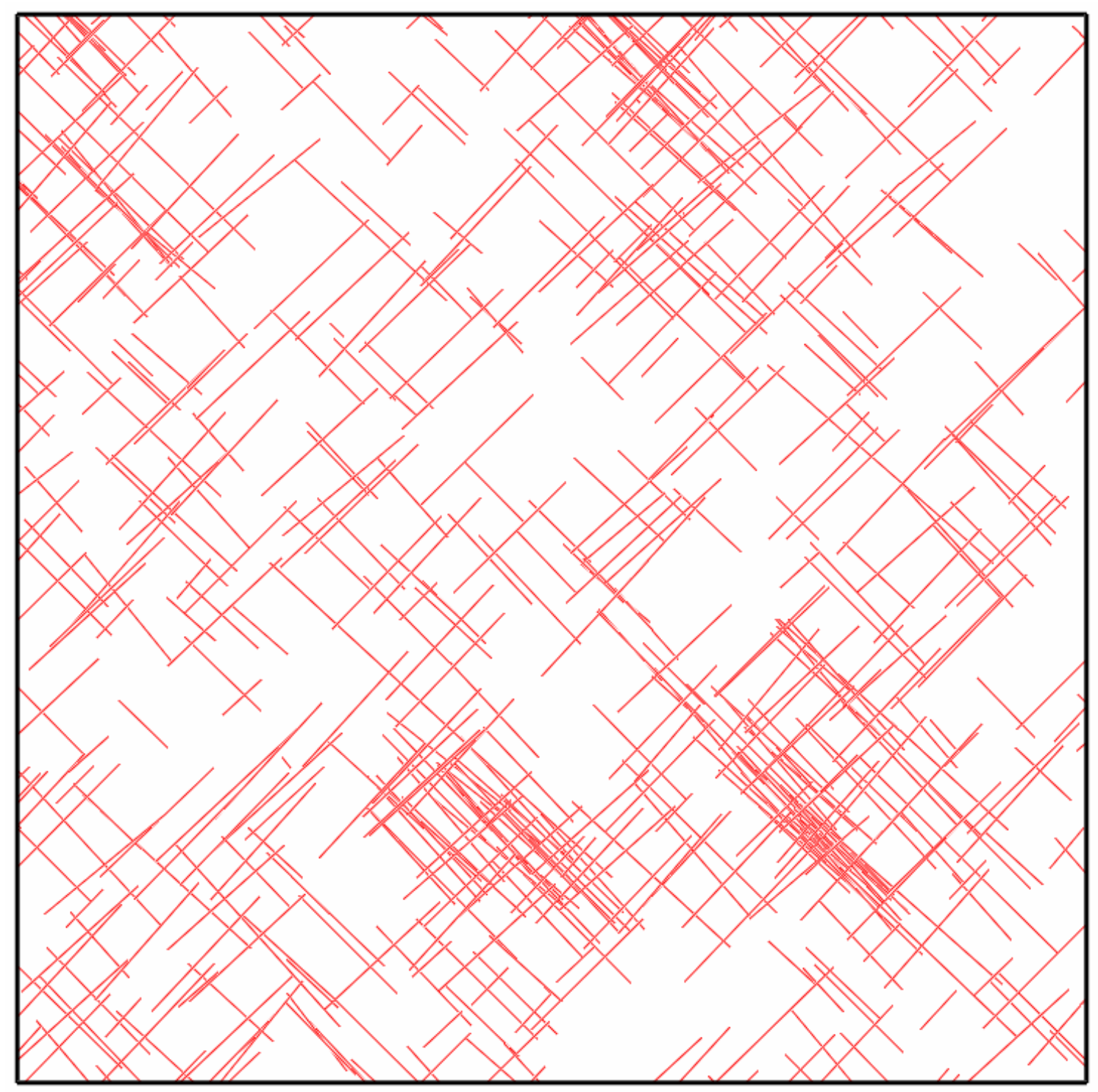

Figure B-14: This type 1 model fracture set has a model length and width of 500 $\mathrm{ft}$. Note that the fracture length is normally distributed around 50 feet in length but the fractures appear to become clustered as a result of matching the frequency of fracture intersection. 


\section{B.3 Modeling Fracture Density}

Fracture center point density as defined by McKoy (2001), is the number of fracture or fracture zone center points per unit representative area $\left(\mathrm{pts} / \mathrm{ft}^{2}\right)$. In order to accurately model an area, the density of fractures needs to be known. If the fracture model is to be viewed, the model area must be adequately scaled. A given modeling area of $500 \mathrm{ft} \times 500 \mathrm{ft}$ will have an area of $250000 \mathrm{ft}^{2}$. Fracture densities of 0.001 fractures $/ \mathrm{ft}^{2}$, 0.01 fractures $/ \mathrm{ft}^{2}, 0.1$ fractures $/ \mathrm{ft}^{2}$, and 0.000001 fractures $/ \mathrm{ft}^{2}$ will produce 250,2500 , 25000, 0.25 fractures, respectively. For comparison purposes Figures B-15, B-16, B-17, and B-18 display four FracGen runs with the above fracture densities for a $500 \mathrm{ft}$ by $500 \mathrm{ft}$ model. 


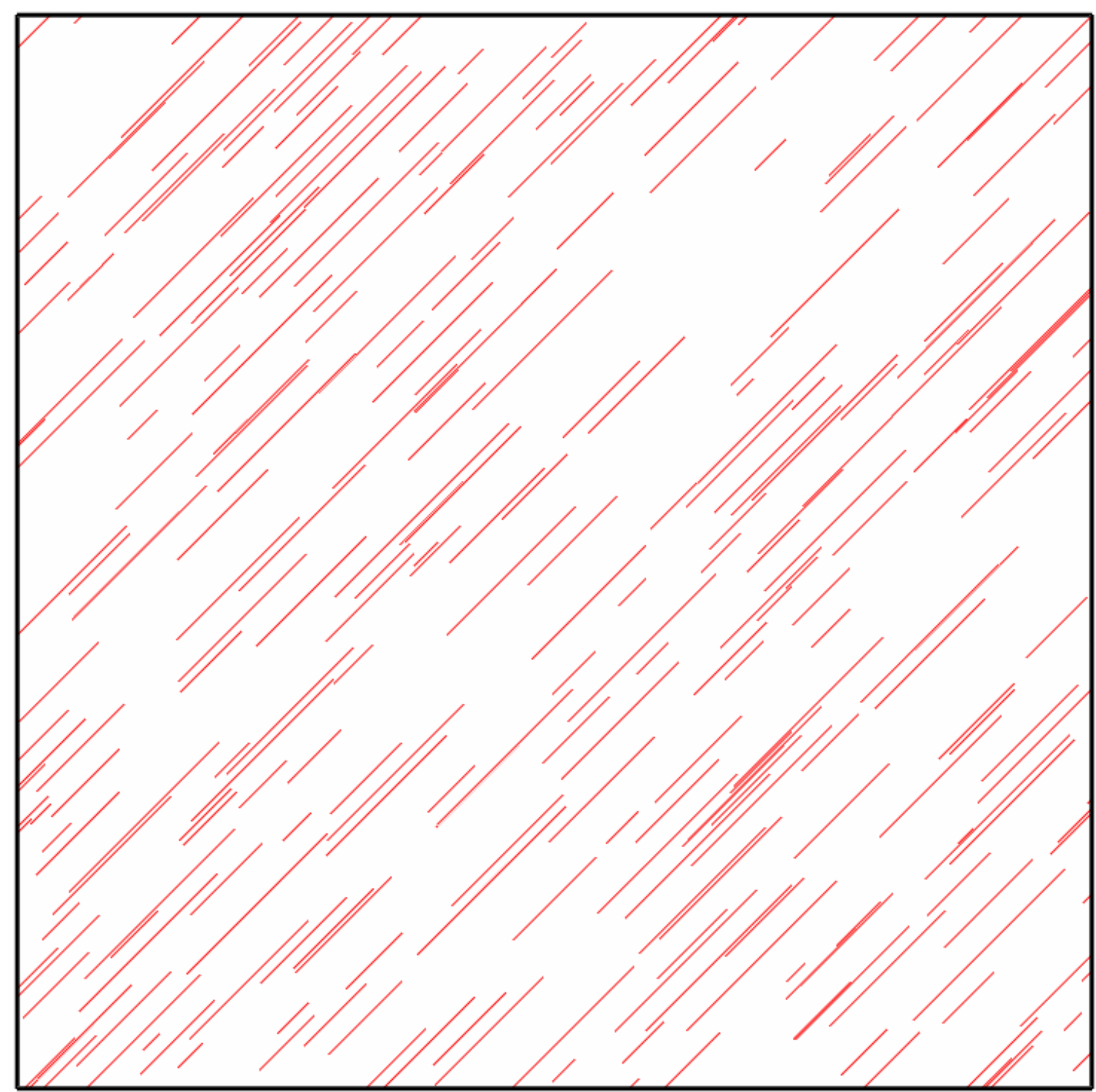

Figure B-15: This type 1 model fracture set has a model length and width of 500 $\mathrm{ft}$. Note that the fracture density is about .001 fractures $/ \mathrm{ft}^{2}$ or 250 fractures for this model's given area. 


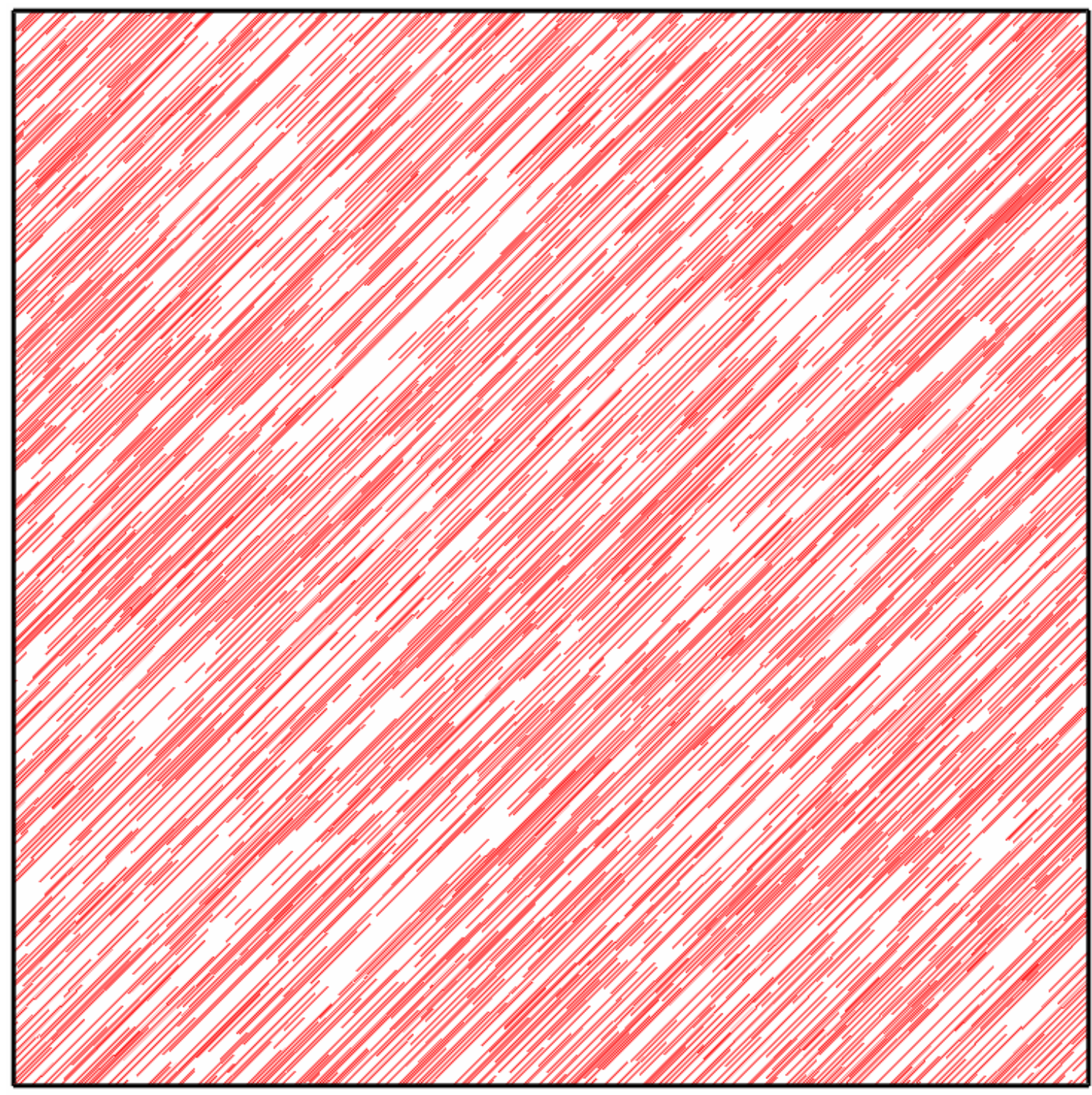

Figure B-16: This type 1 model fracture set has a model length and width of 500 $\mathrm{ft}$. Note that the fracture density is about $.01 \mathrm{fractures} / \mathrm{ft}^{2}$ or 2500 fractures for this model's given area. 


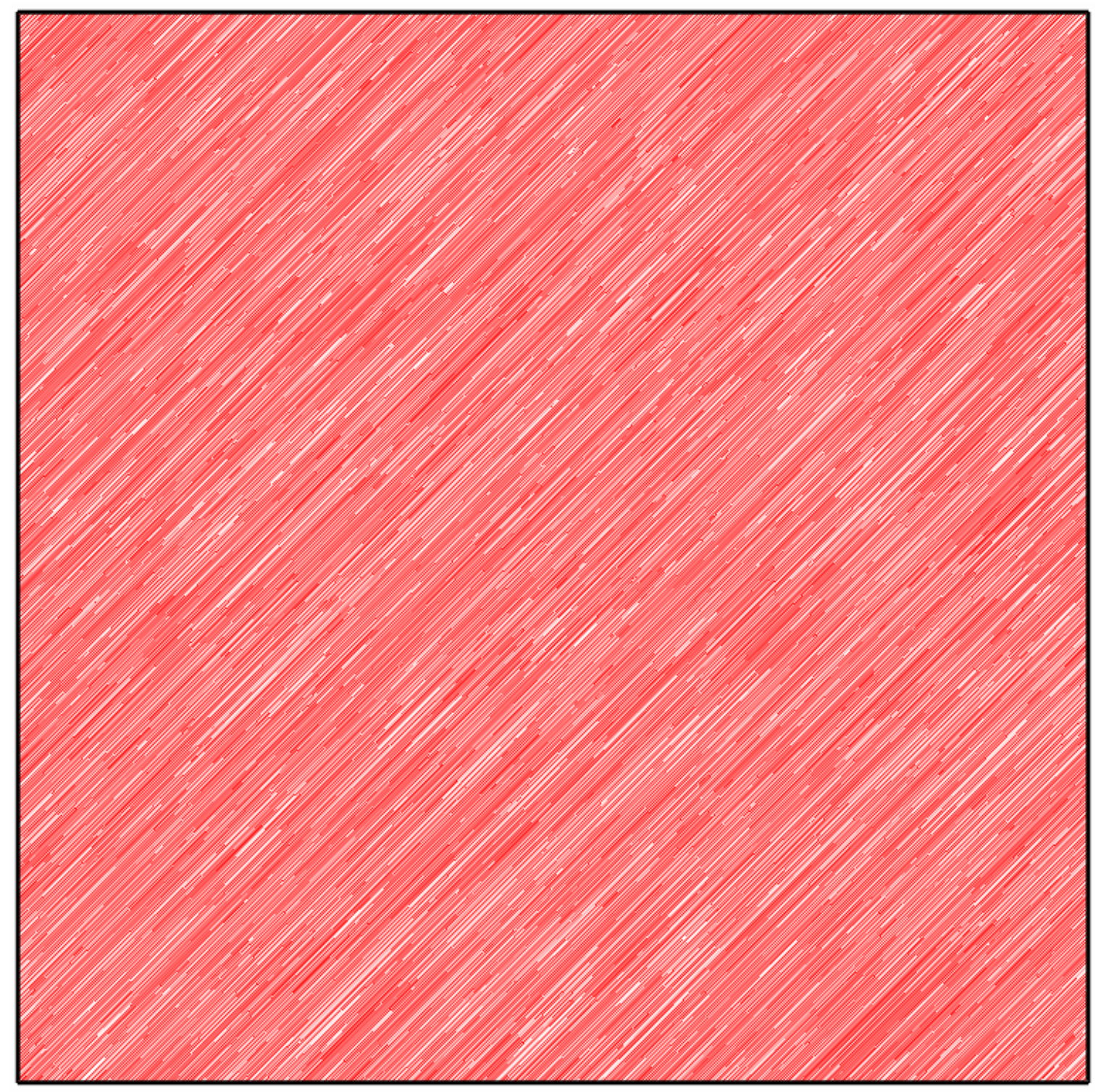

Figure B-17: This type 1 model fracture set has a model length and width of 500 $\mathrm{ft}$. Note that the fracture density is about .01 fractures $/ \mathrm{ft}^{2}$ or 25,000 fractures for this model's given area. 


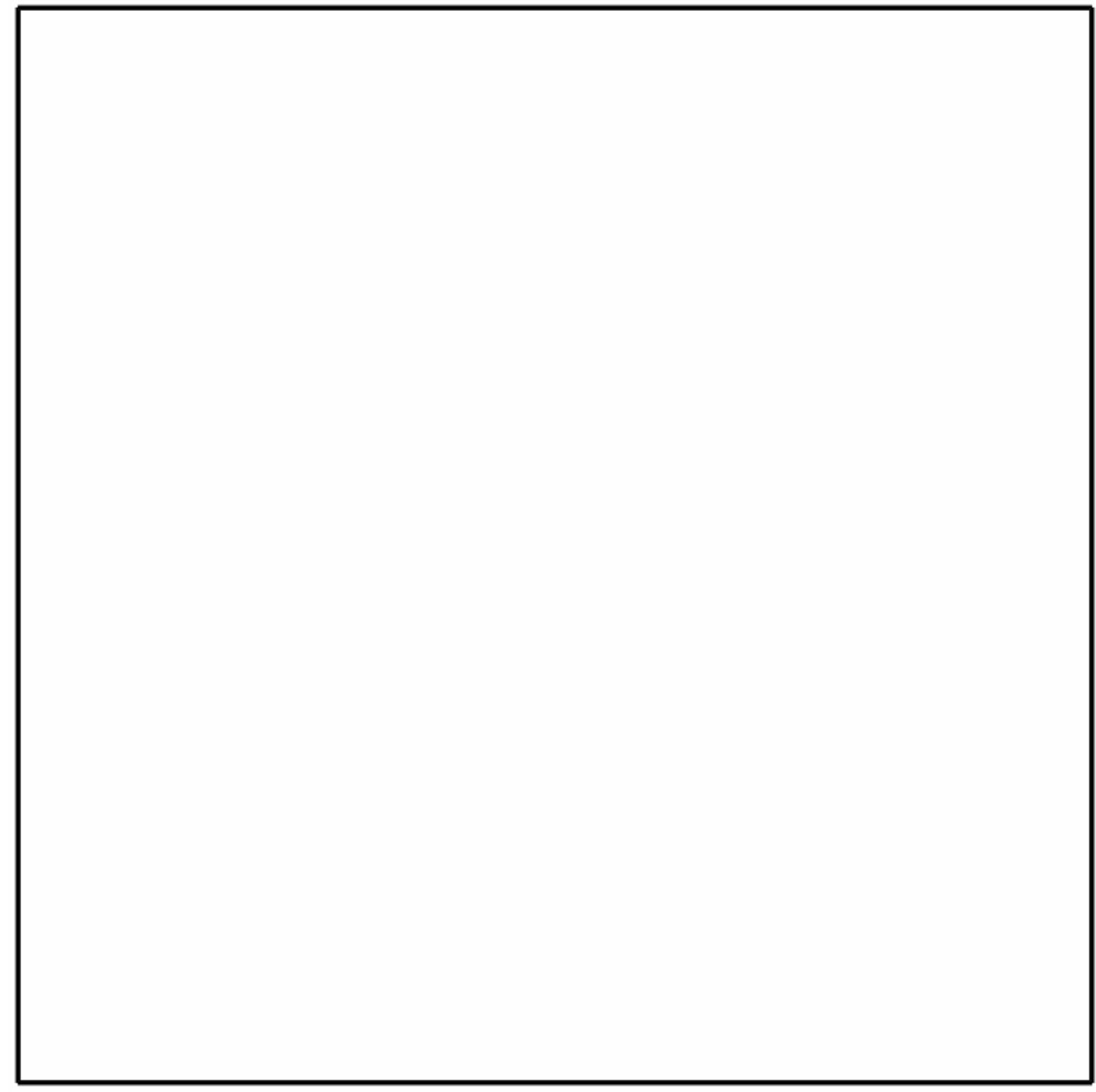

Figure B-18: This type 1 model fracture set has a model length and width of $500 \mathrm{ft}$. Note that the fracture density is about .000001 fractures $/ \mathrm{ft}^{2}$ or 0.25 fractures for this model's given area. Statistically, every fourth model should generate a single fracture. 


\section{References:}

Bai, T., and Pollard, D.D., 2000, Fracture spacing in layered rocks: a new explanation based on the stress transition: Journal of Structural Geology, vol. 22, pp 43-57

Brown, W.G., 1993, Structural style of Laramide Basement-cored uplifts and associated folds, in Snoke, A.W., Steidtmann, J.R., and Roberts, S.M., editors, Geology of Wyoming: Geology Survey of Wyoming Memoir No.5, p 312-371

Carr-Crabaugh, Mary and Dunn, Thomas, 1996, Reservoir Heterogeneity as a Function of Accumulation and Preservation Dynamics, Tensleep Sandstone, Bighorn and Wind River Basins, Wyoming, Society for Sedimentary Geology, Rocky Mountain Section p 305-320

Cooper, S.C., 2000, Deformation within a Basement-Cored anticline: Teapot Dome, Wyoming: Masters Thesis, Department of Earth and Environmental Science, New MexicoTech, Socorro, NM

Cooper, S.C., Lorenz, J.C., and Goodwin, L. B., 2001, Lithologic and Structural Controls on Natural Fracture Characteristics Teapot Dome, Wyoming, DOE-Sandia, Sand2001-1786

Dolton, G.L., Fox, J.E., Clayton, J.L, 1990, Petroleum geology of the Powder River Basin, Wyoming and Montana, Report 88-450 United Stated Department of the Interior - U.S. Geological Survey,

Fisher, M.P., and Wilkerson, M.S., 2000, Predicting the orientation of joints from fold shape: Results of pseudo-three-dimensional modeling and curvature analysis, Geology, Vol. 28, pp 15-18

Friedmann, J., Nummedal, D., and Stamp, V., 2004b, Science and Technology Goals of the Teapot Dome Field Experimental Facility: The Fourth National Conference on Carbon Sequestration, Washington, D. C., p 8

Giangiacomo, L. and Vivas, A., 2000, RMOTC Water Shut-off Treatment Seminar and Demonstration Course Manual, RMOTC, Casper, Wyoming

Gries, R., 1981, Oil and gas prospecting beneath Precambrian of foreland thrust plates in the Rocky Mountains, The Mountain Geologist, vol. 18, pp1-18

Hurley, N.F., Kerr, D.R., and Aviantara, A.A., 2003, Structural and Stratigraphic Compartments in a Horizontal Well Drilled in Eolian Tensleep Sandstone, Byron Field, Wyoming, AAPG Methods in Exploration No. 14, pp 143-159

Hycal Energy Research Laboratories, 2004, DOE-RMOTC - Teapot Dome Miscibility Study, Final Report 
Ji, Shaocheng and Saruwatari, Kazuko, 1998, A revised model for the relationship between joint pacing and layer thickness, Journal of Structural Geology, Vol. 20, pp 1495-1508

Koepsell, R., 2001, Fracture Analysis of FMI log for well 61-2-X-15 for the Department of Energy, Schlumberger-Oil Field Services

Koepsell, R., 2002a, Fracture Analysis of FMI log for well 25-1-X-14 for the Department of Energy, Schlumberger-Oil Field Services

Koepsell, R., 2002b, Fracture Analysis of FMI log for well 67-1-X-10 for the Department of Energy, Schlumberger-Oil Field Services

Koepsell, R., 2002c, Fracture Analysis of FMI log for well 71-1-X-4 for the Department of Energy, Schlumberger-Oil Field Services

Koepsell, R., 2004, Fracture Analysis of FMI log for well 48-X-28 for the Department of Energy, Schlumberger-Oil Field Services

Lorenz, J.C. and Hill, R.E., 1991, Subsurface Fracture Spacing: Comparison of Inferences From Slant/Horizontal Core and Vertical Core in the Mesaverde Reservoirs: Society of Petroleum Engineers paper 21877. Rocky Mountain Regional Meeting and Low Permeabilty Reservoirs Symposium, pp 705-715

McKoy, Mark and Sams, W. Neal, 1997, Tight Gas Reservoir Simulation: Modeling Discrete Irregular Strata-Bound Fracture Networks and Network Flow, Including Dynamic Recharge from the Matrix, USDOE: FETC, DOE Grant \# DE-AC2195MC31346

McKoy, Mark, 2001, FRACGEN Software User's Guide, US Department of EnergyNETL

McKoy, M, 2005, Personal Communication

Millikan, M., 2005, Personal Communication

National Energy Policy, 2001, Report of the National Energy Policy Development Group, http://www.energy.gov/about/nationalenergypolicy.htm

Moros, J.G., 1999, Relationship between fracture aperture and length in sedimentary rocks, Masters Thesis, University of Texas at Austin

Narr, W., and I. Lerche, 1984, A method for estimating subsurface fracture density in core: AAPG Bulletin, v. 68, pp637-648 
Narr, W., 1996, Estimating Average Fracture Spacing in Subsurface Rock, AAPG Bulletin, V. 80, pp 1565-1586

Nilson, T., 1999, Teapot Dome, 54-TPX-10 well: Core descriptions for RMOTC

Nilson, T., 2004, Teapot Dome, 48-x-28 well: Core descriptions for RMOTC

Ozkaya, Sait Ismail, 2003a, Fracture Length Estimation From Borehole Image Logs, Mathematical Geology Vol. 35, pp 737-752

Ozkaya, Sait Ismail and Mattner, Joerg, 2003b, Fracture connectivity from fracture intersections in borehole images, Computers and Geosciences, pp 143-153

Park, Jinsuk C., 1997, The effect of mechanical interaction on the scaling of fracture aperture, Masters Thesis, SUNY-Buffalo

Perez, Orlando, 2002, Fracture-size scaling and Stratigraphic Controls on Fracture Intensity, $\mathrm{PhD}$ dissertation, University of Texas at Austin, TX

Pollard, D. and Segall, P, 1987, Theoretical displacement and stresses near fractures in rock in Fracture Mechanics of Rock, Academic Press, London

Reinecker, J., Heidbach, O., and Mueller, B., 2004, The 2004 release of the World Stress Map (available on line at www.worldstressmap.org)

Sakar, Dudipta, Toksoz, Nafi, and Burns, Daniel, 2002, Fluid Flow Simulation in Fractured Reservoirs, Earth Reserouces Laboratory:MIT, DOE Grant \#DE-FG0s00ER15041,

Sams, W. Neal, 2005, Personal Communications

Sams, W. Neal, 2006, Personal Communications

Schulte, R., 2001, Final Report Electro-Seise, Inc. Airborne Survey: DOE/RMOTC020139, 22p

Sclumberger, 2002, FMI Borehole geology, geomechanics and 3D reservoir modeling, Product Brochure

Stamp, V., 2005, Personal Communications

Stearns, D.W., 1978, Faulting and forced folding in the Rocky Mountains foreland, in Mathews, V., III, ed., Laramide folding associated with basement block faulting in the western United States, Volume memoir 151, Geological Society of America, pp 1-37 
Vermilye, Jan and Scholz, Christopher, 1995, Relationship between vein length and aperture, Journal of Structural Geology, Vol. 17, pp 423-434

Wilson, T.H., 2005, Modeling Natural Fractures Networks in the Context of Flow Simulations: Teapot Dome, Wyoming, Petroleum Research Fund - American Chemical Society Proposal

Wyoming Geo-notes, 2004, Wyoming State Geological Survey, Laramie, Wyoming, Vol. 79

Wyoming Oil and Gas Commission web site http://wogec.state.wy.us/ 